\title{
Effectiveness of brief alcohol interventions in primary care populations (Review)
}

Kaner EFS, Beyer FR, Muirhead C, Campbell F, Pienaar ED, Bertholet N, Daeppen JB, Saunders $\mathrm{JB}$, Burnand B

Kaner EFS, Beyer FR, Muirhead C, Campbell F, Pienaar ED, Bertholet N, Daeppen JB, Saunders JB, Burnand B.

Effectiveness of brief alcohol interventions in primary care populations.

Cochrane Database of Systematic Reviews 2018, Issue 2. Art. No.: CD004148.

DOI: 10.1002/14651858.CD004148.pub4.

www.cochranelibrary.com 
TABLE OF CONTENTS

HEADER

ABSTRACT

PLAIN LANGUAGE SUMMARY

SUMMARY OF FINDINGS

BACKGROUND

OBJECTIVES

METHODS

RESULTS

Figure 1.

Figure 2.

Figure 3.

Figure 4.

Figure 5.

Figure 6.

Figure 7.

Figure 8.

Figure 9.

Figure 10

DISCUSSION

AUTHORS' CONCLUSIONS

ACKNOWLEDGEMENTS

REFERENCES

CHARACTERISTICS OF STUDIES

DATA AND ANALYSES

Analysis 1.1. Comparison 1 Brief intervention versus control, Outcome 1 Quantity of drinking (g/week) at 12 months.

Analysis 1.2. Comparison 1 Brief intervention versus control, Outcome 2 Quantity of drinking (g/week) at 12 months, restricted to trials at low risk of bias due to allocation concealment.

Analysis 1.3. Comparison 1 Brief intervention versus control, Outcome 3 Quantity of drinking (g/week) at 12 months, restricted to trials at low risk of bias due to attrition.

Analysis 1.4. Comparison 1 Brief intervention versus control, Outcome 4 Quantity of drinking (g/week) at 12 months, with imputation of unknown standard deviations.

Analysis 1.5. Comparison 1 Brief intervention versus control, Outcome 5 Quantity of drinking (g/week) at 12 months, subgrouped by cluster/individual randomisation.

Analysis 1.6. Comparison 1 Brief intervention versus control, Outcome 6 Quantity of drinking (g/week) at 12 months, subgrouped by cluster/individual randomisation, varying imputed ICC.

Analysis 1.7. Comparison 1 Brief intervention versus control, Outcome 7 Quantity of drinking (g/week) at 12 months, subgrouped by gender.

Analysis 1.8. Comparison 1 Brief intervention versus control, Outcome 8 Quantity of drinking (g/week) at 12 months, subgrouped by gender, excluding trials of men only.

Analysis 1.9. Comparison 1 Brief intervention versus control, Outcome 9 Quantity of drinking (g/week) at 12 months, subgrouped by adolescents/young adults only versus other.

Analysis 1.10. Comparison 1 Brief intervention versus control, Outcome 10 Quantity of drinking (g/week) at 12 months, subgrouped by general practice/emergency setting.

Analysis 1.11. Comparison 1 Brief intervention versus control, Outcome 11 Quantity of drinking (g/wk) at 12 months, subgrouped by intervention modality (advice versus counselling).

Analysis 1.12. Comparison 1 Brief intervention versus control, Outcome 12 Quantity of drinking (g/week) at 12 months, subgrouped by type of control.

Analysis 1.13. Comparison 1 Brief intervention versus control, Outcome 13 Quantity of drinking (g/week), subgrouped by length of follow-up.

Analysis 1.14. Comparison 1 Brief intervention versus control, Outcome 14 Quantity of drinking (g/week), subgrouped by length of follow-up ( 6 and 12 months) and restricted to trials with information at both times.

Analysis 1.15. Comparison 1 Brief intervention versus control, Outcome 15 Quantity of drinking (g/week) at 12 months, subgrouped by effectiveness/efficacy. 
Analysis 1.16. Comparison 1 Brief intervention versus control, Outcome 16 Frequency of binge drinking (number binges/week) at 12 months.

Analysis 1.17. Comparison 1 Brief intervention versus control, Outcome 17 Frequency of drinking (number binges/week), subgrouped by length of follow-up ( $6 \& 12$ months) and restricted to trials with information at both times.

Analysis 1.18. Comparison 1 Brief intervention versus control, Outcome 18 Frequency of drinking (number days drinking/week) at 12 months.

Analysis 1.19. Comparison 1 Brief intervention versus control, Outcome 19 Frequency of drinking (number days drinking/week), subgrouped by length of follow-up ( $6 \& 12$ months) and restricted to trials with information at both times.

Analysis 1.20. Comparison 1 Brief intervention versus control, Outcome 20 Intensity of drinking (g/drinking day) at 12 months.

Analysis 1.21. Comparison 1 Brief intervention versus control, Outcome 21 Heavy drinkers at 12 months.

Analysis 1.22. Comparison 1 Brief intervention versus control, Outcome 22 Binge drinkers at 12 months.

Analysis 1.23. Comparison 1 Brief intervention versus control, Outcome 23 Laboratory markers - GGT (IU/L) at 12 months. ....

Analysis 1.24. Comparison 1 Brief intervention versus control, Outcome 24 Laboratory markers - GGT (IU/L) at 12 months, subgrouped by gender.

Analysis 2.1. Comparison 2 Extended intervention versus minimal or no intervention, Outcome 1 Quantity of drinking (g/week) at 12 months.

Analysis 2.2. Comparison 2 Extended intervention versus minimal or no intervention, Outcome 2 Frequency of binge drinking (number binges/week) at 12 months.

Analysis 2.3. Comparison 2 Extended intervention versus minimal or no intervention, Outcome 3 Frequency of drinking (number days drinking/week) at 12 months.

Analysis 2.4. Comparison 2 Extended intervention versus minimal or no intervention, Outcome 4 Intensity of drinking (g/ drinking day) at 12 months.

Analysis 2.5. Comparison 2 Extended intervention versus minimal or no intervention, Outcome 5 Heavy drinkers at 12 months.

Analysis 2.6. Comparison 2 Extended intervention versus minimal or no intervention, Outcome 6 Binge drinkers at 12 months.

Analysis 2.7. Comparison 2 Extended intervention versus minimal or no intervention, Outcome 7 Laboratory markers - GGT (IU/ L) at 12 months.

Analysis 3.1. Comparison 3 Extended versus brief intervention, Outcome 1 Quantity of drinking (g/week) at 12 months. ........ Analysis 3.2. Comparison 3 Extended versus brief intervention, Outcome 2 Quantity of drinking (g/week) at 12 months, with imputation of unknown standard deviations.

Analysis 3.3. Comparison 3 Extended versus brief intervention, Outcome 3 Frequency of drinking (number days drinking/week) at 12 months.

Analysis 3.4. Comparison 3 Extended versus brief intervention, Outcome 4 Intensity of drinking (g/drinking day). ..................

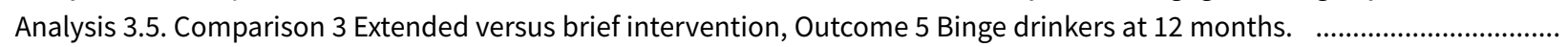

Analysis 3.6. Comparison 3 Extended versus brief intervention, Outcome 6 Laboratory markers - MCV (fl) at 12 months. ......... ADDITIONAL TABLES

APPENDICES

FEEDBACK

WHAT'S NEW

HISTORY

CONTRIBUTIONS OF AUTHORS 
[Intervention Review]

\section{Effectiveness of brief alcohol interventions in primary care populations}

Eileen FS Kaner ${ }^{1}$, Fiona R Beyer ${ }^{1}$, Colin Muirhead ${ }^{1}$, Fiona Campbell ${ }^{2}$, Elizabeth D Pienaar ${ }^{3}$, Nicolas Bertholet ${ }^{4}$, Jean B Daeppen ${ }^{4}$, John B Saunders 5 , Bernard Burnand6

1Institute of Health and Society, Newcastle University, Newcastle upon Tyne, UK. ${ }^{2}$ School of Health and Related Research, The University of Sheffield, Sheffield, UK. ${ }^{3}$ Cochrane South Africa, South African Medical Research Council, Cape Town, South Africa. ${ }^{4}$ Alcohol Treatment Center, Department of Community Medicine and Health, Lausanne University Hospital, Lausanne, Switzerland. 5Department of Psychiatry, Royal Brisbane and Women's Hospital, University of Queensland/Royal Brisbane Hospital, Australia. ${ }^{6}$ Cochrane Switzerland, Institute of Social and Preventive Medicine, Lausanne University Hospital, Lausanne, Switzerland

Contact address: Eileen FS Kaner, Institute of Health and Society, Newcastle University, Richardson Road, Newcastle upon Tyne, NE2 4AX, UK. e.f.s.kaner@newcastle.ac.uk.

Editorial group: Cochrane Drugs and Alcohol Group.

Publication status and date: Edited (no change to conclusions), published in Issue 6, 2018.

Citation: Kaner EFS, Beyer FR, Muirhead C, Campbell F, Pienaar ED, Bertholet N, Daeppen JB, Saunders JB, Burnand B. Effectiveness of brief alcohol interventions in primary care populations. Cochrane Database of Systematic Reviews 2018, Issue 2. Art. No.: CD004148. DOI: 10.1002/14651858.CD004148.pub4.

Copyright @ 2018 The Cochrane Collaboration. Published by John Wiley \& Sons, Ltd.

\section{A B S T R A C T}

\section{Background}

Excessive drinking is a significant cause of mortality, morbidity and social problems in many countries. Brief interventions aim to reduce alcohol consumption and related harm in hazardous and harmful drinkers who are not actively seeking help for alcohol problems. Interventions usually take the form of a conversation with a primary care provider and may include feedback on the person's alcohol use, information about potential harms and benefits of reducing intake, and advice on how to reduce consumption. Discussion informs the development of a personal plan to help reduce consumption. Brief interventions can also include behaviour change or motivationallyfocused counselling.

This is an update of a Cochrane Review published in 2007.

\section{Objectives}

To assess the effectiveness of screening and brief alcohol intervention to reduce excessive alcohol consumption in hazardous or harmful drinkers in general practice or emergency care settings.

\section{Search methods}

We searched the Cochrane Central Register of Controlled Trials (CENTRAL), MEDLINE, and 12 other bibliographic databases to September 2017. We searched Alcohol and Alcohol Problems Science Database (to December 2003, after which the database was discontinued), trials registries, and websites. We carried out handsearching and checked reference lists of included studies and relevant reviews.

\section{Selection criteria}

We included randomised controlled trials (RCTs) of brief interventions to reduce hazardous or harmful alcohol consumption in people attending general practice, emergency care or other primary care settings for reasons other than alcohol treatment. The comparison group was no or minimal intervention, where a measure of alcohol consumption was reported. 'Brief intervention' was defined as a conversation comprising five or fewer sessions of brief advice or brief lifestyle counselling and a total duration of less than 60 minutes. Any more was considered an extended intervention. Digital interventions were not included in this review. 


\section{Data collection and analysis}

We used standard methodological procedures expected by Cochrane. We carried out subgroup analyses where possible to investigate the impact of factors such as gender, age, setting (general practice versus emergency care), treatment exposure and baseline consumption.

\section{Main results}

We included 69 studies that randomised a total of 33,642 participants. Of these, 42 studies were added for this update (24,057 participants). Most interventions were delivered in general practice (38 studies, 55\%) or emergency care (27 studies, 39\%) settings. Most studies (61 studies, $88 \%$ ) compared brief intervention to minimal or no intervention. Extended interventions were compared with brief (4 studies, $6 \%$ ), minimal or no intervention ( 7 studies, 10\%). Few studies targeted particular age groups: adolescents or young adults (6 studies, $9 \%)$ and older adults (4 studies, 6\%). Mean baseline alcohol consumption was $244 \mathrm{~g} /$ week ( 30.5 standard UK units) among the studies that reported these data. Main sources of bias were attrition and lack of provider or participant blinding. The primary meta-analysis included 34 studies (15,197 participants) and provided moderate-quality evidence that participants who received brief intervention consumed less alcohol than minimal or no intervention participants after one year (mean difference (MD) - $20 \mathrm{~g} /$ week, $95 \%$ confidence interval (CI) -28 to -12 ). There was substantial heterogeneity among studies $\left(I^{2}=73 \%\right)$. A subgroup analysis by gender demonstrated that both men and women reduced alcohol consumption after receiving a brief intervention.

We found moderate-quality evidence that brief alcohol interventions have little impact on frequency of binges per week (MD - $0.08,95 \%$ $\mathrm{Cl}-0.14$ to -0.02 ; 15 studies, 6946 participants); drinking days per week (MD $-0.13,95 \% \mathrm{Cl}-0.23$ to $-0.04 ; 11$ studies, 5469 participants); or drinking intensity $(-0.2 \mathrm{~g} /$ drinking day, $95 \% \mathrm{Cl}-3.1$ to $2.7 ; 10$ studies, 3128 participants).

We found moderate-quality evidence of little difference in quantity of alcohol consumed when extended and no or minimal interventions were compared $(-20 \mathrm{~g} /$ week, $95 \% \mathrm{Cl}-40$ to $1 ; 6$ studies, 1296 participants). There was little difference in binges per week (-0.08, 95\% Cl -0.28 to 0.12 ; 2 studies, 456 participants; moderate-quality evidence) or difference in days drinking per week $(-0.45,95 \% \mathrm{Cl}-0.81$ to -0.09 ; 2 studies, 319 participants; moderate-quality evidence). Extended versus no or minimal intervention provided little impact on drinking intensity (9 g/drinking day, 95\% Cl -26 to 9; 1 study, 158 participants; low-quality evidence).

Extended intervention had no greater impact than brief intervention on alcohol consumption, although findings were imprecise (MD $2 \mathrm{~g} /$ week, $95 \% \mathrm{Cl}-42$ to 45; 3 studies, 552 participants; low-quality evidence). Numbers of binges were not reported for this comparison, but one trial suggested a possible drop in days drinking per week $(-0.5,95 \% \mathrm{Cl}-1.2$ to $0.2 ; 147$ participants; low-quality evidence). Results from this trial also suggested very little impact on drinking intensity $(-1.7 \mathrm{~g} /$ drinking day, $95 \% \mathrm{Cl}-18.9$ to 15.5 ; 147 participants; very low-quality evidence).

Only five studies reported adverse effects (very low-quality evidence). No participants experienced any adverse effects in two studies; one study reported that the intervention increased binge drinking for women and two studies reported adverse events related to driving outcomes but concluded they were equivalent in both study arms.

Sources of funding were reported by 67 studies (87\%). With two exceptions, studies were funded by government institutes, research bodies or charitable foundations. One study was partly funded by a pharmaceutical company and a brewers association, another by a company developing diagnostic testing equipment.

\section{Authors' conclusions}

We found moderate-quality evidence that brief interventions can reduce alcohol consumption in hazardous and harmful drinkers compared to minimal or no intervention. Longer counselling duration probably has little additional effect. Future studies should focus on identifying the components of interventions which are most closely associated with effectiveness.

\section{PLAIN LANGUAGE SUMMARY}

\section{Effectiveness of brief alcohol interventions in primary care populations}

\section{What is the aim of this review?}

We aimed to find out whether brief interventions with doctors and nurses in general practices or emergency care can reduce heavy drinking. We assessed the findings from 69 trials that involved a total of 33,642 participants; of these 34 studies (15,197 participants) provided data for the main analysis.

\section{Key messages}

Brief interventions in primary care settings aim to reduce heavy drinking compared to people who received usual care or brief written information. Longer interventions probably make little or no difference to heavy drinking compared to brief intervention.

\section{What was studied in the review?}


One way to reduce heavy drinking may be for doctors and nurses to provide brief advice or brief counselling to targeted people who consult general practitioners or other primary health care providers. People seeking primary healthcare are routinely asked about their drinking behaviour because alcohol use can affect many health conditions.

Brief interventions typically include feedback on alcohol use and health-related harms, identification of high risk situations for heavy drinking, simple advice about how to cut down drinking, strategies that can increase motivation to change drinking behaviour, and the development of a personal plan to reduce drinking. Brief interventions are designed to be delivered in regular consultations, which are often 5 to 15 minutes with doctors and around 20 to 30 minutes with nurses. Although short in duration, brief interventions can be delivered in one to five sessions. We did not include digital interventions in this review.

\section{Search date}

The evidence is current to September 2017.

\section{Study funding}

Funding sources were reported by $60(87 \%)$ studies. Of these, 58 studies were funded by government institutes, research bodies or charitable foundations. One study was partly funded by a pharmaceutical company and a brewers association, another by a company developing diagnostic testing equipment. Nine studies did not report study funding sources.

\section{What are the main results of the review?}

We included 69 controlled trials conducted in many countries. Most studies were conducted in general practice and emergency care. Study participants received brief intervention or usual care or written information about alcohol (control group).

The amount of alcohol people drank each week was reported by 34 trials (15,197 participants) at one-year follow-up and showed that people who received the brief intervention drank less than control group participants (moderate-quality evidence). The reduction was around a pint of beer $(475 \mathrm{~mL})$ or a third of a bottle of wine $(250 \mathrm{~mL})$ less each week.

Longer counselling probably provided little additional benefit compared to brief intervention or no intervention.

One trial reported that the intervention adversely affected binge drinking for women, and two reported that no adverse effects resulted from receiving brief interventions. Most studies did not mention adverse effects.

\section{Quality of the evidence}

Findings may have been affected because participants and practitioners were often aware that brief interventions focused on alcohol. Furthermore, some participants could not be contacted at one-year follow-up to report drinking levels. Overall, evidence was assessed as mostly moderate-quality. This means the reported effect size and direction is likely to be close to the true effect of these interventions. 


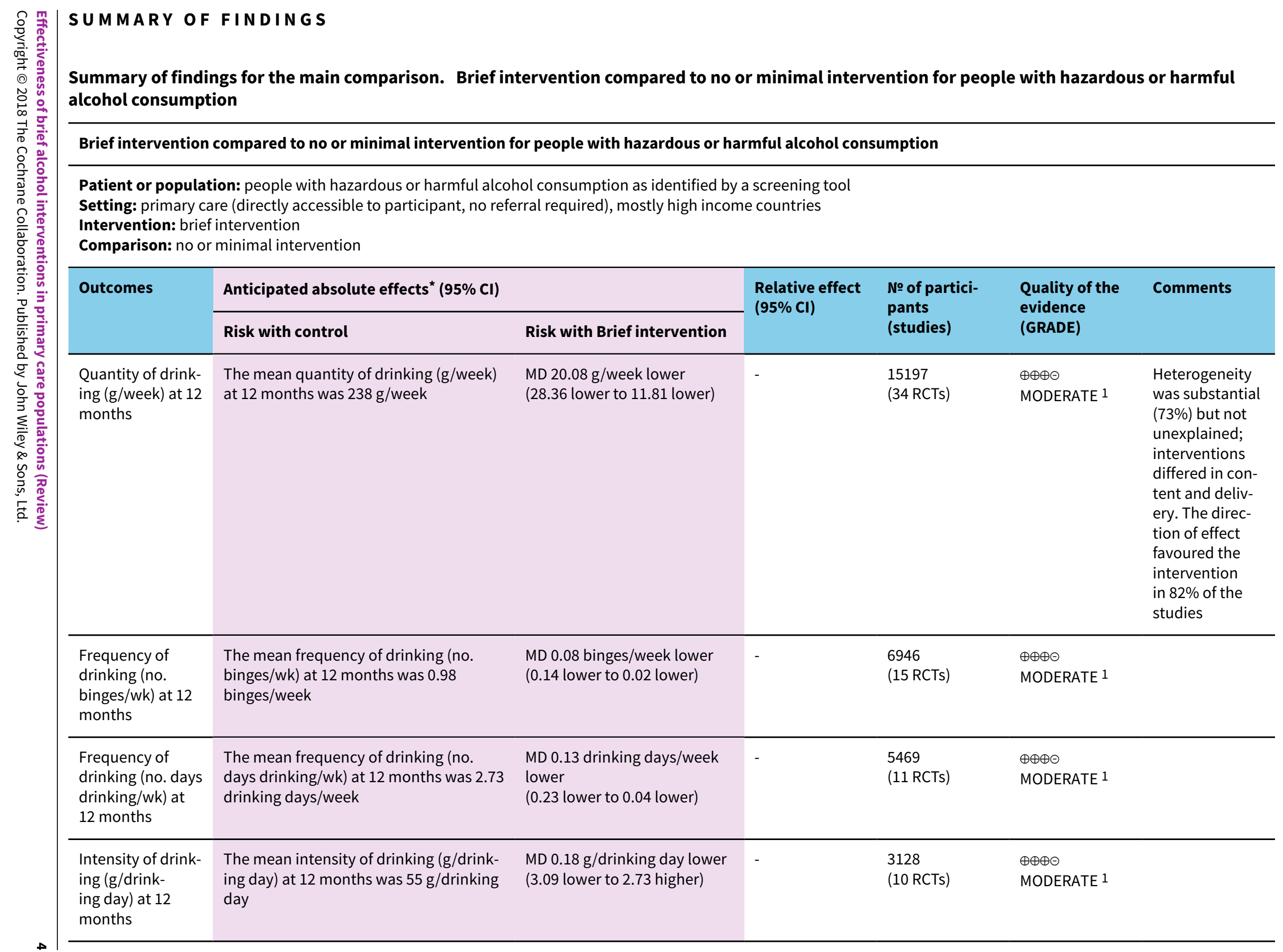

Patient or population: people with hazardous or harmful alcohol consumption as identified by a screening tool

Setting: primary care (directly accessible to participant, no referral required), mostly high income countries

Comparison: no or minimal intervention 
${ }^{\star}$ The risk in the intervention group (and its $95 \%$ confidence interval) is based on the assumed risk in the comparison group and the relative effect of the intervention (and its $95 \% \mathrm{Cl})$.

Cl: Confidence interval; RR: Risk ratio; OR: Odds ratio;

\section{GRADE Working Group grades of evidence}

High quality: We are very confident that the true effect lies close to that of the estimate of the effect

Moderate quality: We are moderately confident in the effect estimate: The true effect is likely to be close to the estimate of the effect, but there is a possibility that it is substantially different

Low quality: Our confidence in the effect estimate is limited: The true effect may be substantially different from the estimate of the effect

Very low quality: We have very little confidence in the effect estimate: The true effect is likely to be substantially different from the estimate of effect

1 High levels of performance bias due to difficulties with blinding participants and providers

2 Downgraded due to inconsistency and imprecision; very few studies provided data, and reporting is inconsistent and data unavailable in a format conducive to meta-analysis

\section{Summary of findings 2. Extended intervention compared to no or minimal intervention for people with hazardous or harmful alcohol consumption}

Extended intervention compared to no or minimal intervention for people with hazardous or harmful alcohol consumption

Patient or population: people with hazardous or harmful alcohol consumption

Setting: primary care (directly accessible to participant, no referral required)

Intervention: extended intervention

Comparison: no or minimal intervention

\begin{tabular}{|c|c|c|c|c|c|c|}
\hline \multirow[t]{2}{*}{ Outcomes } & \multicolumn{2}{|l|}{ Anticipated absolute effects* $(95 \% \mathrm{CI})$} & \multirow{2}{*}{$\begin{array}{l}\text { Relative effect } \\
(95 \% \mathrm{CI})\end{array}$} & \multirow{2}{*}{$\begin{array}{l}\text { № of partici- } \\
\text { pants } \\
\text { (studies) }\end{array}$} & \multirow{2}{*}{$\begin{array}{l}\text { Quality of the } \\
\text { evidence } \\
\text { (GRADE) }\end{array}$} & \multirow[t]{2}{*}{ Comments } \\
\hline & Risk with control & $\begin{array}{l}\text { Risk with Extended inter- } \\
\text { vention }\end{array}$ & & & & \\
\hline $\begin{array}{l}\text { Quantity of drinking } \\
\text { (g/week) at } 12 \text { months }\end{array}$ & $\begin{array}{l}\text { The mean quantity of drinking (g/ } \\
\text { week) at } 12 \text { months was } 236 \mathrm{~g} / \text { week }\end{array}$ & $\begin{array}{l}\text { MD } 19.50 \mathrm{~g} / \text { week lower } \\
\text { (40.47 lower to } 1.48 \text { higher) }\end{array}$ & - & $\begin{array}{l}1296 \\
\text { (6 RCTs) }\end{array}$ & $\begin{array}{l}\oplus \oplus \oplus \ominus \\
\text { MODERATE } 1\end{array}$ & \\
\hline $\begin{array}{l}\text { Frequency of drinking } \\
\text { (no. binges/wk) at } 12 \\
\text { months }\end{array}$ & $\begin{array}{l}\text { The mean frequency of drinking (no. } \\
\text { binges/wk) at } 12 \text { months was } 1.3 \\
\text { binges/week }\end{array}$ & $\begin{array}{l}\text { MD } 0.08 \text { binges/week lower } \\
\text { ( } 0.28 \text { lower to } 0.12 \text { higher) }\end{array}$ & - & $\begin{array}{l}456 \\
(2 \mathrm{RCTs})\end{array}$ & $\begin{array}{l}\oplus \oplus \oplus \ominus \\
\text { MODERATE } 1\end{array}$ & \\
\hline
\end{tabular}




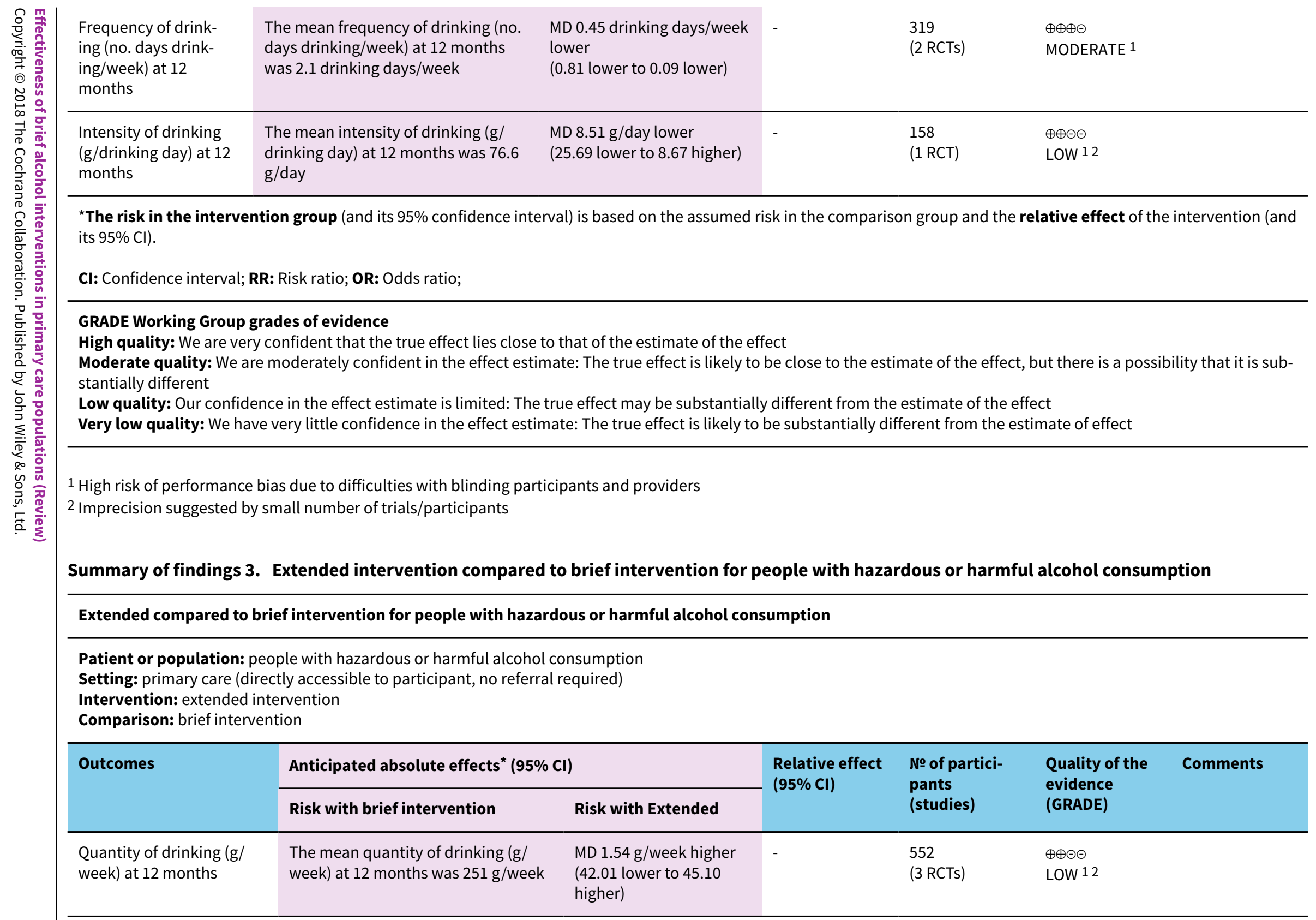




\begin{tabular}{|c|c|c|c|c|c|c|}
\hline 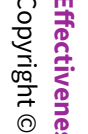 & $\begin{array}{l}\text { Frequency of binge drink- } \\
\text { ing (no. binges/wk) at } 12 \\
\text { months - not measured }\end{array}$ & - & - & - & - & - \\
\hline 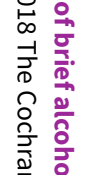 & $\begin{array}{l}\text { Frequency of drinking (no. } \\
\text { days drinking/week) at } 12 \\
\text { months }\end{array}$ & $\begin{array}{l}\text { The mean frequency of drinking (no. } \\
\text { days drinking/week) at } 12 \text { months } \\
\text { was } 2.82 \text { days drinking/week }\end{array}$ & $\begin{array}{l}\text { MD } 0.51 \text { drinking days/ } \\
\text { week lower } \\
\text { (1.21 lower to } 0.19 \text { high- } \\
\text { er) }\end{array}$ & - & $\begin{array}{l}147 \\
(1 \mathrm{RCT})\end{array}$ & $\begin{array}{l}\oplus \oplus \odot \ominus \\
\text { LOW } 23\end{array}$ \\
\hline 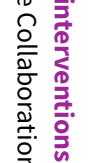 & $\begin{array}{l}\text { Intensity of drinking } \\
\text { (g/drinking day) at } 12 \\
\text { months }\end{array}$ & $\begin{array}{l}\text { The mean intensity of drinking (g/ } \\
\text { drinking day) at } 12 \text { months was } 70 \mathrm{~g} / \\
\text { drinking day }\end{array}$ & $\begin{array}{l}\text { MD } 1.7 \mathrm{~g} / \text { drinking day } \\
\text { lower } \\
\text { (18.86 lower to } 15.46 \\
\text { higher) }\end{array}$ & - & $\begin{array}{l}147 \\
(1 \mathrm{RCT})\end{array}$ & $\begin{array}{l}\oplus \oplus \ominus \ominus \\
\text { VERY LOW } 123\end{array}$ \\
\hline
\end{tabular}

${ }^{\star}$ The risk in the intervention group (and its $95 \%$ confidence interval) is based on the assumed risk in the comparison group and the relative effect of the intervention (and its $95 \% \mathrm{Cl})$.

Cl: Confidence interval; RR: Risk ratio; OR: Odds ratio;

\section{GRADE Working Group grades of evidence}

High quality: We are very confident that the true effect lies close to that of the estimate of the effect

Moderate quality: We are moderately confident in the effect estimate: The true effect is likely to be close to the estimate of the effect, but there is a possibility that it is substantially different

Low quality: Our confidence in the effect estimate is limited: The true effect may be substantially different from the estimate of the effect

Very low quality: We have very little confidence in the effect estimate: The true effect is likely to be substantially different from the estimate of effect

1 Imprecision suggested by very wide confidence intervals

2 High risk of performance bias due to difficulties blinding participants and providers

3 Imprecision suggested by small number of trials/participants 


\section{B A C K G R O U N D}

\section{Description of the condition}

Excessive drinking is a significant cause of mortality, morbidity and social problems in many countries, with a greater global cost to health than for tobacco (WHO 2014). The true impact of alcohol on the health of individuals and the wider community is difficult to estimate because of the many effects resulting from alcohol use, including increased levels of violence, accidents and suicide (GBD 2017). The heavy burden that alcohol use imposes on health, and its significant economic consequences, has led to national and international programmes and policies that seek to reduce consumption levels and so reduce a primary cause of avoidable ill health (Bailey 2011; UK Government 2012).

The impetus for a preventive approach to alcohol problems has been reinforced by epidemiological research. At a population level, most alcohol-related harm is not due to drinkers with severe alcohol dependence but attributable to a much larger group of excessive (hazardous and harmful drinkers) whose consumption exceeds recommended drinking levels (Anderson 1991). Therefore, at a population level, the greatest impact on alcohol-related problems can be made by addressing interventions aimed for excessive rather than dependent drinkers (McGovern 2013).

\section{Description of the intervention}

Early identification and secondary prevention of alcohol problems, using screening and brief interventions in primary care, has long been advocated as a strategy to reduce excessive drinking and is the focus of a great deal of research (O'Donnell 2014).

Brief intervention is grounded in social-cognitive theory and typically incorporates some or all of the following elements:

- feedback on the person's alcohol use and any alcohol-related harm clarification as to what constitutes low risk alcohol consumption;

- information on the harms associated with risky alcohol use;

- benefits of reducing intake;

- advice on how to reduce intake;

- motivational enhancement; analysis of high risk situations for drinking and coping strategies; and

- the development of a personal plan to reduce consumption.

Brief intervention is typically structured according to the FRAMES approach which involves practitioners: giving Feedback on the person's intake, impressing the Responsibility for change onto them, offering Advice, listing a Menu of options for behavioural change, having an Empathic approach and building Self-efficacy in the person receiving the brief intervention (Miller 1994).

Some brief intervention trials have included motivational interviewing (Rollnick 1995) or lifestyle counselling approaches. Although forms of brief intervention vary among studies (Heather 1995), core features in primary care are delivery by generalist healthcare workers, targets excessive (hazardous and harmful) drinkers who tend not to be seeking help for alcohol problems, and aims for reduced consumption and alcohol-related harms. Brief interventions in primary care have focused less frequently on dependent drinkers because these people often need more intensive treatment than is available routinely and are likely to require a goal of total abstinence.

\section{How the intervention might work}

Excessive drinking can be identified routinely in general practice and emergency care. People are often asked about alcohol consumption during new patient registrations, general health checks, specific disease clinics (e.g. hypertension, diabetes) and other health screening procedures. This identification process is often referred to as screening and typically involves asking a relatively small number of standardised questions about alcohol consumption (e.g. quantity, frequency and intensity of use) and any associated effects using a validated questionnaire or screening tool. Screening and brief alcohol intervention in routine primary care typically occurs opportunistically - when the main purpose of the appointment is something other than help with drinking.

The brief intervention must be delivered within the limited time frame of a standard consultation (typically 5 to 15 minutes for general practitioners (GPs), or up to 30 minutes for nurses). It also needs to fit in with routine practice (e.g. initial screening plus either referral to a practice colleague or later return for intervention). However, brief intervention trials have evaluated a wide range of activity. The shortest of these is a single 5 to 10 minute session of structured advice delivered by GPs or nurses. More intense interventions can provide multiple sessions of motivational interviewing or some other form of counselling, accompanied by repeated follow-up and delivered by primary healthcare workers. Other variations relate to the type of population being treated, the amount of training and support received by therapists, the theoretical basis underlying the intervention, and the use of accompanying written material.

\section{Why it is important to do this review}

Although previous reports and reviews have indicated beneficial outcomes of screening and brief intervention for excessive drinkers, crucial questions remain concerning its impact in routine practice and applicability to the broader population (Agosti 1995; Bien 1993; Moyer 2002; NHS CRD 1993; Poikolainen 1999; UK Government 2012; Wilk 1997). Whilst there appears to be little doubt that screening and brief intervention with excessive drinkers can work successfully in research settings where intervention delivery and follow-up is carefully managed (Flay 1986), there has been uncertainty about extrapolation to real world routine primary care (Heather 2014; Holder 1999; Kaner 2001). However, if health professionals are to be encouraged to adopt and administer brief interventions in routine practice, it is necessary to establish a realistic effect size for brief intervention delivered in clinicallyrelevant contexts.

The term 'hazardous and harmful drinkers' contains a number of subgroups (e.g. young people, older people, and ethnic minorities). Little is known about how these subgroups respond to brief intervention in primary care. Differential loss of participants from early brief intervention trials led to a call for caution in generalising results to routine practice (Edwards 1997) but types of participants who were lost remains unclear. Therefore, there is need to characterise the types of drinkers for whom brief interventions have a positive impact and any subgroups who have not been represented in the trials to date. 
This is an update of our 2007 review (Kaner 2007). An update was necessary because many trials have been conducted since initial publication and relevant developments have occurred in the wider literature; consequently we have added 42 new trials and conducted new subgroup analyses. Firstly, specific tools to measure efficacy and effectiveness have been published (Gartlehner 2006; Koppenaal 2011), which supercede the scale used in the 2007 review. Secondly, the concepts of screening reactivity and assessment reactivity have been defined (McCambridge 2011). These definitions describe how the very process of screening for alcohol consumption or having the effects of drinking assessed may influence reported drinking behaviour, independent of any further brief intervention input. Furthermore, recent literature contains a bigger subgroup of trials that focus on emergency care rather than general practice-based primary care, whereas previously the vast majority of the trials took place in primary care. Finally, interventions in more recent trials are often based on counselling techniques such as motivational interviewing rather than simpler advice-based input.

An important development has been in the digitisation of interventions to reduce hazardous and harmful alcohol consumption, using technologies such as websites and smart phone apps. These interventions (and their comparison with faceto-face brief interventions) are the focus of another Cochrane Review (Kaner 2017), and were excluded from this review.

\section{O B JE C T IVES}

\section{Main objective}

To assess the effectiveness of screening and brief alcohol intervention to reduce excessive alcohol consumption in hazardous or harmful drinkers in general practice or emergency care settings.

\section{Secondary objectives}

Specific questions addressed by this review were:

1. Are brief interventions superior to minimal or no intervention?

2. Are extended brief interventions containing more or longer sessions superior to no intervention or to standard brief interventions?

\section{METHODS}

\section{Criteria for considering studies for this review}

\section{Types of studies}

Randomised controlled trials and cluster-randomised controlled trials were eligible for inclusion.

\section{Types of participants}

People who routinely presented to general practice, emergency care or other primary care settings for a range of health problems, whose alcohol consumption was identified by a screening tool as being excessive, or who had experienced harm as a result of their drinking behaviour. Studies that recruited participants who were seeking treatment specifically for an alcohol problem or who were mainly dependent on alcohol were excluded.

We defined primary care as all immediately accessible, general healthcare facilities. People needed to be able to access services on demand rather than through a specialist referral, and services needed to cover a broad range of problems. Participants recruited in emergency departments and trauma centres were included if this was the first contact following the emergency event.

\section{Types of interventions}

Experimental condition: Brief intervention comprised a single session and up to a maximum of five sessions of verbally-delivered information, advice or counselling that was designed to achieve a reduction in risky alcohol consumption, alcohol-related problems, or both (Babor 1994).

Control conditions: screening or assessment only, usual care for the presenting condition or written information such as a health or alcohol education leaflet (described as minimal intervention).

Psychology-based counselling aimed at reducing alcohol consumption or alcohol-related problems that was unlikely to occur in routine practice, for reasons of length or intensity, were referred to as extended intervention. We defined extended interventions as those that consisted of more than five sessions or total combined session durations was more than 60 minutes.

Interventions specifically aimed at people who were dependent on alcohol were excluded. Digital interventions (e.g. websites, smart phone apps or computer programmes) were excluded because these were investigated in another Cochrane Review (Kaner 2017).

\section{Types of outcome measures}

\section{Primary outcomes}

The primary outcome was consumption of alcohol. This was most often reported as:

1. Self-reported or other reports of drinking quantity (e.g. drinks per week).

2. Self-reported or other reports of binge drinking frequency (e.g. number of binges per week).

3. Self-reported or other reports of drinking frequency (e.g. drinking days per week).

4. Self-reported or other reports of drinking intensity (e.g. number of drinks per drinking day).

5. Self-reported or other reports of drinking within recommended limits (e.g. government recommended limits). Although limits vary among countries, practitioners tend to use the national government recommended limits as a guide.

Although not specified in the protocol, we also noted the following consumption outcomes if these were reported.

- Proportion of heavy drinkers (in Kaner 2007 a common example was > 35 units/week, but these definitions have reduced recently)

- Proportion of binge drinkers.

\section{Secondary outcomes}

1. Levels of laboratory markers of reduced alcohol consumption (e.g. serum gamma-glutamyltransferase (GGT), mean corpuscular volume (MCV)).

2. Alcohol-related harm to drinkers or others affected (e.g. via questionnaires such as the drinking problems index). 
3. Patient satisfaction measures.

4. Health-related quality of life.

5. Economic measures including use of health services.

\section{Search methods for identification of studies}

\section{Electronic searches}

\section{Current update searches}

We searched the following databases from 2005 to September 2017:

- Cochrane Central Register of Controlled Trials (CENTRAL) (Issue 8, 2017; searched 25 September 2017);

- Cochrane Database of Systematic Reviews (CDSR) (Issue 9, 2017; searched 25 September 2017);

- Database of Abstracts of Reviews of Effects (DARE) (Issue 2, 2015; searched 25 September 2017);

- MEDLINE (Ovid, 1966 to September week 2, 2017; searched 21 September 2017);

- Embase (Ovid 1980 to 2017 week 38; searched 21 September 2017);

- PsycINFO (Ovid 1840 to September week 3 2017; searched 21 September 2017);

- CINAHL (EBSCO, 1982 to 25 September 2017);

- Science Citation Index Expanded (SCI-EXPANDED) (Web of Science, 2005 to 25 September 2017);

- Conference Proceedings Citation Index - Science (CPCI-S) (2005 to 25 September 2017);

- Social Sciences Citation Index (SSCI) (Web of Science, 2005 to 25 September 2017);

- Emerging Sources Citation Index (ESCI) (Web of Science, 2015 to 25 September 2017);

- NHS-EED (Wiley, issue 2 of 4, 2015; searched 25 September 2017).

Search strategies are reported in Appendix 1; Appendix 2; Appendix 3; Appendix 4; Appendix 5; Appendix 6; Appendix 7; Appendix 8; and Appendix 9.

We applied no language or publication restrictions.

\section{Previous searches}

We searched the following sources from the earliest available date to 2006:

- Cochrane Drug and Alcohol Group specialised register (February 2006);

- Cochrane Central Register of Controlled Trials (CENTRAL);

- MEDLINE (Ovid, 1966 to 2005);

- Embase (Ovid, 1980 to 2005);

- PsycINFO (Ovid, 1840 to 2005);

- CINAHL (EBSCO, 1982 to 2005);

- Social Sciences Citation Index (SSCI) (Web of Knowledge, 1970 to 2005);

- Science Citation Index (SCI) (Web of Knowledge, 1970 to 2005);

- Cochrane Effective Practice and Organisation of Care Group specialised register (2005);

- Alcohol Education and Research Council (AERC) alcohol library, searched 2005;
- HEED (searched 3 December 2014 - no access for the September 2017 search); and

- Alcohol and Alcohol Problems Science Database, ETOH (1972 to 2003, after which the database was discontinued).

\section{Searching other resources}

We handsearched the reference lists of included studies and relevant systematic reviews. We contacted key informants and experts to enquire about unpublished work and ongoing research, particularly through links with the International Network on Brief Interventions for Alcohol and other drugs (INEBRIA).

We also searched clinicaltrials.gov (25 September 2017).

We searched organisational websites for reports of eligible trials on 26 September 2017:

- USA Department of Health and Human Services, Substance Abuse and Mental Health Services Administration (SAMHSA), National Registry of Evidence Based Programs and Practices (NREPP);

- SAMHSA Screening Brief Intervention and Referral to Treatment (SBIRT);

- Information on Drugs and Alcohol (IDA);

- Alcohol Concern;

- Drug and Alcohol Findings;

- International Network on Brief Interventions for Alcohol and Other Drugs (INEBRIA); and

- National Treatment Agency for Substance Misuse.

\section{Data collection and analysis}

\section{Selection of studies}

Two review authors independently assessed titles and abstracts in EndNote (EndNote 2015). If the title, abstract and keywords did not yield enough information to ascertain potential for inclusion then the full paper was retrieved.

We initially piloted the inclusion criteria on six retrieved papers for the original review (Kaner 2007). Two review authors independently assessed the study eligibility for both the original review and this update. Any disagreement was resolved by discussion and consensus, or adjudication by a third review author.

\section{Data extraction and management}

Two review authors independently extracted data using a piloted data extraction form. We extracted citation information, participants' characteristics (e.g. age, gender, baseline alcohol consumption), intervention descriptions (e.g. number, content and frequency of brief intervention sessions), setting and outcome data to RevMan 5 (Review Manager 2014). We also extracted methodological information to enable critical appraisal. Where data were missing or unclear we emailed study authors to request clarification or further data.

In the protocol, we specified the use of an intention-to-treat analysis as a criterion of quality. However, this was revised in light of current Cochrane Handbook guidance (Higgins 2011b). Intentionto-treat analysis is usually understood to mean that participants were analysed in the groups to which they were randomised, regardless of the treatment they actually received. However, it is 
also sometimes understood to imply that all participants were included regardless of whether their outcomes were actually collected, which requires imputation of missing outcomes. Rather than using intention-to-treat analysis as a quality criterion, we attempted to extract data for participants in the groups to which they were randomised, regardless of the treatment they actually received, i.e. corresponding to the more widely agreed definition of intention-to-treat analysis.

Outcome data on quantity of alcohol consumed in a specific time period were converted to grams per week for each study. Drinks and units were converted to grams using either a conversion factor reported in the relevant paper or, if none was reported, using the conversion factor appropriate for the country where the study was conducted (Furtwaengler 2013; Gual 1999; Heather 2006; Miller 1991). Months were converted to weeks by multiplying by 52/12. Drinking intensity, drinking days, drinking sessions and occasions were all assumed to be equivalent to drinking days. For laboratory markers of gamma-glutamyltransferase (GGT) (Israel 1996; Romelsjö 1989; Scott 1990; Wallace 1988), microkatals/litre were converted to international units/litre (IU/L) by multiplying by 60 . Where relevant, values from analyses that involved adjustment for missing data (e.g. through the imputation of baseline values for participants lacking follow-up data) were used in preference to unadjusted values.

\section{Assessment of risk of bias in included studies}

Two review authors independently assessed potential risk of bias resulting from the trial design according to Cochrane's 'Risk of bias' tool as described in the Cochrane Handbook (Higgins 2011). This is a two-part tool, addressing the following domains.

- Sequence generation and allocation concealment (selection bias).

- Blinding of participants and providers (performance bias).

- Blinding of outcome assessor (detection bias).

- Incomplete outcome data (attrition bias).

- Selective outcome reporting (reporting bias).

- Other source of bias.

The first part of the tool involves describing what was reported to have happened in the study. The second part of the tool involves assigning a judgement relating to the risk of bias in terms of low, high or unclear risk. We used the criteria indicated by the Cochrane Handbook adapted to the addiction field to make these judgments (see Appendix 10).

Any discrepancies between review authors were resolved by discussion to achieve consensus.

\section{Measures of treatment effect}

We calculated the mean difference (MD) and standard deviation (SD) between the value of the outcome measure at 12 months following the brief intervention and the corresponding value following the control intervention for each continuous outcome. If standard deviations of final values were not available, the change score (i.e. the difference between the final and initial value of the outcome measure) was used if its standard deviation was available. If no standard deviations were available, these trials were omitted from the primary analysis but included in a sensitivity analysis using imputed standard deviations.
The risk difference (RD) with 95\% confidence intervals were calculated for dichotomous outcomes because 95\% Cls are intuitively clearer and this was consistent with the approach applied previously (Kaner 2007).

\section{Unit of analysis issues}

We extracted a direct estimate of the desired treatment effect and its standard error where analyses accounted for clustering in cluster-randomised trials. We assigned imputed standard deviations to the treatment and control groups, such that the standard error of the treatment effect estimated by the weighted mean difference method in RevMan 5 (Review Manager 2014) was the same as that reported in the analysis accounting for clustering. If the analysis did not account for the cluster design, we extracted the number of clusters randomised to each intervention, the average cluster size in each intervention group, and the outcome data for all participants in each intervention group.

A design effect was estimated using an external estimate of the intra-cluster coefficient (ICC). In this way we inflated the variance of the effect estimate. In the case of dichotomous outcomes, this involved reducing the total number of participants and the number of participants with events, whilst keeping the proportion with events fixed. It was then possible to enter data to RevMan 5 (Review Manager 2014), and combine cluster-randomised trials with individually randomised trials in the same meta-analysis.

\section{Dealing with missing data}

We contacted study authors to obtain missing data and seek clarification where appropriate. Studies with missing standard deviations or for which the number of participants in each arm was not reported were excluded from the main analysis for the associated continuous measure. These studies were included in a sensitivity analysis, using imputed values for the standard deviations or the number of participants in each arm.

\section{Assessment of heterogeneity}

The magnitude of heterogeneity among trials was assessed using the $\mathrm{I}^{2}$ statistic (Higgins 2002; Higgins 2003). The statistical significance of heterogeneity was assessed using $P$ values derived from Chi ${ }^{2}$ tests (Deeks 2001).

\section{Assessment of reporting biases}

We assessed whether studies appeared to have incomplete reporting bias by noting in the risk of bias assessments whether the reported outcomes matched methods sections or any published protocols. We made every effort to minimise publication bias by searching a wide range of databases and sources of grey literature and not restricting by language or publication status. We constructed funnel plots (plots of the effect estimate from each study against the effect standard error) to assess potential for bias related to the size of the trials, which could indicate possible publication bias.

\section{Data synthesis}

The weighted mean difference method was used to estimate pooled effect sizes and $95 \% \mathrm{Cl}$, if sufficient studies reporting the outcome were available. Most trials reported weekly or monthly alcohol consumption and few reported drinking frequency or intensity. Hence, the meta-analysis of alcohol quantity consumed 
per week provided most information and constituted the primary meta-analysis. Statistical analyses were performed using RevMan 5 (Review Manager 2014). Because the populations and interventions evaluated by the trials were so heterogeneous, it was deemed more appropriate to use a random-effects model for all analyses (DerSimonian 1986). Random-effects meta-regression modelling was conducted using the metareg command in Stata version 14.1 (Stata 2015). Meta-regression was used to assess any differences in calculated effect associated with the publication date of studies, baseline consumption of participants, duration of treatment, and efficacy/effectiveness score.

For dichotomous outcomes (participant classified as a heavy or binge drinker), RDs and $95 \% \mathrm{Cls}$ were calculated and pooled in a random-effects meta-analysis using Mantel-Haenszel test weighting.

We addressed variable risk of bias using sensitivity analysis (see Sensitivity analysis).

If trials had more than one control arm and the various control arms were very similar (e.g. Sommers 2013), the results for these arms were combined by calculating weighted means of continuous outcomes and summing dichotomous outcomes; likewise for very similar treatment arms (D'Onofrio 2012).

\section{'Summary of findings' tables}

We used the GRADE approach to assess the quality of the evidence. GRADE takes into account issues related to both internal and external validity, such as directness of results (Atkins 2004; Guyatt 2008; Guyatt 2011). The 'Summary of findings' tables present main review findings in a transparent and simple tabular format. In particular, 'Summary of findings' tables provide key information concerning the quality of evidence, the magnitude of effect of the interventions examined and the sum of available data on the main outcomes.

The GRADE system uses the following criteria for assigning grades of evidence.

- High: we are very confident that the true effect lies close to that of the estimate of the effect.

- Moderate: we are moderately confident in the effect estimate: the true effect is likely to be close to the estimate of the effect, but there is a possibility that it is substantially different.

- Low: our confidence in the effect estimate is limited: the true effect may be substantially different from the estimate of the effect.

- Very low: we have very little confidence in the effect estimate: the true effect is likely to be substantially different from the estimate of effect.

We used GRADEpro GDT 2015 to import data from Review Manager 2014 for the main outcomes of quantity of drinking (g/week) frequency of drinking (days per week and binges per week) and intensity of drinking (drinks/drinking day) for each of the comparisons (brief intervention versus minimal or no intervention, extended intervention versus minimal or no intervention, extended intervention versus brief intervention) (Summary of findings for the main comparison; Summary of findings 2; Summary of findings 3).

\section{Subgroup analysis and investigation of heterogeneity}

We carried out subgroup analyses to address the effects of each of the following:

\section{Applicability issues - population characteristics, setting and mode of intervention}

Where reported, we recorded the gender, age and ethnicity of included participants to assess how applicable brief interventions are to different groups of people presenting to primary care. We conducted subgroup analyses for the primary outcome (alcohol consumption at 12-months follow-up) based on gender and according to adolescents or young adults versus with other age groups. We also examined study settings (general practice or emergency care). We also investigated the modality of the intervention (whether it was reported as advice or counsellingbased).

\section{Variability in treatment exposure, control condition, year of publication, baseline consumption and follow up time scales}

We calculated a measure of treatment exposure as the sum of the duration of the initial brief intervention plus the total duration of all booster sessions, in minutes. If a range of durations was given then we used the mean. If duration was not reported, we assumed the brief intervention to take 5 to 10 minutes, with a mean of 7.5 minutes. We carried out a meta-regression analysis to look for any association between the impact of treatment on the quantity of alcohol consumed at 12 months and the level of treatment exposure. We performed this analysis separately for trials that compared a brief intervention with minimal or no intervention, and for trials that compared an extended intervention with minimal or no intervention. Only results from the comparison of extended intervention versus minimal or no intervention were included in meta-regression analysis for trials that included three intervention arms (minimal or no intervention, brief intervention and extended intervention).

The definition of excessive drinking has changed over time (e.g. NHMRC 2009; UK Department of Health 2016), particularly regarding the threshold for entry into trials. To examine the impact of this and any other temporal factors, trials were classified by year of publication and meta-regression analysis performed to look for any relationship between publication date and the primary outcome measure. This enabled examination of whether the intervention effect had diminished as the definition of excessive drinking has reduced. A meta-regression analysis was also conducted on whether the primary outcome measure was related to the level of consumption at baseline. Because baseline consumption varied over time, meta-regression analysis informed examination of changes when adjustment was made for year of publication. We analysed studies added for this update separately from studies included in the previous review version (Kaner 2007). This analysis was planned to illustrate if primary outcome measure findings were compatible.

The primary analyses reported outcomes at 12 month follow-up, reflecting the large number of studies with information at this time point, and our interest in investigating robust changes in drinking behaviour rather than shorter term or transient changes. Where sufficient information was available (specifically, for quantity of alcohol consumed and frequency of drinking), analyses were 
undertaken based on other follow-up times. The minimum followup time was six months.

\section{Effectiveness and efficacy}

Efficacy trials tend to take place in tightly controlled research environments. They typically recruit a more homogenous group of participants than effectiveness trials. The former involve practitioners or interventionists who are likely to have more skills in alcohol intervention or behaviour change work than generalists working in routine primary care. They may occur in specialist healthcare or university settings and are often well-resourced, supported or closely monitored to ensure that interventions are delivered precisely as intended. Conversely, effectiveness trials are closer to a real world situation and are more representative of routine clinical practice. These tend to have a broader range of participants, involve clinicians who routinely work in primary care and allow more flexibility in the way the intervention is delivered. We developed a scale based on the work of Shadish 2000 to categorise included trials along a spectrum of efficacy to effectiveness.

Two review authors independently classified each trial (see Table 1). If an item appeared to be partially clinically representative on any item, then we gave a midpoint score (either 1 or 0.5 as applicable). If the study authors did not report data relating to a particular item, then we allocated an intermediate score to limit bias in the trial toward the effectiveness or efficacy domain. We resolved disagreements concerning classification by discussion to achieve consensus.

We summed all items for each study to provide an efficacy/ effectiveness score of 0 to 12 . If a study scored highly it was likely to be highly clinically relevant and was considered to be an effectiveness trial with high external validity. Conversely, if a trial scored very low, it was highly research relevant and considered to be an efficacy trial with high internal validity. We plotted the effect of brief intervention compared to minimal or no intervention on the quantity of alcohol consumed, as estimated from random- effects meta-analysis, against the efficacy/effectiveness score. We performed meta-regression analysis to assess whether this treatment effect was related to the efficacy/efficiency score. We also categorised trials as effectiveness or efficacy trials based on score above or below the median and performed subgroup analysis.

\section{Sensitivity analysis}

Sensitivity analyses were performed based on the following characteristics.

1. Risk of bias: the primary meta-analysis was repeated in analyses: a. including only studies at low risk of bias due to allocation concealment; and

b. excluding studies at high risk of bias due to incomplete outcome data (i.e. attrition bias). We did not conduct a sensitivity analysis on the basis of risk of bias due to blinding because it is not possible to mask the nature of the intervention to providers or participants.

2. Missing standard deviations: we imputed the median standard deviation of the relevant outcome from other trials to both treatment and control groups of those with missing SDs.

3. Comparison of outcomes from cluster and individually randomised trials: a sensitivity analysis was performed to investigate the robustness of the conclusions, especially of the effect of varying assumptions about the magnitude of the ICC.

\section{RESULTS}

\section{Description of studies}

\section{Results of the search}

Searches identified 4004 potentially relevant records which were screened by title and abstract for eligibility. We retrieved 165 records for full text assessment. We added 42 studies (73 reports) for this update. The previous version of this review included 29 studies (39 reports) (Kaner 2007). This review included 69 studies (112 reports) (Figure 1; Characteristics of included studies), 
Figure 1. Study flow diagram.

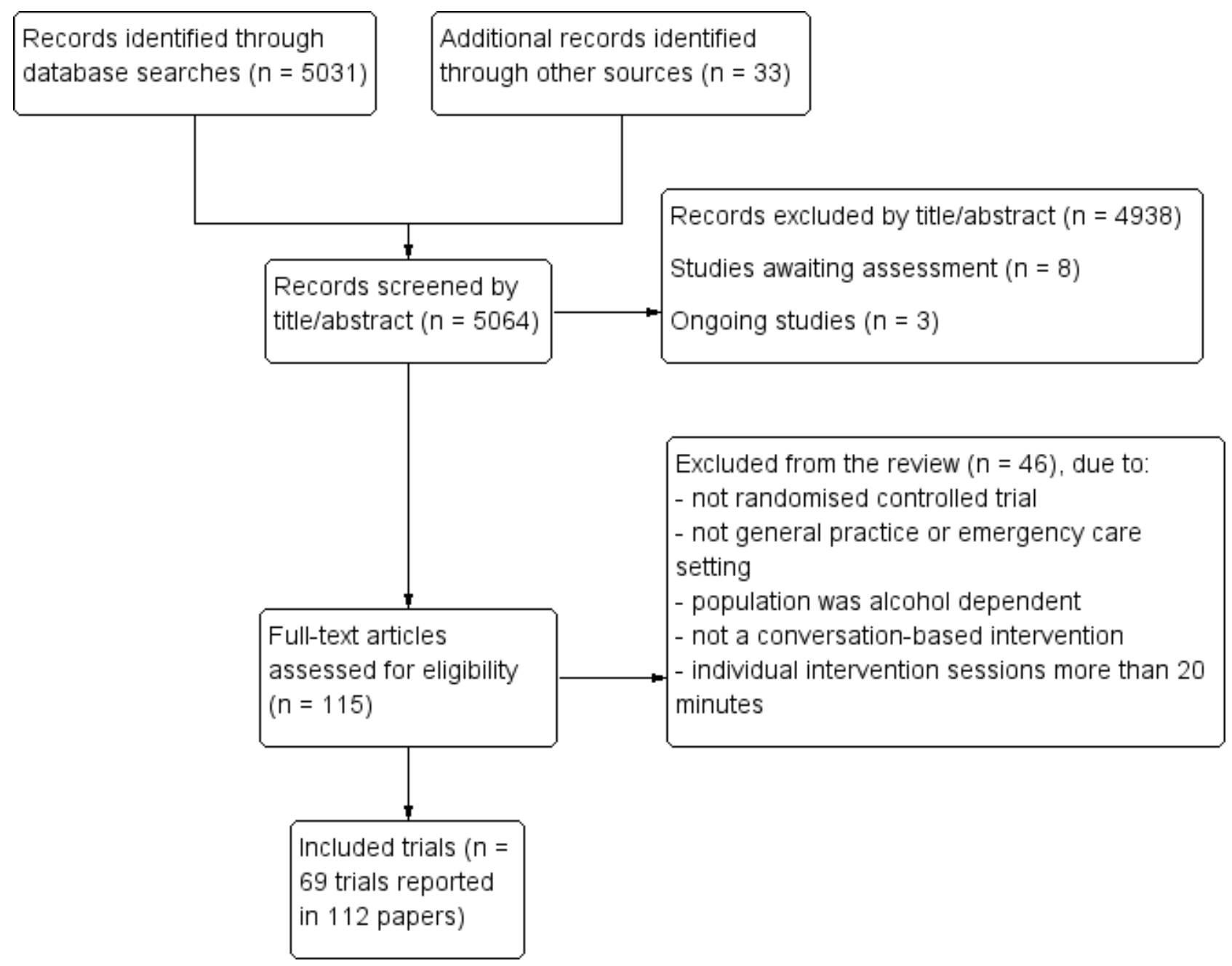

We contacted 10 authors to request missing data or ask for clarification for this update.

\section{Included studies}

\section{Population}

The 69 included trials randomised a total of 33,642 participants (median 378, IQR 152 to 599). The mean percentage of male participants was $70 \%$. Among the 45 trials that reported participants' age, the mean age was 40 years (SD 11.18). Eight trials focused on adolescents, young adults, or both (D'Amico 2008; Mertens 2014; Monti 2007; Segatto 2011; Spirito 2004; Spirito 2011; Tait 2004; Walton 2010). Four trials focused on older adults (aged > 55 years, aged $>60$ years, or aged $>65$ years) (Ettner 2014; Fleming 1999; Moore 2011; Watson 2013). Half the included trials (51\%) reported participants' ethnicity; most participants were Caucasian $(n=28$ trials, $78 \%)$.

In many cases, potential participants were excluded from trials if they were heavily alcohol dependent, already on an alcohol treatment programme, or had been in the previous year. However, some trials did not specify any exclusion criteria and included a proportion of participants who may have been dependent drinkers. These trials were included where most participants were not identified as being dependent on alcohol and the intervention was not aimed at dependent drinkers.

All participants were screened for eligibility into trials. Screening methods included general health questionnaires (such as the Health and Habits Survey), which sometimes incorporated alcohol consumption questions, and established alcohol screening tools such as CAGE, AUDIT or MAST. Some trials used a combination of these tools and determined alternative inclusion criteria to increase the likelihood of picking up relevant participants. Most trials administered the screening tool by telephone or in a clinic as soon as the person had registered for their appointment; one study administered the questionnaire by telephone following the intervention. There were difference in alcohol consumption inclusion criteria among trials, for example by number of units per week, screening tool score, level of binge, or high intensity drinking.

The mean overall baseline consumption for participants in the 32 trials that reported these data was $244 \mathrm{~g} /$ week (SD 119) (about 30 UK units). We included 13 trials that reported baseline consumption for men only (or recruited men only) and also reported the number of men randomised (Aalto 2000; Altisent 1997; Babor 2006; Beich 2007; Córdoba 1998; Díez 2002; Fleming 1997; Huas 2002; Mclntosh 1997; Richmond 1995; Rubio 2010; Scott 1990; Wallace 1988). In 
these trials, the mean baseline consumption was $350 \mathrm{~g} /$ week (around 44 UK units). The corresponding value for the nine trials that reported consumption for women was $190 \mathrm{~g} /$ week (around 24 UK units). Mean baseline consumption differed between older studies included in the original review and the more recent studies included for this update. Previously, the overall mean baseline consumption in 21 trials reporting these data was $313 \mathrm{~g} /$ week (about 39 UK units). Only 11 trials added for this update reported overall mean baseline consumption, which was $181 \mathrm{~g} /$ week (about 23 UK units).

We included 14 trials that reported baseline measures of frequency of drinking which could be converted to days drinking per week; the mean value was 2.07 days/week (Aalto 2000; Bernstein 2010; Cherpitel 2009; Daeppen 2007; Fleming 1997; Fleming 2010; Helstrom 2014; Monti 2007; Noknoy 2010; Rubio 2010; Schaus 2009; Senft 1997; Soderstrom 2007; Spirito 2004). Baseline intensity of drinking was reported in 11 trials, in which the mean baseline value was $69 \mathrm{~g} /$ drinking day.

There was substantial heterogeneity among trials in terms of the mechanisms of screening participants for inclusion and in the content of both control and intervention arms.

\section{Setting}

Most trials $(n=34)$ took place in the USA (Babor 2006; BazarganHejazi 2005; Beckham 2007; Bernstein 2010; Blow 2006; Curry 2003; D'Amico 2008; Désy 2010; D'Onofrio 2008; D'Onofrio 2012; Ettner 2014; Field 2010; Fleming 1997; Fleming 1999; Fleming 2004; Fleming 2010; Helstrom 2014; Kunz 2004; Longabaugh 2001; Maisto 2001; McDevitt-Murphy 2014; Mello 2008; Monti 2007; Moore 2011; Ockene 1999; Schaus 2009; Senft 1997; Soderstrom 2007; Sommers 2006; Sommers 2013; Spirito 2004; Spirito 2011; Walton 2010; Woolard 2013); 10 in the UK (Crawford 2004; Crawford 2010; Drummond 2009; Drummond 2014; Heather 1987; Kaner 2013; Lock 2006; Scott 1990; Wallace 1988; Watson 2013); six in Spain (Altisent 1997; Córdoba 1998; Díez 2002; Fernández 1997; Rodríguez 2003; Rubio 2010); four in Australia (Dent 2008; Lane 2008; Richmond 1995; Tait 2004); two each in Canada (Israel 1996; McIntosh 1997), Finland (Aalto 2000; Seppa 1992) and Sweden (Romelsjö 1989; Tomson 1998); and one each in Denmark (Beich 2007), France (Huas 2002) Germany (Bischof 2008), Poland (Cherpitel 2009), Switzerland (Daeppen 2007), South Africa (Mertens 2014), Kenya (L'Engle 2014), Brazil (Segatto 2011) and Thailand (Noknoy 2010).

Many interventions ( $n=38,55 \%)$ were delivered in general practices (Aalto 2000; Altisent 1997; Babor 2006; Beckham 2007; Beich 2007; Bischof 2008; Córdoba 1998; Curry 2003; D'Amico 2008; Díez 2002; Drummond 2009; Ettner 2014; Fernández 1997; Fleming 1997; Fleming 1999; Fleming 2004; Heather 1987; Helstrom 2014; Huas 2002; Israel 1996; Kaner 2013; L'Engle 2014; Lock 2006; Maisto 2001; McIntosh 1997; Mertens 2014; Moore 2011; Noknoy 2010; Ockene 1999; Richmond 1995; Romelsjö 1989; Rubio 2010; Scott 1990; Senft 1997; Seppa 1992; Tomson 1998; Wallace 1988; Watson 2013) and 27 (39\%) were carried out in emergency departments (BazarganHejazi 2005; Bernstein 2010; Blow 2006; Cherpitel 2009; Crawford 2004; Crawford 2010; D'Onofrio 2008; D'Onofrio 2012; Daeppen 2007; Dent 2008; Désy 2010; Drummond 2014; Field 2010; Kunz 2004; Longabaugh 2001; Mello 2008; Monti 2007; Rodríguez 2003; Segatto 2011; Soderstrom 2007; Sommers 2006; Sommers 2013; Spirito 2004; Spirito 2011; Tait 2004; Walton 2010; Woolard 2013). Two studies took place in college health clinics (Fleming 2010;
Schaus 2009), one in a public sexual health clinic (Lane 2008) and one in a veterans' affairs medical centre (McDevitt-Murphy 2014). The studies by Lane 2008 and McDevitt-Murphy 2014 were included because although they did not take place in general practice clinics, the interventions were available without referral to large groups of people. One study reported findings for two primary care settings and two other settings; only data from primary care settings were included in the meta-analyses (Díez 2002).

\section{Interventions}

\section{Brief intervention}

Most studies ( $n=61)$ compared brief intervention with minimal or no intervention. Of these, five also included an extended intervention arm (Aalto 2000; Bischof 2008; Longabaugh 2001; Maisto 2001; Richmond 1995), and eight included two minimal or no intervention arms (Bernstein 2010; Blow 2006; Cherpitel 2009; Daeppen 2007; D'Onofrio 2012; Heather 1987; Richmond 1995; Sommers 2013). Two studies included two intervention arms with identical content but delivered by different health professionals (Babor 2006; Mclntosh 1997). Three studies included two substantively different intervention arms (Dent 2008; D'Onofrio 2012; Walton 2010). Four studies delivered minimal intervention which was sometimes described as a control condition and sometimes as an intervention condition (Heather 1987; Kaner 2013; Richmond 1995; Sommers 2006). One study compared an extended intervention with a brief intervention (Spirito 2011). Four studies compared only an extended intervention with minimal or no intervention (Israel 1996; L'Engle 2014; Monti 2007; Moore 2011).

All interventions provided feedback on the screening outcome plus structured advice about potential risks of heavy drinking and ways to reduce consumption. Feedback and structured advice took several formats: described as brief Intervention (and assumed to be based on FRAMES where not reported) ( $n=27)$; based on or informed by motivational interviewing, Motivational Enhancement Therapy (MET), or Brief Negotiated Interview (BNI) ( $n=32$ ); or based on Cognitive Behavioural Therapy (CBT) techniques $(n=2)$. Some were backed up by diaries or exercises for the participant to complete at home, and follow-up telephone calls.

A single brief intervention session was evaluated in 29 studies (Bazargan-Hejazi 2005; Beckham 2007; Blow 2006; Cherpitel 2009; Córdoba 1998; Crawford 2004; Crawford 2010; D'Onofrio 2008; Daeppen 2007; Désy 2010; Díez 2002; Drummond 2014; Fernández 1997; Field 2010; Kaner 2013; Kunz 2004; Lane 2008; Lock 2006; Longabaugh 2001; Maisto 2001; McDevitt-Murphy 2014; Mertens 2014; Ockene 1999; Rodríguez 2003; Scott 1990; Segatto 2011; Spirito 2004; Spirito 2011; Walton 2010). In the remaining studies, there were between two and five sessions, where individual sessions varied from one to a maximum of 60 minutes. General practitioners, nurse practitioners, health psychologists or trainee health psychologists administered the interventions.

\section{Extended interventions}

Extended interventions also provided feedback and structured advice but comprised either more than five sessions or more than 60 minutes in total. Extended interventions were based on motivational interviewing (five studies), MET (two studies), multiple FRAMES sessions (two studies), or CBT (one study) approaches. Extended interventions were evaluated in 10 trials (Aalto 2000; Bischof 2008; Israel 1996; L'Engle 2014; Longabaugh 
2001; Maisto 2001; Monti 2007; Moore 2011; Richmond 1995; Spirito 2011), in which the total duration was greater than 60 minutes and the number of sessions delivered to participants ranged from two to seven. The total duration of extended intervention sessions ranged from 60 minutes to 180 minutes.

\section{Total treatment exposure}

Total treatment exposure was calculated as a combination of the initial session plus any additional sessions. Treatment duration in the intervention arm ranged from less than five minutes (Babor 2006; Huas 2002) to 60 minutes (Mclntosh 1997) of advice or counselling. The median duration was 25 minutes and IQR 7.5 to 30.0 minutes. Treatment duration in the control group was up to 10 minutes (Díez 2002; Rodríguez 2003). In the extended intervention conditions, the treatment exposures ranged from 65 minutes to 175 minutes.

\section{Control group content}

Five categories of control condition were reported. Participants received:

1. screening only; or

2. screening and assessment only; or

3. usual care - this was usually not described further but was assumed to be care for the presenting condition or usual advice about alcohol consumption; or

4. general health advice or minimal advice about alcohol, comprising general health information or very limited alcoholrelated information which often included an instruction to cut down drinking; or

5. a leaflet with either general health and lifestyle advice or more specific information about the risks of hazardous alcohol consumption.

Some trials provided control participants with both usual care and a leaflet. One trial did not include a control condition but compared extended intervention with brief motivational intervention (Spirito 2011).

\section{Efficacy/effectiveness scores}

Efficacy/effectiveness scores ranged from 4.5 (Beckham 2007; Fleming 2004; Romelsjö 1989) to 12 (Lock 2006). The median was 8.5 and IQR 7 to 10.5 (Table 2).

\section{Reporting of outcomes}

The included studies reported many different measures of the primary outcome. We could not include 22 studies in meta-analyses (Aalto 2000; Bazargan-Hejazi 2005; Beckham 2007; Crawford 2010; D'Amico 2008; Dent 2008; Désy 2010; Díez 2002; Drummond 2009; Heather 1987; Kunz 2004; L'Engle 2014; Lane 2008; McDevittMurphy 2014; Mello 2008; Mertens 2014; Noknoy 2010; Rodríguez 2003; Segatto 2011; Sommers 2006; Tait 2004; Woolard 2013), either because outcomes were not reported at 12 months, or outcome measures differed from those prespecified for this review (such as AUDIT score).

\section{Quantity of alcohol consumed in a specified time period}

Quantity of alcohol consumed in a specified time period (usually a week or a month) was reported in 51 studies that compared a brief intervention with minimal or no intervention. Of these, 27 studies reported quantity and corresponding standard deviation at 12 months (Altisent 1997; Beich 2007; Bernstein 2010; Blow 2006; Córdoba 1998; Crawford 2004; Daeppen 2007; D'Onofrio 2008; D'Onofrio 2012; Drummond 2014; Fleming 1997; Fleming 1999; Fleming 2004; Fleming 2010; Helstrom 2014; Kaner 2013; Lock 2006; Maisto 2001; Richmond 1995; Rubio 2010; Schaus 2009; Scott 1990; Senft 1997; Soderstrom 2007; Sommers 2013; Wallace 1988; Watson 2013). The authors of one study provided unpublished data on the corresponding standard deviation (Curry 2003). A further six studies reported the change between baseline and the end of follow-up (change score) in the quantity of alcohol consumed in a specified time period and the corresponding standard deviation (Bischof 2008; Fernández 1997; Field 2010; Huas 2002; Ockene 1999; Romelsjö 1989). We included 34 studies in the primary metaanalysis comparing the effects of a brief intervention with minimal or no intervention on the quantity of alcohol consumed per week, reported at 12 months follow-up. Two studies reported the quantity of alcohol consumed per week both as assessed by structured interview and as reported on a self-completed questionnaire; we used the interview data (Scott 1990; Wallace 1988).

Five studies reported the final values of the quantity of alcohol consumed in a specified time period at 12 months but without corresponding standard deviations (Babor 2006; Cherpitel 2009; Ettner 2014; Mclntosh 1997; Spirito 2004). These studies could not be included in the primary meta-analysis but were included in a sensitivity analysis with imputed standard deviations.

Six studies compared an extended intervention with minimal or no intervention and reported quantity of alcohol consumed at 12 months (Bischof 2008; Israel 1996; Maisto 2001; Monti 2007; Moore 2011; Richmond 1995). Three of these studies also compared an extended intervention to a brief intervention (Bischof 2008; Maisto 2001; Richmond 1995). One study, which compared an extended to a brief intervention, was included in a meta-analysis with imputed standard deviations (Spirito 2011).

The units of alcohol used in each trial with the conversion factor used to convert to grams of alcohol are presented in Table 2.

\section{Frequency of drinking (number of drinking sessions in a specified time period)}

We included 15 trials that compared brief intervention to no or minimal intervention and reported frequency of drinking in terms of number of binge drinking occasions each week or each month at six or 12 months (Blow 2006; Daeppen 2007; D'Onofrio 2008; D'Onofrio 2012; Fleming 1997; Fleming 1999; Fleming 2004; Fleming 2010; Helstrom 2014; Longabaugh 2001; Ockene 1999; Rubio 2010; Spirito 2004; Soderstrom 2007; Schaus 2009). Two trials reported this outcome for extended versus no or minimal intervention (Longabaugh 2001; Monti 2007).

Frequency of drinking in terms of number of days drinking each week or each month was reported by 11 trials at 6 or 12 months (Bernstein 2010; Cherpitel 2009; Crawford 2004; Curry 2003; Daeppen 2007; Field 2010; Fleming 2010; Helstrom 2014; Maisto 2001; Senft 1997; Spirito 2004). Longabaugh 2001 reported the number of days drinking but the number of participants assessed was not reported. Two trials reported this outcome for extended versus no or minimal intervention (Maisto 2001; Monti 2007), and one for extended versus brief intervention (Maisto 2001). 
Intensity of drinking (amount of alcohol consumed in a drinking session)

We included 10 trials that compared brief intervention to no or minimal intervention and reported intensity of alcohol consumption in terms of number of drinks per occasion at 12 months (Bernstein 2010; Cherpitel 2009; Crawford 2004; Curry 2003; Daeppen 2007; Helstrom 2014; Maisto 2001; Schaus 2009; Senft 1997; Spirito 2004). One trial reported this outcome for extended intervention versus no or minimal intervention and versus brief intervention (Maisto 2001).

\section{Laboratory markers}

We included seven studies that compared brief intervention to no or minimal intervention and reported gamma-glutamyltransferase (GGT) (Aalto 2000; Beckham 2007; Noknoy 2010; Romelsjö 1989; Scott 1990; Tomson 1998; Wallace 1988). Romelsjö 1989 reported change scores whereas the other studies reported final values; only three studies reported at 12 months. One study reported this outcome for extended versus no or minimal intervention (Israe 1996).

One trial reported mean corpuscular volume (MCV) for this comparison (Seppa 1992).

\section{Alcohol-related harm}

A measure of alcohol-related consequences or harm (e.g. Drinker Inventory of Consequences - DrInC; Alcohol Problems Quesionnaire - APQ) was reported by 21 studies (Blow 2006; Cherpitel 2009; D'Onofrio 2012; Drummond 2009; Drummond 2014; Fleming 2010; Heather 1987; Helstrom 2014; Kaner 2013; Lane 2008; Longabaugh 2001; McDevitt-Murphy 2014; McIntosh 1997; Mello 2008; Mont 2007; Romelsjö 1989; Schaus 2009; Spirito 2004; Walton 2010; Watson 2013; Woolard 2013).

\section{Secondary outcomes}

The percentage of heavy or binge drinkers at 12 months was reported by 19 studies (Altisent 1997; Beich 2007; Cherpite 2009; Córdoba 1998; Curry 2003; Daeppen 2007; D'Onofrio 2008; Drummond 2014; Ettner 2014; Fernández 1997; Fleming 1997; Fleming 1999; Fleming 2004; Kaner 2013; Rubio 2010; Scott 1990; Sommers 2013; Wallace 1988; Walton 2010). Definitions of binge drinking varied, and were based on exceeding government recommendations, AUDIT scores, or a trial-defined number of drinks per week (for heavy drinking) or occasion (for binge drinking). Older studies tended to define higher limits (e.g. $>35$ units/week by Wallace 1988) than more recent studies (e.g. > 18 drinks/week by Rubio 2010).

Two studies reported patient satisfaction measures (Drummond 2009; Kaner 2013), and six studies reported measures of health status or quality of life (Crawford 2004; Daeppen 2007; Drummond 2014; Kaner 2013; Lock 2006; Tait 2004). Two studies reported costs (Drummond 2009; Ettner 2014) and two studies reported economic evaluations (Lock 2006; Watson 2013). Nine studies reported measures of healthcare utilisation (Babor 2006; Crawford 2004; Dent 2008; Désy 2010; Ettner 2014; Fleming 1997; Fleming 2010; Kaner 2013; Tait 2004).

\section{Reporting of outcomes by gender}

Two studies reported on male and female participants in separate papers (Aalto 2000; Scott 1990). Seven studies reported on male and female participants separately in the same paper (Beich 2007; Richmond 1995; Rubio 2010; Scott 1990; Senft 1997; Seppa 1992; Wallace 1988). Data on men and women in the same trial were combined for the primary meta-analysis.

Two studies reported the final values of the quantity of alcohol consumed in a specified time period by gender but did not report the number of men and women assessed (Fleming 1997; Ockene 1999). Therefore, these studies could not be included in the metaanalysis of quantity of alcohol consumed in a specified time period, subgrouped by gender.

\section{Outcomes reported at several follow-up time points}

Many studies reported at several time points, although not all outcomes were reported at all time points. The TrEAT study reported after follow-up of one and four years (Fleming 1997). The HEALTH study reported at six-months and one-year follow-up (Ockene 1999). Richmond 1995 reported outcomes at six months and one year. Curry 2003 reported outcomes at three months and one year.

If outcomes were reported at several time points, data for one-year follow up were used in the meta-analyses if available.

\section{Cluster-randomised trials}

We included eight cluster-randomised trials (Babor 2006; Córdoba 1998; Drummond 2014; Ettner 2014; Huas 2002; Kaner 2013; Lock 2006; Ockene 1999). Córdoba 1998 and Lock 2006 randomised 33 and 40 general practices respectively with averages of 6.9 and 2.0 participants per practice. Huas 2002 randomised 88 primary care physicians with an average of 4.8 participants per physician, and Ettner 2014 recruited 31 primary care providers with a total of 1186 participants. Kaner 2013 recruited 34 general practices with a target of 31 participants per practice. Ockene 1999 randomised four internal medicine practice sites with an average of 111 participants per site. Babor 2006 recruited five managed care organisations, which provided 15 practices. Drummond 2014 recruited nine emergency departments with an average of 135 participants per site. Clustering was accounted for in analyses by five studies (Babor 2006; Drummond 2014; Kaner 2013; Lock 2006; Ockene 1999). For the three studies that did not account for clustering (Córdoba 1998; Ettner 2014; Huas 2002), we extracted reported standard deviations for treatment and control groups and inflated them, assuming an ICC of 0.06 to allow for the clustered design (Higgins 2011a; Lock 2006).

\section{Study funding sources}

Most studies reported sources of funding ( $n=60,87 \%$ ). With two exceptions, funding was provided by government institutes, research bodies or charitable foundations. One study was partly funded by a pharmaceutical company and a brewers association (Wallace 1988) and another by a company developing diagnostic testing equipment (Fleming 2004).

\section{Excluded studies}

We excluded 46 studies. The most common reason for exclusion was that participants were not recruited from primary care settings $(n=22)$. Other reasons included that the intervention was not conversation-based $(n=6)$, the intervention or comparator did not fit our prespecified criteria $(n=5)$ and the trial reported implementation rather than effectiveness outcomes $(n=2)$. We 
excluded two trials from the original review for this update. Chang 1997 compared brief intervention to alcohol treatment referral, which is not an analogous control group with the included trials. Participants in another trial (Gentilello 1999) were inpatients and the trial is included in a Cochrane Review of brief interventions in patients admitted to hospital.. See Excluded studies.

\section{Studies awaiting classification}

Searches identified eight studies which await classification (Arnaud 2017; Cherpitel 2016; Crawford 2015; Diaz Gomez 2017; Mello 2016; Monti 2015; Nadkarni 2017; Walton 2015; Characteristics of studies awaiting classification).

Mello 2016 and Monti 2015 recruited adult participants from emergency departments in the USA and administered brief motivational interventions. Monti 2015 reported improvement in the intervention group and Mello 2016 reported no clinically important difference between the groups at follow-up. Four studies recruited adolescents or young adults from emergency departments and administered brief interventions based on motivational interviewing or brief negotiation interviews (Arnaud 2017; Cherpitel 2016; Diaz Gomez 2017; Walton 2015). Two of these (Diaz Gomez 2017; Walton 2015) reported a significant improvement in the intervention group (although one (Walton 2015) noted it was a small effect) and two reported that consumption in both groups was reduced (Arnaud 2017; Cherpitel 2016).

Nadkarni 2017 recruited adult men in primary care centres in India and administered a multi-session (extended) intervention called Counselling for Alcohol Problems (CAP), reporting a significant improvement in the intervention group.

Crawford 2015 recruited adults from a primary care sexual health clinic in the UK and administered very brief advice followed by the opportunity to see an alcohol health worker for a FRAMES-based intervention; no clinically important difference was seen between the groups.

These studies will be assessed for inclusion in a future update.

\section{Ongoing studies}

Three potentially eligible studies are ongoing. One is a UK trial of adolescents aged 14 to 17 who present to the emergency department and are randomised to a face-to-face intervention, a control arm, or a smart phone intervention (ISRCTN45300218). A second trial is recruiting young adults (aged 18 to 35 years) from a Swiss emergency department and administering brief motivational interviewing to the intervention group (ISRCTN13832949). The third is a trial taking place in adult women (aged over 18 years) presenting to Brazilian primary care clinics (RBR-65262c). Participants in the intervention group are to receive two brief intervention sessions, each lasting 20 to 30 minutes.

These studies will be assessed for inclusion in a future update.

\section{Risk of bias in included studies}

The main sources of bias were attrition and performance bias. Performance bias occurred because it is not possible to blind participants or providers to a conversation-based intervention. Otherwise, very few trials were at high risk of bias. Many domains were assessed as unclear risk of bias because there was insufficient information reported in study reports to make a clear decision. This was largely because many included studies were published before CONSORT reporting guidelines appeared in 2010 (Schulz 2010).

Risk of bias and reasons for judgements are presented in Characteristics of included studies and graphic summaries in Figure 2 and Figure 3.

\section{Figure 2. Risk of bias graph: review authors' judgements about each risk of bias item presented as percentages across all included studies.}

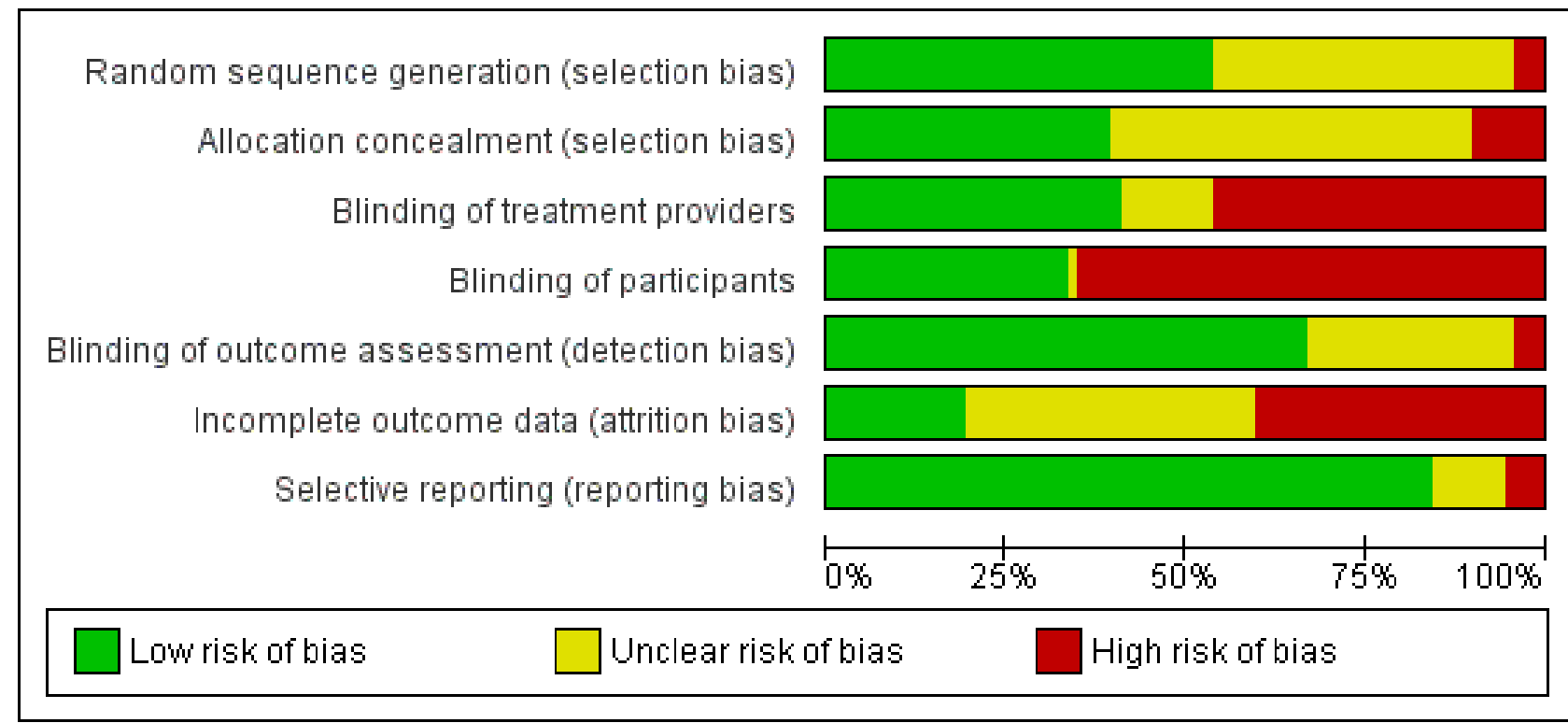


Figure 3. Risk of bias summary: review authors' judgements about each risk of bias item for each included study.

\begin{tabular}{|c|c|c|c|c|c|c|c|}
\hline & 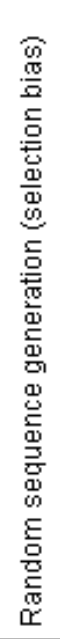 & 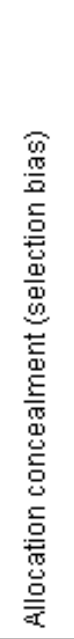 & 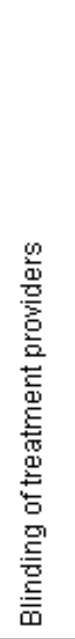 & 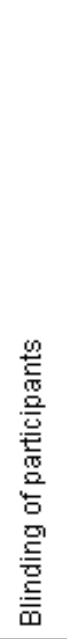 & 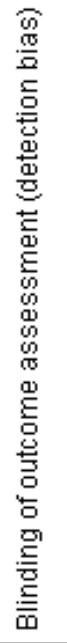 & 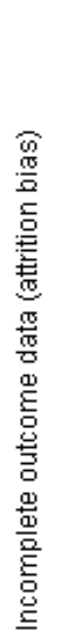 & 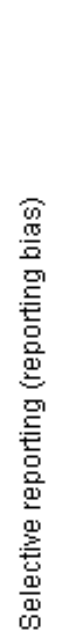 \\
\hline Aalto 2000 & + & $O$ & $\odot$ & $\odot$ & $?$ & $\odot$ & $?$ \\
\hline Altisent 1997 & + & + & $\odot$ & $\ominus$ & $?$ & $\odot$ & $\oplus$ \\
\hline Babor 2006 & + & $\odot$ & + & $\odot$ & $\odot$ & $\odot$ & $\odot$ \\
\hline Bazargan-Hejazi 2005 & $\odot$ & $\odot$ & $\odot$ & $\odot$ & $\odot$ & $\odot$ & $?$ \\
\hline Beckham 2007 & + & $?$ & $\odot$ & $\odot$ & $?$ & $?$ & + \\
\hline Beich 2007 & $?$ & $\odot$ & - & $\Theta$ & $\odot$ & $\odot$ & $\odot$ \\
\hline Bernstein 2010 & + & + & $?$ & $\odot$ & $\odot$ & $?$ & $\odot$ \\
\hline Bischof 2008 & $\odot$ & + & $\odot$ & $\Theta$ & $\odot$ & $\odot$ & $\odot$ \\
\hline Blow 2006 & + & $?$ & + & $\ominus$ & $?$ & $\odot$ & + \\
\hline Cherpitel 2009 & $?$ & $?$ & + & $\Theta$ & $\odot$ & $\odot$ & $\odot$ \\
\hline Córdoba 1998 & $?$ & $\odot$ & $\odot$ & $\odot$ & $?$ & 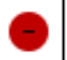 & $\oplus$ \\
\hline Crawford 2004 & + & $?$ & + & $\ominus$ & $\odot$ & $\odot$ & + \\
\hline Crawford 2010 & + & $?$ & + & $\odot$ & $\odot$ & $\odot$ & + \\
\hline Curry 2003 & $?$ & $?$ & + & + & $?$ & $?$ & + \\
\hline D'Amico 2008 & $\odot$ & 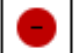 & $?$ & + & $?$ & ? & + \\
\hline D'Onofrio 2008 & $?$ & + & $?$ & $\odot$ & $\odot$ & $?$ & + \\
\hline D'Onofrio 2012 & $?$ & $?$ & + & $\odot$ & $\odot$ & $\odot$ & + \\
\hline Daeppen 2007 & + & $?$ & 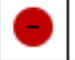 & + & $\odot$ & $?$ & + \\
\hline Dent 2008 & $\odot$ & + & - & $\Theta$ & $\odot$ & $\odot$ & + \\
\hline Désy 2010 & + & $?$ & + & $\Theta$ & $?$ & $\odot$ & + \\
\hline \multirow[t]{2}{*}{ Díez 2002} & $?$ & $?$ & $\odot$ & $\Theta$ & $?$ & $\odot$ & 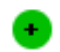 \\
\hline & 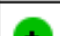 & 10 & ת & 0 & 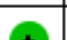 & $=$ & \\
\hline
\end{tabular}


Figure 3. (Continued)

\begin{tabular}{|c|c|c|c|c|c|c|c|}
\hline \multirow{2}{*}{$\begin{array}{l}\text { Lies } 2002 \\
\text { Drummond } 2009\end{array}$} & $:$ & $:$ & $\bullet$ & $\bullet$ & : & 0 & - \\
\hline & + & $?$ & $\odot$ & + & + & $?$ & + \\
\hline Drummond 2014 & + & + & + & 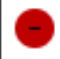 & + & $\Theta$ & 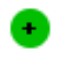 \\
\hline Ettner 2014 & + & + & + & $\theta$ & + & $?$ & + \\
\hline Fernández 1997 & + & 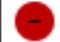 & $?$ & $\theta$ & + & $\theta$ & + \\
\hline Field 2010 & + & + & $\Theta$ & $\theta$ & + & $\theta$ & $\Theta$ \\
\hline Fleming 1997 & + & + & + & + & + & $?$ & + \\
\hline Fleming 1999 & $?$ & + & + & + & + & + & + \\
\hline Fleming 2004 & $?$ & $?$ & + & O & + & $?$ & + \\
\hline Fleming 2010 & + & + & + & + & + & + & + \\
\hline Heather 1987 & $?$ & + & $\theta$ & $O$ & + & + & + \\
\hline Helstrom 2014 & $?$ & $?$ & + & 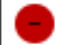 & $?$ & ? & + \\
\hline Huas 2002 & $?$ & + & $?$ & - & $?$ & + & + \\
\hline Israel 1996 & + & $\odot$ & $\theta$ & $\odot$ & + & $?$ & $\odot$ \\
\hline Kaner 2013 & + & + & + & $\theta$ & + & $\odot$ & $?$ \\
\hline Kunz 2004 & $?$ & $?$ & $\Theta$ & - & + & $\Theta$ & + \\
\hline L'Engle 2014 & + & + & $\Theta$ & 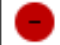 & + & $?$ & $?$ \\
\hline Lane 2008 & $?$ & $?$ & $\Theta$ & 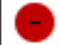 & + & $?$ & + \\
\hline Lock 2006 & + & + & + & - & + & - & + \\
\hline Longabaugh 2001 & $?$ & - & $\Theta$ & - & + & $?$ & + \\
\hline Maisto 2001 & + & + & $?$ & $\Theta$ & $?$ & $?$ & + \\
\hline McDevitt-Murphy 2014 & ? & $?$ & $\theta$ & - & $?$ & $?$ & + \\
\hline McIntosh 1997 & $?$ & $?$ & $?$ & - & $?$ & $?$ & + \\
\hline Mello 2008 & + & $?$ & $\odot$ & $\Theta$ & + & $?$ & + \\
\hline Mertens 2014 & $?$ & $?$ & $\Theta$ & $\theta$ & + & $?$ & + \\
\hline Monti 2007 & + & $?$ & $\Theta$ & O & + & $?$ & + \\
\hline Moore 2011 & + & + & + & + & + & $?$ & $\Theta$ \\
\hline Noknoy 2010 & + & $?$ & + & + & + & $?$ & + \\
\hline Ockene 1999 & + & + & + & + & + & + & + \\
\hline Richmond 1995 & $?$ & $?$ & - & + & + & $\Theta$ & + \\
\hline Rodríguez 2003 & ? & - & $\odot$ & - & + & C & + \\
\hline & $?$ & $a$ & & $a$ & $a$ & & \\
\hline
\end{tabular}


Figure 3. (Continued)

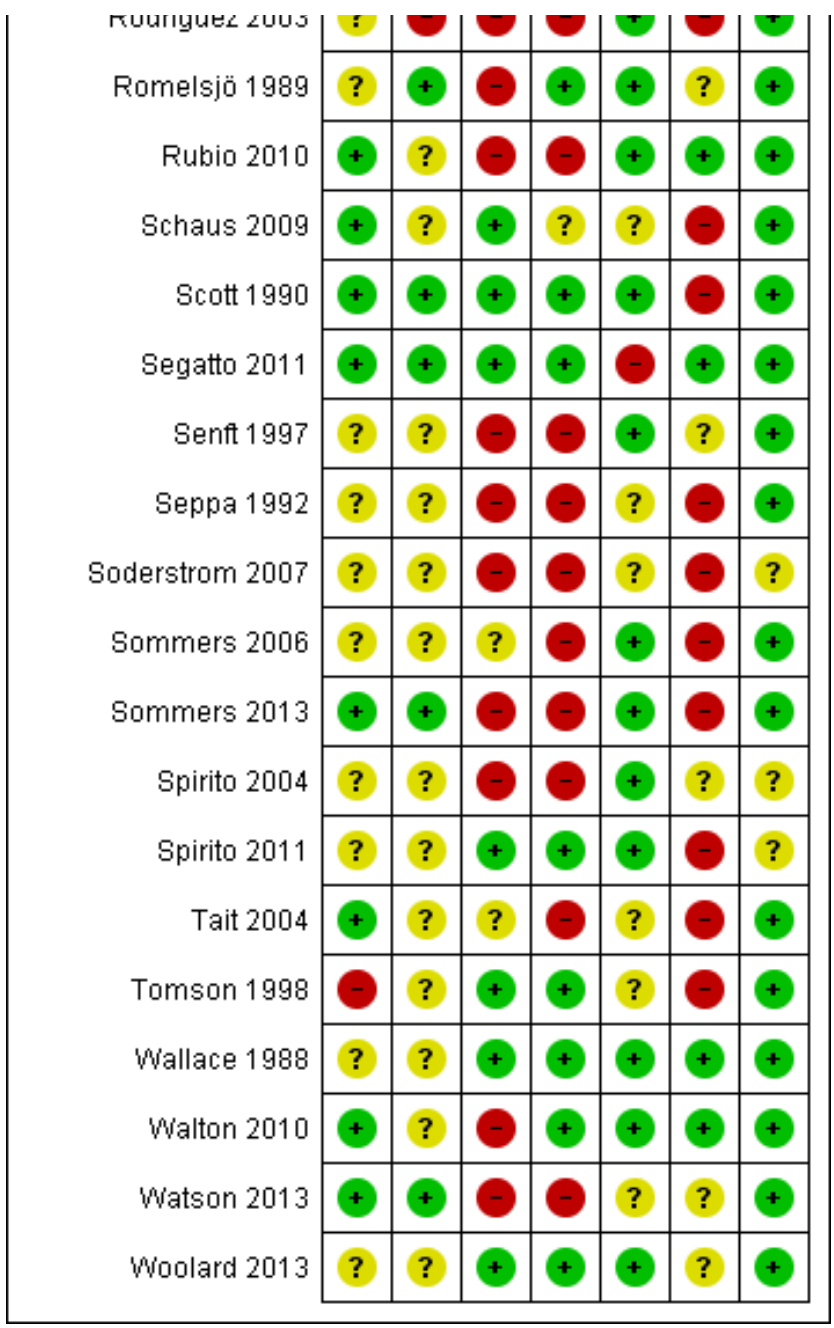

\section{Allocation}

\section{Generation of randomisation sequence}

The risk of selection bias due to randomisation methods was judged to be low in 37 trials (54\%) (Aalto 2000; Altisent 1997; Babor 2006; Beckham 2007; Bernstein 2010; Bischof 2008; Blow 2006; Crawford 2004; Crawford 2010; Daeppen 2007; Dent 2008; Désy 2010; Drummond 2009; Drummond 2014; Ettner 2014; Fernández 1997; Field 2010; Fleming 1997; Fleming 2010; Israel 1996; Kaner 2013; L'Engle 2014; Lock 2006; Maisto 2001; Mello 2008; Monti 2007; Moore 2011; Noknoy 2010; Ockene 1999; Rubio 2010; Schaus 2009; Scott 1990; Segatto 2011; Sommers 2013; Tait 2004; Walton 2010; Watson 2013).

Risk of selection bias was assessed as high in three trials (4\%) (Bazargan-Hejazi 2005; D'Amico 2008; Tomson 1998). Participants in these trials were assigned to treatment arms alternately or according to date of birth, or researchers changed the allocation process during the trial.

Randomisation methods were unclear in 29 trials.

\section{Concealment of allocation}

The risk of selection bias due to allocation concealment methods was judged to be low in 25 trials (36\%) (Altisent 1997; Babor 2006; Beich 2007; Bernstein 2010; Bischof 2008; Córdoba 1998; Dent 2008; D'Onofrio 2008; Drummond 2014; Ettner 2014; Field 2010; Fleming 1997; Fleming 1999; Fleming 2010; Kaner 2013; L'Engle 2014; Lock 2006; Maisto 2001; Moore 2011; Ockene 1999; Romelsjö 1989; Scott 1990; Segatto 2011; Sommers 2013; Watson 2013).

Risk of bias was judged to be high in seven trials (10\%) because participant allocation to arms was predictable, or those delivering the intervention opened a sealed envelope (no detail of numbering or other feature designed to protect allocation concealment) (Aalto 2000; Bazargan-Hejazi 2005; D'Amico 2008; Fernández 1997; Israel 1996; Longabaugh 2001; Rodríguez 2003).

Risk of allocation concealment bias was unclear in 37 trials.

\section{Blinding}

Due to the nature of the advice- or counselling-based interventions used in trials, it was not possible to blind either the participants or care providers. The automatic judgement of high risk of bias in this domain is considered by some as a limitation of the tool 
and, consequently, we judged trials to be at low risk of bias if they explicitly described a mechanism to overcome one of these biases. Detection bias was also affected by the fact that outcomes were self-reported by participants.

However, 28 trials $(41 \%)$ were designed (either through clusterrandomisation or other design feature) so providers delivering the intervention had no contact with control participants, meaning there was no contamination between arms. These 28 studies were assigned low risk of bias for provider blinding (Babor 2006; Blow 2006; Cherpitel 2009; Córdoba 1998; Crawford 2004; Crawford 2010; Curry 2003; D'Onofrio 2012; Désy 2010; Drummond 2014; Ettner 2014; Fleming 1997; Fleming 1999; Fleming 2004; Fleming 2010; Helstrom 2014; Kaner 2013; Lock 2006; Moore 2011; Noknoy 2010; Ockene 1999; Schaus 2009; Scott 1990; Segatto 2011; Spirito 2011; Tomson 1998; Wallace 1988; Woolard 2013).

Researchers reported attempt to blind participants in 22 trials (32\%) and were assigned low risk of bias for participant blinding at enrolment (Bazargan-Hejazi 2005; Curry 2003; D'Amico 2008; D'Onofrio 2008; D'Onofrio 2012; Daeppen 2007; Drummond 2009; Fleming 1997; Fleming 1999; Fleming 2010; Moore 2011; Noknoy 2010; Ockene 1999; Richmond 1995; Romelsjö 1989; Scott 1990; Segatto 2011; Spirito 2011; Tomson 1998; Wallace 1988; Walton 2010; Woolard 2013). Participants were blinded either because they did not know there was an alternate arm, or because the alcohol focus was masked during screening and assessment by other health-related questions.

Outcome assessors were reported to be blinded in 46 trials $(67 \%)$ and were judged at low risk of detection bias (Babor 2006; Bazargan-Hejazi 2005; Bernstein 2010; Bischof 2008; Cherpitel 2009; Crawford 2004; Crawford 2010; D'Onofrio 2008; D'Onofrio 2012; Daeppen 2007; Drummond 2009; Drummond 2014; Ettner 2014; Fernández 1997; Field 2010; Fleming 1997; Fleming 1999; Fleming 2004; Fleming 2010; Heather 1987; Israel 1996; Kaner 2013; Kunz 2004; L'Engle 2014; Lane 2008; Lock 2006; Longabaugh 2001; Mello 2008; Mertens 2014; Monti 2007; Moore 2011; Noknoy 2010; Ockene 1999; Richmond 1995; Rodríguez 2003; Romelsjö 1989; Rubio 2010; Scott 1990; Senft 1997; Sommers 2006; Sommers 2013; Spirito 2004; Spirito 2011; Wallace 1988; Walton 2010; Woolard 2013). We assessed three trials (4\%) to be at high risk of detection bias because they stated that the outcome assessor was not blinded (Beich 2007; Dent 2008; Segatto 2011). We assessed 20 studies at unclear risk of bias for blinding.

\section{Incomplete outcome data}

We assessed 28 trials (40\%) at high risk of attrition bias. Of these, 24 studies reported over 30\% losses to follow-up (Aalto 2000; Altisent 1997; Bazargan-Hejazi 2005; Beich 2007; Cherpitel 2009; Córdoba 1998; Crawford 2004; D'Onofrio 2012; Dent 2008; Drummond 2014; Fernández 1997; Field 2010; Lock 2006; Richmond 1995; Rodríguez 2003; Schaus 2009; Scott 1990; Seppa 1992; Soderstrom 2007; Sommers 2006; Sommers 2013; Spirito 2011; Tait 2004; Tomson 1998). Four studies reported completers' data only (Babor 2006; Blow 2006; Désy 2010; Kunz 2004).

The risk of attrition bias was judged to be unclear in 28 studies. Losses to follow-up were not reported according to study arm in five studies (Beckham 2007; Helstrom 2014; Israel 1996; Longabaugh 2001; McIntosh 1997). Reasons for losses to follow-up were not reported in 18 studies (Bernstein 2010; Curry 2003; Daeppen 2007; D'Onofrio 2008; Fleming 2004; L'Engle 2014; Lane 2008; Maisto 2001; McDevitt-Murphy 2014; Mello 2008; Mertens 2014; Monti 2007; Noknoy 2010; Romelsjö 1989; Senft 1997; Spirito 2004; Watson 2013; Woolard 2013). There were unexplained differences between losses to follow-up in the intervention and control arms in five studies (D'Amico 2008; Drummond 2009; Ettner 2014; Fleming 1997; Moore 2011).

\section{Selective reporting}

We assessed four trials (6\%) at high risk of reporting bias because some aspect of reporting changed between protocol or methods section and reporting of results (Babor 2006; Bernstein 2010; Field 2010; Moore 2011). Seven were judged to be unclear and the rest low.

\section{Effects of interventions}

See: Summary of findings for the main comparison Brief intervention compared to no or minimal intervention for people with hazardous or harmful alcohol consumption; Summary of findings 2 Extended intervention compared to no or minimal intervention for people with hazardous or harmful alcohol consumption; Summary of findings 3 Extended intervention compared to brief intervention for people with hazardous or harmful alcohol consumption

All forest plots are presented with trials listed in chronological order.

\section{Brief intervention versus minimal or no intervention}

See Summary of findings for the main comparison.

\section{Quantity of alcohol consumed per week (Analyses 1.1 to 1.16)}

\section{Primary meta-analysis (Analysis 1.1)}

The primary meta-analysis included 34 trials that reported consumption at 12 months (Analysis 1.1). A total of 15,197 participants were included in this analysis (median 413, range 64 to 1493), with a mean age of 43 years (SD 8.86). Seven studies in the primary meta-analysis included men only (Altisent 1997; Córdoba 1998; Crawford 2010; Díez 2002; Drummond 2009; Fernández 1997; Huas 2002); one included women only (McDevitt-Murphy 2014); and 26 trials recruited both men and women. Participants' ethnicity was reported in 19 trials (Bernstein 2010; Blow 2006; Córdoba 1998; Curry 2003; D'Onofrio 2008; D'Onofrio 2012; Drummond 2014; Field 2010; Fleming 1997; Fleming 2004; Fleming 2010; Helstrom 2014; Kaner 2013; Maisto 2001; Ockene 1999; Schaus 2009; Senft 1997; Soderstrom 2007; Sommers 2013). With the exception of four studies, most participants (68\%) were white.

After 12 months, participants receiving a brief intervention drank a mean $20 \mathrm{~g}$ alcohol a week less than those with minimal or no intervention ( $95 \% \mathrm{Cl} 12$ to 28 ; moderate-quality evidence; $\mathrm{I}^{2}=73 \%$ ). The funnel plot (Figure 4) indicated asymmetry, suggesting the possibility of under-reporting of results with little or no evidence of an intervention effect. 
Figure 4. Funnel plot for quantity of drinking at 12 months, with pseudo $95 \%$ confidence limits.

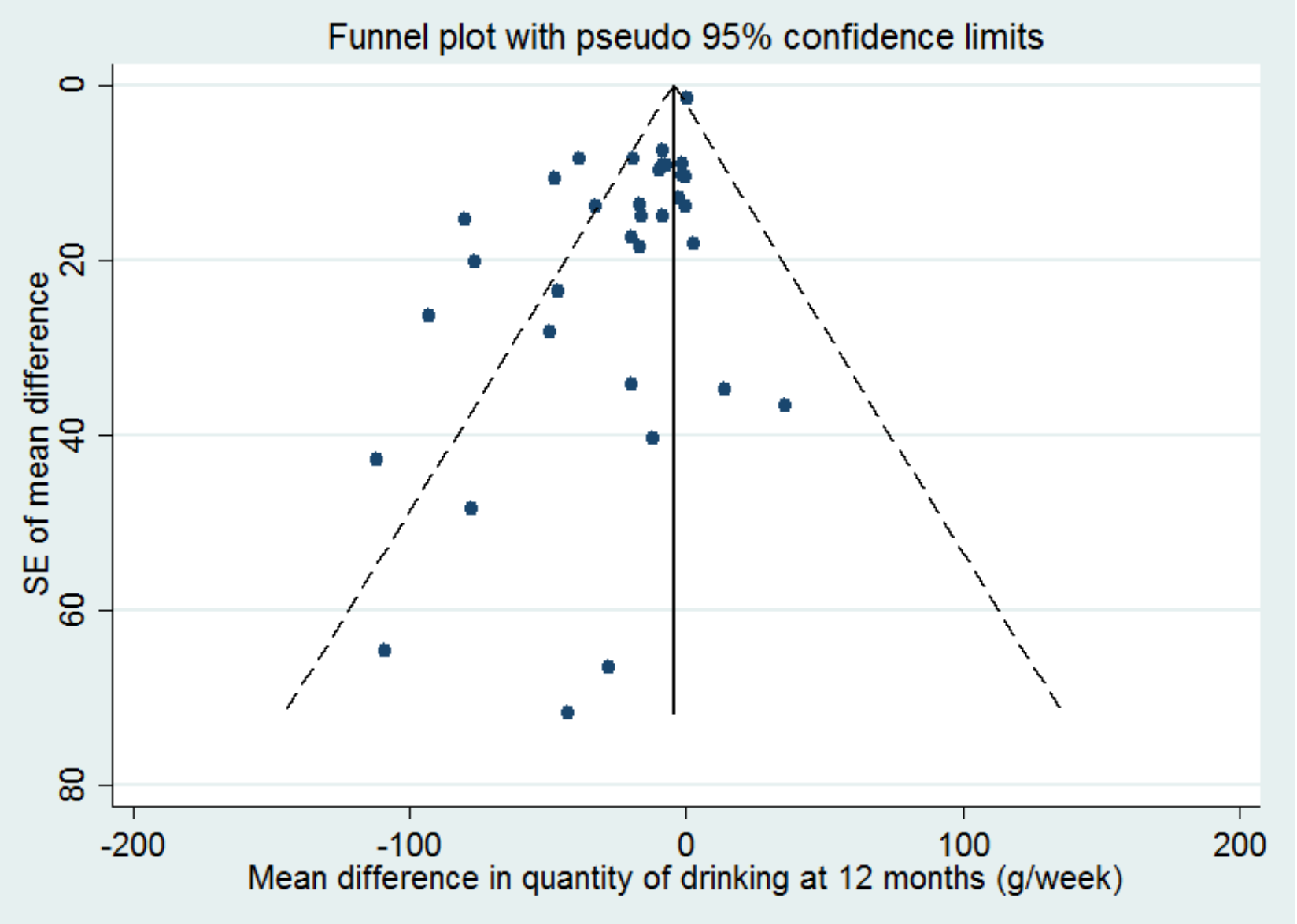

Sensitivity analyses to account for risk of bias and missing standard deviations (Analysis 1.2; Analysis 1.3; Analysis 1.4)

A sensitivity analysis restricted to 19 trials assessed at low risk of bias for allocation concealment showed very similar results to the primary meta-analysis (Analysis 1.2). Participants receiving brief intervention drank $20 \mathrm{~g} /$ week less than those with minimal or no intervention ( $95 \% \mathrm{Cl} 10$ to 30$)$. Heterogeneity was substantial $\left(I^{2}=74 \%\right)$. Of the 19 trials, 14 were also at low risk of bias for randomisation; five were assessed at unclear risk.

A sensitivity analysis that omitted the 15 trials at high risk of bias due to incomplete outcome data also showed very similar results to the primary meta-analysis (Analysis 1.3). Participants receiving brief intervention drank $21 \mathrm{~g} /$ week less than those with minimal or no intervention ( $95 \% \mathrm{Cl} 10$ to 32$)$. Heterogeneity was substantial ( $I^{2}$ $=80 \%)$.

A sensitivity analysis included five additional trials (compared to the primary meta-analysis) which did not report standard deviation. We imputed a median standard deviation of $167 \mathrm{~g} /$ week to both treatment and minimal or no intervention groups (Babor 2006; Cherpitel 2009; Ettner 2014; McIntosh 1997; Spirito 2004; Analysis 1.4). The addition of these trials made little difference; pooling of all 39 trials showed that participants who received brief intervention drank $19 \mathrm{~g} /$ week less than those with minimal or no intervention ( $95 \% \mathrm{Cl} 12$ to 27 ).

\section{Impact of cluster randomisation (Analysis 1.6)}

The six cluster-randomised trials (2588 participants) from the primary meta-analysis showed broadly similar results (MD -25 g/ week, $95 \% \mathrm{Cl}-43$ to -8$)$ to the 28 individually randomised trials (12,609 participants) (MD -19 g/week, 95\% Cl -28 to -10; Córdoba 1998; Drummond 2014; Huas 2002; Kaner 2013; Lock 2006; Ockene 1999; Analysis 1.5). A sensitivity analysis showed that results from the cluster-randomised trials (MD $-20 \mathrm{~g} /$ week, $95 \% \mathrm{Cl}-34$ to -7 ) were very similar to the individually randomised trials (Analysis 1.6). We assumed an intra-cluster correlation coefficient (ICC) of 0.32 (as found in Lock 2006, unpublished data) for the two clusterrandomised trials that did not allow for cluster-randomisation in their analyses (Córdoba 1998; Huas 2002),

\section{Impact of participant characteristics (Analysis 1.7; Analysis 1.8; Analysis 1.9)}

Only 11 trials reported sufficient information (mean, standard deviation and number of participants assessed by treatment arm) by gender on the primary outcome measure at 12 months to permit meta-analysis subgrouped by men and women (Analysis 1.7). Both men (3486 participants) and women (1350 participants) appeared to experience significant benefits of brief intervention (MD for men $-42 \mathrm{~g} /$ week, $95 \% \mathrm{Cl}-65$ to -20 ; for women $-30 \mathrm{~g} /$ week, $95 \% \mathrm{Cl}-59$ to -2). The difference between men and women was not statistically significant. 
We repeated Analysis 1.7, excluding four trials that recruited only men, to reduce confounding (Analysis 1.8). Results were similar: both men and women experienced significant benefits of brief intervention, with no significant difference in the treatment effect between men and women.

Three trials in the primary meta-analysis (1638 participants) recruited only adolescents or young adults (defined as maximum 21 years, 24 years and 25 years in Bernstein 2010; Fleming 2010; Schaus 2009, respectively). We separated these studies from the trials that did not impose age restrictions (13,559 participants). The treatment effect was smaller in the younger population (MD $-7 \mathrm{~g} /$ week, $95 \% \mathrm{Cl}-17$ to 3 compared to $-23 \mathrm{~g} /$ week, $95 \% \mathrm{Cl}-32$ to -13 for all adults; Analysis 1.9). However, all trials in younger people were relatively recent and meta-regression showed that, having adjusted for year of publication of the trial, there was no evidence that the intervention effect was lower in the trials of adolescents or young adults, compared to trials in adults $(P=0.58)$.

\section{Impact of setting (Analysis 1.10)}

We included 10 trials (6386 participants) in the primary metaanalysis that took place in an emergency department (Bernstein 2010; Blow 2006; Crawford 2004; D'Onofrio 2008; D'Onofrio 2012; Daeppen 2007; Drummond 2014; Field 2010; Soderstrom 2007; Sommers 2013). These studies showed less impact on alcohol consumption than trials based in general practice settings (8811 participants) (MD $-10 \mathrm{~g} /$ week, $95 \% \mathrm{Cl}-18$ to -2 versus $-26 \mathrm{~g} /$ week, $95 \% \mathrm{Cl}-37$ to -14 ; Analysis 1.10). There was no evidence that the treatment effect differed between the sets of trials after adjusting for year of publication in meta-regression analysis.

\section{Impact of intervention modality (Analysis 1.11)}

A total of 20 trials tested advice-based interventions (8243 participants). These trials showed greater impact on alcohol consumption than the 12 counselling-based intervention trials (5537 participants, MD $-33 \mathrm{~g} /$ week, $95 \% \mathrm{Cl}-46$ to -20 versus $-0.2 \mathrm{~g} /$ week, $95 \% \mathrm{Cl}-3$ to 3 ; Analysis 1.11). Two trials were not included in this subgroup analysis because they contained arms that included both intervention types (Drummond 2014; Kaner 2013). There was no evidence that the treatment effect differed between the sets of trials after adjusting for year of publication in meta-regression analysis.

Impact of alcohol-related content in control condition (Analysis 1.12)

Half the trials in the primary meta-analysis provided some kind of alcohol-related advice or leaflet to control arm participants (Analysis 1.12). The mean difference in the 16 trials that provided alcohol-related content in the control arm (6591 participants) was lower ( $-13 \mathrm{~g} /$ week, $95 \% \mathrm{Cl}-23$ to -3 ) than in 18 trials (8606 participants) where control group participants received no alcohol content (e.g. general health information, screening or assessment only) (-24 g/week, $95 \% \mathrm{Cl}-36$ to -12). However, the test for subgroup differences was not significant.

\section{Impact of publication date and baseline consumption}

Meta-regression showed that for every year going forward in time, the mean difference in consumption between brief intervention and minimal or no intervention groups decreased by $2.3 \mathrm{~g} /$ week (95\% Cl 1.3 to 3.4; Figure 5). There was a smaller difference in consumption between intervention and control participants in more recent trials. The residual heterogeneity $\left(I^{2}=42 \%\right)$ was notably lower than in the unadjusted analysis. Meta-regresion adjustment of the funnel plot based on year of publication provided less evidence of asymmetry than the unadjusted funnel plot (Figure 4; Figure 6). 
Figure 5. Meta-regression of quantity of drinking at 12 months on year of publication of trial.

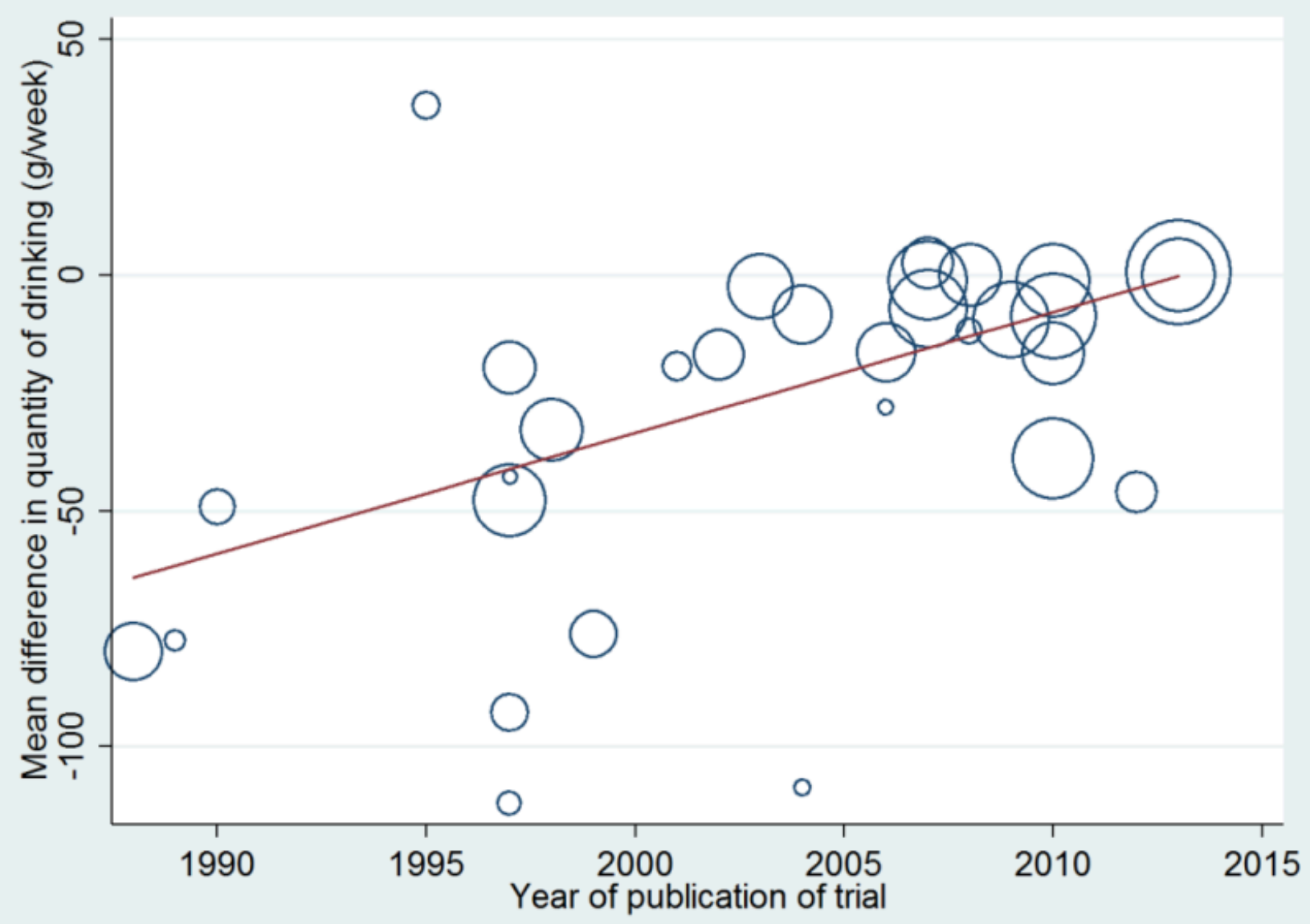


Figure 6. Funnel plot for quantity of drinking at 12 months, adjusted for year of publication, with pseudo $95 \%$ confidence limits.

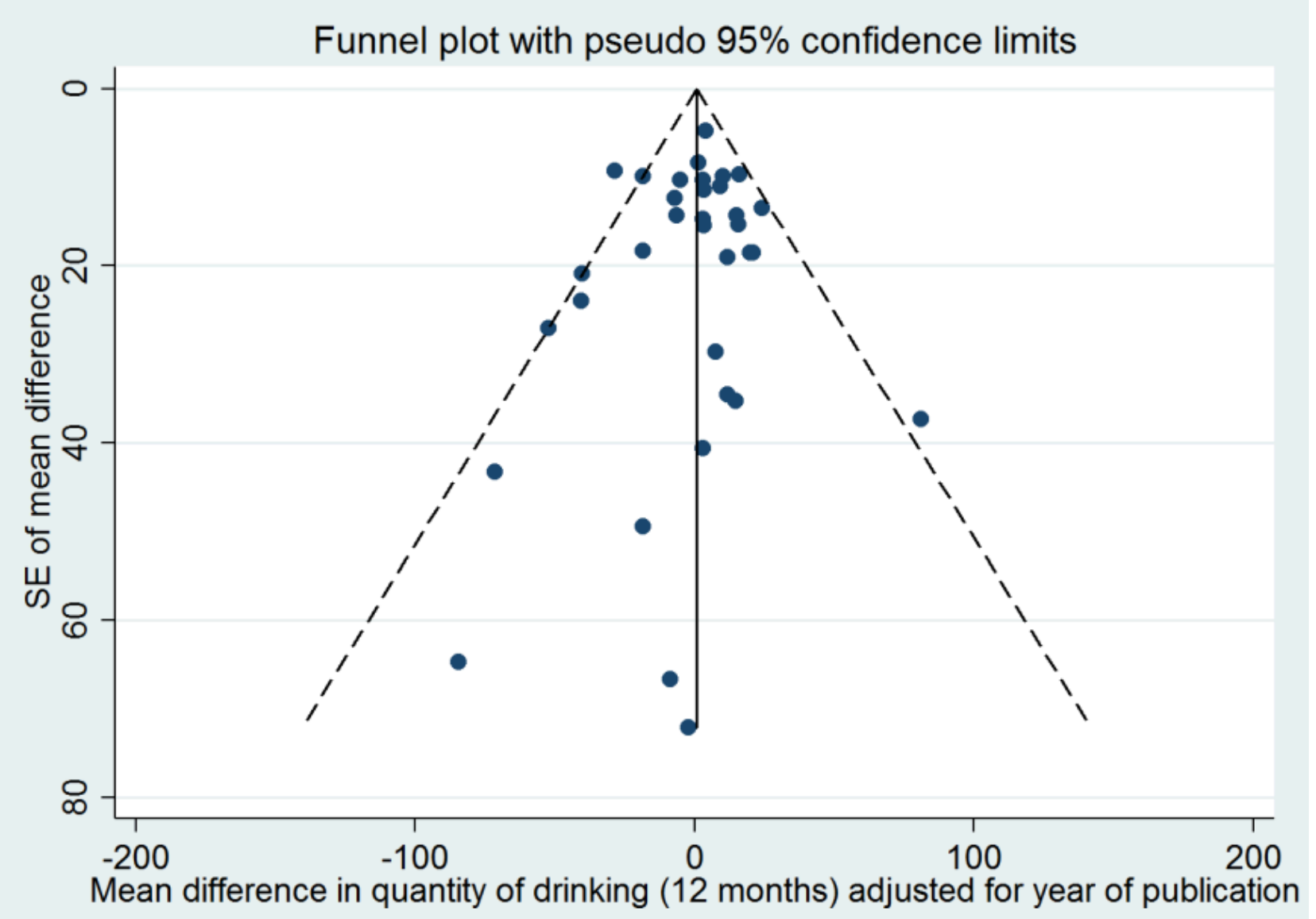

We investigated the association of baseline consumption with effectiveness in a second meta-regression analysis (Figure 7). Results showed that for every g/week increase in baseline consumption, the mean difference in consumption between brief intervention and minimal or no intervention participants increased by $0.16 \mathrm{~g} /$ week $(95 \% \mathrm{Cl} 0.10$ to 0.23$)$. There was a bigger difference in consumption between intervention and minimal or no intervention participants where baseline consumption was greater.
The residual heterogeneity $\left(I^{2}=39 \%\right)$ was notably lower than in the unadjusted analysis. Including both baseline consumption and year of publication in the meta-regression further reduced residual heterogeneity $\left(I^{2}=29 \%\right)$. The mean difference between the brief intervention and minimal or no intervention arms decreased by $0.10 \mathrm{~g} /$ week $(95 \% \mathrm{Cl} 0.03$ to 0.18 ) for each increase of $1 \mathrm{~g} /$ week in baseline consumption, and increased by $1.5 \mathrm{~g} /$ week $(95 \% \mathrm{Cl} 0.1$ to 2.9) for each year increment in year of publication. 
Figure 7. Meta-regression of quantity of drinking at 12 months on baseline consumption.

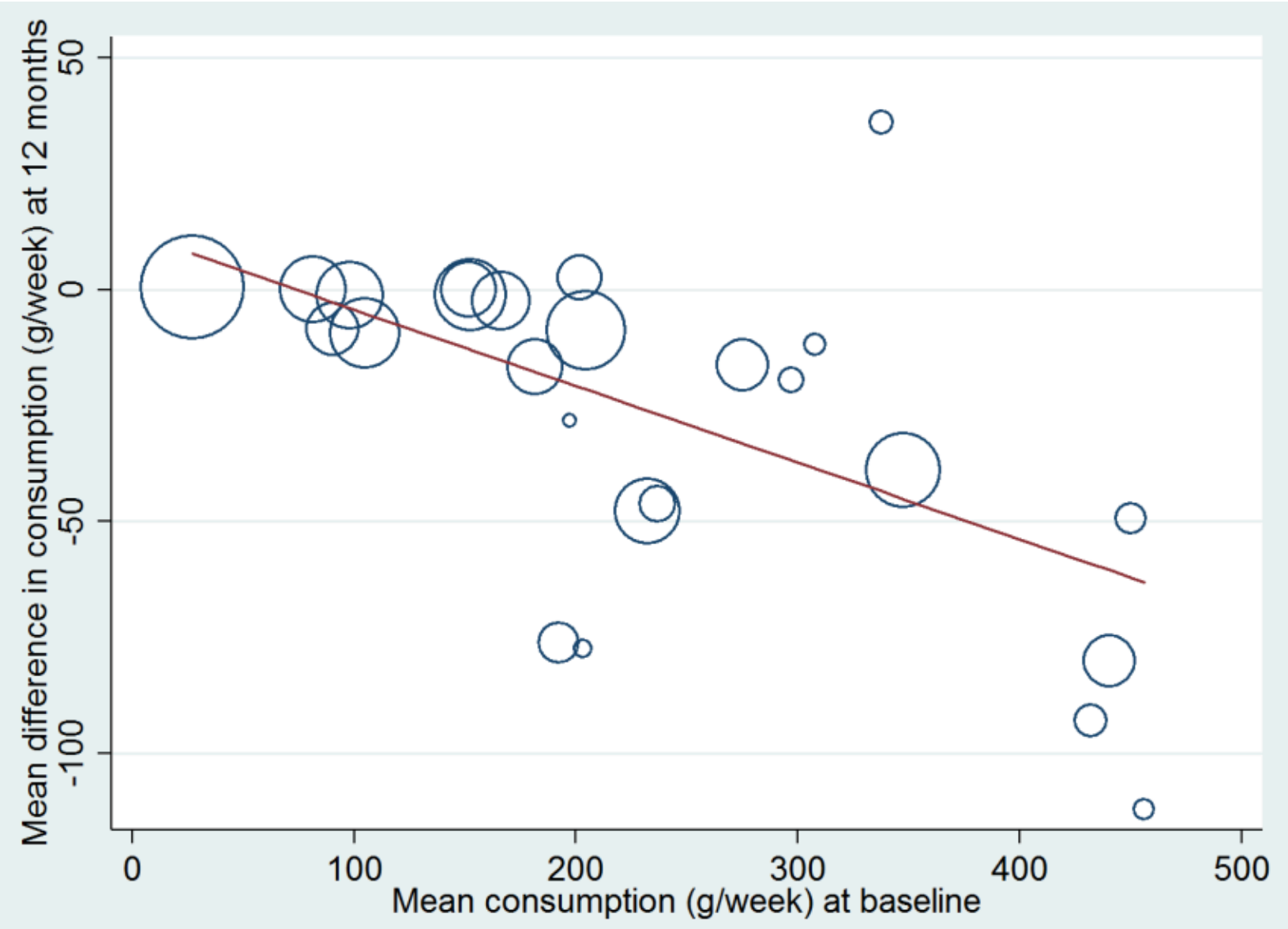

\section{Treatment exposure}

Meta-regression suggested little association between quantity of alcohol consumed at 12 months and increasing treatment exposure. Results showed an increase in the mean difference between the brief intervention and minimal or no intervention arms of $0.2 \mathrm{~g} /$ week ( $95 \% \mathrm{Cl}-0.5$ to $0.9 ; \mathrm{P}=0.57$, for each increase of 1 minute in the treatment exposure; Figure 8). 
Figure 8. Meta-regression of quantity of drinking at 12 months on treatment exposure (mean duration of intervention for the participants in the trial), for trials comparing brief intervention with control.

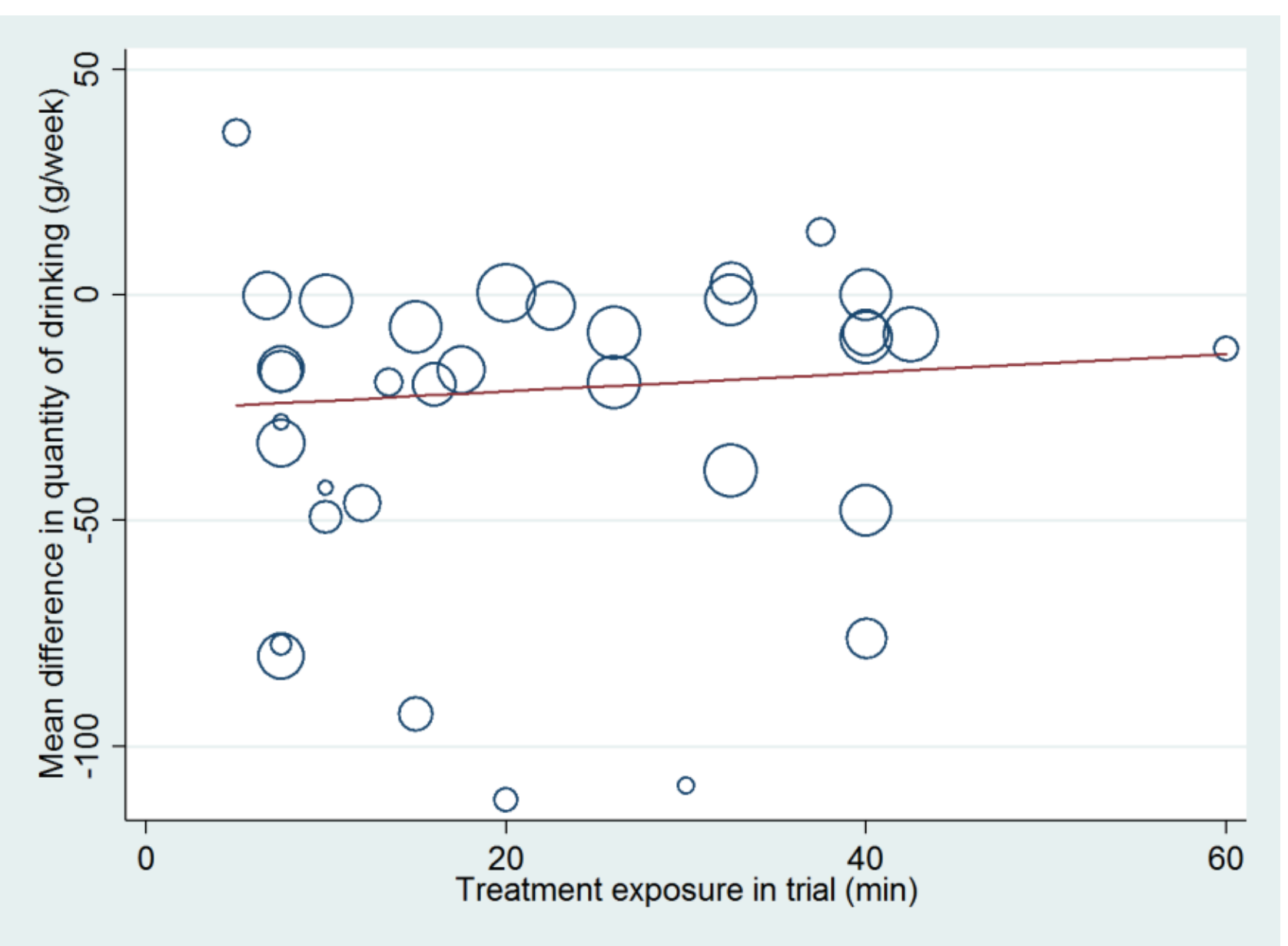

Impact of follow-up time (Analysis 1.3; Analysis 1.14)

A sensitivity analysis by length of follow-up suggested no decay in impact of the intervention over the first 12 months. Only two trials reported data at eight to nine months, and only one at each 36 and 48 months. The pooled effect on consumption at six months (10,313 participants, MD -22 g/week, $95 \% \mathrm{Cl}-32$ to -12 ) was similar to 12 months $(15,197$ participants, MD $-20 \mathrm{~g} /$ week, $95 \% \mathrm{Cl}-28$ to -12 ; Analysis 1.13). Results were similar when the analysis was restricted to studies that reported outcomes at both 6 months and 12 months (Analysis 1.14).

We excluded 16 studies (3816 participants) from the primary meta-analysis that reported at less than 12 months. One study (414 participants) reported at more than 12 months (Aalto 2000). Many trials reported that alcohol consumption reduced in both intervention and control group participants, with greater reduction in the intervention group, but the difference did not reach statistical significance. This suggests these studies followed the same trend as reported in the meta-analysis and would be unlikely to change the conclusion.

\section{Efficacy and effectiveness score (Analysis 1.15)}

There was no significant difference between the pooled findings of the effectiveness trials and the pooled findings of the efficacy trials in terms of the quantity of alcohol consumed at 12 months (Analysis 1.15). The 16 effectiveness trials (7091 participants) showed that intervention participants drank $27 \mathrm{~g} /$ week $(95 \% \mathrm{Cl}$ 13 to 41 ) less than minimal or no intervention participants. The 18 efficacy trials (8106 participants) also showed a benefit of brief intervention; participants in the intervention group drank $14 \mathrm{~g} /$ week less than minimal or no intervention group participants (95\% $\mathrm{Cl} 5$ to 24). Meta-regression analysis showed that with each increase in unit of effectiveness efficacy score, the mean difference between intervention and minimal or no intervention increased by $4.1 \mathrm{~g} /$ week ( $95 \% \mathrm{Cl}-1.3$ to 9.5 ). Trials that were more clinically representative tended to demonstrate greater effectiveness (Figure 9). 
Figure 9. Meta-regression of quantity of drinking at 12 months on effectiveness/efficacy score of trial. Lower scores indicate greater efficacy.

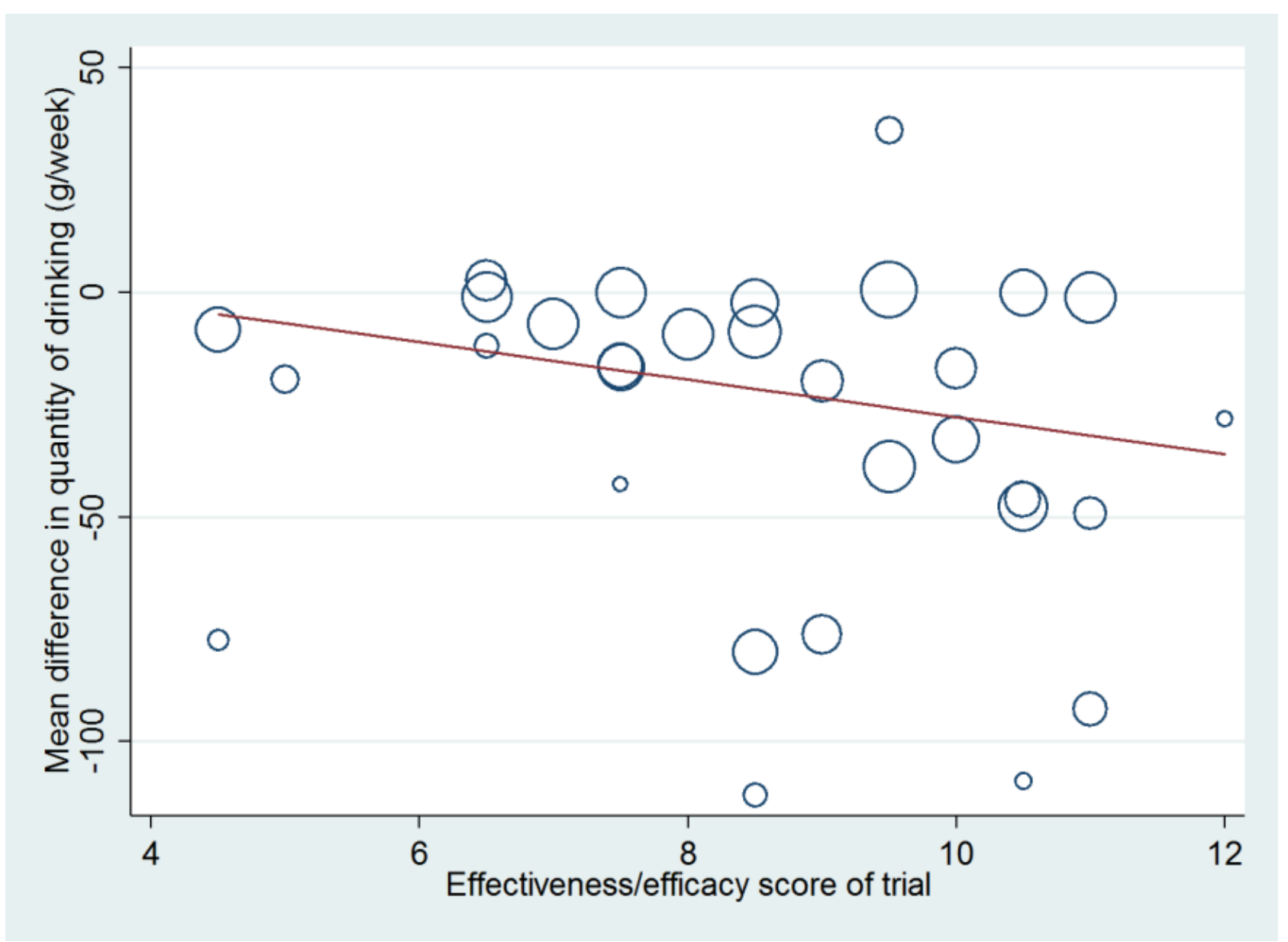

\section{Frequency of drinking and frequency of binge drinking (Analyses} 1.16 to 1.19)

Binge drinking frequency (binges/week at 12 month) was reported in 15 trials (6946 participants) (Blow 2006; Daeppen 2007; D'Onofrio 2008; D'Onofrio 2012; Fleming 1997; Fleming 1999; Fleming 2004; Fleming 2010; Helstrom 2014; Longabaugh 2001; Ockene 1999; Rubio 2010; Schaus 2009; Soderstrom 2007; Spirito 2004; Analysis 1.16). Results showed moderate-quality evidence of a very small impact on binge drinking frequency (MD - 0.08 binges/week, 95\% $\mathrm{Cl}-0.14$ to -0.02 ). We analysed 11 trials (5469 participants) that reported the number of days drinking/week (Bernstein 2010; Cherpitel 2009; Crawford 2004; Curry 2003; Daeppen 2007; Field 2010; Fleming 2010; Helstrom 2014; Maisto 2001; Senft 1997; Spirito 2004). Analysis results indicated a very small impact (MD -0.13 days/week, $95 \% \mathrm{Cl}-0.23$ to -0.04 ; Analysis 1.18 ; moderate-quality evidence). There was little difference between results at 6 months and 12 months for both outcomes (Analysis 1.17 and Analysis 1.19 respectively).

\section{Intensity of drinking (Analysis 1.20)}

Drinking intensity (g/drinking day, or a unit that could be converted to g/day) was reported by 10 trials (3128 participants) (Bernstein 2010; Cherpitel 2009; Crawford 2004; Curry 2003; Daeppen 2007; Helstrom 2014; Maisto 2001; Schaus 2009; Senft 1997; Spirito 2004).
Results showed moderate-quality evidence of no impact at 12 months (MD -0.2 g/drinking day, $95 \% \mathrm{Cl}-3.1$ to 2.7; Analysis 1.20).

\section{Heavy and binge drinkers (Analysis 1.21; Analysis 1.22)}

Percentages of heavy or at risk drinkers at 12 months was reported in 18 trials (7623 participants) (Altisent 1997; Beich 2007; Cherpitel 2009; Córdoba 1998; Curry 2003; D'Onofrio 2008; Daeppen 2007; Drummond 2014; Ettner 2014; Fernández 1997; Fleming 1997; Fleming 1999; Fleming 2004; Kaner 2013; Rubio 2010; Sommers 2013; Wallace 1988; Walton 2010). However, the definition of heavy drinking varied among trials. The difference between the brief intervention and minimal or no intervention arms in the percentage of heavy drinkers at 12 months was $-9 \%(95 \% \mathrm{Cl}-13$ to -4 ; Analysis $1.21)$, although there was substantial heterogeneity $\left(I^{2}=77 \%\right)$.

A total of 10 trials (4456 participants) reported the percentage of binge drinkers at 12 months (Beich 2007; Bischof 2008; Curry 2003; Ettner 2014; Fleming 1997; Fleming 1999; Rubio 2010; Scott 1990; Sommers 2013; Walton 2010). Overall, results showed a significant reduction in the percentage of binge drinkers in the brief intervention group compared to the minimal or no intervention group (RD $-7 \%, 95 \% \mathrm{Cl}-12$ to -2 ; Analysis 1.22). There was substantial heterogeneity $\left(I^{2}=76 \%\right)$. 


\section{Secondary outcomes}

\section{Laboratory markers of drinking (Analysis 1.23; Analysis 1.24)}

We included three trials (1166 participants) that reported GGT at 12 months (Romelsjö 1989; Scott 1990; Wallace 1988). Analysis showed no significant difference between brief intervention and minimal or no intervention; there was no heterogeneity among trials (MD $-0.9 \mathrm{IU} / \mathrm{L}, 95 \% \mathrm{Cl}-3.9$ to $2.1, \mathrm{I}^{2}=0 \%$; Analysis 1.23). In two trials which reported GGT by gender, there was no significant difference in the effect size between men and women (Scott 1990; Wallace 1988; Analysis 1.24). Seppa 1992 (95 participants) reported MCV and reported no significant difference between brief intervention and minimal or no intervention, both overall (MD $0.6 \mathrm{fl}, 95 \% \mathrm{Cl}-1.6$ to 2.8) and for each gender separately.

\section{Alcohol-related harms}

We assessed 20 studies that reported a measure of alcohol related harm (Blow 2006; Cherpitel 2009; D'Onofrio 2008; D'Onofrio 2012; Drummond 2009; Drummond 2014; Fleming 2010; Helstrom 2014; Kaner 2013; Lock 2006; Longabaugh 2001; McDevitt-Murphy 2014; Mello 2008; Monti 2007; Romelsjö 1989; Schaus 2009; Spirito 2004; Walton 2010; Watson 2013; Woolard 2013). However, this outcome could not be analysed because of the large number of scales used to measure different types of harm. Sixteen studies reported no significant difference between the intervention and control groups in the chosen measure of alcohol-related problems or harm. Blow 2006 reported a reduction in DrlnC score in all groups. Two studies (Kaner 2013; Schaus 2009) reported a short-term change. Kaner 2013 reported fewer problems in the brief counselling group compared to the patient information leaflet group using the Alcohol Problems Questionnaire (APQ) at six months only. Schaus 2009 reported fewer problems in the intervention group using the Rutgers Alcohol Problem Index (RAPI) at six months and nine months.

\section{Patient satisfaction and quality of life measures}

Only two studies reported patient satisfaction (Drummond 2014; Kaner 2013). Drummond 2014 reported no significant difference between groups. Kaner 2013 stated that participants in the brief counselling group reported greater satisfaction than those in the patient information leaflet group.

\section{Adverse effects}

Five studies reported whether adverse effects were experienced by trial participants (Beich 2007; Bischof 2008; Sommers 2006; Sommers 2013; Watson 2013). Beich 2007 reported that for women in the intervention group, binge drinking increased on average (ARR $-30 \%, 95 \% \mathrm{Cl}-47$ to -9 ). However, Blow 2006 explicitly stated that younger adult women were most likely to decrease heavy episodic drinking after the intervention. Two trials reported that no adverse effects were experienced by any of the trial participants (Bischof 2008; Watson 2013). Two trials reported adverse driving events but concluded there were no more in the intervention group than the control group (Sommers 2006; Sommers 2013).

\section{Health-related quality of life}

Daeppen 2007 reported a marginal significant improvement in the physical composite scale of SF-36 in the brief alcohol intervention group compared to the control groups. Tait 2004 reported a significantly greater improvement in the intervention group in well-being as measured by the GHQ-12. Four studies reported no significant differences between intervention and control groups in quality of life measures (Crawford 2004; Drummond 2009; Kaner 2013; Lock 2006).

\section{Economic evaluations}

Six studies either reported an economic evaluation in the trial report (Drummond 2009; Kunz 2004; Lock 2006) or as a separate publication (Babor 2006; Crawford 2004; Fleming 1997). Most suggested that the intervention was likely to be cost-effective. This finding is consistent with the results of a recent systematic review of cost-effectiveness, which reported strong evidence that brief intervention programs in primary care are a cost-effective option for tackling alcohol misuse (Angus 2014).

\section{Extended intervention versus minimal or no intervention}

See Summary of findings 2.

\section{Quantity of alcohol consumed per week (Analysis 2.1)}

The impact of an extended intervention versus minimal or no intervention on consumption of alcohol at 12 months was reported by six trials (1296 participants) (Bischof 2008; Israel 1996; Maisto 2001; Monti 2007; Moore 2011; Richmond 1995). Most used the principles of motivational interviewing in the counselling intervention; Israel 1996 used cognitive behavioural therapy. These trials showed moderate-quality evidence of a reduction in consumption at 12 months (MD $-20 \mathrm{~g} /$ week, $95 \% \mathrm{Cl}-40$ to 1 ; Analysis 2.1). The level of heterogeneity in these findings was low $\left(I^{2}=23 \%\right)$.

\section{Frequency of drinking and frequency of binge drinking (Analysis} 2.2; Analysis 2.3)

At 12 months, two trials (456 participants) reported the frequency of binge drinking, providing moderate-quality evidence of very little difference between the groups (MD -0.08 binges/week, $95 \% \mathrm{Cl}-0.28$ to 0.12; Longabaugh 2001; Monti 2007; Analysis 2.2). Maisto 2001 and Monti 2007 reported moderate-quality evidence for a small reduction in drinking days per week (MD $-0.45,95 \% \mathrm{Cl}-0.81$ to -0.09 ; two studies, 319 participants; Analysis 2.3).

\section{Intensity of drinking (Analysis 2.4)}

Maisto 2001 recruited 158 participants and compared extended versus minimal intervention at 12 months. Results indicated little impact (MD -9 g/drinking day, $95 \% \mathrm{Cl}-26$ to 9; Analysis 2.4; lowquality evidence).

\section{Heavy and binge drinkers (Analysis 2.5; Analysis 2.6)}

Moore 2011 (521 participants) reported the percentage of heavy drinkers at 12 months (Analysis 2.5). Bischof 2008 and Moore 2011 (777 participants) reported numbers of binge drinkers at 12 months (Analysis 2.6). There was very little difference between the extended intervention and minimal intervention arms for both outcomes.

\section{Secondary outcomes}

\section{Laboratory markers of drinking (Analysis 2.7)}

Israel 1996 reported GGT at 12 months. There was no significant difference between extended intervention and minimal intervention (MD $-5.7 \mathrm{IU} / \mathrm{L}, 95 \% \mathrm{Cl}-20.3$ to 8.9; Analysis 2.7). However, this result was based on only 59 participants. 


\section{Alcohol-related harms}

Only Monti 2007 reported alcohol-related harms. There was no significant difference between groups in Rutgers Alcohol Problem Index score.

\section{Other secondary outcomes}

No studies reported patient satisfaction or health-related quality of life outcomes for this comparison.

Meta-regression of quantity of alcohol consumed on treatment exposure, including both brief and extended interventions

The meta-regression of quantity of alcohol consumed at 12 months on treatment exposure, reported above for trials which compared brief intervention with minimal or no intervention, was repeated, adding trials that assessed an extended intervention. This provided greater statistical power for the meta-regression, not only through inclusion of three extra trials (Israel 1996; Monti 2007; Moore 2011), but also through inclusion of trials with greater treatment exposure. Specifically, for the three trials that included both a brief intervention and an extended intervention (Bischof 2008; Maisto 2001; Richmond 1995), only the extended intervention results were compared with minimal or no intervention. As with the analysis restricted to the comparison of brief intervention with minimal or no intervention, meta-regression suggested no evidence of association between quantity of alcohol consumed at 12 months and increasing treatment exposure (an increase in the mean difference between the brief intervention and minimal or no intervention arms of $0.1 \mathrm{~g} /$ week $(95 \% \mathrm{Cl}-0.3$ to $0.5, \mathrm{P}=0.72$, for each increase of 1 minute in the treatment exposure; Figure 10).

Figure 10. Meta-regression of quantity of drinking at $\mathbf{1 2}$ months on treatment exposure (mean duration of counselling for the participants in the trial), for trials comparing brief or extended intervention with control.

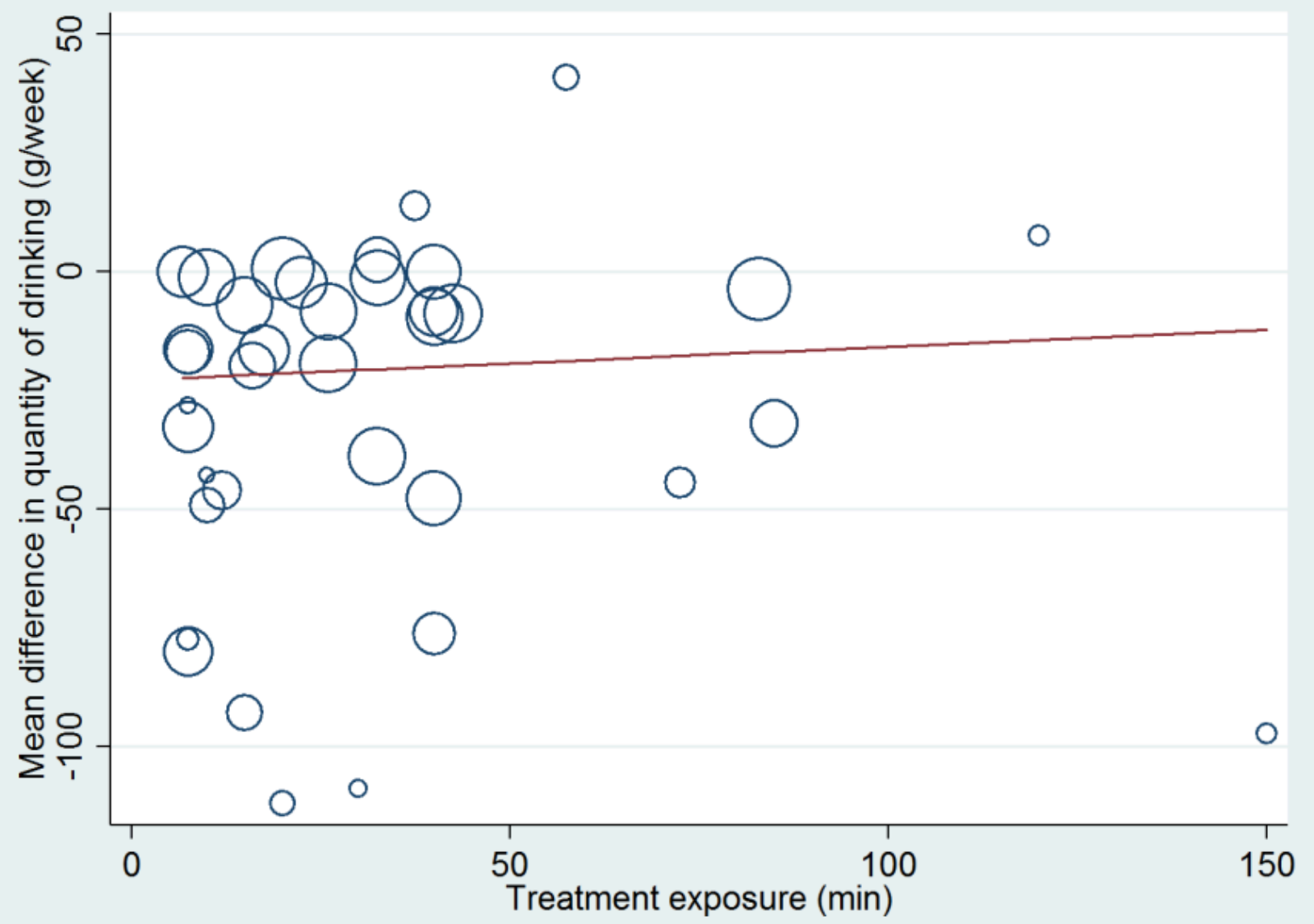

\section{Extended intervention versus brief intervention}

See Summary of findings 3.

Quantity of alcohol consumed per week (Analysis 3.1; Analysis 3.2)

We included three trials (552 participants) in the meta-analysis comparing alcohol consumption at 12 months for extended versus brief interventions (Bischof 2008; Maisto 2001; Richmond 1995).
There was no difference in consumption between participants who received an extended intervention and those who received a brief intervention, although the associated confidence interval was very wide (MD $2 \mathrm{~g} /$ week, $95 \% \mathrm{Cl}-42$ to 45; Analysis 3.1; low-quality evidence). The extended interventions varied. Bischof 2008 provided four half hour telephone sessions based on motivational interviewing. Maisto 2001 provided one 30 to 45 minute motivational interview followed by two shorter sessions. Richmond 1995 provided five sessions totaling over 60 minutes. 
We performed sensitivity analysis that included an additional trial (Spirito 2011) and imputed unreported standard deviations (Analysis 3.2). This made little difference to the result (MD $1 \mathrm{~g} /$ week, $95 \% \mathrm{Cl}-39$ to 41$)$.

\section{Frequency and intensity of drinking (Analysis 3.3; Analysis 3.4)}

No trials reported the number of binges per week for extended versus brief intervention. Maisto 2001 reported frequency in terms of number of drinking days per week and intensity in terms of drinks per drinking day at 12 months for this comparison (Analysis 3.3; Analysis 3.4). There was low-quality evidence of little difference between extended and brief interventions for both outcomes (MD -0.5 drinking days/week, $95 \% \mathrm{Cl}-1.2$ to $0.2 ; \mathrm{MD}-1.7 \mathrm{~g} /$ drinking day, $95 \% \mathrm{Cl}-18.9$ to $15.5 ; 147$ participants).

\section{Heavy and binge drinkers (Analysis 3.5)}

Two trials reported numbers of binge drinkers at 12 months (Bischof 2008; Spirito 2011). Pooled data showed no statistically significant difference in the percentage of binge drinkers between extended and brief interventions (RD $2 \%, 95 \% \mathrm{Cl}-8$ to $12 ; 339$ participants; Analysis 3.5).

No trials that compared extended and brief interventions reported numbers of heavy drinkers.

\section{Secondary outcomes}

No trials that compared extended and brief interventions reported laboratory markers at 12 months. The trials did not report any measures of alcohol-related harm, patient satisfaction or quality of life.

\section{DISCUSSION}

\section{Summary of main results}

We included 69 studies (33,642 participants), of which 34 studies (15,197 participants) provided data for our primary outcome. At 12 months, when compared with minimal or no intervention, brief intervention reduced the quantity of alcohol consumed by $20 \mathrm{~g} /$ week (95\% Cl 12 to 28), which equates to two to three UK standard units. We undertook three sensitivity analyses that indicated the effect is robust. Excluding trials that did not report adequate allocation concealment, including trials where standard deviations were imputed, and assuming different intra-cluster correlation coefficients for cluster-randomised trials, all showed a similar degree of benefit to the primary analysis. A funnel plot showed some evidence of publication bias but this diminished after adjustment for year of publication (Figure 4).

Most participants were male (70\%). Ethnicity was poorly reported, but in those trials that provided these data, most participants were white (70\%). Mean baseline consumption was about $310 \mathrm{~g} /$ week, but this varied among trials from about 90 to $460 \mathrm{~g} /$ week (11 to 57 UK standard units).

There was substantial heterogeneity among trials in terms of setting (general practice or emergency care settings), populations enrolled, screening instruments used, baseline consumption of alcohol, and the brief intervention and minimal or no intervention conditions delivered. Therefore, the statistical heterogeneity in the meta-analyses was not surprising. Subgroup analyses showed that heterogeneity of findings was restricted to individually randomised trials and trials with high treatment exposure.

Further meta-analyses demonstrated very small significant impact of brief intervention in terms of days of drinking and binge days per week, amounting to a reduction of one day per two months and no significant impact on amount consumed per drinking day. The percentage of heavy and binge drinkers at 12 months showed a small but significant decrease of $9 \%$ and $7 \%$ respectively at 12 months in the intervention groups compared to participants receiving minimal or no intervention.

Further meta-analyses suggested that people receiving an extended intervention may reduce their consumption compared to participants receiving minimal or no intervention at 12 months, but provided no evidence that extended interventions reduce consumption any more or less than brief interventions. These meta-analyses were less robust. They were based on much smaller groups of participants than the primary meta-analysis and may be confounded by the fact that attendance at multiple sessions was not always reported (i.e. participants may not all have received a full 'extended' intervention). Extended interventions differed from brief interventions not only in terms of contact time with participants but also because they were more likely to involve counselling (shorter interventions may 'draw on' counselling techniques but are likely to be too short to make full use of them).

We assessed the impact of both duration and type (advice or counselling) of intervention on drinking outcomes. Firstly, we performed a meta-regression, which found little evidence of a link between treatment exposure time and reported alcohol consumption. This seems to support the meta-analysis suggesting that there is little difference in impact between brief and extended intervention approaches. Secondly, we carried out a subgroup analysis according to whether interventions were advice- or counselling-based. This suggested that counsellingbased interventions, despite being more intensive and providing more contact with participants, may be associated with smaller reductions in consumption than advice-based interventions. Taken together, these analyses suggest little evidence of a dose response effect, either in terms of longer duration or higher intensity of intervention.

\section{Clinical importance}

At baseline, the mean level of consumption of participants was 244 $\mathrm{g} /$ week (equivalent to $30 \mathrm{UK}$ standard units), although this differed according to year of publication (older studies $313 \mathrm{~g} /$ week versus newer studies $181 \mathrm{~g} /$ week). The mean reduction provided by a brief intervention reported here of $20 \mathrm{~g} /$ week (2.5 UK units) would mean that many participants would continue to drink at a level that would be considered hazardous according to recommendations in most countries. However, this reduction is still likely to be beneficial at an individual level, given the number of disease conditions at least partly attributable to alcohol and given that the higher the baseline level of drinking, the stronger the effects of any given reduction in terms of all-cause mortality (Rehm 2013). At a population level, any reduction is likely to have a significant impact on health, quality of life and healthcare resource use, given that over $5 \%$ of the global burden of disease is attributable to alcohol (WHO 2014). 


\section{Effectiveness/efficacy}

There was no significant difference between trials classified as effectiveness and efficacy trials in the effect of brief intervention on the quantity of alcohol consumed, although meta-regression suggested that trials with higher scores on our scale (i.e. more clinically representative or 'real world' trials) may show more intervention effect. This difference is counterintuitive. One would expect that higher scoring trials would result in smaller effect sizes because they are less tightly controlled, but there may be some interaction with publication date or some other feature of the trials. Other tools (e.g. Gartlehner 2006; Wieland 2017) have been developed to more precisely measure and assess efficacy/ effectiveness status and we plan to carry out comparative work using these tools.

This lack of evidence of any difference in the current review may indicate insensitivity in our descriptive classification tool. In some papers, authors did not report information relating to certain items. In these cases, we ascribed a mid-value score for that item so as not to tip the study toward the efficacy or effectiveness domain. This may have reduced variation in the final scores (there were not many extreme scores, particularly on the efficacy side of the scale) and led to clustering of trials toward the middle of this scale. However, although the trials were skewed toward the effectiveness domain, they were distributed along a continuum. Moreover, it is highly unlikely that there would be any pure efficacy studies, since the trial protocol would need to be acceptable and relevant to clinicians (and ethics committees) before it could be enacted in health service contexts. It is possible that any intervention effect may be related to individual factors, which were combined in the overall efficacy/effectiveness score. It is beyond the scope of this review to investigate this further.

\section{Screening}

It was clear in this review (as in other work) that many trials reported reductions in alcohol consumption in minimal or no intervention arms at follow-up. It is difficult to assess if this might be due to regression to the mean or an impact of the screening itself. One trial reported that a significant proportion of participants reduced their drinking between screening and assessment, and so the brief intervention was delivered to some participants who were no longer eligible for such an approach (McIntosh 1997). Therefore, it is possible that screening alone might represent an impetus for change (McCambridge 2011). This should be further investigated in future work.

\section{Publication date}

Several plausible reasons might explain why more recent trials tend to demonstrate less impact on alcohol consumption than older trials. Firstly, the definition of excessive drinking has reduced over time in terms of consumption per week. In the earliest published trial included in this review (Wallace 1988), the inclusion criteria stipulated at least 35 and 21 units/week for men and women respectively. However, a more recent study recruited participants drinking at least 21 units/week (men) or 14 units/week (women) (Helstrom 2014). Mean baseline consumption in brief alcohol intervention trials has correspondingly reduced over time. In the original review, mean baseline consumption was $313 \mathrm{~g} /$ week (around 39 UK units/week), whereas in newly added studies for this update it was $181 \mathrm{~g} /$ week (around 23 UK units/week).
Typically, trials did not report the upper cut-off point for exclusion in terms of consumption levels but these differences between baseline characteristics of participants in older versus more recent trials demonstrates the lowering of inclusion criteria over the years. Moreover, many recent trial participants have been enrolled with consumption levels only just above recommended drinking levels. Consequently, with lower baseline alcohol consumption, there is less change required before participants reach a lower risk drinking level.

Secondly, minimal or no intervention conditions in more recent trials are more likely to provide some kind of alcohol-related advice or information, which might highlight alcohol consumption to control group participants and encourage them to decrease their consumption, reducing the difference in effect between intervention and control groups. A subgroup analysis by content of control condition appeared to support this, suggesting a larger difference between intervention and control group where no alcohol-related information is provided (Analysis 1.12).

Finally, most earlier trials took place in general practice-based primary care, whereas more recently published trials were more likely to take place in emergency departments, where the effect size appears to be smaller (Analysis 1.10).

\section{Overall completeness and applicability of evidence}

This review suggests that brief interventions are effective at reducing alcohol consumption compared to minimal or no intervention in hazardous and harmful drinkers presenting to general practice or emergency care. This finding does not apply to low risk or alcohol dependent drinkers, or necessarily to other health or social care settings. This update saw the inclusion of a greater proportion of trials which took place in emergency departments, which enabled us to formally compare effectiveness between emergency care and general practice. Although the raw subgroup analysis suggests a difference in effectiveness between settings, this result is confounded by publication date since so many of the emergency care trials are recent.

Whereas the previous published version of our review reported there was no evidence of a significant effect for women, the addition of further data has changed this conclusion, although there are still only seven trials reporting data separately for 1350 women. This analysis suggests that brief intervention has a significant impact on weekly alcohol consumption compared to women experiencing minimal or no intervention conditions. In the context of the reported closing of the gap between hazardous and harmful alcohol consumption by women compared to men, this is an important finding (Slade 2016). The significant effect for men also stands from the original review.

Only four trials were based in countries not defined as high income by the WHO, so this evidence cannot be assumed to apply to countries where the structure or functioning of primary care differs, or where less liberal attitudes to alcohol consumption may exist. Most of the participants in trials were also Caucasian and so any future evaluations should specifically aim to enrol a wider diversity of participants.

\section{Quality of the evidence}

The direction of evidence is broadly consistent. Most studies in the primary meta-analysis ( $82 \%$ ) reported a reduction in consumption 
for brief intervention compared to minimal or no intervention participants.

We downgraded the evidence quality assessment to moderate due to a systematic risk of bias in the studies. Blinding is notoriously difficult in trials of complex conversation-based interventions, because the intervention cannot easily be disguised from participants, and this is something that is unlikely to change. Indeed, it has been suggested that GRADE assessments may not adequately describe the evidence base of complex interventions and an extension is required to adequately reflect them (Movsisyan 2016). Empirical research has shown that trials where the participant and treatment provider are not blinded may be more likely to report significant effects of the intervention (Schulz 1995). Attrition bias also tends to be high in these types of trials. If participants who dropped out of the brief intervention groups had higher alcohol consumption than those who did not, our estimated reduction in alcohol consumption due to brief intervention would be an over-estimate of the real effect.

Nevertheless, the estimated reduction in the quantity of alcohol consumed per week was sufficiently marked that the real effect is likely to be a reduction in alcohol consumption. Furthermore, the random-effects model which we used assumes that the effect of treatment is different in different populations and that the estimated reduction in alcohol consumption of $20 \mathrm{~g} /$ week is the mean treatment effect, averaged over all populations. Therefore, the findings provide strong evidence that brief interventions are effective in many populations.

As in the original review, an analysis had been planned linked to the level of loss to follow-up, but was not possible. Loss to followup was defined in different ways across the studies, and it was not always clear whether allowance had been made for loss to followup in the reported results. However, an analysis that excluded trials at high risk of bias due to incomplete outcome data gave similar results to those from the primary meta-analysis. Further research should elucidate how to reduce this effect.

\section{Potential biases in the review process}

We made every effort to locate all existing eligible trials, regardless of publication status or language, and we searched grey literature and references in addition to bibliographic databases to reduce publication bias. We contacted authors to clarify the reporting of data used in the meta-analyses where necessary. We further assessed potential bias from selective reporting by comparing the outcomes proposed in the protocols (where available) or methods sections with those in the final study report. The results of these assessments appear in the risk of bias tables (Characteristics of included studies).

We worked hard to ensure that the inclusion criteria were applied consistently to potentially eligible studies. The term 'brief intervention' is used to describe many different types of interventions, and so we further defined the inclusion criteria in terms of number and duration of intervention sessions. It was sometimes difficult to tell whether the setting fit our definition of 'primary care', and in some studies there was a mixture of hazardous, harmful and potentially dependent drinkers. The eligibility of all the studies was assessed by two of the review authors independently, but where they were uncertain the study was always discussed by two authors (EK, FB) to make the final decisions as consistent as possible.

One potential weakness of the studied outcomes is that they are predominantly self-reported, so may be susceptible to social desirability bias. Many of the studies made efforts to minimise this effect and a recent trial suggests that for questions about alcohol consumption this may not be a big problem (albeit the participants were students, not the general public) (Kypri 2016).

The addition of 42 studies to the updated review provided a lot of extra data. Some of these data were added to existing analyses, but others enabled us to carry out subgroup analyses which were not proposed in the original protocol, often because they could not have been foreseen at the time. For example, brief interventions were rarely carried out in emergency departments 10 years ago, but many of the newly added studies were, enabling subgroup analysis of brief interventions in general practice versus emergency care. Although it can introduce bias to carry out subgroup analyses which were not pre-specified in the review protocol, we feel that each of the additional subgroup analyses in this update is backed up by findings in the wider literature.

\section{Agreements and disagreements with other studies or reviews}

Several reviews have been published since the previous version of this review was publsied in 2007. A systematic review of reviews of brief interventions in primary care assessed 24 systematic reviews containing a total of 56 trials (O'Donnell 2014). The review concluded that although there was good evidence of effectiveness of these interventions, there were gaps in terms of particular populations (e.g. women, younger and older drinkers, ethnic minorities) and the optimum length and frequency of such interventions. Since then, further reviews have addressed some of these issues.

Another review of seven systematic reviews suggested that 15 minutes of brief intervention was better than usual care or longer input, and that more sessions were better than single session (Álvarez-Bueno 2015). Our review suggests little extra impact from longer duration, but this indicates that splitting that longer duration into multiple sessions may increase the effect. A systematic review addressed alcohol interventions (including digital or telephone delivered) across settings aimed at women, or reporting by gender (De Paula Gebara 2013). Only three (of 36) trials took place in primary care and their results were mixed. Two reviews addressed brief interventions in a younger population. One included trials of adolescents and young adults aged between 11 and 30 years and found a significant reduction in consumption and alcohol-related problems for up to one year, which did not appear to vary across participant demographics, intervention length, or intervention format (TannerSmith 2015). A second reviewed included seven trials along with practice projects, a pilot study and an observational study of adolescents and young adults aged between 12 and 25 years in emergency care and reported inconclusive results, although it also reported that six trials found reductions in alcohol use for all participants (Diestelkamp 2016). Four trials reported reductions in consumption or harms but none reported both. Another review of brief interventions in emergency care included 28 trials (comprising digital and non face-to-face interventions as well as face-to-face brief interventions) and reported a small significantly 
significant reduction in consumption at 12 months (Schmidt 2016). Schmidt 2016 also carried out moderator analyses for intervention type (face-to-face versus not), duration of intervention $(<15$ minutes versus $>15$ minutes), intervention deliverer (emergency department staff versus external), study quality (low risk of bias versus high) and control ingredients (treatment as usual, leaflet, unspecific advice, personalised alcohol feedback) and reported that none of these features altered the direction or significance of the meta-analysis results.

The systematic review referenced in our original review reported a $-38 \mathrm{~g} /$ week reduction in alcohol consumption attributed to brief intervention, as did our previous meta-analysis (Bertholet 2005). This update reports a reduced effect size resulting from brief alcohol intervention, which may be due to the enrolment of less heavy drinkers into these types of trials as well as increasing alcohol content in control conditions. This update agrees with most other reviews in reporting a small but significant impact of brief interventions on hazardous and harmful drinkers in primary care settings.

Brief interventions are increasingly being enhanced or replaced by digital interventions (Kaner 2017), which may prove less costly to deliver and maintain (after development work is complete). It is plausible that digital interventions may have a greater reach to populations who do not engage with primary care, since people will be able to access them through a computer or mobile device anywhere or at any time. However, it is also possible that digital delivery will not suit some people and some may be less likely to complete an intervention if there is no personal encouragement. Nevertheless, digital input may be able to support practitioners' work in helping participants reduce their alcohol consumption by providing additional self-assessment, self care or self-monitoring resources. Kaner 2017 provides comparison and further discussion of digital versus practitioner-delivered interventions.

\section{AUTHORS' CONCLUSIONS}

\section{Implications for practice}

This review provides moderate-quality evidence that brief interventions delivered in primary care reduce alcohol consumption in hazardous and harmful drinkers by an average of 20 $\mathrm{g} /$ week (the equivalent of approximately two to three UK standard drinks) compared to controls receiving usual care, screening or assessment only, or minimal alcohol advice. Whilst the effect sizes due to brief alcohol intervention are relatively small, because of the high proportion of the population who attends primary care, this is likely to result in a positive public health or population level benefit. The effect is robust and was found up to one year following the brief intervention. Brief interventions appear to be effective for both men and women but there was insufficient evidence to make any judgements about differential effectiveness in different ethnic groups. There was a suggestion of a reduced effect in younger people compared to the general population aged 18 years or more, and in emergency care compared to general practice, but this disappeared when adjusted for the overall reduction in effect size due to newer trials. Longer or more intensive intervention appeared to have little effect in significantly improving outcomes. The effects of brief alcohol interventions are typically found in trials that report outcomes in terms of weekly alcohol consumption. It is not clear why the impact seems smaller for frequency or intensity of drinking, although, within a weekly (7-day) frame of reference, the scope for variability in days drinking or number of high intensity ('binge') events is relatively low. A further challenge in this field is the very wide range of different outcome measures, which are reported over greatly varying periods of time. There were too few trials reporting many of these outcome measures to provide sufficient statistical power to detect potentially small effects.

\section{Implications for research}

Although brief interventions seem to be effective at reducing hazardous and harmful consumption in adult men and women primarily based in high income countries, there is a clear need for more evaluative research on brief interventions with younger people, from cultural minority groups and also in low and lowermiddle income countries. Moreover, there is some suggestion that screening alone may result in alcohol consumption reduction and this should be investigated further. A quarter of the included trials in this review could not contribute to the meta-analysis, either because they did not report a measure of consumption that could be converted to $\mathrm{g} /$ week of alcohol, or because the follow-up time was too short ( $<6$ months). There is an urgent need for standardisation of outcomes in alcohol trials and future trials should report longer follow-up times to aid understanding of the duration of effect. Future studies should aim to capture adverse effects of brief interventions. A further methodological improvement would be to address the issues of high attrition bias within these interventions and to enable GRADE to make a more sophisticated judgement of quality in trials of complex conversation-based interventions. Finally, future research direction should focus on implementation issues, including a more precise specification of brief intervention components.

\section{ACKNOWLEDGEMENTS}

We thank Dr Marta Roque of the Iberian Cochrane Centre for assistance with data extraction. We are grateful to Dr Gallus Bischof (University of Lübeck), Professor Mike Crawford (Imperial College London), Dr Eseme Csipke (King's College London), Dr Sue Curry (University of Illinois), Professor Colin Drummond (King's College London), Dr Craig Field (University of Texas at Austin), Professor Marilyn Sommers (University of Pennsylvania School of Nursing) and $\mathrm{Dr}$ Maureen Walton (University of Michigan) for addressing queries, supplying unpublished data or both.

We thank Dr Carla Schlesinger, Professor Nick Heather and Dr Heather Dickinson for their work on previous versions of this review and Ms Brenda Nyakang'o and Ms Janice Armstrong for invaluable administrative assistance.

We are grateful to Dr Ellen Lynch, Jen Bradley and Hannah Kaner for assistance with data extraction, and Patience Kunonga for proof reading.

We are grateful to Lindsey Elstub and Eugenie Johnson for administrative assistance and invaluable advice. 


\section{R E F E R E N C E S}

\section{References to studies included in this review}

Aalto 2000 \{published data only\}

* Aalto M, Saksanen R, Laine P, Forsström R, Raikaa M, Kiviluoto $M$, et al. Brief intervention for female heavy drinkers in routine general practice: a 3-year randomized, controlled study. Alcoholism, Clinical and Experimental Research 2000;24(11):1680-6.

Aalto M, Seppä K, Mattila P, Mustonen H, Ruuth KH, Hyvärinen $\mathrm{H}$, et al. Brief intervention for male heavy drinkers in routine general practice: $A$ three-year randomized controlled study. Alcohol and Alcoholism (Oxford, Oxfordshire) 2001;36(3):224-30

\section{Altisent 1997 \{published data only\}}

Altisent R, Córdoba R, Delgado MT, Pico MV, Melús E, Aranguren F, et al. Multicenter study on the efficacy of advice for the prevention of alcoholism in primary health care. Medicina Clinica 1997;109(4):121-4.

\section{Babor 2006 \{published data only\}}

* Babor TF, Higgins-Biddle JC, Dauser D, Burleson JA, Zarkin GA, Bray J. Brief interventions for at-risk drinking: patient outcomes and cost-effectiveness in managed care organizations. Alcohol and Alcoholism (Oxford, Oxfordshire) 2006;41(6):624-31.

Bray JW, Zarkin GA, Davis KL, Mitra D, Higgins-Biddle JC, Babor TF. The effect of screening and brief intervention for risky drinking on health care utilization in managed care organizations. Medical Care 2007;45(2):177-82.

Zarkin GA, Bray JW, Davis KL, Babor TF, Higgins-Biddle JC. The costs of screening and brief intervention for risky alcohol use. Journal of Studies on Alcohol 2003;64(6):849-57.

\section{Bazargan-Hejazi 2005 \{published data only\}}

Bazargan-Hejazi S, Bing E, Bazargan M, Der-Martirosian C, Hardin E, Bernstein J, et al. Evaluation of a brief intervention in an inner-city emergency department. Annals of Emergency Medicine 2005;46(1):67-76.

\section{Beckham 2007 \{published data only\}}

Beckham N. Motivational interviewing with hazardous drinkers. Journal of the American Academy of Nurse Practitioners 2007;19(2):103-10.

\section{Beich 2007 \{published data only\}}

Beich A, Gannik D, Saelan H, Thorsen T. Screening and brief intervention targeting risky drinkers in Danish general practice - a pragmatic controlled trial. Alcohol and Alcoholism 2007;42(6):593-603.

\section{Bernstein 2010 \{published data only\}}

Bernstein J, Heeren T, Edward E, Dorfman D, Bliss C, Winter M, et al. A brief motivational interview in a pediatric emergency department, plus 10-day telephone follow-up, increases attempts to quit drinking among youth and young adults who screen positive for problematic drinking. Academic Emergency Medicine 2010;17(8):890-902.

Bischof 2008 \{published and unpublished data\} Bischof G. Brief alcohol interventions [personal communication]. Email to: C Muirhead 25 March 2014.

* Bischof G, Grothues JM, Reinhardt S, Meyer C, John U, Rumpf HJ. Evaluation of a telephone-based stepped care intervention for alcohol-related disorders: a randomized controlled trial. Drug and Alcohol Dependence 2008;93(3):244-51.

Grothues JM, Bischof G, Reinhardt S, Meyer C, John U, Rumpf HJ. Effectiveness of brief alcohol interventions for general practice patients with problematic drinking behavior and comorbid anxiety or depressive disorders. Drug and Alcohol Dependence 2008;94(1-3):214-20.

Reinhardt S, Bischof G, Grothues J, John U, Meyer C, Rumpf HJ. Gender differences in the efficacy of brief interventions with a stepped care approach in general practice patients with alcohol-related disorders. Alcohol and Alcoholism 2008;43(3):334-40

Blow 2006 \{published data only\}

* Blow FC, Barry KL, Walton MA, Maio RF, Chermack ST, Bingham CR, et al. The efficacy of two brief intervention strategies among injured, at-risk drinkers in the emergency department: impact of tailored messaging and brief advice. Journal of Studies on Alcohol 2006;67(4):568-78.

Blow FC, Ilgen MA, Walton MA, Czyz EK, McCammon R, Chermack ST, et al. Severity of baseline alcohol use as a moderator of brief interventions in the emergency department. Alcohol and Alcoholism 2009;44(5):486-90.

Walton MA, Goldstein AL, Chermack ST, McCammon RJ, Cunningham RM, Barry KL, et al. Brief alcohol intervention in the emergency department: moderators of effectiveness. Journal of Studies on Alcohol and Drugs 2008; Vol. 69, issue 4:550-60.

\section{Cherpitel 2009 \{published data only\}}

* Cherpitel CJ, Korcha RA, Moskalewicz J, Swiatkiewicz G, Ye Y, Bond J. Screening, brief intervention, and referral to treatment (SBIRT): 12-month outcomes of a randomized controlled clinical trial in a Polish emergency department. Alcoholism, Clinical and Experimental Research 2010;34(11):1922-8.

Cherpitel CJ, Moskalewicz J, Swiatkiewicz G, Ye Y, Bond J. Screening, brief intervention, and referral to treatment (SBIRT) in a Polish emergency department: three-month outcomes of a randomized, controlled clinical trial. Journal of Studies on Alcohol and Drugs 2009;70(6):982-90.

\section{Córdoba 1998 \{published data only\}}

Córdoba R, Delgado MT, Pico V, Altisent R, Fores D, Monreal A. Effectiveness of brief intervention on non-dependent alcohol drinkers (EBIAL): a Spanish multi-centre study. Family Practice 1998;15(6):562-8. 


\section{Crawford 2004 \{published data only\}}

Barrett B, Byford S, Crawford MJ, Patton RE, Drummond C, Henry JA, et al. Cost-effectiveness of screening and referral to an alcohol health worker in alcohol misusing patients attending an accident and emergency department: a decision-making approach. Drug and Alcohol Dependence 2006;81(1):47-54.

* Crawford MJ, Patton R, Touquet R, Drummond C, Byford S, Barrett B, et al. Screening and referral for brief intervention of alcohol-misusing patients in an emergency department: a pragmatic randomised controlled trial. Lancet 2004;364(9442):1334-9.

Drummond C, Deluca P, Coulton S, Perryman K, Bland M, Cassidy $\mathrm{P}$, et al. Implementing screening and brief intervention in emergency departments in England. Alcoholism, Clinical and Experimental Research 2010;34(8):75A.

Patton R, Crawford M, Touquet R, Reece B, Barrett B, Drummond $C$, et al. A pragmatic randomised controlled trial of referral for brief intervention for patients misusing alcohol in an accident and emergency department. AERC final report; alcoholresearchuk.org/downloads/finalReports/AERC_ FinalReport_0020.pdf. Imperial College London, 2004.

\section{Crawford 2010 \{published and unpublished data\}}

Crawford MJ, Csipke E, Brown A, Reid S, Nilsen K, Redhead J, et al. The effect of referral for brief intervention for alcohol misuse on repetition of deliberate self-harm: an exploratory randomized controlled trial. Psychological Medicine 2010;40(11):1821-8.

\section{Curry 2003 \{published and unpublished data\}}

Curry SJ, Ludman EJ, Grothaus LC, Donovan D, Kim E. A randomized trial of a brief primary-care-based intervention for reducing at-risk drinking practices. Health Psychology 2003;22(2):156-65.

\section{D'Amico 2008 \{published data only\}}

* D'Amico EJ, Miles JN, Stern SA, Meredith LS. Brief motivational interviewing for teens at risk of substance use consequences: a randomized pilot study in a primary care clinic. Journal of Substance Abuse Treatment 2008;35(1):53-61.

Stern SA, Meredith LS, Gholson J, Gore P, D'Amico EJ. Project CHAT: a brief motivational substance abuse intervention for teens in primary care. Journal of Substance Abuse Treatment 2007;32(2):153-65.

\section{D'Onofrio 2008 \{published data only\}}

D'Onofrio G, Pantalon MV, Degutis LC, Fiellin DA, Busch SH, Chawarski MC, et al. Brief intervention for hazardous and harmful drinkers in the emergency department. Annals of Emergency Medicine 2008;51(6):742-50.

\section{D'Onofrio 2012 \{published data only\}}

D'Onofrio G, Fiellin DA, Pantalon MV, Chawarski MC, Owens PH, Degutis LC, et al. A brief intervention reduces hazardous and harmful drinking in emergency department patients. Annals of Emergency Medicine 2012;60(2):181-92.

\section{Daeppen 2007 \{published data only\}}

* Daeppen JB, Gaume J, Bady P, Yersin B, Calmes JM, Givel JC, et al. Brief alcohol intervention and alcohol assessment do not influence alcohol use in injured patients treated in the emergency department: a randomized controlled clinical trial. Addiction (Abingdon, England) 2007;102(8):1224-33.

Daeppen JB, Gaume J, Bady P, Yersin B, Calmes JM, Givel JC, et al. Erratum: Brief alcohol intervention and alcohol assessment do not influence alcohol use in injured patients treated in the emergency department: a randomized controlled clinical trial. Addiction (Abingdon, England) 2007;102(12):1995.

Dent 2008 \{published data only\}

Dent AW, Weiland TJ, Phillips GA, Lee NK. Opportunistic screening and clinician-delivered brief intervention for highrisk alcohol use among emergency department attendees: a randomized controlled trial. Emergency Medicine Australasia 2008;20(2):121-8.

\section{Désy 2010 \{published data only\}}

Désy PM, Howard PK, Perhats C, Li S. Alcohol screening, brief intervention, and referral to treatment conducted by emergency nurses: an impact evaluation. Journal of Emergency Nursing 2010;36(6):538-45.

\section{Díez 2002 \{published data only\}}

Díez JF, Peña C, García E, Gaite L. Brief intervention in Cantabria (Spain) in alcohol related problems [Intervención breve en Cantabria en problemas relacionados con el alcohol]. Adicciones 2002;14(1):13-24.

\section{Drummond 2009 \{published data only\}}

Drummond C, Coulton S, James D, Godfrey C, Parrott S, Baxter J, et al. Effectiveness and cost-effectiveness of a stepped care intervention for alcohol use disorders in primary care: pilot study. British Journal of Psychiatry 2009;195(5):448-56.

\section{Drummond 2014 \{published data only\}}

Drummond C, Deluca P, Coulton S, Bland M, Cassidy P, Crawford M. The effectiveness of alcohol screening and brief intervention in emergency departments: a multicentre pragmatic cluster randomized controlled trial. PLoS One 2014;9(6):e99463.

\section{Ettner 2014 \{published data only\}}

Duru OK, Xu H, Moore AA, Mirkin M, Ang A, Tallen L, et al. Examining the impact of separate components of a multicomponent intervention designed to reduce atrisk drinking among older adults: the Project SHARE study. Alcoholism, Clinical and Experimental Research 2015;39(7):1227-35.

* Ettner SL, Xu H, Duru OK, Ang A, Tseng CH, Tallen L, et al. The effect of an educational intervention on alcohol consumption, at-risk drinking, and health care utilization in older adults: the Project SHARE study. Journal of Studies on Alcohol and Drugs 2014;75(3):447-57. 
Fernández 1997 \{published data only\}

Fernández San Martín MI, Bermejo Caja CJ, Alonso Pérez M, Herreros Taberneros B, Nieto Candenas M, Novoa A, et al. Effectiveness of brief medical counseling to reduce drinkers' alcohol consumption. Atencion Primaria 1997;19(3):127-32.

Field 2010 \{published data only\}

Field C, Hungerford DW, Dunn C. Brief motivational interventions: an introduction. Journal of Trauma 2005;59:S21-6.

* Field CA, Caetano R, Harris TR, Frankowski R, Roudsari B. Ethnic differences in drinking outcomes following a brief alcohol intervention in the trauma care setting. Addiction (Abingdon, England) 2010;105(1):62-73.

Roudsari B, Caetano R, Field C. Alcohol intoxication/ dependence, ethnicity and utilisation of health care resources in a level I trauma center. Injury 2011;42(1):66-71.

Roudsari B, Caetano R, Frankowski R, Field C. Do minority or white patients respond to brief alcohol intervention in trauma centers? A randomized trial. Annals of Emergency Medicine 2009;54(2):285-93.

\section{Fleming 1997 \{published data only\}}

* Fleming MF, Barry KL, Manwell LB, Johnson K, London R. Brief physician advice for problem alcohol drinkers: a randomized controlled trial in community-based primary care practices. JAMA 1997;277(13):1039-45.

Fleming MF, Mundt MP, French MT, Manwell LB, Stauffacher EA Barry KL. Benefit-cost analysis of brief physician advice with problem drinkers in primary care settings. Medical Care 2000;38(1):7-18.

Fleming MF, Mundt MP, French MT, Manwell LB, Stauffacher EA, Barry KL. Brief physician advice for problem drinkers: longterm efficacy and benefit-cost analysis. Alcoholism, Clinical and Experimental Research 2002;26(1):36-43.

Grossberg PM, Brown DD, Fleming MF. Brief physician advice for high-risk drinking among young adults. Annals of Family Medicine 2004;2(5):474-80.

Manwell LB, Fleming MF, Mundt MP, Stauffacher EA, Barry KW. Treatment of problem alcohol use in women of childbearing age: results of a brief intervention trial. Alcoholism, Clinical and Experimental Research 2000;24(10):1517-24.

Mundt MP. Analyzing the costs and benefits of brief intervention. Alcohol Research and Health 2006;29(1):34-6.

\section{Fleming 1999 \{published data only\}}

Fleming MF, Manwell LB, Barry KL, Adams W, Stauffacher EA. Brief physician advice for alcohol problems in older adults: a randomized community-based trial. Journal of Family Practice 1999;48(5):378-84.

\section{Fleming 2004 \{published data only\}}

Fleming M, Brown R, Brown D. The efficacy of a brief alcohol intervention combined with \%CDT feedback in patients being treated for type 2 diabetes and/or hypertension. Journal of Studies on Alcohol 2004;65(5):631-7.

Fleming 2010 \{published data only\}

* Fleming MF, Balousek SL, Grossberg PM, Mundt MP, Brown D, Wiegel JR, et al. Brief physician advice for heavy drinking college students: a randomized controlled trial in college health clinics. Journal of Studies on Alcohol and Drugs 2010;71(1):23-31.

Mundt MP. College Alcohol Abuse and Alcohol Related Harms [PhD dissertation]. Madison (WI): University of Wisconsin, 2008.

Heather 1987 \{published data only\}

Heather N, Campion PD, Neville RG, Maccabe D. Evaluation of a controlled drinking minimal intervention for problem drinkers in general practice (the DRAMS scheme). Journal of the Royal College of General Practitioners 1987;37(301):358-63.

\section{Helstrom 2014 \{published data only\}}

Helstrom AW, Ingram E, Wang W, Small D, Klaus J, Oslin D. Treating heavy drinking in primary care practices: evaluation of a telephone-based intervention program. Addictive Disorders and Their Treatment 2014;13(3):101-9. [TCM]

\section{Huas 2002 \{published data only\}}

Huas D, Pessione F, Bouix J, Demeaux J, Alemand H, Rueff B. Efficacy of a brief intervention for problematic alcohol users [Efficacité à un an d'une intervention brève auprès des consommateurs d'alcool à problèmes]. Revue du Praticien Medecine Generale 2002;586:1343-8.

\section{Israel 1996 \{published data only\}}

Israel Y, Hollander O, Sanchez-Craig M, Booker S. Screening for problem drinking and counseling by the primary care physiciannurse team. Alcoholism, Clinical and Experimental Research 1996;20(8):1443-50.

\section{Kaner 2013 \{published and unpublished data\}}

Drummond C. Effectiveness of brief alcohol interventions [personal communication]. Email to: C Muirhead 14 July 2015.

* Kaner E, Bland M, Cassidy P, Coulton S, Dale V, Deluca P, et al. Effectiveness of screening and brief alcohol intervention in primary care (SIPS trial): pragmatic cluster randomised controlled trial. BMJ (Clinical Research Ed.) 2013;346:e8501.

Kaner E, Bland M, Cassidy P, Coulton S, Deluca P, Drummond C. Screening and brief interventions for hazardous and harmful alcohol use in primary care: a cluster randomised controlled trial protocol. BMC Public Health 2009;9(1):287.

\section{Kunz 2004 \{published data only\}}

Kunz MF, French MT, Bazargan-Hejazi S. Cost-effectiveness analysis of a brief intervention delivered to problem drinkers presenting at an inner-city hospital emergency department. Journal of Studies on Alcohol 2004;65(3):363-70.

\section{L'Engle 2014 \{published data only\}}

L'Engle KL, Mwarogo P, Kingola N, Sinkele W, Weiner DH. $A$ randomized controlled trial of a brief intervention to reduce alcohol use among female sex workers in Mombasa, 
Kenya. Journal of Acquired Immune Deficiency Syndromes 2014;67(4):446-53.

\section{Lane 2008 \{published data only\}}

Lane J, Proude EM, Conigrave KM, de Boer JP, Haber PS. Nurse-provided screening and brief intervention for risky alcohol consumption by sexual health clinic patients. Sexually Transmitted Infections 2008;84(7):524-7.

\section{Lock 2006 \{published data only\}}

Lock CA, Kaner E, Heather N, Doughty J, Crawshaw A, McNamee $P$, et al. Effectiveness of nurse-led brief alcohol intervention: a cluster randomized controlled trial. Journal of Advanced Nursing 2006;54(4):426-39.

\section{Longabaugh 2001 \{published data only\}}

Baird J, Longabaugh R, Lee CS, Nirenberg TD, Woolard R, Mello MJ, et al. Treatment completion in a brief motivational intervention in the emergency department: the effect of multiple interventions and therapists' behavior. Alcoholism, Clinical and Experimental Research 2007;31(Suppl 10):71-5S.

Choo EK, McGregor AJ, Mello MJ, Baird J. Gender, violence and brief interventions for alcohol in the emergency department. Drug and Alcohol Dependence 2013;127(1):115-21.

* Longabaugh R, Woolard RF, Nirenberg TD, Minugh AP, Becker B, Clifford PR, et al. Evaluating the effects of a brief motivational intervention for injured drinkers in the emergency department. Journal of Studies on Alcohol 2001;62(6):806-16.

Mello MJ, Nirenberg TD, Longabaugh R, Woolard R, Minugh A, Becker B, et al. Emergency department brief motivational interventions for alcohol with motor vehicle crash patients. Annals of Emergency Medicine 2005;45(6):620-5.

Stein LA, Minugh PA, Longabaugh R, Wirtz P, Baird J, Nirenberg TD, et al. Readiness to change as a mediator of the effect of a brief motivational intervention on posttreatment alcohol-related consequences of injured emergency department hazardous drinkers. Psychology of Addictive Behaviors 2009;23(2):185-95.

\section{Maisto 2001 \{published data only\}}

Gordon AJ, Conigliaro J, Maisto SA, McNeil M, Kraemer KL, Kelley ME. Comparison of consumption effects of brief interventions for hazardous drinking elderly. Substance Use and Misuse 2003;38(8):1017-35.

* Maisto SA, Conigliaro J, McNeil M, Kraemer K, Conigliaro RL, Kelley ME. Effects of two types of brief intervention and readiness to change on alcohol use in hazardous drinkers. Journal of Studies on Alcohol 2001;62(5):605-14.

\section{McDevitt-Murphy 2014 \{published data only\}}

McDevitt-Murphy ME, Murphy JG, Williams JL, Monahan CJ, Bracken-Minor KL, Fields JA. Randomized controlled trial of two brief alcohol interventions for OEF/OIF veterans. Journal of Consulting and Clinical Psychology 2014;82(4):562-8.
McIntosh 1997 \{published data only\}

McIntosh MC, Leigh G, Baldwin NJ, Marmulak J. Reducing alcohol consumption. Comparing three brief methods in family practice. Canadian Family Physician Medecin de Famille Canadien 1997;43:1959-62.

Mello 2008 \{published data only\}

Mello MJ, Baird J, Nirenberg TD, Lee C, Woolard R, Longabaugh R. DIAL: a randomised trial of a telephone brief intervention for alcohol. Injury Prevention 2013;19(1):44-8.

* Mello MJ, Longabaugh R, Baird J, Nirenberg T, Woolard R. DIAL: a telephone brief intervention for high-risk alcohol use with injured emergency department patients. Annals of Emergency Medicine 2008;51(6):755-64.

\section{Mertens 2014 \{published data only\}}

Mertens JR, Ward CL, Bresick GF, Broder T, Weisner CM. Effectiveness of nurse-practitioner-delivered brief motivational intervention for young adult alcohol and drug use in primary care in South Africa: a randomized clinical trial. Alcohol and Alcoholism (Oxford, Oxfordshire) 2014;49(4):430-8.

\section{Monti 2007 \{published data only\}}

Gwaltney CJ, Magill M, Barnett NP, Apodaca TR, Colby SM, Monti PM. Using daily drinking data to characterize the effects of a brief alcohol intervention in an emergency room. Addictive Behaviors 2011;36(3):248-50.

* Monti PM, Barnett NP, Colby SM, Gwaltney CJ, Spirito A, Rohsenow DJ, et al. Motivational interviewing versus feedback only in emergency care for young adult problem drinking. Addiction (Abingdon, England) 2007;102(8):1234-43.

\section{Moore 2011 \{published data only\}}

Borok J, Galier P, Dinolfo M, Welgreen S, Hoffing M, Davis JW, et al. Why do older unhealthy drinkers decide to make changes or not in their alcohol consumption? Data from the Healthy Living as You Age study. Journal of the American Geriatrics Society 2013;61(8):1296-1302

Lin JC, Karno MP, Barry KL, Blow FC, Davis JW, Tang L, et al. Determinants of early reductions in drinking in older at-risk drinkers participating in the intervention arm of a trial to reduce at-risk drinking in primary care. Journal of the American Geriatric Society 2010;58(2):227-33.

Lin JC, Karno MP, Tang L, Barry KL, Blow FC, Davis JW, et al. Do health educator telephone calls reduce at-risk drinking among older adults in primary care?. Journal of General Internal Medicine 2010;25(4):334-9.

* Moore AA, Blow FC, Hoffing M, Welgreen S, Davis J, Lin JC, et al. Primary care-based intervention to reduce at-risk drinking in older adults: a randomized controlled trial. Addiction (Abingdon, England) 2010;106(1):111-20.

\section{Noknoy 2010 \{published data only\}}

Noknoy S, Rangsin R, Saengcharnchai P, Tantibhaedhyangkul U, McCambridge J. RCT of effectiveness of motivational enhancement therapy delivered by nurses for hazardous 
drinkers in primary care units in Thailand. Alcohol and Alcoholism (Oxford, Oxfordshire) 2010;45(3):263-70.

\section{Ockene 1999 \{published data only\}}

* Ockene JK, Adams A, Hurley TG, Wheeler EV, Hebert JR. Brief physician- and nurse practitioner-delivered counseling for high-risk drinkers: does it work? Archives of Internal Medicine 1999;159(18):2198-205.

Ockene JK, Reed GW, Reiff-Hekking S. Brief patient-centered clinician-delivered counseling for high-risk drinking: 4-year results. Annals of Behavioral Medicine 2009;37(3):335-42.

Reiff-Hekking S, Ockene JK, Hurley TG, Reed GW. Brief physician and nurse practitioner-delivered counseling for high-risk drinking. Results at 12 months follow-up. Journal of General Internal Medicine 2005;20(1):7-13.

\section{Richmond 1995 \{published data only\}}

* Richmond R, Heather N, Wodak A, Kehoe L, Webster I. Controlled evaluation of a general practice-based brief intervention for excessive drinking. Addiction (Abingdon, England) 1995;90(1):119-32.

\section{Rodríguez 2003 \{published data only\}}

Dauer ARM, Rubio ES, Coris ME, Valls MJ. Brief intervention in alcohol-positive traffic casualties: is it worth the effort?. Alcohol and Alcoholism (Oxford, Oxfordshire) 2006;41(1):76-83.

Dauer ARM, Rubio ES, Gómez XM, Novella LT, Coris ME, Valls MJ, et al. Early identification and brief intervention in alcohol-related traffic casualties: preliminary results [Identificación precoz e intervención breve en lesionados de trafico con presencia d alcohol: primeros resultados]. Adicciones 2003;15(3):191-202.

* Rodríguez-Martos A, Santamariña E, Torralba L, Escayola M, Martí J, Plasència A. Short-term effectiveness of brief interventions in alcohol-positive traffic casualties [Efectividad a corto plazo de las interventiones breves realizadas en pacientes lesionados por accidente de tráfico con alcoholemia positiva]. Gaceta Sanitaria 2005;19(1):45-9.

\section{Romelsjö 1989 \{published data only\}}

Romelsjö A, Andersson L, Barrner H, Borg S, Granstrand C, Hultman $\mathrm{O}$, et al. A randomized study of secondary prevention of early stage problem drinkers in primary health care. British Journal of Addiction 1989;84(11):1319-27.

\section{Rubio 2010 \{published data only\}}

Rubio G, Jiménez-Arriero MA, Martínez I, Ponce G, Palomo T. Efficacy of physician-delivered brief counseling intervention for binge drinkers. American Journal of Medicine 2010;123(1):72-8.

\section{Schaus 2009 \{published data only\}}

Schaus JF, Sole ML, McCoy TP, Mullett N, O'Brien MC. Alcohol screening and brief intervention in a college student health center: a randomized controlled trial. Journal of Studies on Alcohol and Drugs. Supplement 2009;16:131-41.
Scott 1990 \{published data only\}

Anderson P, Scott $E$. The effect of general practitioners' advice to heavy drinking men. British Journal of Addiction 1992;87(6):891-900.

* Scott E, Anderson P. Randomized controlled trial of general practitioner intervention in women with excessive alcohol consumption. Drug and Alcohol Review 1990;10(4):313-21.

Segatto 2011 \{published data only\}

Segatto ML, Andreoni S, de Souza e Silva R, Diehl A, Pinsky I. Brief motivational interview and educational brochure in emergency room settings for adolescents and young adults with alcohol-related problems: a randomized single-blind clinical trial. Revista Brasileira de Psiquiatria (Sao Paulo, Brazil : 1999) 2011;33(3):225-33.

\section{Senft 1997 \{published data only\}}

Senft RA, Polen MR, Freeborn DK, Hollis JF. Brief intervention in a primary care setting for hazardous drinkers. American Journal of Preventive Medicine 1997;13(6):464-70.

\section{Seppa 1992 \{published data only\}}

* Seppa K. Intervention in alcohol abuse among macrocytic patients in general practice. Scandinavian Journal of Primary Health Care 1992;10(3):217-22.

\section{Soderstrom 2007 \{published data only\}}

Dischinger PC. Request for further information on the Delta study [personal communication]. Email to: FR Beyer 7 May 2014.

* Soderstrom CA, DiClemente CC, Dischinger PC, Hebel JR, McDuff DR, Auman KM, et al. A controlled trial of brief intervention versus brief advice for at-risk drinking trauma center patients. Journal of Trauma 2007;62(5):1102-11.

\section{Sommers 2006 \{published data only\}}

Sommers MS, Dyehouse JM, Howe SR, Fleming M, Fargo JD, Schafer JC. Effectiveness of brief interventions after alcoholrelated vehicular injury: a randomized controlled trial. Journal of Trauma 2006;61(3):523-31.

\section{Sommers 2013 \{published and unpublished data\}}

Sommers MS. Effectiveness of brief alcohol interventions [personal communication]. Email to: C Muirhead 24 June 2014.

* Sommers MS, Lyons MS, Fargo JD, Sommers BD, McDonald CC, Shope JT, et al. Emergency department-based brief intervention to reduce risky driving and hazardous/ harmful drinking in young adults: a randomized controlled trial. Alcoholism, Clinical and Experimental Research 2013;37(10):1753-62.

\section{Spirito 2004 \{published data only\}}

Spirito A, Monti PM, Barnett NP, Colby SM, Sindelar H, Rohsenow DJ, et al. A randomized clinical trial of a brief motivational intervention for alcohol-positive adolescents treated in an emergency department. Journal of Pediatrics 2004;145(3):396-402. 
Spirito 2011 \{published data only\}

Spirito A, Sindelar-Manning H, Colby SM, Barnett NP, Lewander W, Rohsenow DJ, et al. Individual and family motivational interventions for alcohol-positive adolescents treated in an emergency department: results of a randomized clinical trial. Archives of Pediatrics and Adolescent Medicine 2011;165(3):269-74.

\section{Tait 2004 \{published data only\}}

Tait R. Including your trial in our Cochrane review...? [personal communication]. Email to: FR Beyer 9 October 2013.

Tait RJ, Hulse GK. Adolescent substance use and hospital presentations: a record linkage assessment of 12-month outcomes. Drug and Alcohol Dependence 2005;79(3):365-71.

* Tait RJ, Hulse GK, Robertson SI. Effectiveness of a briefintervention and continuity of care in enhancing attendance for treatment by adolescent substance users. Drug and Alcohol Dependence 2004;74(3):289-96.

Tait RJ, Hulse GK, Robertson SI, Sprivulis PC. Emergency department-based intervention with adolescent substance users: 12 -month outcomes. Drug and Alcohol Dependence 2005;79(3):359-63.

\section{Tomson 1998 \{published data only\}}

* Tomson Y, Romelsjö A, Aberg H. Excessive drinking - brief intervention by a primary health care nurse: a randomized controlled trial. Scandinavian Journal of Primary Health Care 1998;16(3):188-92.

\section{Wallace 1988 \{published data only\}}

* Wallace P, Cutler S, Haines A. Randomised controlled trial of general practitioner intervention in patients with excessive alcohol consumption. British Medical Journal 1988;297(6649):663-8.

\section{Walton 2010 \{published and unpublished data\}}

Cunningham RM, Chermack ST, Zimmerman MA, Shope JT, Bingham CR, Blow FC, et al. Brief motivational interviewing intervention for peer violence and alcohol use in teens: oneyear follow-up. Pediatrics 2012;129(6):1083-90.

* Cunningham RM, Walton MA, Goldstein A, Chermack ST, Shope JT, Bingham CR, et al. Three-month follow-up of brief computerized and therapist interventions for alcohol and violence among teens. Academic Emergency Medicine 2009;16(11):1193-207.

Walton M. Effectiveness of brief alcohol interventions [personal communication]. Email to: C Muirhead 14 October 2014.

Walton MA, Chermack ST, Shope JT, Bingham CR, Zimmerman MA, Blow FC, et al. Effects of a brief intervention for reducing violence and alcohol misuse among adolescents: a randomized controlled trial. JAMA 2010;304(5):527-35.

\section{Watson 2013 \{published data only\}}

Watson J, Crosby H, Dale V, Tober G, Wu Q, Lang J, et al. AESOPS: a randomised controlled trial of the clinical effectiveness and cost-effectiveness of opportunistic screening and stepped care interventions for older hazardous alcohol users in primary care. Health Technology Assessment 2013;17:1-158.

\section{Woolard 2013 \{published data only\}}

Woolard R, Baird J, Longabaugh R, Nirenberg T, Lee CS, Mello MJ, et al. Project REDUCE: reducing alcohol and marijuana misuse: effects of a brief intervention in the Emergency Department. Addictive Behaviors 2013;38(3):1732-9.

\section{References to studies excluded from this review \\ Academic ED SBIRT 2007 \{published data only\}}

Academic ED SBIRT Research Collaborative. The impact of screening, brief intervention and referral for treatment in emergency department patients' alcohol use: a 3-, 6-and 12month follow-up. Alcohol and Alcoholism (Oxford, Oxfordshire) 2010;45(6):514-9.

Academic ED SBIRT Research Collaborative. The impact of screening, brief intervention, and referral for treatment on emergency department patients' alcohol use. Annals of Emergency Medicine 2007;50(6):699-710.

\section{Ameratunga 2011 \{published data only\}}

Ameratunga S, Whittaker R, Kool B, Civil I, Reid P, Thornton V, et al. Feasibility of a mobile phone delivered intervention to reduce harmful drinking and injury among trauma patients: the MoDeRATE trial. 8th Conference of INEBRIA. Boston, USA, 2011.

\section{Apodaca 2007 \{published data only\}}

Apodaca TR, Miller WR, Schermer CR, Amrhein PC. A pilot study of bibliotherapy to reduce alcohol problems among patients in a hospital trauma center. Journal of Addictions Nursing 2007;18(4):167-73.

\section{Areesantichai 2010 \{published data only\}}

Areesantichai C, lamsupasit S, Marsden J, Perngparn U, Taneepanichskul S. Effect of "tailored goal oriented community brief intervention model" on AUDIT reduction in Thai communities. Journal of the Medical Association of Thailand 2010;93(8):992-7.

\section{Areesantichai 2013 \{published data only\}}

Areesantichai C, Chapman RS, Perngparn U. Effectiveness of a Tailored Goal Oriented Community Brief Intervention (TGCBI) in reducing alcohol consumption among risky drinkers in Thailand: a quasi-experimental study. Journal of Studies on Alcohol and Drugs 2013;74(2):311-9.

\section{Babor 1996 \{published data only\}}

WHO Brief Intervention Study Group. A cross-national trial of brief interventions with heavy drinkers. American Journal of Public Health 1996;86(7):948-55.

\section{Baker 2014 \{published data only\}}

Baker AL, Turner A, Kelly PJ, Spring B, Callister R, Collins CE, et al. 'Better Health Choices' by telephone: a feasibility trial of improving diet and physical activity in people diagnosed with psychotic disorders. Psychiatry Research 2014;220(1):63-70. 
Ball 2007 \{published data only\}

Ball SA, Todd M, Tennen H, Armeli S, Mohr C, Affleck G, et al. Brief motivational enhancement and coping skills interventions for heavy drinking. Addictive Behaviors 2007;32(6):1105-18.

\section{Boekeloo 2004 \{published data only\}}

Boekeloo BO, Jerry J, Lee-Ougo WI, Worrell KD, Hamburger EK, Russek-Cohen E, et al. Randomized trial of brief office-based interventions to reduce adolescent alcohol use. Archives of Pediatrics \& Adolescent Medicine 2004;158(6):635-42.

\section{Ceperich 2011 \{published data only\}}

Ceperich SD, Ingersoll KS. Motivational interviewing + feedback intervention to reduce alcohol-exposed pregnancy risk among college binge drinkers: determinants and patterns of response. Journal of Behavioral Medicine 2011;34(5):381-95.

\section{Chander 2015 \{published data only\}}

Chander G, Hutton HE, Lau B, Xu X, McCaul ME. Brief intervention decreases drinking frequency in HIV-infected, heavy drinking women: results of a randomized controlled trial. Journal of Acquired Immune Deficiency Syndromes 2015;70(2):137-45.

\section{Chang 1997 \{published data only\}}

Chang G, Behr H, Goetz M, Hiley A, Bigby J. Women and alcohol abuse in primary care: identification and intervention. American Journal on Addictions / American Academy of Psychiatrists in Alcoholism and Addictions 1997;6(3):183-92.

Field 2014 \{published data only\}

Field C, Walters S, Marti CN, Jun J, Foreman M, Brown C. A multisite randomized controlled trial of brief intervention to reduce drinking in the trauma care setting: how brief is brief?. Annals of Surgery 2014;259(5):873-80.

\section{Gentilello 1999 \{published data only\}}

Gentilello LM, Rivara FP, Donovan DM, Jurkovich GJK, Daranciang E, Dunn CW, et al. Alcohol interventions in a trauma center as a means of reducing the risk of injury recurrence. Annals of Surgery 1999;230(4):473-83.

\section{Gwadz 2008 \{published data only\}}

Gwadz MV, Leonard NR, Cleland CM, Riedel M, Arredondo GN, Wolfe $\mathrm{H}$, et al. Behavioral interventions for HIV infected and uninfected mothers with problem drinking. Addiction Research \& Theory 2008;16(1):47-65.

\section{Haller 2014 \{published data only\}}

Haller DM, Meynard A, Lefebvre D, Ukoumunne OC, Narring F, Broers B. Effectiveness of training family physicians to deliver a brief intervention to address excessive substance use among young patients: a cluster randomized controlled trial. CMAJ : Canadian Medical Association Journal 2014;186(8):E263-72.

\section{Hansen 2012 \{published data only\}}

Hansen ABG, Becker U, Nielsen AS, Gronbaek M, Tolstrup JS, Thygesen LC. Internet-based brief personalized feedback intervention in a non-treatment seeking population of adult heavy drinkers: a randomized controlled trial. Journal of Medical Internet Research 2012;14(4):e98.

\section{Hansen 2012a \{published data only\}}

Hansen AB, Becker U, Nielsen AS, Grønbaek M, Tolstrup JS. Brief alcohol intervention by newly trained workers versus leaflets: comparison of effect in older heavy drinkers identified in a population health examination survey: a randomized controlled trial. Alcohol and Alcoholism (Oxford, Oxfordshire) 2012;47(1):25-32.

\section{Hansson 2007 \{published data only\}}

Hansson H, Rundberg J, Zetterlind U, Johnsson KO, Berglund $M$. Two-year outcome of an intervention program for university students who have parents with alcohol problems: a randomized controlled trial. Alcoholism, Clinical and Experimental Research 2007;31(11):1927-33.

\section{Hilbink 2012 \{published data only\}}

Hilbink M, Voerman G, van Beurden I, Penninx B, Laurant M. A randomized controlled trial of a tailored primary care program to reverse excessive alcohol consumption. Journal of the American Board of Family Medicine 2012;25(5):712-22.

\section{Houry 2011 \{published data only\}}

Houry D, Hankin A, Daugherty J, Smith LS, Kaslow N. Effect of a targeted women's health intervention in an inner-city emergency department. Emergency Medicine International 2011 December 10 [Epub ahead of print]. [DOI: $10.1155 / 2011 / 543493]$

\section{Hyman 2007 \{published data only\}}

Hyman Z. Brief interventions for high-risk drinkers. Journal of Clinical Nursing 2007;15(11):1383-96.

\section{Ingersoll 2013 \{published data only\}}

Ingersoll KS, Ceperich SD, Hettema JE, Farrell-Carnahan L, Penberthy JK. Preconceptional motivational interviewing interventions to reduce alcohol-exposed pregnancy risk. Journal of Substance Abuse Treatment 2013;44(4):407-16.

\section{Ivanets 1991 \{published data only\}}

Ivanets NN, Lukomskaya MI. Evaluation of early intervention strategies used in primary health care: a report on the World Health Organization (WHO) Project on Identification and management of alcohol-related problems in primary health care. Alcohol and Alcoholism (Oxford, Oxfordshire). Supplement 1991;1:489-91.

\section{Jessop 2008 \{published data only\}}

Jessop DC, Wade J. Fear appeals and binge drinking: a terror management theory perspective. British Journal of Health Psychology 2008;13(4):773-88.

\section{Kristenson 1983 \{published data only\}}

Kristenson H, Ohlin H, Hulten-Nosslin MB, Trell E, Hood B. Identification and intervention of heavy drinking in middleaged men: results and follow-up of 24-60 months of longterm study with randomized controls. Alcoholism, Clinical and Experimental Research 1983;7(2):203-9.

Kulesza 2013 \{published data only\}

Kulesza M, McVay MA, Larimer ME, Copeland AL. A randomized clinical trial comparing the efficacy of two active conditions of a 
brief intervention for heavy college drinkers. Addictive Behaviors 2013;38(4):2094-101.

\section{Lang 2007 \{published data only\}}

Lang S, Kuttler H. Project HaLT [Projekt HaLT - Hart am LimiT. Frühintervention und kommunal verankerte Strategie zur Verhinderung von riskantem Rauschtrinken bei Kindern und Jugendlichen]. Viennese Journal of Addiction Research 2007;30(1):27-37.

\section{Maheswaran 1992 \{published data only\}}

Maheswaran R, Beevers M, Beevers DG. Effectiveness of advice to reduce alcohol consumption in hypertensive patients. Hypertension 1992;19(1):79-84.

\section{Massey 2015 \{published data only\}}

Massey LS, Barry KL, Walton MA, Chermack ST, Cunningham RM, Bohnert ASB, et al. Computer and therapist delivered brief alcohol interventions for adult risky drinkers in the emergency department: health explorer study post-test. Alcoholism, Clinical and Experimental Research 2015;39:22A.

\section{McDevitt-Murphy 2015 \{published data only\}}

McDevitt-Murphy ME, Williams JL, Murphy JG, Monahan CJ, Bracken-Minor KL. Brief intervention to reduce hazardous drinking and enhance coping among OEF/OIF/OND veterans. Professional Psychology, Research and Practice 2015;46(2):83-9.

\section{Mezzani 2007 \{published data only\}}

Mezzani L, Patussi V, Rossi A, Russo R, Scafato E. Establishing an Italian general practitioner brief intervention pilot project for problem drinkers. Substance Use \& Misuse 2007;42(12-13):1979-89.

\section{Milner 2010 \{published data only\}}

Milner KK, Barry KL, Blow FC, Welsh D. Brief interventions for patients presenting to the psychiatric emergency service (PES) with major mental illnesses and at-risk drinking. Community Mental Health Journal 2010;46(2):149-55.

\section{Monti 1999 \{published data only\}}

Monti PM, Spirito A, Myers MCSM, Barnett NP, Pohsenow DJ, Woolard RLW. Brief intervention for harm reduction with alcohol positive older adolescents in a hospital emergency department. Journal of Consulting and Clinical Psychology 1999;67(6):989-94.

\section{Nayak 2015 \{published data only\}}

Nayak MB, Bond JC, Ye Y, Cherpitel CJ, Woolard R, Bernstein E, et al. Readiness to change and to accept help and drinking outcomes in young adults of Mexican origin. Journal of Studies on Alcohol and Drugs 2015;76(4):602-6.

\section{Nilssen 1991 \{published data only\}}

Nilssen 0 . The Tromsø study: identification of and a controlled intervention on a population of early stage risk drinkers. Preventive Medicine 1991;20(4):518-28.
North India community-based sample followed for 3 months. Alcohol and Alcoholism (Oxford, Oxfordshire) 2007;42(4):328-32.

Palm 2016 \{published data only\}

Palm A, Olofsson N, Danielsson I, Skalkidou A, Wennberg P, Högberg U. Motivational interviewing does not affect risk drinking among young women: a randomised, controlled intervention study in Swedish youth health centres. Scandinavian Journal of Public Health 2016;44(6):611-8.

Rhodes 2015 \{published data only\}

Rhodes KV, Rodgers M, Sommers M, Hanlon A, Chittams J, Doyle A, et al. Brief motivational intervention for intimate partner violence and heavy drinking in the emergency department: a randomized clinical trial. JAMA 2015;314(5):466-77.

\section{Shetty 2011 \{published data only\}}

Shetty V, Murphy DA, Zigler C, Yamashita DD, Belin TR. Randomized controlled trial of personalized motivational interventions in substance using patients with facial injuries. Journal of Oral and Maxillofacial Surgery 2011;69(9):2396-411.

\section{Sterling 2017 \{published data only\}}

Sterling SA, Kline-Simon A, Jones A, Brumder-Ross T, Weisner C. Outcomes from a trial of screening, brief intervention and referral to treatment for adolescents in pediatric primary care: implications for adolescent girls. Alcoholism: Clinical and Experimental Research 2017;41:336A.

\section{Toft 2009 \{published data only\}}

Toft U, Pisinger C, Aadahl M, Lau C, Linneberg A, Ladelund S, et al. The impact of a population-based multi-factorial lifestyle intervention on alcohol intake: the Inter99 study. Preventive Medicine 2009;49(2-3):115-21.

\section{UKATT 2005 \{published data only\}}

UKATT Research Team. Cost effectiveness of treatment for alcohol problems: findings of the randomised UK alcohol treatment trial (UKATT). BMJ (Clinical Research Ed.) 2005;331(7516):544.

\section{Walton 2015a \{published data only\}}

Walton MA, Chermack ST, Blow FC, Ehrlich PF, Barry KL, Booth BM, et al. Components of brief alcohol interventions for youth in the emergency department. Substance Abuse 2015;36(3):339-49.

\section{Worden 2011 \{published data only\}}

Worden BL. Effectiveness of a feedback-based brief intervention for alcohol use disorders in community care [PhD thesis]. New Jersey: Rutgers University, 2011.

\section{Wutzke 2002 \{published data only\}}

Wutzke S, Conigrave K, Saunders J, Hall W. The long-term effectiveness of brief interventions for unsafe alcohol consumption: a 10-year follow-up. Addiction 2002;97(6):665-75.

\section{Pal 2007 \{published data only\}}

Pal HR, Yadav D, Mehta S, Mohan I. A comparison of brief intervention versus simple advice for alcohol use disorders in a 


\section{References to studies awaiting assessment}

\section{Arnaud 2017 \{published data only\}}

Arnaud N, Diestelkamp S, Wartberg L, Sack PM, Daubmann A, Thomasius R. Short- to midterm effectiveness of a brief motivational intervention to reduce alcohol use and related problems for alcohol intoxicated children and adolescents in pediatric emergency departments: a randomized controlled trial. Academic Emergency Medicine 2017;24(2):186-200.

\section{Cherpitel 2016 \{published data only\}}

Cherpitel CJ, Ye Y, Bond J, Woolard R, Villalobos S, Bernstein J, et al. Brief intervention in the emergency department among Mexican-origin young adults at the US-Mexico border: outcomes of a randomized controlled clinical trial using promotores. Alcohol and Alcoholism (Oxford, Oxfordshire) 2016;51(2):154-63.

\section{Crawford 2015 \{published data only\}}

Crawford MJ, Sanatinia R, Barrett B, Byford S, Dean M, Green J, et al. The clinical and cost-effectiveness of brief advice for excessive alcohol consumption among people attending sexual health clinics: a randomised controlled trial. Sexually Transmitted Infections 2015;91(1):37-43.

\section{Diaz Gomez 2017 \{published data only\}}

Diaz Gomez C, Ngantcha M, Le Garjean N, Brouard N, Lasbleiz M, Perennes $\mathrm{M}$, et al. Effect of a brief motivational intervention in reducing alcohol consumption in the emergency department: a randomized controlled trial. European Journal of Emergency Medicine 2017 July 12 [Epub ahead of print]. [DOI: 10.1097/ MEJ.0000000000000488]

\section{Mello 2016 \{published data only\}}

Mello MJ, Baird J, Lee C, Strezsak V, French MT, Longabaugh R. A randomized controlled trial of a telephone intervention for alcohol misuse with injured emergency department patients. Annals of Emergency Medicine 2016;67(2):263-75.

\section{Monti 2015 \{published data only\}}

Monti PM, Mastroleo NR, Barnett NP, Colby SM, Kahler CW, Operario D. Brief motivational intervention to reduce alcohol and HIV/sexual risk behavior in emergency department patients: A randomized controlled trial. Journal of Consulting and Clinical Psychology 2016;84(7):580.

Monti PM, Mastroleo NR, Kahler CW, Barnett NB, Colby SM, Operario D. Effects of a brief intervention in the emergency department for alcohol and HIV/sexual risk. Alcoholism, Clinical and Experimental Research 2015;39:305A.

\section{Nadkarni 2017 \{published data only\}}

Nadkarni A, Weobong B, Weiss HA, McCambridge J, Bhat B, Katti B, et al. Counselling for Alcohol Problems (CAP), a lay counsellor-delivered brief psychological treatment for harmful drinking in men, in primary care in India: a randomised controlled trial. Lancet 2017;389(10065):186-95.

\section{Walton 2015 \{published data only\}}

Walton MA, Chermack ST, Ehrlich P, Carter P, Booth BM, Blow F, et al. Project $U$ Connect: a randomized controlled trial testing alcohol interventions among underage drinkers in the emergency department. Alcoholism, Clinical and Experimental Research 2015;39:22A

\section{References to ongoing studies \\ ISRCTN13832949 \{published data only\}}

ISRCTN13832949. Development and evaluation of the efficacy of a brief motivational intervention among young adults admitted in the emergency room while being alcohol intoxicated [A process study and randomized controlled trial examining the efficacy and mechanisms of motivational interviewing for alcohol Intoxicated young adults admitted to the emergency room]. www.isrctn.com/ISRCTN13832949 (first received 26 November 2016).

\section{ISRCTN45300218 \{published data only\}}

Deluca P, Coulton S, Alam MF, Cohen D, Donoghue K, Gilvarry E, et al. Linked randomised controlled trials of face-to-face and electronic brief intervention methods to prevent alcohol related harm in young people aged 14-17 years presenting to Emergency Departments (SIPS Junior). BMC Public Health 2015;15(1):345.

* ISRCTN45300218. Developing and evaluating interventions for adolescents with alcohol use disorders who present through emergency departments: randomised feasibility study and exploratory randomised controlled trial. www.isrctn.com/ ISRCTN45300218 (first received 5 June 2014).

\section{RBR-65262c \{published data only\}}

RBR-65262c. Brief intervention for hazardous and harmful women's alcohol consumption [Intervenção breve para mulheres que fazem uso de risco ou nocivo de álcool]. www.ensaiosclinicos.gov.br/rg/RBR-65262c/ (first received 20 March 2017).

\section{Additional references}

\section{Agosti 1995}

Agosti V. The efficacy of treatments in reducing alcohol consumption: a meta-analysis. International Journal of the Addictions 1995;30(8):1067-77.

\section{Anderson 1991}

Anderson P. Alcohol as a key area. BMJ (Clinical Research Ed.) 1991;303(6805):766-9.

\section{Angus 2014}

Angus C, Latimer N, Preston L, Li J, Purshouse R. What are the implications for policy makers? A systematic review of the cost-effectiveness of screening and brief interventions for alcohol misuse in primary care. Frontiers in Psychiatry / Frontiers Research Foundation 2014;5:114.

\section{Atkins 2004}

Atkins D, Best D, Briss PA, Eccles M, Falck-Ytter Y, Flottorp S, et al. Grading quality of evidence and strength of recommendations. BMJ (Clinical Research Ed.) 2004;328(7454):1490-4 


\section{Babor 1994}

Babor TE. Avoiding the horrid and beastly sin of drunkenness: does dissuasion make a difference?. Journal of Consulting and Clinical Psychology 1994;62(6):1127-40.

\section{Bailey 2011}

Bailey J, Poole R, Zinovieff F, Robinson CA, Parry O, Tocque K. Achieving positive change in the drinking culture of Wales (2011). www.drugsandalcohol.ie/16080/. Bangor: Alcohol Concern, (accessed prior to 8 February 2018).

\section{Bertholet 2005}

Bertholet N, Daeppen JB, Wietlisbach V, Fleming M, Burnand B. Reduction of alcohol consumption by brief intervention in primary care: systematic review and meta-analysis. Archives of Internal Medicine 2005;165(9):986-95.

\section{Bien 1993}

Bien TH, Miller WR, Tonigan JS. Brief interventions for alcohol problems: a review. Addiction 1993;90(8):315-35.

\section{De Paula Gebara 2013}

De Paula Gebara CF, de Castro Bhona FM, Ronzani TM, Lourenço LM, Noto AR. Brief intervention and decrease of alcohol consumption among women: a systematic review. Substance Abuse Treatment, Prevention, and Policy 2013;8(1):1.

\section{Deeks 2001}

Deeks JJ, Altman DG, Bradburn MJ. Chapter 15. Statistical methods for examining heterogeneity and combining results from several studies in meta-analysis. Systematic Reviews in Health Care. Second Edition. London: BMJ Books, 2001.

\section{DerSimonian 1986}

DerSimonian R, Laird N. Meta-analysis in clinical trials. Controlled Clinical Trials 1986;7(3):177-88.

\section{Diestelkamp 2016}

Diestelkamp S, Drechsel M, Baldus C, Wartberg L, Arnaud N, Thomasius R. Brief in person interventions for adolescents and young adults following alcohol-related events in emergency care: a systematic review and European evidence synthesis. European Addiction Research 2016;22(1):17-35.

\section{Edwards 1997}

Edwards AGK, Rollnick S. Outcome studies of brief alcohol intervention in general practice: the problem of lost subjects. Addiction 1997;92(12):1699-1704.

\section{EndNote 2015 [Computer program]}

Thomson Reuters. EndNote X7. Version (accessed prior to 27 November 2017). Philadelphia (PA): Thomson Reuters, 2015.

\section{Flay 1986}

Flay BR. Efficacy and effectiveness trials (and other phases of research) in the development of health promotion programs. Preventive Medicine 1986;15(5):451-74.

\section{Furtwaengler 2013}

Furtwaengler NAFF, de Visser RO. Lack of international consensus in low-risk drinking guidelines. Drug and Alcohol Review 2013;32(1):11-8

\section{Gartlehner 2006}

Gartlehner G, Hansen RA, Nissman D, Lohr KN, Carey TS. A simple and valid tool distinguished efficacy from effectiveness studies. Journal of Clinical Epidemiology 2006;59(10):1040-8.

\section{GBD 2017}

GBD Risk Factors Collaborators. Global, regional, and national comparative risk assessment of 84 behavioural, environmental and occupational, and metabolic risks or clusters of risks, 1990-2016: a systematic analysis for the Global Burden of Disease Study 2016. Lancet 2017;390(10100):1345-422.

\section{GRADEpro GDT 2015 [Computer program]}

McMaster University (developed by Evidence Prime). GRADEpro Guideline Development Tool. Version (accessed prior to 27 November 2017). Hamilton (ON): McMaster University (developed by Evidence Prime), 2015.

\section{Gual 1999}

Gual A, Rodriguez Martos A, Lligoña A, Llopis J. Does the concept of a standard drink apply to viticultural societies?. Alcohol and Alcoholism (Oxford, Oxfordshire) 1999;34(2):153-60.

\section{Guyatt 2008}

Guyatt GH, Oxman AD, Vist GE, Kunz R, Falck-Ytter Y, AlonsoCoello $P$, et al. GRADE: an emerging consensus on rating quality of evidence and strength of recommendations. BMJ (Clinical Research Ed.) 2008;336(7560):924-6.

\section{Guyatt 2011}

Guyatt G, Oxman AD, Akl EA, Kunz R, Vist G, Brozek J, et al. GRADE guidelines 1. Introduction-GRADE evidence profiles and summary of findings tables. Journal of Clinical Epidemiology 2011;64(4):383-94.

\section{Heather 1995}

Heather N. Interpreting the evidence on brief interventions for excessive drinkers: the need for caution. Alcohol and Alcoholism (Oxford, Oxfordshire) 1995;30(3):287-96.

\section{Heather 2006}

Heather N (ed). WHO collaborative project on identification \& management of alcohol-related problems in primary health care. Report on Phase IV: development of country-wide strategies for implementing early identification and brief intervention in primary health care. Geneva: WHO Press, 2006.

\section{Heather 2014}

Heather N. The efficacy-effectiveness distinction in trials of alcohol brief intervention. Addiction Science \& Clinical Practice 2014;9(1):1.

\section{Higgins 2002}

Higgins JPT, Thompson SG. Quantifying heterogeneity in a meta-analysis. Statistics in Medicine 2002;21(11):1539-58. 


\section{Higgins 2003}

Higgins JPT, Thompson SG, Deeks JJ, Altman DG. Measuring inconsistency in meta-analyses. BMJ (Clinical Research Ed.) 2003;327(7414):557-60.

\section{Higgins 2011}

Higgins JPT, Altman DG, Sterne JAC. Chapter 8: Assessing risk of bias in included studies. In: Higgins JP, Green S, editor(s). Cochrane Handbook for Systematic Reviews of Interventions Version 5.1.0 (updated March 2011). The Cochrane Collaboration, 2011. Available from handbook.cochrane.org.

\section{Higgins 2011a}

Higgins JPT, Deeks JJ, Altman DG (editors). Chapter 16: Special topics in statistics. Approximate analyses of clusterrandomized trials for a meta-analysis: Inflating standard errors. In: Higgins JP, Green S, editor(s). Cochrane Handbook for Systematic Reviews of Interventions Version 5.1.0 (updated March 2011). The Cochrane Collaboration, 2011. Available from handbook.cochrane.org. Chichester, UK: John Wiley \& Sons, Ltd.

\section{Higgins 2011b}

Higgins JPT, Deeks JJ, Altman DG. Chapter 16: Special topics in statistics. Intention-to-treat issues. In: Higgins JP, Green $\mathrm{S}$, editor(s). Cochrane Handbook for Systematic Reviews of Interventions Version 5.1.0 (updated March 2011). The Cochrane Collaboration, 2011. Available from handbook.cochrane.org.

\section{Holder 1999}

Holder H, Flay B, Howard J, Boyd G, Voas R, Grossman M. Phases of alcohol problem prevention research. Alcoholism, Clinical and Experimental Research 1999;23(1):183-94.

\section{Kaner 2001}

Kaner E, Heather N, Brodie J, Lock CA, McAvoy B. Patient and practitioner characteristics predict brief alcohol intervention in primary care. British Journal of General Practice 2001;51(471):822-7.

\section{Kaner 2017}

Kaner EF, Beyer FR, Garnett C, Crane D, Brown J, Muirhead C, et al. Personalised digital interventions for reducing hazardous and harmful alcohol consumption in community-dwelling populations. Cochrane Database of Systematic Reviews 2017, Issue 9. [DOI: 10.1002/14651858.CD011479.pub2]

\section{Koppenaal 2011}

Koppenaal T, Linmans J, Knottnerus JA, Spigt M. Pragmatic vs. explanatory: an adaptation of the PRECIS tool helps to judge the applicability of systematic reviews for daily practice. Journal of Clinical Epidemiology 2011;64(10):1095-101.

\section{Kypri 2016}

Kypri K, Wilson A, Attia J, Sheeran P, Miller P, McCambridge J. Social desirability bias in the reporting of alcohol consumption: a randomized trial. Journal of Studies on Alcohol and Drugs 2016;77(3):526-31.

\section{McCambridge 2011}

McCambridge J, Kypri K. Can simply answering research questions change behaviour? Systematic review and meta analyses of brief alcohol intervention trials. PloS One 2011;6(10):e23748.

\section{McGovern 2013}

McGovern R, Kaner EFS. Alcohol prevention and treatment: interventions for hazardous, harmful and dependent drinkers. The Handbook of Health Behavior Change. New York (NY): Springer, 2013:211-27.

\section{Miller 1991}

Miller WR, Heather N, Hall W. Calculating standard drink units: international comparisons. British Journal of Addiction 1991;86(1):43-7.

\section{Miller 1994}

Miller WR, Sanchez VC. Motivating young adults for treatment and lifestyle change. In: Howard G editor(s). Issues in Alcohol Use and Misuse by Young Adults. Notre Dame (IN): University of Notre Dame Press, 1994.

\section{Movsisyan 2016}

Movsisyan A, Melendez-Torres GJ, Montgomery P. Outcomes in systematic reviews of complex interventions never reached "high" GRADE ratings when compared with those of simple interventions. Journal of Clinical Epidemiology 2016;78:22-33.

\section{Moyer 2002}

Moyer A, Finney JW, Swearingen CE, Vergun P. Brief interventions for alcohol problems: a meta-analytic review of controlled investigations in treatment and non-treatmentseeking populations. Addiction 2002;97(3):279-92.

\section{NHMRC 2009}

National Health and Medical Research Council (NHMRC) Australia. Australian guidelines to reduce health risks from drinking alcohol 2009. www.nhmrc.gov.au/guidelinespublications/ds10 (accessed prior to 27 November 2017).

\section{NHS CRD 1993}

University of York. NHS Centre for Reviews and Dissemination. Brief interventions and alcohol use. Effective Health Care 1993;1(7):13.

\section{O'Donnell 2014}

O'Donnell A, Anderson P, Newbury-Birch D, Schulte B, Schmidt C, Reimer J, et al. The impact of brief alcohol interventions in primary healthcare: a systematic review of reviews. Alcohol and Alcoholism (Oxford, Oxfordshire) 2014;49(1):66-78.

\section{Poikolainen 1999}

Poikolainen K. Effectiveness of brief interventions to reduce alcohol intake in primary health care populations: a metaanalysis. Preventive Medicine 1999;28(5):503-9.

\section{Rehm 2013}

Rehm J, Roerecke, M. Reduction of drinking in problem drinkers and all-cause mortality. Alcohol and Alcoholism (Oxford, Oxfordshire) 2013;48(4):509-13. 


\section{Review Manager 2014 [Computer program]}

Nordic Cochrane Centre, The Cochrane Collaboration. Review Manager (RevMan). Version 5.3. Copenhagen: Nordic Cochrane Centre, The Cochrane Collaboration, 2014.

\section{Rollnick 1995}

Rollnick S, Miller WR. What is motivational interviewing?. Behavioural and Cognitive Psychotherapy 1995;23(4):325-34.

\section{Schmidt 2016}

Schmidt CS, Schulte B, Seo HN, Kuhn S, O'Donnell A, Kriston L, et al. Meta-analysis on the effectiveness of alcohol screening with brief interventions for patients in emergency care settings. Addiction 2016;111(5):783-94.

\section{Schulz 1995}

Schulz KF, Chalmers I, Hayes RJ, Altman D. Empirical evidence of bias. Dimensions of methodological quality associated with estimates of treatment effects in controled trials. JAMA 1995;273(5):408-12.

\section{Schulz 2010}

Schulz KF, Altman DG, Moher D. CONSORT 2010 statement: updated guidelines for reporting parallel group randomized trials. Annals of Internal Medicine 2010;152(11):726-32.

\section{Shadish 2000}

Shadish WD, Navarro AM, Matt GE, Philips G. The effects of psychological therapies under clinically representative conditions: a meta-analysis. Psychological Bulletin 2000;126(4):512-29.

\section{Slade 2016}

Slade T, Chapman C, Swift W, Keyes K, Tonks Z, Teesson M. Birth cohort trends in the global epidemiology of alcohol use and alcohol-related harms in men and women: systematic review and metaregression. BMJ Open 2016;6:e011827.

\section{Stata 2015 [Computer program]}

StataCorp. Stata Statistical Software. Version Release 14. College Station (TX): StataCorp, 2015.

\section{Tanner-Smith 2015}

Tanner-Smith EE, Lipsey MW. Brief alcohol interventions for adolescents and young adults: a systematic review and metaanalysis. Journal of Substance Abuse Treatment 2015;51:1-18.

\section{UK Department of Health 2016}

UK Department of Health. UK Chief Medical Officers' low risk drinking guidelines 2016. www.gov.uk/government/

\section{CHARACTERISTICS OF STUDIES}

Characteristics of included studies [ordered by study ID] publications/alcohol-consumption-advice-on-low-risk-drinking Department of Health, (accessed prior to 27 November 2017).

\section{UK Government 2012}

UK Government. The Government's alcohol strategy 2012. www.gov.uk/government/uploads/system/uploads/ attachment_data/file/224075/alcohol-strategy.pdf (accessed prior to 27 November 2017).

\section{WHO 2014}

World Health Organization. Global status report on alcohol and health 2014. www.who.int/substance_abuse/publications/ global_alcohol_report/en/ (accessed prior to 27 November 2017).

\section{Wieland 2017}

Wieland LS, Berman BM, Altman DG, Barth J, Bouter LM, D'Adamo CR, et al. Rating of included trials on the efficacyeffectiveness spectrum: development of a new tool for systematic reviews. Journal of Clinical Epidemiology 2017;84(Suppl C):95-104.

\section{Wilk 1997}

Wilk A, Jensen NM, Havighurst TC. Meta-analysis of randomized control trials addressing brief interventions in heavy alcohol drinkers. Journal of General Internal Medicine 1997;12(5):274-83.

\section{Álvarez-Bueno 2015}

Álvarez-Bueno C, Rodríguez-Martín B, García-Ortiz L, GómezMarcos MA, Martínez-Vizcaíno V. Effectiveness of brief interventions in primary health care settings to decrease alcohol consumption by adult non-dependent drinkers: a systematic review of systematic reviews. Preventive Medicine 2015;76:S33-8.

\section{References to other published versions of this review} Kaner 2007

Kaner EF, Dickinson HO, Beyer FR, Campbell F, Schlesinger C, Heather $\mathrm{N}$, et al. Effectiveness of brief alcohol interventions in primary care populations. Cochrane Database of Systematic Reviews 2007, Issue 2. [DOI: 10.1002/14651858.CD004148]

\section{Kaner 2009}

Kaner EFS, Dickinson HO, Beyer FR, Pienaar E, Schlesinger C, Campbell $\mathrm{F}$, et al. The effectiveness of brief alcohol interventions in primary care settings: a systematic review. Drug and Alcohol Review 2009;28(3):301-23.

* Indicates the major publication for the study

\section{Aalto 2000}

Methods

Parallel group RCT: extended brief intervention versus brief intervention versus active control. ITT: outcome data were based on imputation of baseline values to participants lost to follow-up. 
Aalto 2000 (Continued)

Participants

Setting: Finland; primary care clinic.

Participants 20 to 60 years, consuming $\geq 280 \mathrm{~g}$ absolute ethanol/week or CAGE $\geq 3$ for men, $\geq 190 \mathrm{~g}$ absolute ethanol/week or CAGE $\geq 2$ for women; excluded if severe psychiatric disease, or at least one detox treatment, or alcohol dependence, or alcohol-related disease; screened by self-administered health questionnaire including CAGE and quantity-frequency consumption questions.

Number randomised $=414 ; 71 \%$ male; mean age $=41.6$ years; $18 \%$ comprehensive school, $7.3 \%$ vocational school, $12.7 \%$ college or university; $18.7 \%$ working/studying, $13.6 \%$ unemployed, $6 \%$ retired. At baseline: mean drinking amount per week $=286 \mathrm{~g}$ for men, $165.5 \mathrm{~g}$ for women, $259.8 \mathrm{~g}$ overall; mean drinking times per week $=2.2$ for men, 2.1 for women; mean usual drinking amount per occasion = $139.2 \mathrm{~g}$ for men, $85.8 \mathrm{~g}$ for women; mean CAGE $=3.2$ for men, 2.8 for women.

Interventions

Group A ( $N=149$ ) received brief intervention from GP or nurse at baseline, 2, 6, 12, 18, 24 and 30 months. Intervention was 10 to 20 minutes based on FRAMES according to the needs of individual participants.

Group $B(N=137)$ received the same intervention less frequently: at baseline, 12 and 24 months. Group $C(N=128)$ received advice to reduce drinking and contact their $G P$ in the event of health problems; were not told about 36 month follow-up.

Outcomes

Mean drinking amount per week; drinking times per week; usual drinking amount per occasion; CDT, AST, ALT, GGT, MCV.

Assessed at 36 months (blood tests additionally assessed at each brief intervention).

\begin{tabular}{ll}
\hline Funding source & Not reported. \\
\hline Declaration of interests & Not reported. \\
\hline Notes & Lahti project. \\
& Loss to follow-up: \\
& - Group A: $61 / 149(41 \%)$. \\
& - Group B: $55 / 137(40 \%)$. \\
& Group C: $55 / 128(43 \%)$. \\
\hline
\end{tabular}

\section{Risk of bias}

\begin{tabular}{lll}
\hline Bias & Authors' judgement & Support for judgement \\
\hline $\begin{array}{ll}\text { Random sequence genera- } \\
\text { tion (selection bias) }\end{array}$ & Low risk & "Randomisation was performed by each participating general practitioner: be- \\
& & $\begin{array}{l}\text { fore a participant arrived for a feedback session, the general practitioner drew } \\
\text { a card from a mixed pack that included equal numbers of A, B, and C signs } \\
\text { to refer the participant to the group which the participant was to be allocat- } \\
\text { ed" (p. 1682). }\end{array}$ \\
\hline
\end{tabular}

Allocation concealment High risk GP could see allocation and it was possible to subvert.
(selection bias)

\begin{tabular}{|c|c|c|}
\hline $\begin{array}{l}\text { Blinding of treatment } \\
\text { providers }\end{array}$ & High risk & $\begin{array}{l}\text { GP provided intervention to all arms therefore risk of contamination between } \\
\text { arms was high. }\end{array}$ \\
\hline
\end{tabular}

\begin{tabular}{lll}
\hline Blinding of participants & High risk & No reported attempt to blind participants. \\
\hline $\begin{array}{l}\text { Blinding of outcome as- } \\
\text { sessment (detection bias) }\end{array}$ & Unclear risk & Unclear whether outcome assessors were blinded. \\
All outcomes & \\
\hline
\end{tabular}


Aalto 2000 (Continued)

Incomplete outcome data High risk $\quad$ Loss to follow-up $>30 \%$.
(attrition bias)

All outcomes

Selective reporting (re- Unclear risk Did not specify exact alcohol outcome measures in the methods.
porting bias)

\section{Altisent 1997}

Methods Parallel group RCT: brief intervention versus active control.

ITT: no.

Petting: Spain; primary care clinic.
Participants aged 15 to 75 years with a weekly consumption of $>280 \mathrm{~g}$ for men and $>168 \mathrm{~g}$ for women;
excluded if current treatment for alcohol problems or hepatologic problems or concomitant diseases
requiring alcohol abstinence or MALT $>11$; screened by MALT scale for alcohol dependence.
Number randomised = $139 ; 100 \%$ male; mean age $=45$ years; $47 \%$ comprehensive school, $19 \%$ voca-
tional school, $33 \%$ college/university; $49 \%$ working/studying, $36 \%$ unemployed, $15 \%$ retired.
At baseline: mean weekly alcohol consumption $=57$ units $(1$ unit $=8 \mathrm{~g}$ alcohol).

Interventions

Intervention group $(\mathrm{N}=75)$ received five minutes general advice from $\mathrm{GP}$ with support material plus a five-visit program over the year. NB, 21 participants were subsequently excluded; 54 received intervention treatment.

Control group ( $N=64)$ received a single session of brief advice from GP. NB, 19 were subsequently excluded; 45 received the control treatment.

\begin{tabular}{ll}
\hline Outcomes & $\begin{array}{l}\text { Percentage reduction in alcohol consumption; MALT test; Goldberg score; per cent drinking < 35 units/ } \\
\text { week. }\end{array}$ \\
& Assessed at 12 months. \\
\hline Funding source & $\begin{array}{l}\text { Este trabajo se realizo con la ayuda proporcionada por la Beca FS 93/0882. [This work was conducted } \\
\text { with support provided by scholarship/grant number FS 93/0882]. }\end{array}$ \\
\hline Declaration of interests & Not reported. \\
\hline Notes & Loss to follow-up: \\
& Intervention group: $20 / 54(37 \%)$. \\
\hline & Control group: $15 / 45(33 \%)$. \\
\hline
\end{tabular}

\section{Risk of bias}

\begin{tabular}{lll}
\hline Bias & Authors' judgement & Support for judgement \\
\hline $\begin{array}{l}\text { Random sequence genera- } \\
\text { tion (selection bias) }\end{array}$ & Low risk & $\begin{array}{l}\text { States only that assignment was made by simple randomisation ("aleatoriza- } \\
\text { cion simple", p. 122). }\end{array}$ \\
\hline $\begin{array}{l}\text { Allocation concealment } \\
\text { (selection bias) }\end{array}$ & Low risk & $\begin{array}{l}\text { Consecutively numbered, sealed envelopes ("los sobres cerrados y numera- } \\
\text { dos", p. 122). }\end{array}$ \\
\hline $\begin{array}{l}\text { Blinding of treatment } \\
\text { providers }\end{array}$ & High risk & Not blinded. \\
\hline
\end{tabular}


Altisent 1997 (Continued)

Blinding of participants High risk No reported attempt to blind participants.

\begin{tabular}{|c|c|c|}
\hline $\begin{array}{l}\text { Blinding of outcome as- } \\
\text { sessment (detection bias) } \\
\text { All outcomes }\end{array}$ & Unclear risk & Not reported. \\
\hline
\end{tabular}

Incomplete outcome data High risk $\quad$ Loss to follow-up $>30 \%$.
(attrition bias)
All outcomes

Selective reporting (re- Low risk Outcomes specified in methods were reported in results.

porting bias)

\section{Babor 2006}

Methods Cluster RCT: brief intervention (two arms delivered by different professionals) versus usual care; 15
practices randomised.

Used a pre-post repeated measures group design.

ITT: yes.

\section{Participants}

Setting: USA; family or internal medicine clinics in a managed care organisation (MCO)

Participants $\geq 18$ years were screened with Health Assessment Survey including AUDIT and selected if they scored $8+$ (men) or $7+$ (women).

Number of clinics randomised $=15$; number of participants randomised $=50,411,60 \%$ male; mean age followed up at 3 months $(n=1379)=45.9$ years.

At baseline: mean drinks per week (defined by AUDIT questions 1 to 2 ) $=13.8$ (men); 8.7 (women).

\section{Interventions}

Group $\mathrm{P}(\mathrm{N}=17,257$ randomised, 1151 sampled for follow-up) received brief intervention (according to their level of drinking - see below for detail) from physician or physician assistant.

Group S ( $N=15,938$ randomised, 1124 sampled for follow-up) received brief intervention from specialist, i.e. mostly nurses.

Group C ( $N=17,216$ randomised, 1955 sampled for follow-up) was the control group and received "patient care as usual" (not defined).

Within each group treatment allocated by drinking level: Zone I (modified AUDIT 7 to 15 for women and men aged $>65$ years; 8 to 15 for men $<65$ years) participants received simple advice ( 3 to 5 minutes) and an information brochure; Zone II (AUDIT 16 to 19) received advice and a more extensive self-help manual; Zone III (AUDIT > 19) specified advice and referral to specialty care for alcohol assessment and treatment.

Advice comprised:

- feedback of screening scores and any problems or symptoms identified;

- discussion of the participant's risk level;

- connection of drinking risk to actual or potential problems and information about safer drinking limits;

- commitment to a goal of cutting back or stopping; and

- presentation of the brochure and encouragement to reach the established goal.

Outcomes

Number of drinks per week; per cent at risk drinkers who had changed drinking at three months; health care utilisation (all days, outpatients visits, inpatient days, emergency department visits, ADM-related days (mental health). 
Babor 2006 (Continued)

Assessed at 3 and 12 months.

Funding source This research was supported by grant no. 029620 from the Robert Wood Johnson Foundation.

Declaration of interests Not reported.

Notes Cutting Back programme.

Payment: the MCOs were reimbursed; participants received no payment.

Loss to follow-up: 81/575 (14\%) overall (not reported by arm).

\section{Risk of bias}

\begin{tabular}{|c|c|c|}
\hline Bias & Authors' judgement & Support for judgement \\
\hline $\begin{array}{l}\text { Random sequence genera- } \\
\text { tion (selection bias) }\end{array}$ & Low risk & Random numbers from table generated by independent statistician (p. 625). \\
\hline $\begin{array}{l}\text { Allocation concealment } \\
\text { (selection bias) }\end{array}$ & Low risk & Allocation by independent statistician - not a member of the team (p. 625). \\
\hline $\begin{array}{l}\text { Blinding of treatment } \\
\text { providers }\end{array}$ & Low risk & $\begin{array}{l}\text { Cluster-randomised trial and all participants from a particular clinic received } \\
\text { the same intervention, so therefore risk of contamination between arms was } \\
\text { low. }\end{array}$ \\
\hline Blinding of participants & High risk & No reported attempt to blind participants. \\
\hline $\begin{array}{l}\text { Blinding of outcome as- } \\
\text { sessment (detection bias) } \\
\text { All outcomes }\end{array}$ & Low risk & $\begin{array}{l}\text { Computer-assisted telephone interview by independent survey organisation - } \\
\text { interviewers not aware of the study condition (p. 625). }\end{array}$ \\
\hline $\begin{array}{l}\text { Incomplete outcome data } \\
\text { (attrition bias) } \\
\text { All outcomes }\end{array}$ & High risk & Only reported data from those who completed, not those randomised. \\
\hline $\begin{array}{l}\text { Selective reporting (re- } \\
\text { porting bias) }\end{array}$ & High risk & Only primary outcome fully reported. \\
\hline
\end{tabular}

Bazargan-Hejazi 2005

Methods Parallel group RCT: brief intervention versus usual care.

ITT: yes.

Participants Setting: USA; emergency department.

Participants Aged $\geq 18$ years, English or Spanish speaking, excluded if received alcohol counselling in last year, or cognitive impairment precluded informed consent, or medical treatment prevented them being interviewed, or in policy custody; screened with CAGE $\geq 1$.

Number randomised $=295 ; 80 \%$ male; mean age $=38.8$ years; $64 \%$ Black, $30 \%$ Hispanic, $6 \%$ other; $84 \%$ high school or above, $16 \%$ less than high school diploma.

At baseline: mean number of drinks per day $=3.29$; number drinking at least 6 drinks per occasion at least weekly $=186$. 
Bazargan-Hejazi 2005 (Continued)

Both groups received a health packet that contained a variety of health information (not restricted to alcohol).

Intervention group ( $\mathrm{N}=139$ ) received a brief negotiated semi-scripted interview lasting 15 to 20 minutes from peer educators, which integrates elements of motivational interviewing and readiness to change.

Control group $(\mathrm{N}=142)$ received usual care (undefined). These participants received a referral to local treatment programs only if the participant requested one of the physicians or if the treating physician made an independent diagnosis and referral.

\begin{tabular}{ll} 
Outcomes & Percentage moving to a lower risk category (based on AUDIT); percentage scoring > 7 on AUDIT. \\
& Assessed at 3 months. \\
\hline Funding source & $\begin{array}{l}\text { Supported by grants from the Center for Minority Health and Health Disparities, National Institute on } \\
\text { Alcohol Abuse and Alcoholism (U24AA11899-05) and the National Institutes of Health, National Center } \\
\text { for Research Resources and Research Centers in Minority Institutions (G12-RR03026-16). }\end{array}$ \\
\hline Declaration of interests & Not reported. \\
\hline Notes & Payment: USD 10 for baseline assessment, USD 25 for follow-up interview session. \\
& Loss to follow-up: \\
- Intervention group: $51 / 139(37 \%)$. \\
C Control group: $45 / 142(32 \%)$.
\end{tabular}

\section{Risk of bias}

Bias Authors' judgement Support for judgement

Random sequence genera- High risk tion (selection bias)
"Each of the three health promotion advocates performed random allocation for their own enrollees, assigning the first participant by a flip of a coin, and alternating status thereafter" (p. 69).

\begin{tabular}{lll}
\hline $\begin{array}{l}\text { Allocation concealment } \\
\text { (selection bias) }\end{array}$ & High risk & Alternate allocation is predictable. \\
\hline $\begin{array}{l}\text { Blinding of treatment } \\
\text { providers }\end{array}$ & High risk & $\begin{array}{l}\text { Health promotion advocates delivered the intervention and interacted with } \\
\text { participants from both arms of the study. }\end{array}$ \\
\hline $\begin{array}{l}\text { Blinding of participants } \\
\text { Llinding of outcome as- }\end{array}$ & Low risk & $\begin{array}{l}\text { "Alcohol information was not included in the health packet [received by all } \\
\text { participants] to avoid contamination" (p. 69). }\end{array}$ \\
$\begin{array}{l}\text { All outcomes } \\
\text { Incomplete outcome data } \\
\text { (attrition bias) } \\
\text { All outcomes }\end{array}$ & High risk & $\begin{array}{l}\text { "Enrollees were not followed up by the same health promotion advocate who } \\
\text { assessed them initially. Participants were notified not to reveal their group as- } \\
\text { signments to project staff at any time" (p. 69). }\end{array}$ \\
\hline $\begin{array}{l}\text { Selective reporting (re- } \\
\text { porting bias) }\end{array}$ & Unclear risk & $\begin{array}{l}\text { Loss to follow-up > 30\%. } \\
\text { Number of participants for follow-up in each AUDIT subgroup was not speci- } \\
\text { fied. However, we did not include these subgroups in analyses, so this aspect } \\
\text { did not introduce bias. }\end{array}$ \\
\hline
\end{tabular}


Beckham 2007

Methods
ITT: no.
Participants were "given the opportunity to assess themselves" for hazardous alcohol use with AUDIT,
i.e. self-selecting not comprehensive sample.

\section{Participants}

Setting: USA; rural community healthcare centres.

Participants: Aged $\geq 18$ years with AUDIT 8+; 64\% had some psychiatric diagnoses; excluded if pregnant or suicidal; screened with AUDIT.

Number randomised $=28 ; 46 \%$ male; $97 \%$ Caucasian; age range $=19$ to 55 years.

Baseline information for total sample not reported.

\begin{tabular}{ll} 
Interventions & Both groups received AUDIT for screening and 30 minute baseline assessment. \\
& Motivational interviewing group ( $\mathrm{N}=12$ assessed) received one 45 to 60 minute motivational interview- \\
ing session, also utilising FRAMES, from a nurse practitioner. & $\begin{array}{l}\text { Control group ( } \mathrm{N}=13 \text { assessed) received usual care; after six week follow-up received GGT results and } \\
\text { local referral for low-cost local alcohol treatment. }\end{array}$ \\
\hline Outcomes & Drinks per day (1 drink = 12 ounces of beer, 5 ounces of wine, 1.5 ounces of spirits or hard liquor); GGT. \\
& Assessed at 6 weeks. \\
\hline Funding source & Not reported. \\
\hline Declaration of interests & $\begin{array}{l}\text { "No relationship exists between the author and any commercial entity or product mentioned in the ar- } \\
\text { ticle that night represent a conflict of interest. No inducements have been made by any commercial en- } \\
\text { tity to submit the manuscript for publication", } p .110 .\end{array}$
\end{tabular}

Notes

Loss to follow-up not reportable: number randomised to each arm at baseline not reported.

\section{Risk of bias}

\begin{tabular}{|c|c|c|}
\hline Bias & Authors' judgement & Support for judgement \\
\hline $\begin{array}{l}\text { Random sequence genera- } \\
\text { tion (selection bias) }\end{array}$ & Low risk & $\begin{array}{l}\text { "Participants were randomly assigned to the intervention or control group us- } \\
\text { ing a table of random numbers" (p. 106). }\end{array}$ \\
\hline $\begin{array}{l}\text { Allocation concealment } \\
\text { (selection bias) }\end{array}$ & Unclear risk & Allocation concealment not described. \\
\hline $\begin{array}{l}\text { Blinding of treatment } \\
\text { providers }\end{array}$ & High risk & Not blinded; no reported attempt to reduce bias. \\
\hline Blinding of participants & High risk & No reported attempt to blind participants. \\
\hline $\begin{array}{l}\text { Blinding of outcome as- } \\
\text { sessment (detection bias) } \\
\text { All outcomes }\end{array}$ & Unclear risk & Blinding of outcome assessor not described. \\
\hline $\begin{array}{l}\text { Incomplete outcome data } \\
\text { (attrition bias) } \\
\text { All outcomes }\end{array}$ & Unclear risk & Loss to follow-up not reported. \\
\hline
\end{tabular}


Beckham 2007 (Continued)

Selective reporting (re- Low risk Outcomes specified in methods were reported in results. porting bias)

Beich 2007

Methods Parallel group RCT: brief intervention versus inactive control.

ITT: yes.

Participants Setting: Denmark; general practice surgery.

Participants aged 18 to 64 years, scheduled to see 39 general practitioners, AUDIT score between 8 and 21 (those with AUDIT > 12 were screened for dependency and referred if necessary); excluded if they reported weekly consumption $>35$ drinks, had severe acute illness, or reading disability or spoke a foreign language, or illiterate, or had mental or physical impairment, or inebriated, or currently being treated for an alcohol use disorder, or pregnant; screened with AUDIT.

Number randomised $=906 ; 67 \%$ male; other characteristics not reported for sample.

At baseline: usual weekly consumption reported $>35$ drinks $=24 \%$ of men, $17 \%$ of women; previous weekly consumption reported $>35$ drinks $=38 \%$ of men, $32 \%$ of women; weekly binge drinking (defined as $6+$ units) $=41 \%$ of men, $21 \%$ of women; monthly binge drinking $=82 \%$ of men, $69 \%$ of women.

Interventions Both groups received AUDIT for screening, which also provided many baseline data, and a secondary baseline questionnaire (time not reported).

Intervention group $(\mathrm{N}=442)$ received one 10 minute session from the GP based on the 'drink less' protocol used by the WHO collaborative study on brief interventions, including feedback on present drinking, advice on reducing drinking with suggestions on how to do it, a self-help booklet, and an open invitation for a follow-up consultation at the earliest convenience.

Control group $(\mathrm{N}=464)$ received no feedback or intervention.

Outcomes Mean number of drinks (12 $\mathrm{g}$ alcohol) in a "usual" week, mean number of drinks consumed last week, number of participants usually consuming over the recommended limit (21 units for men, 14 units for women), number of participants binge drinking (defined as $6+$ units) at least once a week; all reported separately for men and women.

Assessed at 12 months.

Funding source

This work was supported in part by grants from Alkoholpolitisk Kontaktudvalg (Danish Ministry and Board of Health), Forskningsfonden (Association of County Councils in Denmark), and Fonden til Laegevidenskabens Fremme.

\begin{tabular}{ll}
\hline Declaration of interests & Not reported. \\
\hline Notes & Loss to follow-up: \\
& - Intervention group: $204 / 442(46 \%)$. \\
& C Control group: $165 / 464(36 \%)$. \\
\hline
\end{tabular}

\section{Risk of bias}

\begin{tabular}{lll}
\hline Bias & Authors' judgement & Support for judgement \\
\hline $\begin{array}{l}\text { Random sequence genera- } \\
\text { tion (selection bias) }\end{array}$ & Unclear risk & Sequence generation not described. \\
\hline
\end{tabular}


Beich 2007 (Continued)

$\begin{array}{ll}\begin{array}{l}\text { Allocation concealment } \\ \text { (selection bias) }\end{array} & \text { Low risk } \\ \end{array}$

\begin{tabular}{|c|c|c|}
\hline $\begin{array}{l}\text { Blinding of treatment } \\
\text { providers }\end{array}$ & High risk & $\begin{array}{l}\text { "Blinding was not feasible, either for participants and GPs, or for outcome as- } \\
\text { sessment and statistical analysis" (p. 594). }\end{array}$ \\
\hline
\end{tabular}

\begin{tabular}{lll}
\hline Blinding of participants & High risk & $\begin{array}{l}\text { "Blinding was not feasible, either for participants and GPs, or for outcome as- } \\
\text { sessment and statistical analysis (p. 594). }\end{array}$ \\
\hline $\begin{array}{l}\text { Blinding of outcome as- } \\
\begin{array}{l}\text { sessment (detection bias) } \\
\text { All outcomes }\end{array}\end{array}$ & High risk & $\begin{array}{l}\text { Blinding was not feasible, either for participants and GPs, or for outcome as- } \\
\text { sessment and statistical analysis" (p. 594). }\end{array}$ \\
\hline $\begin{array}{l}\text { Incomplete outcome data } \\
\begin{array}{l}\text { (attrition bias) } \\
\text { All outcomes }\end{array}\end{array}$ & High risk & Loss to follow-up > 30\%. \\
\hline $\begin{array}{l}\text { Selective reporting (re- } \\
\text { porting bias) }\end{array}$ & Low risk & Outcomes specified in methods were reported in results. \\
\hline
\end{tabular}

\section{Bernstein 2010}

Methods Parallel group RCT: brief intervention versus standard-assessed active control versus minimally as-
sessed active control.

ITT: no.

\section{Participants}

Setting: USA; paediatric emergency department within level 1 trauma centre.

Participants: Aged 14 to 21 years who reported binging ( $\geq$ five drinks in two hours for males or $\geq$ four drinks in two hours for females), and/or high risk behaviours in conjunction with alcohol use, and/or AUDIT $\geq 4$ for those aged 14 to 17 years or $\geq 8$ for those aged. 18 to 21 years; screened with adolescent version of AUDIT; excluded if they:

- were not alert and oriented to person, time, and place;

- could not be interviewed separately from accompanying family;

- planned to leave area in next three months;

- could not provide reliable contact information;

- were currently in a residential substance abuse treatment facility;

- were in custody or institutionalised;

- presented for rape exam or psychiatric evaluation for suicide precautions; or if

- parents opted out for those aged < 18 years, or could not speak English, Spanish, Haitian Creole, or Cape Verdean Creole.

Number randomised $=853 ; 45 \%$ male; $2.0 \%$ American Indian/Alaskan, 1.4\% Asian, 51.3\% Black/African American, 19.2\% Hispanic/Latino, 0.5\% Native Hawaiian/Pacific Islander, 25.6\% White; $25 \%$ in employment; $21 \%$ attending school, $57 \%$ high school graduate or equivalent, $22 \%$ dropped out of high school; mean age of total sample not reported.

Baseline information for total sample not reported. assessed control) and I (intervention) groups received an assessment battery (duration not reported) including a 30-day Timeline Followback calendar, Adolescent Injury Checklist, Drinking and Driving Scale, and other more general health-related questionnaires.

Intervention group $(\mathrm{N}=283)$ received 20 to 30 minute motivational interview from trained peer educators, plus one 5 to 10 minute telephone booster session 10 days post-enrolment. 
Bernstein 2010 (Continued)

Standard assessed control group $(\mathrm{N}=284)$ received the same assessment as the intervention group, and a brief written handout containing advice about alcohol risks, a list of community resources and adolescent treatment facilities, and appointments to return at 3 and 12 months.

Minimally assessed control group received the same brief written handout as standard assessed control group, and an appointment to return in 12 months.

\begin{tabular}{ll}
\hline Outcomes & $\begin{array}{l}\text { Mean number of drinking days per month, mean number of drinks per dring } \\
\text { drinks per week, maximum number of drinks per day. } \\
\text { Assessed at } 3 \text { months (intervention and assessed control groups only) a }\end{array}$ \\
\hline Funding source & $\begin{array}{l}\text { Supported in part by NIAAA P60AA13759, NIAAA Youth Alcohol Prevention } \\
\text { funding = USD } 2.5 \text { million (direct). }\end{array}$ \\
\hline Declaration of interests & Not reported. \\
\hline Notes & Project RAP: Reaching Adolescents for Prevention. \\
& Payment: USD 10 at enrolment, USD 35 at subsequent follow-up visits. \\
& Loss to follow-up at 3 months: \\
- Intervention group: $81 / 283$ (29\%). & Assessed control group: $87 / 284$ (31\%). \\
Loss to follow-up at 12 months: \\
- Intervention group: $76 / 283$ (27\%). \\
- Assessed control group: $75 / 284$ (26\%). \\
- Minimally assessed control group: $88 / 286$ (31\%).
\end{tabular}

\section{Risk of bias}

\begin{tabular}{|c|c|c|}
\hline Bias & Authors' judgement & Support for judgement \\
\hline $\begin{array}{l}\text { Random sequence genera- } \\
\text { tion (selection bias) }\end{array}$ & Low risk & $\begin{array}{l}\text { "Randomisation was based on computer-generated lists, blocked to balance } \\
\text { assignment after every nine subjects and stratified by age group (14 to } 17 \text { and } \\
18 \text { to } 21 \text { years)" (p. 892). }\end{array}$ \\
\hline $\begin{array}{l}\text { Allocation concealment } \\
\text { (selection bias) }\end{array}$ & Low risk & $\begin{array}{l}\text { A two-stage assignment was carried out using a double opaque envelope sys- } \\
\text { tem. The first envelope indicated randomization to either minimal assessment } \\
\text { (MAC) or assessed status (I or AC). The second sealed envelope (inside the first) } \\
\text { distinguish between assessed controls and those participants eligible for an } \\
\text { intervention (AC vs. l) (p. 892). }\end{array}$ \\
\hline
\end{tabular}

\begin{tabular}{|c|c|c|}
\hline $\begin{array}{l}\text { Blinding of treatment } \\
\text { providers }\end{array}$ & Unclear risk & $\begin{array}{l}\text { Appears that peer educators who delivered the intervention only saw interven- } \\
\text { tion participants but this is not clear. }\end{array}$ \\
\hline
\end{tabular}

\begin{tabular}{lll}
\hline Blinding of participants & High risk & No reported attempt to blind participants. \\
\hline $\begin{array}{l}\text { Blinding of outcome as- } \\
\text { sessment (detection bias) }\end{array}$ & Low risk & "Participants were cautioned not to discuss their enrolment procedures or al- \\
All outcomes & location with research assistants who conducted their follow-up" (p. 892).
\end{tabular}

Incomplete outcome data Unclear risk Loss to follow-up reported, but reasons not given.

(attrition bias)

All outcomes 
Bernstein 2010 (Continued)

Selective reporting (re- High risk Abstinence was recorded as first primary outcome, but this was not reported porting bias) in results.

Bischof 2008

Methods Parallel group RCT: 'full care' telephone-based brief intervention versus stepped care telephone-based brief intervention versus inactive control.

ITT: yes.

Setting: Germany; 84 primary care practices.
Participants: Aged 18 to 64 years with average consumption > 20/30 g alcohol per day for women/men
within the last four weeks, or regular heavy drinking episodes ("binge drinking”) defined as $>60 / 80 \mathrm{~g}$ al-
cohol for women/men on at least two occasions within the last four weeks; included if assessed as al-
cohol dependent; excluded if they had an acute or terminal illness, or severe drug dependence, or no
telephone, or did not understand German, or unable to read, or were in alcohol treatment, or reported
no alcohol consumption in the last four weeks; screened with AUDIT and LAST (Luebeck Alcohol depen-
dence and abuse Screening Test).

Number randomised $=408 ; 68 \%$ male; mean age not reported for total sample.

Baseline characteristics not reported for total sample.

Interventions

All three groups received a health questionnaire incorporating AUDIT and LAST for screening; this served as baseline assessment.

Full care group ( $N=131$ ) received computerised feedback immediately after assessment; followed by one 30 minute session of brief intervention counselling by telephone by trained psychologists based on motivational interviewing and structured elements of behaviour change counselling straight after assessment; followed by three similar booster sessions at 1, 3 and 6 months.

Stepped care group $(\mathrm{N}=138)$ received the same computerised feedback as full care immediately after assessment but no intervention at this point; they received a maximum of three 30 to 40 minute brief intervention sessions at 1, 3 and 6 months. If stepped care participants reported a reduction of alcohol consumption below the inclusion criteria for the trial and indicated high self-efficacy to maintain the change, no further contact was made until the 12 month follow-up.

Control participants $(\mathrm{N}=139)$ received a booklet on health behaviour.

Outcomes Grams per day of alcohol, percentage meeting binge criteria.

Assessed at 12 months.

Funding source

"Funding for this study was provided by German Federal Ministry of Research and Education grant no. 01 EB 0121. The German Federal Ministry of Research and Education had no further role in study design; in the collection, analysis and interpretation of data; in the writing of the report; or in the decision to submit the paper for publication", p. 250.

Declaration of interests Conflict of interest: None.

Notes SIP (Stepped Interventions for Problem drinkers)

Loss to follow-up:

- Full care group: $15 / 131(11 \%)$.

- Stepped care group: 6/138 (4\%).

- Control group: 13/139 (9\%). 
Bischof 2008 (Continued)

We contacted the authors, who supplied missing data.

\section{Risk of bias}

Bias Authors' judgement Support for judgement

Random sequence genera- Low risk tion (selection bias)

"Randomisation of subjects to one of the three groups was carried out prior to the telephone interview using sealed cards drawn by study staff from one container" [analogous to card shuffle described in Cochrane Handbook as low risk of selection bias] (p. 245).

\begin{tabular}{ll}
\hline $\begin{array}{l}\text { Allocation concealment } \\
\text { (selection bias) }\end{array}$ & Low risk \\
& $\begin{array}{l}\text { Final study participants were randomly allocated, using coloured cards in } \\
\text { sealed, non-transparent envelopes (drawn envelopes were not put back), to ei- } \\
\text { ther the control group or to one of two intervention groups (p. 245). }\end{array}$
\end{tabular}

\begin{tabular}{|c|c|c|}
\hline $\begin{array}{l}\text { Blinding of treatment } \\
\text { providers }\end{array}$ & High risk & $\begin{array}{l}\text { "Due study design, blinding could not be conducted for the individual study } \\
\text { participant and the staff member providing the counselling session" (p. 245). }\end{array}$ \\
\hline
\end{tabular}

\begin{tabular}{ll}
\hline Blinding of participants $\quad$ High risk & "Due to our study design, blinding could not be conducted for the individual \\
study participant and the staff member providing the counselling session" ( $\mathrm{p}$. \\
245).
\end{tabular}

\begin{tabular}{|c|c|c|}
\hline $\begin{array}{l}\text { Blinding of outcome as- } \\
\text { sessment (detection bias) } \\
\text { All outcomes }\end{array}$ & Low risk & $\begin{array}{l}\text { "A blinded personal interview was conducted by study staff who had no con- } \\
\text { tact with the participant prior to the outcome assessment which mainly was } \\
\text { assessed by telephone" (p. 247). }\end{array}$ \\
\hline
\end{tabular}

Incomplete outcome data Low risk Loss to follow-up reported with reasons.
(attrition bias)
All outcomes

\begin{tabular}{l}
\hline $\begin{array}{l}\text { Selective reporting (re- } \\
\text { porting bias) }\end{array}$ \\
\hline
\end{tabular}

Blow 2006

Methods Parallel group RCT: brief intervention and tailored booklet versus brief intervention and generic booklet versus tailored booklet only (active control) versus generic booklet only (active control).

ITT: yes.

Participants Setting: USA; emergency department level 1 trauma centre.

Participants: Aged $\geq 19$ years and injured, displaying at risk or heavy episodic drinking. At risk drinking was defined as:

- $\geq 15$ drinks per week for men aged $<65$ years;

- $\geq 12$ drinks per week for women aged $<65$ years and men aged $\geq 65$ years; and

- $\geq 9$ drinks per week for women aged $\geq 65$ years

in the previous 3 months.

Heavy episodic drinking was defined as

- $\geq 5$ drinks/occasion on $>4$ occasions in the last month (i.e. weekly episodes) for men $<65$ years;

- $\geq 4$ drinks per occasion on $>4$ occasions in the last month for men $\geq 65$ years and all women.

Excluded if:

- severely injured (e.g. unconscious); 
Blow 2006 (Continued)

- in need of immediate life-saving procedures;

- blood alcohol level > $200 \mathrm{mg} / \mathrm{dL}$;

- self-inflicted injury, sexual assault, overdose, poisoning, near-drowning, chronic injury without specific event associated with re-injury;

- pregnant;

- prisoner; or

- non-English speaking.

Screened with computerised health survey incorporating AUDIT-C and DrInC; participants also received an alcohol salivary test before intervention, which proceeded once blood alcohol concentration reached $100 \mathrm{mg} / \mathrm{dL}$ or less.

Number randomised = 575 (but following data are for 494 participants who were followed-up); $71 \%$ male; mean age 27.8 years; $86 \%$ White, $6 \%$ Black, $8 \%$ other race; $80 \%$ some college education or higher.

At baseline: mean number of drinks per week $=21$.

Interventions

Participants were screened with a health survey incorporating AUDIT-C and DrInC which served as baseline assessment (duration was not reported).

Tailored manual/brief advice group $(\mathrm{N}=129)$ received brief intervention before leaving the emergency department from a research social worker, during which the tailored booklet was reviewed with the participant. The tailored booklet was generated according to responses to the computerised screening tool.

Tailored manual/no brief advice group $(\mathrm{N}=121)$ received a tailored booklet from the research social worker who told them that, based on their responses to the health screen, they scored as at-risk for hazardous drinking and should review the booklet.

Generic manual/brief advice group $(\mathrm{N}=124)$ received brief intervention before they left the emergency department from a research social worker, during which the generic booklet was reviewed with the participant. The generic booklet was identical to the tailored booklet in length, content and graphics but included standard rather that tailored text/graphics.

Generic manual/no brief advice group $(\mathrm{N}=120)$ received the generic booklet from the research social worker who told them that, based on their responses to the health screen, they scored as at-risk for hazardous drinking and should review the booklet.

Duration of intervention was not reported.

Outcomes

Mean number of drinks per week, number of binge drinking episodes ( $>5$ drinks for men, $>4$ drinks for women) in previous month, DrInC score (alcohol-related consequences).

Assessed at 3 and 12 months.

Funding source This study was supported by NIAAA grant AA111629.

Declaration of interests Not reported.

Notes

Participants willing to complete the survey were entered into a monthly draw for USD 100. Participants were paid USD 20 for three month telephone follow-up interview and USD 30 for 12 month telephone follow-up.

Loss to follow-up: 81/575 (14\%) (not reported according to study arms).

Data (including baseline data) were reported only for participants who were followed up.

\section{Risk of bias}


Blow 2006 (Continued)

Random sequence genera- Low risk "A computer program automatically determined eligibility for the RCT and tion (selection bias)

randomly assigned participants to one of four intervention conditions" (Blow 2006, p. 570). "To prevent the possibility that staff could unwittingly manipulate assignment to intervention condition, participants were randomly assigned to conditions via the computer using an urn randomisation technique" (Blow 2009, p. 487).

\begin{tabular}{lll}
\hline $\begin{array}{l}\text { Allocation concealment } \\
\text { (selection bias) }\end{array}$ & Unclear risk & Not reported. \\
\hline $\begin{array}{l}\text { Blinding of treatment } \\
\text { providers }\end{array}$ & Low risk & $\begin{array}{l}\text { Cluster randomised - treatment providers only had contact with one arm and } \\
\text { only delivered one intervention, reducing the chance of cross contamination. }\end{array}$ \\
\hline Blinding of participants & High risk & No reported attempt to blind participants. \\
\hline $\begin{array}{l}\text { Blinding of outcome as- } \\
\text { sessment (detection bias) } \\
\text { All outcomes }\end{array}$ & Unclear risk & Not reported. \\
\hline
\end{tabular}

Incomplete outcome data High risk

Reported data only from those who completed not those randomised.

(attrition bias)

All outcomes

Selective reporting (re- Low risk $\quad$ Outcomes stated in methods were reported.
porting bias)

\section{Cherpitel 2009}

Methods only active control.

ITT: yes.

Participants Setting: Poland; emergency department.

Participants: Aged $\geq 18$ years not presently being treated for an alcohol-related problem, willing to give informed consent to be randomised into one of three groups, willing to provide contact information for at least two individuals who would always know participant's whereabouts, screened as consuming $\geq$ 11 drinks per week for men ( $\geq 6$ for women); or $\geq 4$ drinks on one occasion for men ( $\geq 3$ for women); or $\geq 1$ on the RAPS (Remorse, Amnesia, Perform, Starter) tool. Participants who reported drinking an average of more than six drinks per day at baseline on both quantity/frequency screening and 30 day timeline follow back were excluded from the analysis.

Number randomised $=446 ; 85 \%$ male; mean age not reported for total sample.

Baseline characteristics not reported for total sample.

Interventions

Participants were screened with the RAPS tool and quantity/frequency questions. The assessed group and brief negotiated interview groups underwent assessment (duration not reported) as follows: blood alcohol concentration measure with a breathalyser, self-reported drinking in the previous six hours using the Timeline Followback, consequences of drinking using the Short Inventory of Problems SIPs +6, stage of change using the Readiness to Change Ruler, risk-taking assessed with questions from Eysenk and Jackson, and sensation seeking assessed with questions adapted from Zuckerman.

Brief negotiated interview group $(\mathrm{N}=147)$ received a 15 to 20 minute brief negotiated interview from a trained emergency department nurse, which included engagement and permission, feedback, information and norms, decisional balance and pros and cons, readiness to change, menus of options, and pre- 
Cherpitel 2009 (Continued)

scription for change. A list of AA groups and specialised services for alcohol treatment and counselling was provided to the participant.

Assessed group $(\mathrm{N}=152)$ received the same list of AA groups and specialised alcohol services.

Screened group $(\mathrm{N}=147)$ received no assessment or intervention.

\begin{tabular}{ll}
\hline Outcomes & $\begin{array}{l}\text { Per cent exhibiting at-risk drinking, per cent with RAPS }>1 \text {, drinking days per week, drinks per drinking } \\
\text { day, maximum drinks on one occasion, number of negative consequences. }\end{array}$ \\
& Assessed at 3 and 12 months. \\
\hline Funding source & This research was supported by NIAAA grant R21 AA 016081-01. \\
\hline Declaration of interests & Not reported. \\
\hline Notes & Loss to follow-up at three months: \\
- Brief negotiated interview group: $26 / 147$ (18\%). & Assessed group: $23 / 152$ (15\%). \\
- Screened group: $12 / 147$ (8\%). \\
Loss to follow-up at 12 months: \\
- Brief negotiated interview group: $60 / 147$ (41\%). \\
- Assessed group: $53 / 152$ (35\%). \\
- Screened group 55/147 (37\%).
\end{tabular}

\section{Risk of bias}

\begin{tabular}{lll}
\hline Bias & Authors' judgement & Support for judgement \\
\hline $\begin{array}{l}\text { Random sequence genera- } \\
\text { tion (selection bias) }\end{array}$ & Unclear risk & Randomisation process not described. \\
\hline $\begin{array}{l}\text { Allocation concealment } \\
\text { (selection bias) }\end{array}$ & Unclear risk & $\begin{array}{l}\text { "Participants were first randomised to the screen-only or assessment condi- } \\
\text { tion by the study interviewer, who drew an envelope [does not specify sealed } \\
\text { or opaque] with the condition assignment. The envelope of those receiving an } \\
\text { assessment contained a second envelope, which was opened by the interview- } \\
\text { er following assessment to determine whether the participant was assigned to } \\
\text { the intervention condition" (p. 984). }\end{array}$
\end{tabular}

Blinding of treatment Low risk Nurse who delivered the intervention only saw intervention participants.
providers

\begin{tabular}{|c|c|c|}
\hline Blinding of participants & High risk & No reported attempt to blind participants. \\
\hline $\begin{array}{l}\text { Blinding of outcome as- } \\
\text { sessment (detection bias) } \\
\text { All outcomes }\end{array}$ & Low risk & Assessment interviewer was blind to group status (p. 986). \\
\hline $\begin{array}{l}\text { Incomplete outcome data } \\
\text { (attrition bias) } \\
\text { All outcomes }\end{array}$ & High risk & Loss to follow-up $>30 \%$. \\
\hline $\begin{array}{l}\text { Selective reporting (re- } \\
\text { porting bias) }\end{array}$ & Low risk & $\begin{array}{l}\text { RAPS }+1 \text { not reported at three months, but because we focused on } 6 \text { and } 12 \\
\text { month outcomes, there was little impact. }\end{array}$ \\
\hline
\end{tabular}


Crawford 2004

\begin{tabular}{|c|c|}
\hline Methods & $\begin{array}{l}\text { Parallel group RCT: brief intervention versus active control. } \\
\text { ITT: yes. }\end{array}$ \\
\hline \multirow[t]{2}{*}{ Participants } & Setting: UK. \\
\hline & $\begin{array}{l}\text { Participants: Aged } \geq 18 \text { years, English speakers, resident in greater London, alert and oriented, consum- } \\
\text { ing }>8 \text { units in any one session at least once a week for men or }>6 \text { units for women, or believing their } \\
\text { attendance at accident and emergency is related to alcohol; excluded if already in contact with alcohol } \\
\text { services, or requesting help with alcohol problems; recruited from accident and emergency; screened } \\
\text { by PAT. } \\
\text { Number randomised }=599 ; 78.1 \% \text { male; mean age = } 44 \text { years (range } 18 \text { to } 90 \text { years). } \\
\text { At baseline: mean units consumed during drinking session }=21.2 \text {. }\end{array}$ \\
\hline Interventions & $\begin{array}{l}\text { Experimental group }(\mathrm{N}=287) \text { received a } 30 \text { minute session with an experienced alcohol worker to dis- } \\
\text { cuss current and previous drinking in a manner tailored to the subject, plus a health information leaflet } \\
\text { containing contact details for national and local alcohol support agencies. } \\
\text { Control group }(\mathrm{N}=312) \text { received the leaflet only. }\end{array}$ \\
\hline Outcomes & $\begin{array}{l}\text { Mean weekly units consumed, mean units consumed per drinking day, mean proportion days abstinent } \\
\text { all assessed at six and } 12 \text { months; mean number of attendances at local emergency department, mean } \\
\text { EQ-5D single score both assessed at } 12 \text { months only; mean score on GHQ assessed at six months only. }\end{array}$ \\
\hline Funding source & "We are grateful to the Alcohol and Education Research Council who funded the study". (p.1338) \\
\hline Declaration of interests & "We declare that we have no conflict of interest". (p.1338) \\
\hline Notes & $\begin{array}{l}\text { Loss to follow-up: } \\
\text { - Experimental group: } 98 / 287(34 \%) \text {. } \\
\text { - Control group: } 117 / 312(37.5 \%) \text {. }\end{array}$ \\
\hline
\end{tabular}

\section{Risk of bias}

\begin{tabular}{|c|c|c|}
\hline Bias & Authors' judgement & Support for judgement \\
\hline $\begin{array}{l}\text { Random sequence genera- } \\
\text { tion (selection bias) }\end{array}$ & Low risk & "Computer generated list of random numbers" (p. 1335). \\
\hline $\begin{array}{l}\text { Allocation concealment } \\
\text { (selection bias) }\end{array}$ & Unclear risk & $\begin{array}{l}\text { "Opaque envelopes marked with a unique patient identification number pre- } \\
\text { pared according to randomisation list" (p. 1335). }\end{array}$ \\
\hline $\begin{array}{l}\text { Blinding of treatment } \\
\text { providers }\end{array}$ & Low risk & $\begin{array}{l}\text { Participants re-attended with alcohol health worker to receive brief interven- } \\
\text { tion; therefore, no contamination. }\end{array}$ \\
\hline Blinding of participants & High risk & No reported attempt to blind participants. \\
\hline $\begin{array}{l}\text { Blinding of outcome as- } \\
\text { sessment (detection bias) } \\
\text { All outcomes }\end{array}$ & Low risk & $\begin{array}{l}\text { "Follow-up interviews were done either by telephone or in person by a re- } \\
\text { searcher blinded to allocation status" (p. 1335). }\end{array}$ \\
\hline $\begin{array}{l}\text { Incomplete outcome data } \\
\text { (attrition bias) } \\
\text { All outcomes }\end{array}$ & High risk & Loss to follow-up $>30 \%$. \\
\hline $\begin{array}{l}\text { Selective reporting (re- } \\
\text { porting bias) }\end{array}$ & Low risk & Outcomes specified in the methods were reported. \\
\hline
\end{tabular}


Crawford 2010

Parallel group RCT: brief intervention and health information leaflet versus health information leaflet
only.
ITT: yes.

\begin{tabular}{|c|c|}
\hline \multirow[t]{2}{*}{ Participants } & Setting: UK, emergency department. \\
\hline & $\begin{array}{l}\text { Participants: Aged }>18 \text { years presenting after an episode of deliberate self harm; consume }>8 \text { (men) } \\
\text { or }>6 \text { (women) units of alcohol in a drinking session at least weekly. Excluded if unable or unwilling to } \\
\text { provide verbal consent to participate (non-English language or impaired consciousness), or no fixed } \\
\text { address in greater London, or already in contact with alcohol misuse services, or made a specific re- } \\
\text { quest for help with alcohol problem at the time of assessment. }\end{array}$ \\
\hline
\end{tabular}

Number randomised $=103 ; 51 \%$ male; mean age $=37.2$ years, age range 18 to 65 years

At baseline: participants reported drinking up to a mean of 21 units of alcohol per drinking session.

Interventions Participants were screened with the PAT (Paddington Alcohol Test) which served as baseline assess-
ment.

Experimental group $(\mathrm{N}=51)$ received approximately 30 minutes of assessment and discussion of current and previous drinking based on the FRAMES approach from an alcohol nurse specialist (ANS). Following the appointment the ANS had the option of referring the participant for further help, such as individual alcohol counselling or detoxification services. The ANS took a patient-centred and non-confrontational approach. Participants also received the information leaflet "Think about Drink", which contains information about the health damaging effects of excessive alcohol consumption, details of benchmarks for recommended limits and contact details for national alcohol help lines.

Control group $(\mathrm{N}=52)$ received the information leaflet only.

\begin{tabular}{ll}
\hline Outcomes & $\begin{array}{l}\text { Units of alcohol per drinking session, mean AUDIT score. } \\
\text { Assessed at } 3 \text { and } 6 \text { months. }\end{array}$ \\
\hline Funding source & This study was funded by St Mary's Paddington Charitable Trust. \\
\hline Declaration of interests & Declaration of Interest: None. \\
\hline Notes & GBP 15 shopping voucher. \\
& Loss to follow-up: \\
& Experimental group: $17 / 51(33 \%)$. \\
& Control group: $11 / 52(21 \%)$.
\end{tabular}

\section{Risk of bias}

\begin{tabular}{lll}
\hline Bias & Authors' judgement & Support for judgement \\
\hline $\begin{array}{l}\text { Random sequence genera- } \\
\text { tion (selection bias) }\end{array}$ & Low risk & $\begin{array}{l}\text { An independent team used random number tables. Regular checks were made } \\
\text { to ensure that eligible participants were allocated according to the sequence } \\
\text { on the randomisation list (p. 1822). }\end{array}$ \\
\hline $\begin{array}{l}\text { Allocation concealment } \\
\text { (selection bias) }\end{array}$ & Unclear risk & $\begin{array}{l}\text { Pre-prepared sealed opaque envelopes contained identical pieces of card - } \\
\text { either an appointment card for an alcohol nurse specialist or a blank card (p. } \\
1822) .\end{array}$ \\
\hline
\end{tabular}


Crawford 2010 (Continued)

Blinding of treatment Low risk Experimental arm was randomised to a separate appointment with alcohol providers nurse specialist who did not see control group participants, therefore little chance of cross contamination.

\begin{tabular}{lll}
\hline Blinding of participants & High risk & No reported attempt to blind participants. \\
\hline $\begin{array}{lll}\text { Blinding of outcome as- } \\
\text { sessment (detection bias) }\end{array}$ & Low risk & "All follow-up data were collected and managed by a researcher who was \\
All outcomes & masked to allocation status" (p. 1823).
\end{tabular}

Incomplete outcome data Low risk Loss to follow-up reported with reasons.
(attrition bias)
All outcomes

All outcomes

Selective reporting (re- Low risk Outcomes specified in methods are reported.

porting bias)

\section{Curry 2003}

\begin{tabular}{|c|c|}
\hline Methods & $\begin{array}{l}\text { Parallel group RCT: brief motivational message plus booster telephone calls versus usual care } \\
\text { ITT: paper reported multiple imputation to impute outcome data for non-respondents; unpublished } \\
\text { data supplied to the reviewers was based on } 222 / 333(67 \%) \text { of those randomised. }\end{array}$ \\
\hline \multirow[t]{2}{*}{ Participants } & Setting: USA, primary care clinic. \\
\hline & $\begin{array}{l}\text { Participants: (no age restrictions), presenting for pre-booked appointment; screened by telephone } \\
\text { interviews to select those with AUDIT score }<=15 \text { and consuming } \geq 2 \text { alcoholic drinks per day in past } \\
\text { month (chronic drinking), or } \geq 2 \text { episodes of binge drinking ( } \geq 5 \text { drinks) in past week (binge drinkers), or } \\
\geq 1 \text { episode of driving after } \geq 3 \text { drinks; excluded if alcoholic, pregnant, terminally ill, or cognitively im- } \\
\text { paired. } \\
\text { Number randomised = } 333 ; 65 \% \text { male; mean age } 46.9 \text { years; } 16 \% \text { unemployed; } 91 \% \text { post-high school } \\
\text { education; } 68 \% \text { income }>\$ 35,000 \text { per year; } 80 \% \text { Caucasian. } \\
\text { Number assessed = } 222(67 \%) \text {. } \\
\text { At baseline: } \text { mean drinking amount = } 166 \mathrm{~g} / \text { week; } 42 \% \text { chronic drinkers; } 33 \% \text { binge drinkers. }\end{array}$ \\
\hline
\end{tabular}

Interventions Intervention group ( $N=166)$ received: a) a brief motivational message of 1 to 5 minutes from the primary care physician during the planned routine visit; b) self-help manual; c) written personalised feedback; d) up to three telephone counselling calls over 10 weeks by a psychology graduate.

Control group ( $\mathrm{N}=167$ ) received usual care (no intervention or any information about their participation in the study in their notes).

\begin{tabular}{ll}
\hline Outcomes & $\begin{array}{l}\text { Drinks per week, drinking days per week, binges per week, grams of alcohol per drinking day, per- } \\
\text { centage of binge drinkers, percentage of heavy drinkers (average of }>1 \text { drink per day for women or }>2 \\
\text { drinks per day for men. }\end{array}$ \\
& Assessed at 3 and 12 months. \\
\hline Funding source & $\begin{array}{l}\text { This study was supported by National Institute on Alcohol Abuse and Alcoholism Grant RO1 AA09175 } \\
\text { (to Susan J. Curry, Principal Investigator). }\end{array}$ \\
\hline Declaration of interests & Not reported. \\
\hline Notes & $\begin{array}{l}\text { Loss to follow-up: } \\
\text { Intervention group: } 66 / 166 ~(40 \%) . \\
\text { Control group: } 45 / 167(27 \%) . \\
\text { Analyses of frequency and intensity of drinking are based on unpublished data on } 222 \text { cases }\end{array}$
\end{tabular}


Curry 2003 (Continued)

Analysis of quality of alcohol consumed/week are based on published means and unpublished SDs.

\title{
Risk of bias
}

\begin{tabular}{|c|c|c|}
\hline Bias & Authors' judgement & Support for judgement \\
\hline $\begin{array}{l}\text { Random sequence genera- } \\
\text { tion (selection bias) }\end{array}$ & Unclear risk & Method of sequence generation not reported. \\
\hline $\begin{array}{l}\text { Allocation concealment } \\
\text { (selection bias) }\end{array}$ & Unclear risk & Method of allocation concealment not described. \\
\hline $\begin{array}{l}\text { Blinding of treatment } \\
\text { providers }\end{array}$ & Low risk & Treatment providers only interacted with intervention participants. \\
\hline Blinding of participants & Low risk & $\begin{array}{l}\text { During recruitment participants were blinded to the focus of the study on alco- } \\
\text { hol. }\end{array}$ \\
\hline $\begin{array}{l}\text { Blinding of outcome as- } \\
\text { sessment (detection bias) } \\
\text { All outcomes }\end{array}$ & Unclear risk & Unclear if outcome assessor was blinded (p. 157). \\
\hline $\begin{array}{l}\text { Incomplete outcome data } \\
\text { (attrition bias) } \\
\text { All outcomes }\end{array}$ & Unclear risk & $\begin{array}{l}\text { Loss to follow-up reported per arm but not reasons. Uneven follow-up be- } \\
\text { tween arms; used multiple imputation which uses a regression-type approach } \\
\text { that can remove bias that is due to differential non-response if the imputation } \\
\text { model contains variables that are good predictors of the outcome and of non- } \\
\text { response. }\end{array}$ \\
\hline
\end{tabular}

Selective reporting (re- Low risk Outcomes specified in methods are reported.

porting bias)

\section{Córdoba 1998}

\begin{tabular}{|c|c|}
\hline Methods & $\begin{array}{l}\text { Cluster RCT: brief intervention versus active control; } 74 \text { primary care practices were randomised, aver- } \\
\text { age cluster size }=6.9 . \\
\text { ITT: } \text { unclear. }\end{array}$ \\
\hline
\end{tabular}

ITT: unclear.

\section{Participants}

\begin{abstract}
Setting: Spain, primary care practices.
Participants: Men aged 14 to 50 years with either weekly alcohol consumption over 35 units, or over 10 units on any given day at least once a month ( 1 unit $=8 \mathrm{~g})$; excluded if alcohol dependency or previous advice to reduce drinking or chronic pathology/treatment requiring $>3$ months abstinence or CAGE score > 1; recruited from general practice; screened by lifestyle questionnaire with embedded CAGE Number randomised = 546 (all data reported for 229 followed up participants); $100 \%$ male; mean age 36.5 years; $100 \%$ Hispanic; $70.1 \%$ married; $78.7 \%$ middle-lower or lower social status; $95.6 \%$ employed; $64.1 \%$ further education

At baseline: mean weekly alcohol consumption $=54.0$ units; CAGE $=1$ for $63.2 \%$ of participants (data given for 229 heavy throughout-week drinkers only)
\end{abstract}

\section{Interventions}

Both groups were screened using a lifestyle questionnaire incorporating CAGE questions, this served as baseline assessment

Intervention group ( $\mathrm{N}=104$ participants) received from the GP 15 minutes cognitive-behavioural therapy consisting of a self-informative booklet including day diary for registration of consumption, individualised agreement of consumption targets, and offer of follow-up and support Control group ( $\mathrm{N}=125$ ) received from the GP five minute 'simple advice' which reproduced usual care 
Córdoba 1998 (Continued)

Outcomes

Per cent of participants cutting down to under 35 units per week

Assessed at 12 months

\begin{tabular}{ll}
\hline Funding source & Not reported \\
\hline Declaration of interests & Not reported \\
\hline Notes & EBIAL trial \\
& Loss to follow-up not reported by arm \\
\hline
\end{tabular}

\section{Risk of bias}

\begin{tabular}{lll}
\hline Bias & Authors' judgement & Support for judgement \\
\hline $\begin{array}{l}\text { Random sequence genera- } \\
\text { tion (selection bias) }\end{array}$ & Unclear risk & Method of sequence generation is unclear \\
\hline $\begin{array}{l}\text { Allocation concealment } \\
\text { (selection bias) }\end{array}$ & Low risk & $\begin{array}{l}\text { All research workers in one centre conducted the same intervention, and they } \\
\text { were not aware of the details of the other intervention; allocation unit was the } \\
\text { primary care practice (p.563) }\end{array}$ \\
\hline $\begin{array}{l}\text { Blinding of treatment } \\
\text { providers }\end{array}$ & Low risk & $\begin{array}{l}\text { Cluster randomised: treatment providers only had contact with one arm and } \\
\text { only delivered one intervention, reducing the chance of cross contamination }\end{array}$ \\
\hline $\begin{array}{l}\text { Blinding of participants } \\
\text { Blinding of outcome as- } \\
\text { sessment (detection bias) } \\
\text { All outcomes }\end{array}$ & High risk & No reported attempt to blind participants \\
\hline
\end{tabular}

Incomplete outcome data $\quad$ High risk $\quad$ Overall loss to follow-up 49\%
(attrition bias)

All outcomes

Selective reporting (re- Low risk Outcomes described in the methods section are reported
porting bias)

\section{D'Amico 2008}

\begin{tabular}{ll}
\hline Methods & Parallel RCT: motivational interview versus control. \\
& ITT: no. \\
\hline Participants & Setting: USA; primary care clinic providing free care to underserved populations, described as unin- \\
sured (working poor, homeless, runaway and high-risk youth). & \\
& Participants: 12 to 18 years who reported alcohol consumption or drug use and consequences due to \\
& use, English-speaking, able to return for 15 to 20 minute appointment. \\
& $\begin{array}{l}\text { Number randomised = } 64 \text { (of which } 42 \text { completed and are in the analysis, following percentages are of } \\
\text { 42 completers); } 48 \% \text { male; mean age of total sample not reported; } 85.7 \% \text { Hispanic/Latino, } 9.5 \% \text { African } \\
\text { American, } 4.8 \% \text { White; } 42.9 \% \text { completed high school, } 42.9 \% \text { didn't complete high school, } 14.3 \% \text { don't } \\
\text { know; } 31.0 \% \text { attended at least some college, } 52.4 \% \text { didn't attend at least some college, } 16.7 \% \text { don't } \\
\text { know (some are below college age). }\end{array}$
\end{tabular}


D'Amico 2008 (Continued)

At baseline: $78.6 \%$ reported alcohol use in the last 30 days; $100 \%$ reported alcohol use in their lifetime.

Interventions Participants were screened with CRAFFT plus six filler questions on health, and both groups completed a baseline survey (duration not reported).

MI group ( $\mathrm{N}=38$ randomised, 22 completers in analysis) received a 15 to 20 minute motivational interviewing intervention plus a 5 to 10 minute booster telephone call one month after intervention from case managers who worked in the mental health division of the clinic. The motivational interviewing session focused on assessing motivation to change (five to seven minutes), enhancing motivation for change (5 to 7 minutes), and making a plan ( 5 to 7 minutes). The booster call briefly reiterated what the teen had discussed in the Project CHAT session, reviewed their goals and whether they had been able to implement any of the strategies they had discussed during the session, and revised goals as necessary.

Control group ( $\mathrm{N}=26$ randomised, 20 completers in analysis) were screened and assessed; no detail is given about their care.

Outcomes Number of days consumed alcohol in the last month, how many drinks consumed, number of days consumed more than three drinks.

Assessed at 3 months.

Funding source Work on this article was supported by a grant from the National Institute on Drug Abuse (R21DA018854) to Elizabeth J D'Amico.

\begin{tabular}{ll}
\hline Declaration of interests & Not reported. \\
\hline Notes & Project CHAT. \\
& Participants received USD 15 for baseline survey; USD 25 for 3-month survey; USD 15 for completion. \\
& During the study incentive was increased to USD 30, and 22 teens received this payment. \\
& Loss to follow-up: \\
& MI group: $22 / 38(42 \%)$. \\
& Control group: $20 / 26(23 \%)$.
\end{tabular}

\section{Risk of bias}

\begin{tabular}{lll}
\hline Bias & Authors' judgement & Support for judgement \\
\hline $\begin{array}{l}\text { Random sequence genera- } \\
\text { tion (selection bias) }\end{array}$ & High risk & $\begin{array}{l}\text { "Initially the youth were randomised on a one-to-one basis... as the trial pro- } \\
\text { gressed, we recognised that dropout rates were unequal between groups... } \\
\text { thus, to maximise power, we altered the allocation schedule such that the } \\
\text { probability of being allocated to the intervention was higher." i.e. the re- } \\
\text { searchers changed the randomisation procedure (p. 56). }\end{array}$ \\
\end{tabular}

\begin{tabular}{lll}
\hline $\begin{array}{l}\text { Allocation concealment } \\
\text { (selection bias) }\end{array}$ & High risk & $\begin{array}{l}\text { As above, researchers changed allocation procedure whilst the trial was in } \\
\text { progress to alter the allocation. }\end{array}$ \\
\hline $\begin{array}{l}\text { Blinding of treatment } \\
\text { providers }\end{array}$ & Unclear risk & $\begin{array}{l}\text { Unclear whether treatment provider has contact with both intervention and } \\
\text { control participants. }\end{array}$ \\
\hline
\end{tabular}

$\begin{array}{ll}\text { Blinding of participants Low risk } & \begin{array}{l}\text { Screening questionnaire had filler questions to mask recruitment criteria ( } \mathrm{p} . \\ 57) .\end{array}\end{array}$

\begin{tabular}{|c|c|c|}
\hline $\begin{array}{l}\text { Blinding of outcome as- } \\
\text { sessment (detection bias) } \\
\text { All outcomes }\end{array}$ & Unclear risk & Not described. \\
\hline
\end{tabular}


D'Amico 2008 (Continued)

Incomplete outcome data Unclear risk Differential in missing data across groups. This is one of the few studies that (attrition bias)

did not exclude hard to reach populations such as homeless people.

All outcomes

Selective reporting (re- Low risk Outcomes specified in methods are reported.

porting bias)

\section{D'Onofrio 2008}

Methods

Parallel RCT: brief negotiated interview versus scripted discharge instructions.

ITT: yes.

Participants Setting: USA, emergency department.

Participants: $\geq 18$ years who reported consuming in excess of NIAAA limits, or whose emergency department visit related to an injury associated with alcohol use; excluded if non-English speaking, AUDIT > 19, or using drugs daily, or currently enrolled in a substance abuse treatment program, or seeking treatment for an acute psychiatric complaint or hospitalised for a psychiatric problem in the past year, or critically ill or injured, or cognitively impaired.

Number randomised $=500$ (of which 494 in analysis, following percentages are of 494 ); $68 \%$ male; mean age of total group not reported; $67 \%$ White, $20 \%$ Black, $11 \%$ Hispanic, $2 \%$ Other; $47 \%$ high school or less, $36 \%$ some college, $17 \%$ college degree or more.

Baseline characteristics for total sample not reported.

Interventions

Participants were screened with an 18-item health screening questionnaire, including multiple health factors and the NIAAA quantity/frequency questions embedded. Both groups received baseline assessment (duration not reported), including alcohol consumption for the past 30 days as measured by Time Line Follow-Back method, and questions concerning drinking-related consequences such as drinking after driving, injury sustained while drinking, and arrests. Readiness to change was assessed by the Contemplation Ladder, and the Short Form Health Survey was used to assess health status in mental and physical domains.

$\mathrm{BNI}$ group ( $\mathrm{N}=250$ randomised, 247 analysed) received brief negotiated interview from one of a group of trained emergency practitioners - a manual-guided intervention using techniques based on motivational interviewing, brief advice, and behavioral contracting and designed to be delivered in less than ten minutes. The four primary steps were: (1) raise the subject of alcohol; (2) provide feedback by reviewing the participant's screening data, make a connection between alcohol and the visit/illness or injury if possible, review National Institute on Alcohol Abuse and Alcoholism guidelines for low-risk drinking; (3) enhance motivation with motivational interviewing techniques; and (4) negotiate and advise by summarising the participant's reasons for change and negotiating a drinking goal. Participants were then asked to complete and sign a drinking agreement.

The control group ( $\mathrm{N}=250$ randomised, 247 analysed) received scripted discharge instructions read by the emergency practitioner, designed to be less than one minute in length (although actual mean length was 1.4 minutes). This included a statement recommending that the participant decrease alcohol intake and, if appropriate, use seatbelts, exercise regularly, and stop smoking. A handout was provided with more information related to all identified health risks.

Outcomes

Average drinks per week, binge episodes in last month, proportion over NIAA guidelines, number who have driven after drinking, number arrested or pulled over for driving under the influence, number who had motor vehicle crash whilst intoxicated, number who were injured while drinking one or more times, contact with legal system, missed 1 workday in past 30 days.

Assessed at 12 months. 
D'Onofrio 2008 (Continued)

Funding source $\quad$ Funded by National Institute on Alcohol Abuse and Alcoholism grant R01 AA12417-01A1 (Dr D'Onofrio), National Institute on Drug Abuse grant K23 DA15144 (Dr Pantalon), and Robert Wood Johnson Generalist Physician Faculty Scholar Award (Dr Fiellin).

\begin{tabular}{|c|c|}
\hline Declaration of interests & None (says all conflicts must be reported but none were specified). \\
\hline \multirow[t]{3}{*}{ Notes } & Project ED Health. \\
\hline & $\begin{array}{l}\text { USD } 20 \text { at intake visit (from research associate); USD } 40 \text { at six months by post; USD } 50 \text { at } 12 \text { months by } \\
\text { post. }\end{array}$ \\
\hline & $95 \%$ follow-up at six months; $92 \%$ at 12 months. \\
\hline
\end{tabular}

\section{Risk of bias}

\begin{tabular}{lll}
\hline Bias & Authors' judgement & Support for judgement \\
\hline $\begin{array}{l}\text { Random sequence genera- } \\
\text { tion (selection bias) }\end{array}$ & Unclear risk & $\begin{array}{l}\text { Participants were randomly assigned with } 100 \text { block randomisation but does } \\
\text { not say how the sequence was generated. }\end{array}$ \\
\hline
\end{tabular}

\begin{tabular}{|c|c|c|}
\hline $\begin{array}{l}\text { Allocation concealment } \\
\text { (selection bias) }\end{array}$ & Low risk & $\begin{array}{l}\text { "Research associates were provided with sealed, opaque envelopes for each of } \\
\text { the } 500 \text { randomised study identification numbers. The identification number } \\
\text { appeared on the outside, and the assigned treatment condition was specified } \\
\text { inside the envelope" (p. 744). }\end{array}$ \\
\hline $\begin{array}{l}\text { Blinding of treatment } \\
\text { providers }\end{array}$ & Unclear risk & $\begin{array}{l}\text { Treatment provider provides both intervention and control, but control state- } \\
\text { ment is scripted and reported duration of control arm suggests contamination } \\
\text { is unlikely. }\end{array}$ \\
\hline Blinding of participants & Low risk & $\begin{array}{l}\text { "The screen included questions related to smoking, exercise, and seatbelt use } \\
\text { to mask alcohol as the central focus" (p. 744). }\end{array}$ \\
\hline $\begin{array}{l}\text { Blinding of outcome as- } \\
\text { sessment (detection bias) } \\
\text { All outcomes }\end{array}$ & Low risk & $\begin{array}{l}\text { "Interviews were conducted by research associates blinded to subject treat- } \\
\text { ment assignment" (p. 744). }\end{array}$ \\
\hline $\begin{array}{l}\text { Incomplete outcome data } \\
\text { (attrition bias) } \\
\text { All outcomes }\end{array}$ & Unclear risk & $\begin{array}{l}\text { Follow-up rates were high and comparable, but reasons for loss to follow-up } \\
\text { not reported. }\end{array}$ \\
\hline $\begin{array}{l}\text { Selective reporting (re- } \\
\text { porting bias) }\end{array}$ & Low risk & Outcomes specified in methods are reported. \\
\hline
\end{tabular}

D'Onofrio 2012

Methods Parallel RCT: brief negotiated interview (BNI) plus booster versus BNI versus scripted discharge instructions (SC) versus scripted discharge instructions with no assessment (SC-no assessment).

ITT: yes.
Participants
Setting: USA, emergency department.
Participants: Aged $\geq 18$ years who reported alcohol consumption exceeding the NIAAA's low-risk limits ("hazardous drinkers") or whose index emergency department visit was related to an injury associat- ed with alcohol use ("harmful drinkers"), screened with NIAA quantity frequency questions; excluded if non-English speaking, or AUDIT > 19, or using drugs daily, or currently enrolled in a substance abuse 
D'Onofrio 2012 (Continued)

treatment program, or seeking treatment for an acute psychiatric complaint or hospitalised for a psychiatric problem in the past year, or critically ill or injured, or cognitively impaired.

Number randomised $=889 ; 72 \%$ male; mean age of total group not reported; $63 \%$ White, $22 \%$ Black, $13 \%$ Hispanic, $2 \%$ Other; $40 \%$ high school or less, $42 \%$ some college, $14 \%$ college degree or more (missing data in SC-no assessment group).

Baseline characteristics for total sample not reported.

Interventions

Participants were screened with a 17 -item health screening questionnaire, including multiple health factors and the NIAAA quantity/frequency questions embedded. The BNI+booster, BNI and SC groups received a baseline assessment (details not given).

$\mathrm{BNI}+$ booster group $(\mathrm{N}=295)$ received brief negotiated interview from trained emergency practitioners - a manual-guided intervention using techniques based on motivational interviewing, brief advice, behavioural contracting and designed to be delivered in less than 10 minutes. The four primary steps were: 1 ) raise the subject of alcohol; 2) provide feedback by reviewing the participant's screening data, make a connection between alcohol and the visit/illness or injury if possible, review NIAAA guidelines for low-risk drinking; 3) enhance motivation using motivational interviewing techniques; and 4) negotiate and advise by summarising the participant's reasons for change and negotiating a drinking goal. Participants were then asked to complete and sign a drinking agreement. They received an additional telephone booster intervention at 1 month from a trained primary care nurse: if participants had reduced their drinking to low risk they received reinforcement and relapse prevention; if they were still above low-risk limits the nurse attempted to negotiate a new agreement and consider a change in the future. Coping skills and stressors were assessed and motivational strategies for change were offered.

$\mathrm{BNI}$ group $(\mathrm{N}=297)$ received $\mathrm{BNI}$ only.

SC group $(N=148)$ received no further screening beyond the general health questionnaire or intervention targeting alcohol use.

SC-NA group $(\mathrm{N}=149)$ received no assessment or intervention.

Outcomes

Mean number of drinks in the past seven days, mean number of binge drinking days in the past 28 days, reported driving after drinking more than three drinks at least once in the past 12 months, Short Inventory of Problems score, Injury Behaviour Checklist score.

Assessed at 6 and 12 months.

Funding source

Funded by National Institute on Alcohol Abuse and Alcoholism grant 1R01AA14963.

Declaration of interests None (says all conflicts must be reported but none were specified).

Notes

USD 20 at index visit and at the 6 month and 12 month assessments.

Loss to follow-up at 6 months (for primary outcomes which were collected by interactive voice response):

BNI + booster group: 121/295 (41.0\%).

BNI group: 118/297 (39.7\%).

SC group: $75 / 148(50.1 \%)$.

Loss to follow-up at 12 months (for primary outcomes which were collected by interactive voice response):

BNI+booster group: 126/295 (42.7\%).

BNI group: 116/297 (39.1\%).

SC group: $62 / 148(41.9 \%)$. 
D'Onofrio 2012 (Continued)

SC-NA group: 75/149 (50.3\%).

\section{Risk of bias}

\begin{tabular}{lll}
\hline Bias & Authors' judgement & Support for judgement \\
\hline $\begin{array}{l}\text { Random sequence genera- } \\
\text { tion (selection bias) }\end{array}$ & Unclear risk & $\begin{array}{l}\text { Participants were randomly assigned with } 100 \text { block randomisation but } \\
\text { doesn't say how the sequence was generated. }\end{array}$ \\
\hline $\begin{array}{l}\text { Allocation concealment } \\
\text { (selection bias) }\end{array}$ & Unclear risk & $\begin{array}{l}\text { "Research associates were provided with sealed envelopes for each of the } \\
\text { study identification numbers" (p.183). In the previous study by the same au- } \\
\text { thors (D'Onofrio 2008), researchers were provided with sealed, opaque, num- } \\
\text { bered envelopes. }\end{array}$
\end{tabular}

\begin{tabular}{ll}
\hline $\begin{array}{l}\text { Blinding of treatment } \\
\text { providers }\end{array}$ & Low risk \\
& $\begin{array}{l}\text { Control group were assessed by researcher and then received nothing more; } \\
\text { clinicians administered the same intervention to all intervention participants, } \\
\text { a research nurse administered the booster; therefore the chances of contami- } \\
\text { nation between arms are low. }\end{array}$
\end{tabular}

\begin{tabular}{ll}
\hline Blinding of participants $\quad$ Low risk & Quantity and frequency questions recommended by the National Institute \\
on Alcohol Abuse and Alcoholism to identify hazardous and harmful drinkers \\
were embedded in a 17-item general health questionnaire. They controlled for \\
social desirability bias by using IVR to collect consumption data (p. 184).
\end{tabular}

$\begin{array}{ll}\begin{array}{l}\text { Blinding of outcome as- } \\ \text { sessment (detection bias) }\end{array} \quad \text { Low risk } & \begin{array}{l}\text { Research associates collecting data were blind to study group assignment, } \\ \text { many data were collected by interactive voice response (p. 184). }\end{array}\end{array}$

All outcomes

\begin{tabular}{lll}
\hline $\begin{array}{l}\text { Incomplete outcome data } \\
\text { (attrition bias) } \\
\text { All outcomes }\end{array}$ & High risk & Loss to follow-up $>30 \%$. \\
\hline $\begin{array}{l}\text { Selective reporting (re- } \\
\text { porting bias) }\end{array}$ & Low risk & Outcomes specified in methods are reported.
\end{tabular}

\section{Daeppen 2007}

\begin{tabular}{|c|c|}
\hline \multirow[t]{2}{*}{ Methods } & $\begin{array}{l}\text { Parallel RCT: brief alcohol intervention versus control with assessment versus control without assess- } \\
\text { ment. }\end{array}$ \\
\hline & ITT: unclear. \\
\hline
\end{tabular}

Participants Setting: Switzerland, emergency department.

Participants: $\geq 18$ years who were admitted to emergency department for an injury; excluded if history of alcohol-related treatment over the last 12 months, or clinically intoxicated, or medical condition that precluded a face-to-face interview, or if not qualifying as hazardous drinker over the last 30 days.

Number randomised $=987 ; 78 \%$ male; mean age $=36.7$ years.

Baseline data not reported for total sample.

Interventions Participants were screened with a 10-item lifestyle questionnaire including three alcohol-related questions. BAI and CA groups received a 30 minute assessment.

Brief Alcohol Intervention (BAI) group ( $N=310)$ received a single motivation style brief intervention session lasted approximately 15 minutes and covered six steps: (1) to thank the participant for participation and provide reassurance about confidentiality; (2) to provide feedback about participant's alco- 
hol use compared to similar measures for men and women in the Swiss community and ask the participant's opinion of the feedback; (3) to ask the participant to explore the pros and cons of their alcohol use; (4) to use a 1 to 10 scale to explore participant's importance and readiness to change their drinking patterns; (5) to ask if the participant feels ready to set an objective and provide positive reinforcement about the ability to achieve this objective; and (6) to give each participant written material, including their AUDIT score, drinking pattern percentiles compared to the Swiss community and their drinking pattern objectives.

Control with assessment $(\mathrm{CA})$ group $(\mathrm{N}=342)$ received assessment and "usual care" (not defined).

Control no assessment $(C)$ group $(\mathrm{N}=335)$ received "usual care" only.

$\begin{array}{ll}\text { Outcomes } & \text { Per cent hazardous drinkers, mean number of days drinking per week in previous } 12 \text { months, mean } \\ \text { number of drinks per occasion in last } 12 \text { months, mean number of binge drinking occasions per month } \\ \text { in last } 12 \text { months, mean number of drinks in last seven days, mean AUDIT score, mean SF-12 score } \\ \text { (mental and physical). }\end{array}$

Assessed at 12 months.

Funding source $\quad$ Funded by grant no. 3200-067949 of the Swiss National Science Foundation. The Swiss National Science Foundation is the government agency funding scientific research in Switzerland.

\begin{tabular}{ll}
\hline Declaration of interests & Not reported. \\
\hline Notes & Loss to follow-up: \\
& BAl: $74 / 310(24 \%)$. \\
& CA: $65 / 342(19 \%)$. \\
C: $78 / 335(23 \%)$. \\
\hline
\end{tabular}

\section{Risk of bias}

\begin{tabular}{lll}
\hline Bias & Authors' judgement & Support for judgement \\
\hline $\begin{array}{l}\text { Random sequence genera- } \\
\text { tion (selection bias) }\end{array}$ & Low risk & $\begin{array}{l}\text { "Each participant was randomised and assigned to experimental or control } \\
\text { group based by block of ten participants on a computer-generated allocation } \\
\text { method" (p. 1226). }\end{array}$
\end{tabular}

\begin{tabular}{lll}
\hline $\begin{array}{l}\text { Allocation concealment } \\
\text { (selection bias) }\end{array}$ & Unclear risk & Not described. \\
\hline $\begin{array}{ll}\text { Blinding of treatment } \\
\text { providers }\end{array}$ & High risk & "A group of five female and two male research assistants were recruited and \\
& & $\begin{array}{l}\text { selected to do the screening, assessment and BAl at baseline, depending on } \\
\text { their ability to apply research procedures and to conduct BAl... Research as- } \\
\text { sistants conducted the motivational style BAI right after the assessment" (p. } \\
\text { 1228). }\end{array}$ \\
\hline
\end{tabular}

\begin{tabular}{ll}
\hline Blinding of participants $\quad$ Low risk & "One of the goals of the trial was to blind subjects assigned to the control \\
& groups to minimize possible intervention effects. The subjects in both control \\
& groups were told that the trial focused on general health behaviours, including \\
alcohol use" (p. 1228).
\end{tabular}

\begin{tabular}{lll}
\hline $\begin{array}{l}\text { Blinding of outcome as- } \\
\begin{array}{l}\text { sessment (detection bias) } \\
\text { All outcomes }\end{array}\end{array}$ & Low risk & $\begin{array}{l}\text { "Research assistants at follow up were blinded to the participant assignment, } \\
\text { and because this interview conducted no evaluation of the BAl they were un- } \\
\text { aware from which group the participants came" (p. 1228). }\end{array}$ \\
\hline $\begin{array}{l}\text { Incomplete outcome data } \\
\text { (attrition bias) }\end{array}$ & Unclear risk & Loss to follow-up reported but reasons not reported by arm.
\end{tabular}


Daeppen 2007 (Continued)

All outcomes

Selective reporting (re- Low risk Outcomes specified in methods are reported.
porting bias)

porting bias)

\title{
Dent 2008
}

Methods Parallel RCT: motivational interview (extended) versus brief intervention versus standard care; only brief intervention and standard care groups used because the motivational interview was not comparable to other trials, and very few participants received the intervention.

ITT: yes.

\begin{abstract}
Participants Setting: Australia, emergency department.
Participants: Aged $\geq 18$ years presenting to emergency department for any reason; excluded if inability or refusal to give informed consent (including lack of communication in English, intoxication preventing coherent answers to questions), or previous enrolment and inability to be followed up (e.g. travellers, no phone contact).

Number randomised $=468 ; 78 \%$ male; mean age of total sample not reported.

Baseline data not reported for total sample.

Interventions

Participants were screened with PAT (Paddington Alcohol Test), and this served as baseline data.

Bl group ( $N=159$ ) received a semi scripted informative discussion from a trained nurse or doctor, median five minutes (range 1 to 30 minutes), including the risks of high-risk drinking, a definition of a standard drink, advice on safe drinking, tips on cutting down and incorporated empathy and encouragement. A purpose-designed pamphlet reinforcing the information discussed was also provided.

SC group ( $N=161$ ) received standard care, i.e. no counselling unless the clinician would have accessed addiction services as part of clinical duty or the participant requested counselling.

MI group ( $\mathrm{N}=148)$ received an appointment at a specialist drug and alcohol centre.

A separate control group (not randomised) was comprised of non-consenting participants who screened positive.
\end{abstract}

Outcomes

Self-reported most drinks in a day, number of participants exceeding daily alcohol limit once per week, emergency department attendances.

Assessed at 1 and 3 months.

Funding source An Alcohol Education and Rehabilitation Foundation Grant supported the present study.

Declaration of interests Not reported.

Notes Loss to follow-up:

Bl group: 83/159 (52\%).

SC group: 95/161 (59\%).

\section{Risk of bias}

\section{Bias}

Authors' judgement Support for judgement 
Dent 2008 (Continued)
Random sequence genera- Low risk Computer generated block-randomisation process (p. 122). tion (selection bias)

Allocation concealment $\quad$ Low risk
(selection bias)

\begin{tabular}{ll}
\hline $\begin{array}{l}\text { Blinding of treatment } \\
\text { providers }\end{array}$ & High risk \\
\end{tabular}

\begin{tabular}{lll}
\hline Blinding of participants & High risk & $\begin{array}{l}\text { "Group allocation was not blinded to the participant, clinicians performing in- } \\
\text { terventions or the researchers conducting follow-up interviews" (p. 123). }\end{array}$ \\
\hline $\begin{array}{l}\text { Blinding of outcome as- } \\
\begin{array}{l}\text { sessment (detection bias) } \\
\text { All outcomes }\end{array}\end{array}$ & High risk & $\begin{array}{l}\text { "Group allocation was not blinded to the participant, clinicians performing in- } \\
\text { terventions or the researchers conducting follow-up interviews" (p. 123). }\end{array}$ \\
\hline $\begin{array}{l}\text { Incomplete outcome data } \\
\begin{array}{l}\text { (attrition bias) } \\
\text { All outcomes }\end{array}\end{array}$ & High risk & Loss to follow-up > 30\%. \\
\hline
\end{tabular}

Selective reporting (re- Low risk

Outcomes specified in methods are reported.

porting bias)

Drummond 2009

Methods Parallel RCT: stepped care brief intervention versus brief advice.

ITT: yes.

Participants Setting: Wales, primary care practices.

Participants: Aged $\geq 18$ years presenting to primary care clinic and screening AUDIT $\geq 8$, may also have diagnosis of alcohol use disorder, or be drinking above Department of Health guidelines ( $>21$ units per week or $>8$ units per day), must live within commuting distance of PC practice, and not have received treatment for alcohol use disorder in previous 180 days; excluded if primary drug dependence other than alcohol, or severe mental or physical illness, or severe cognitive impairment or legal issues that might interfere with follow-up.

Number randomised $=112 ; 100 \%$ male; mean age $=42.7$ years.

At baseline: mean AUDIT score $=13.7$.

Interventions Stepped Care group $(\mathrm{N}=54)$ received:

Step 1. 40-minute session of behaviour change counselling from a trained practice nurse. Each participant was invited for follow-up with the same nurse 28 days after the initial session. Participants who had consumed $>21$ units of alcohol in any one week or $>10$ units in any one day during the 28-day period were referred to step 2 .

Step 2. All participants referred to step 2 were offered a maximum of four 50 -minute sessions of motivational enhancement therapy conducted by a trained alcohol counsellor. Sessions were held at the primary care practice and scheduled for one per week over a four week period. Each participant was invited for a follow-up with the practice nurse 28 days after the final session. Participants who had consumed $>21$ units in any one week or $>10$ units in any one day in the 28-day period were referred to step 3.

Step 3. Participants were referred to the local community alcohol team for specialist intervention. There was no limit on duration or intensity of treatment, which could encompass, where necessary, 
Drummond 2009 (Continued)

detoxification, inpatient treatment, outpatient counselling, relapse prevention and drug therapy. The clinical protocol included a caveat that any participant in the intervention group who needed urgent referral to step 3 at any stage could be referred without going through intermediate care steps.

Minimal intervention group $(N=58)$ received a five minute directive advice session from a practice nurse addressing the need for them to reduce their alcohol consumption. Participants also received a short self-help booklet outlining the consequences of excessive alcohol consumption and including details on where to seek help locally for alcohol problems.

\begin{tabular}{ll}
\hline Outcomes & $\begin{array}{l}\text { Total drinks in previous } 180 \text { days, mean drinks per drinking day, per cent days abstinent, alcohol prob- } \\
\text { lems questionnaire (APQ), quality of life (SF-12), health utility (EQ-5D), mean costs. } \\
\text { Assessed at } 6 \text { months. }\end{array}$ \\
\hline Funding source & $\begin{array}{l}\text { The study was funded by the Wales Office for Research and Development. All of the authors are inde- } \\
\text { pendent of the funding body. }\end{array}$ \\
\hline Declaration of interests & Declaration of interest: None. \\
\hline Notes & Loss to follow-up: \\
& Stepped Care: $15 / 54(28 \%)(52$ received step 1, 17 received step 2, 1 received step 3). \\
Minimal intervention: $6 / 58(10 \%)$ (all received intervention).
\end{tabular}

\section{Risk of bias}

\begin{tabular}{|c|c|c|}
\hline Bias & Authors' judgement & Support for judgement \\
\hline $\begin{array}{l}\text { Random sequence genera- } \\
\text { tion (selection bias) }\end{array}$ & Low risk & $\begin{array}{l}\text { "Randomisation was conducted remote from the research centres by the trial } \\
\text { randomisation service at the University of York" (p. 449). }\end{array}$ \\
\hline $\begin{array}{l}\text { Allocation concealment } \\
\text { (selection bias) }\end{array}$ & Unclear risk & $\begin{array}{l}\text { "Block randomisation with seeded random elements was used to minimise the } \\
\text { possibility of subversion" (p. 449). }\end{array}$ \\
\hline $\begin{array}{l}\text { Blinding of treatment } \\
\text { providers }\end{array}$ & High risk & Treatment providers not blinded. \\
\hline Blinding of participants & Low risk & $\begin{array}{l}\text { Participants completed "an AUDIT questionnaire embedded within a general } \\
\text { lifestyle questionnaire" (p. 449). }\end{array}$ \\
\hline $\begin{array}{l}\text { Blinding of outcome as- } \\
\text { sessment (detection bias) } \\
\text { All outcomes }\end{array}$ & Low risk & $\begin{array}{l}\text { "Follow-up was conducted by a researcher masked to the allocated group" (p. } \\
\text { 449). }\end{array}$ \\
\hline $\begin{array}{l}\text { Incomplete outcome data } \\
\text { (attrition bias) } \\
\text { All outcomes }\end{array}$ & Unclear risk & $\begin{array}{l}\text { Loss to follow-up is reported with reasons. Loss to follow-up is } 10 \% \text { versus } \\
28 \% \text { but stepped care design means that not all participants received all steps. }\end{array}$ \\
\hline $\begin{array}{l}\text { Selective reporting (re- } \\
\text { porting bias) }\end{array}$ & Low risk & Outcomes specified in methods are reported. \\
\hline
\end{tabular}

\section{Drummond 2014}

\section{Methods}

Cluster RCT: patient information leaflet versus brief advice versus brief lifestyle counselling, average cluster size $=135$. 
Drummond 2014 (Continued)

ITT: yes.

Participants Setting: England, emergency departments.

Participants: Aged $\geq 18$, who were screened positive on an alcohol screening test, sufficiently alert and orientated to provide informed consent, living within the catchment area of the ED, and being able to speak, read or write English sufficiently well to complete study questionnaires; excluded if already seeking alcohol treatment, or participating in another study of alcohol interventions, or having sustained a severe injury, or suffering from a serious mental health problem, or grossly intoxicated, or being of no fixed abode; screened by one of three alcohol screening tools: the modified Single Alcohol Screening Question (M-SASQ), or the FAST Alcohol Screening Test, or a modified version of Paddington Alcohol Test (SIPS-PAT) (EDs were randomly assigned to one of the three screening approaches).

Number randomised: $1204 ; 65 \%$ male; mean age $=34.6$ years, $88 \%$ white, $65 \%$ continued with education after the age of 16 years, over $45 \%$ current smokers.

At baseline: mean AUDIT score $=12.4$ (SD 6.9).

Interventions

Brief Lifestyle Counseling $(B L C)$ group $(N=395)$ received the patient information leaflet $(\mathrm{PIL})$ and brief advice (BA) from emergency department staff. The following day (or as soon as possible thereafter), they received 20 minutes of lifestyle counselling alcohol intervention based on the 'How much is too much?' intervention pack used for the PIL group, delivered by Alcohol Health Workers (AHW) with specialist training and experience in alcohol motivational interventions.

B) group ( $N=403$ ) received five minutes of brief advice about drinking using the SIPS brief advice tool ('Brief Advice About Alcohol Risk') developed for the trial and based on the 'How much is too much?' intervention pack. Following brief advice, the PIL was delivered in the same manner as in the minimal intervention group.

PIL group $(\mathrm{N}=406)$ received simple clinical feedback using a standard script that their test result indicated they were drinking above the government's 'safe' drinking levels, and were given a PIL - the Department of Health's 'Drinking and You: How Much is Too Much?' leaflet, including information on local alcohol services where further help could be sought by the patient themselves.

Outcomes

AUDIT status (score of $<8$ versus $\geq 8$ ) on the extended item AUDIT questionnaire; average number of drinks per day using the quantity-frequency questions of the extended AUDIT, alcohol related problems using the Alcohol Problems.

Alcohol Screening and Brief Intervention in Emergency Care Questionnaire (APQ), readiness to change using a modified Readiness Ruler, patient satisfaction using a modified version of the Patient Satisfaction Questionnaire measured (at 12 months only).

Assessed at 6 and 12 months.

Funding source

The study was funded by the UK Department of Health. The Department of Health, proposed the general study design, but the details of the methodology were determined by the study team. The sponsor had no role in data collection, data analysis, interpretation of the results or writing the report. The corresponding author had full access to the data and had final responsibility for the decision to submit for publication.

Declaration of interests

Competing interests: all authors had financial support from the Department of Health in England (Alcohol Policy Unit) for the submitted work; no financial relationships with any organisations that might have an interest in the submitted work in the previous three years; no other relationships or activities that could appear to have influenced the submitted work.

Notes

Loss to follow-up at 6 months:

Patient information leaflet: 114/406 (28\%).

Brief advice: 99/403 (25\%).

Brief lifestyle counselling: 128/395 (32\%). 
Drummond 2014 (Continued)

Loss to follow-up at 12 months:

Patient information leaflet: 142/406 (35\%).

Brief advice: 108/403 (27\%).

Brief lifestyle counselling: 144/395 (36\%).

Payment: GBP 10 voucher for baseline assessment.

\section{Risk of bias}

\begin{tabular}{|c|c|c|}
\hline Bias & Authors' judgement & Support for judgement \\
\hline $\begin{array}{l}\text { Random sequence genera- } \\
\text { tion (selection bias) }\end{array}$ & Low risk & $\begin{array}{l}\text { "Randomisation was conducted using a remote secure randomisation service } \\
\text { (p. 3). }\end{array}$ \\
\hline $\begin{array}{l}\text { Allocation concealment } \\
\text { (selection bias) }\end{array}$ & Low risk & Cluster randomised trial. \\
\hline $\begin{array}{l}\text { Blinding of treatment } \\
\text { providers }\end{array}$ & Low risk & $\begin{array}{l}\text { Treatment providers not blinded but cluster randomisation means little } \\
\text { chance of contamination. }\end{array}$ \\
\hline Blinding of participants & High risk & Participants were not blinded. \\
\hline $\begin{array}{l}\text { Blinding of outcome as- } \\
\text { sessment (detection bias) } \\
\text { All outcomes }\end{array}$ & Low risk & $\begin{array}{l}\text { "Researchers conducting } 6 \text { and } 12 \text { month follow up were blinded to the partic- } \\
\text { ipants allocated treatment condition and efforts were made to prevent partici- } \\
\text { pants from inadvertently revealing the intervention they received" (p. 3). }\end{array}$ \\
\hline $\begin{array}{l}\text { Incomplete outcome data } \\
\text { (attrition bias) } \\
\text { All outcomes }\end{array}$ & High risk & Loss to follow-up $>30 \%$. \\
\hline $\begin{array}{l}\text { Selective reporting (re- } \\
\text { porting bias) }\end{array}$ & Low risk & Outcomes specified in methods were reported. \\
\hline
\end{tabular}

\section{Désy 2010}

Methods Parallel RCT: SBIRT versus usual care.

ITT: no.

Participants Setting: USA; emergency department.

Participants: $\geq 18$ years presenting to emergency department with non life-threatening injuries; excluded due to age, language, level of consciousness or acuity; screened with NIAA quantity/frequency questions and CAGE.

Number randomised $=94 ; 60 \%$ male; mean age 39 years, age range 19 to 69 years; $77 \%$ White, $13 \%$ African American, $9 \%$ Hispanic, $1 \%$ Other ethnicity; education and employment status not reported. Baseline data not reported for total sample.

Interventions

SBIRT group ( $N=49)$ received one session of 5 to 10 minutes of motivational counselling from an emergency department staff nurse, plus educational brochures and a list of community resources where further intervention and treatment could be sought, plus special discharge instructions that provided resources for follow-up care and community services appropriate to their alcohol use risk level. Control group $(\mathrm{N}=42)$ received usual care. 
Désy 2010 (Continued)

Outcomes

Mean number of drinks per week, mean drinking days per week, per cent with recurring emergency department visits.

Assessed at 3 months.

\begin{tabular}{ll}
\hline Funding source & This work was supported by a grant from the National Highway Traffic Administration. \\
\hline Declaration of interests & Not reported. \\
\hline Notes & Loss to follow-up: \\
& SBIRT group: $23 / 49(47 \%)$. \\
& Control group: $22 / 42(52 \%)$.
\end{tabular}

\section{Risk of bias}

\begin{tabular}{|c|c|c|}
\hline Bias & Authors' judgement & Support for judgement \\
\hline $\begin{array}{l}\text { Random sequence genera- } \\
\text { tion (selection bias) }\end{array}$ & Low risk & $\begin{array}{l}\text { "Before the start of the study, subject numbers were computer generated in } \\
\text { blocks of } 100 \text { " (p. 541). }\end{array}$ \\
\hline $\begin{array}{l}\text { Allocation concealment } \\
\text { (selection bias) }\end{array}$ & Unclear risk & $\begin{array}{l}\text { "Before the start of the study, subject numbers were... placed in sequentially } \\
\text { numbered sealed enrolment packets" (p. 541). }\end{array}$ \\
\hline $\begin{array}{l}\text { Blinding of treatment } \\
\text { providers }\end{array}$ & Low risk & $\begin{array}{l}\text { "Nurses... were blinded to the group assignment for all study subjects" (p. } \\
\text { 541). }\end{array}$ \\
\hline Blinding of participants & High risk & $\begin{array}{l}\text { Participants were not blinded, screening questions concern alcohol consump- } \\
\text { tion (National Institute on Alcohol Abuse and Alcoholism quantity and fre- } \\
\text { quency questions and the CAGE questionnaire). }\end{array}$ \\
\hline $\begin{array}{l}\text { Blinding of outcome as- } \\
\text { sessment (detection bias) } \\
\text { All outcomes }\end{array}$ & Unclear risk & Not reported. \\
\hline $\begin{array}{l}\text { Incomplete outcome data } \\
\text { (attrition bias) } \\
\text { All outcomes }\end{array}$ & High risk & $\begin{array}{l}\text { Loss to follow-up was high compared to other studies, although participants } \\
\text { commonly considered 'hard-to-reach' (such as homeless or non-local people) } \\
\text { were not excluded. }\end{array}$ \\
\hline $\begin{array}{l}\text { Selective reporting (re- } \\
\text { porting bias) }\end{array}$ & Low risk & Outcomes specified in methods were reported. \\
\hline
\end{tabular}

Díez 2002

\begin{tabular}{ll}
\hline Methods & Parallel RCT: brief intervention versus control. \\
ITT: unclear. & \\
\hline Participants & Setting: Spain, recruited from university hospital or urban general practice or rural general practice or \\
industrial occupational health clinic. & \\
& Participants: men between 18 to 65 years with a weekly alcohol consumption of 21 to 95 units ( 1 unit \\
$=$ & $8 \mathrm{~g}) ;$ screened by an evaluation survey with drinking questions embedded with general health ques- \\
tions; excluded if alcohol dependence (defined as alcohol consumption $>95$ units per week) or psychi- \\
atric disorders. \\
Number randomised = $1022 ; 100 \%$ male; mean age 42.4 years (of those evaluated not randomised). \\
At baseline: mean weekly consumption $=47.1$ units; $\%$ risk drinkers ( $>35$ units/wk) $=62 \%$.
\end{tabular}


Díez 2002 (Continued)

Interventions Intervention group $(\mathrm{N}=592)$ received the evaluation survey (10 minutes) plus a self-help manual containing methods to evaluate their drinking and its effects on their lifestyle, and guidelines for consumption, with an extra 10 minutes of advice and explanation of the manual

Control group $(\mathrm{N}=430)$ received the evaluation survey only (10 minutes), with no comment or advice.

Weekly alcohol consumption; per cent at-risk drinkers ( $>35$ units per week); all reported by setting
at six months for the university hospital, urban general practice, and rural general practice, and 12
months for the industrial occupational health clinic.
months for the industrial occupational health clinic.

\begin{tabular}{ll}
\hline Funding source & Not reported. \\
\hline Declaration of interests & Not reported. \\
\hline Notes & Loss to follow-up: \\
& Intervention group: $111 / 592(19 \%)$. \\
& Control group: $84 / 430(20 \%)$. \\
& Extracted data for C Urbano and C Rural groups only, others were not based in primary health care. \\
& Loss to follow-up for these two groups: \\
& Intervention group: $49 / 255(19 \%)$. \\
& Control group: 43/229 (19\%). \\
\hline
\end{tabular}

\section{Risk of bias}

\begin{tabular}{|c|c|c|}
\hline Bias & Authors' judgement & Support for judgement \\
\hline $\begin{array}{l}\text { Random sequence genera- } \\
\text { tion (selection bias) }\end{array}$ & Unclear risk & $\begin{array}{l}\text { Random allocation was performed by order of entering the study, controlling } \\
\text { by age (p. 17). }\end{array}$ \\
\hline $\begin{array}{l}\text { Allocation concealment } \\
\text { (selection bias) }\end{array}$ & Unclear risk & Not reported. \\
\hline $\begin{array}{l}\text { Blinding of treatment } \\
\text { providers }\end{array}$ & High risk & Not blinded; no reported attempt to reduce bias. \\
\hline Blinding of participants & High risk & Not blinded; no reported attempt to reduce bias. \\
\hline $\begin{array}{l}\text { Blinding of outcome as- } \\
\text { sessment (detection bias) } \\
\text { All outcomes }\end{array}$ & Unclear risk & Not reported. \\
\hline $\begin{array}{l}\text { Incomplete outcome data } \\
\text { (attrition bias) } \\
\text { All outcomes }\end{array}$ & Low risk & Loss to follow-up is reported with reasons. \\
\hline $\begin{array}{l}\text { Selective reporting (re- } \\
\text { porting bias) }\end{array}$ & Low risk & Outcomes specified in methods are reported. \\
\hline
\end{tabular}

\section{Ettner 2014}

Methods Cluster RCT: brief intervention plus telephone boosters versus usual care.

ITT: yes.

Participants

Setting: USA, primary care clinic. 
Ettner 2014 (Continued)

Participants: aged $>60$ years invited by letter, who had consumed at least one alcoholic beverage in the past three months and was physically and cognitively well enough to participate; excluded if severe cognitive impairment, or terminally ill or deceased, or residing in a skilled nursing facility, or moving out of the area in the next year, or did not speak English, or no longer a patient of the physician, or did not drink alcohol; patients could also be excluded at the discretion of the physician; screened with CARET (an updated and revised version of the Alcohol-Related Problems Survey).

Number randomised $=1186 ; 66 \%$ male; $96 \%$ White, $<1 \%$ Black, $<1 \%$ Asian/Pacific, $1.4 \%$ American Indian; $3 \%$ less than high school, $10 \%$ high school graduate, $27 \%$ some college, $25 \%$ college graduate, $35 \%$ graduate degree.

At baseline: mean drinks per week $=13.6$ (SD 8.0).

Interventions

Intervention group $(\mathrm{N}=546)$ received a mailed personalised patient report, an educational booklet on alcohol and aging, a drinking diary to track alcohol consumption, and, depending on the individual patient's reported alcohol-associated risks (as identified on the CARET screening tool), up to 13 'tip sheet$s^{\prime}$ (e.g. on drinking sensibly, sleep, preventing falls and fractures, gout, etc.). Their physician received a copy of the patient report attached to the front of the patient's notes, and used it in the patient's appointment to discuss the patient's drinking and associated risks, and to advice them to reduce consumption if appropriate. Patients then received telephone calls from a health educator who answered questions about the written materials and engaged in the following five steps: (a) assessment and direct feedback; (b) negotiation and goal setting; (c) behavioural modification techniques; (d) self-helpdirected bibliotherapy, and; (e) follow-up and reinforcement.

Control group $(\mathrm{N}=640)$ received usual care, which could include alcohol-related advice.

Outcomes At-risk drinking, drinks per week, recollection of alcohol-related discussions, health care utilisation, costs.

Funding source

This project was funded by National Institute on Alcohol Abuse and Alcoholism (NIAAA) Grant 1RO1AA013990 (Principal investigator: Susan L. Ettner). Alison A. Moore's time was additionally supported by NIAAA Grants R01 AA15957 and K24 AA15957 (Principal investigator: Alison A. Moore). O. Kenrik Duru's time was supported by National Institute on Aging Grants 5P30AG021684-12 and 5K08AG033630-05.

\begin{tabular}{ll}
\hline Declaration of interests & Conflict of interest: all authors declared no potential conflicts of interest. \\
\hline Notes & Project SHARE. \\
& Loss to follow-up at 12 months: \\
& Intervention group: $107 / 546(20 \%)$. \\
& Control group: $30 / 640(5 \%)$.
\end{tabular}

\section{Risk of bias}

Bias Authors' judgement Support for judgement

Random sequence genera- Low risk tion (selection bias)

\begin{abstract}
"We aimed to match each participating physician to another with the same specialty and clinic site. Physicians from each of the matched pairs were randomly assigned by a statistician who drew random numbers from a uniform $[0,1]$ distribution for the pair; the physician having the lower number was assigned to the intervention group. The patient's treatment assignment was then based on the random assignment of the patient's primary care physician" (p. 448).
\end{abstract}

Allocation concealment $\quad$ Low risk
(selection bias)


Ettner 2014 (Continued)

$\begin{array}{ll}\begin{array}{l}\text { Blinding of treatment } \\ \text { providers }\end{array} & \text { "Randomisation at the level of participating physicians was used so that physi- } \\ \text { cians would not see patients in both the intervention and control arms of the } & \text { study, thereby avoiding contamination effects" (p. 448). }\end{array}$

\begin{tabular}{lll}
\hline Blinding of participants & High risk & Not blinded; no reported attempt to reduce bias. \\
\hline $\begin{array}{ll}\text { Blinding of outcome as- } \\
\text { sessment (detection bias) }\end{array}$ & Low risk & $\begin{array}{l}\text { "Research assistants, blinded to treatment allocation, entered all data collect- } \\
\text { ed" (p. 448). }\end{array}$ \\
All outcomes & \\
\hline
\end{tabular}

Incomplete outcome data Unclear risk

Loss to follow-up is reported with reasons, but big differential between arms.

(attrition bias)

All outcomes

Selective reporting (re- Low risk $\quad$ Outcomes specified in methods were reported.
porting bias)

\section{Fernández 1997}

\begin{tabular}{ll}
\hline Methods & Parallel RCT: brief intervention versus control. \\
& ITT: unclear. \\
\hline Participants & Setting: Spain, general practice. \\
& Participants: Men aged 18 to 64 years consuming $>21$ International Units per week; screened by alcohol \\
& consumption questionnaires; excluded if other drug consumption or psychiatric disorders or previous \\
attendance at specialised alcohol dependence programs & Number randomised $=152 ; 100 \%$ male; mean age $=40.3$ years; $73.5 \%$ employed, $15.9 \%$ unemployed, \\
& $8.6 \%$ retired, $2.0 \%$ studying; $1.3 \%$ higher education level, $17.8 \%$ standard, $78.9 \%$ lower.
\end{tabular}

\begin{tabular}{ll}
\hline Interventions & $\begin{array}{l}\text { Intervention group }(\mathrm{N}=67) \text { received } 10 \text { minutes counselling backed up by didactic material } \\
\text { Control group }(\mathrm{N}=85) \text { received no intervention. }\end{array}$ \\
\hline Outcomes & $\begin{array}{l}\text { Number of participants with weekly intake } \geq 35 \text { IU at } 6 \text { to } 18 \text { months; number of participants with week- } \\
\text { ly intake } \geq 21 \text { IU at } 6 \text { to } 18 \text { months. }\end{array}$ \\
\hline Funding source & $\begin{array}{l}\text { Este studio ha sido financiado parcialmente por la ayuda de investigacion FIS 94/0179 [This study was } \\
\text { funded partially by the help of FIS 94/0179 research]. }\end{array}$ \\
\hline Declaration of interests & Not reported. \\
\hline Notes & $\begin{array}{l}\text { Loss to follow-up: } \\
\text { Intervention group: } 29 / 67(43 \%) . \\
\text { Control group: } 35 / 85(41 \%) .\end{array}$ \\
\hline
\end{tabular}

\section{Risk of bias}

\begin{tabular}{lll}
\hline Bias & Authors' judgement & Support for judgement \\
\hline $\begin{array}{l}\text { Random sequence genera- } \\
\text { tion (selection bias) }\end{array}$ & Low risk & Block randomisation (p. 128). \\
\hline $\begin{array}{l}\text { Allocation concealment } \\
\text { (selection bias) }\end{array}$ & High risk & Doctor carried out allocation at the appointment (p. 128). \\
\hline
\end{tabular}


Fernández 1997 (Continued)

$\begin{array}{ll}\begin{array}{l}\text { Blinding of treatment } \\ \text { providers }\end{array} & \text { Unclear risk } \\ \end{array}$

Blinding of participants High risk No reported attempt to blind participants.

Blinding of outcome as- Low risk The nurse who performed the assessment was unaware of allocation (p. 129).

sessment (detection bias)

All outcomes

Incomplete outcome data High risk $\quad$ Loss to follow-up $>30 \%$.
(attrition bias)

All outcomes

Selective reporting (re- Low risk porting bias)

Outcomes specified in methods are reported.

Field 2010

Methods Parallel RCT: brief motivational intervention versus treatment as usual + assessment.

ITT: unclear.

Participants Setting: USA, trauma unit.

Participants: Aged $\geq 18$ years who presented with an injury, demonstrated orientation to person, place and time, and identified themselves as white, Hispanic or black, screened with stepwise procedure: (i) clinical indication of acute intoxication or alcohol use or positive blood alcohol concentration; (ii) self-reported drinking six hours prior to injury; (iii) at-risk drinking as per NIAAA guidelines ( 7 drinks per week for women, 14 drinks per week for men; > 4 drinks per day in men, > 3 drinks per day in women); (iv) positive on CAGE questionnaire, 40 minute assessment procedure; excluded if they spoke neither English nor Spanish, or no identifiable residence, or under arrest or in police custody at admission, or actively suicidal or psychotic, or victims of sexual assault, or their medical condition precluded face-toface interview, or Glasgow Coma Score $\geq 14$ that did not resolve prior to discharge.

Number randomised $=1493 ; 82 \%$ male; mean age of total sample not reported; $45 \%$ White, $19 \%$ Black, $36 \%$ Hispanic.

Interventions

BMI group ( $N=737$ ) received brief motivational intervention lasting 15 minutes from a trained health educator; the primary components consist of acknowledging the patient's responsibility for changing drinking, encouraging the patient to explore the pros and cons of drinking, assessing importance, confidence and readiness to change drinking behaviour, reinforcing the patient's sense of self-efficacy and providing support for any efforts or intention to quit drinking or reduce harm associated with drinking, including injury.

TAU + group ( $\mathrm{N}=756)$ received treatment as usual, which included referral to a drug and alcohol counsellor or other appropriate hospital services, and a patient handout regarding the effect of alcohol.

\section{Outcomes}

Volume consumed per week, maximum amount consumed per occasion, percentage days abstinent, percentage days heavy drinking.

Assessed at 6 and 12 months.

Funding source

This work was supported by a grant (R01 013824; principle investigator: R. Caetano) from the National Institute on Alcohol Abuse and Alcoholism to the University of Texas School of Public Health. The lead author would like to acknowledge the support of the NIH Health Disparities Loan Repayment Program funded by the National Center of Minority Health and Health Disparities. 
Field 2010 (Continued)

Declaration of interests Declarations of interest: none.

Notes MARIA study

USD 25 for baseline assessment and USD 50 for 6 month and 12 month follow-up assessments

Loss to follow-up:

BMI: 317/737 (43.0\%).

TAU+: 309/756 (40.9\%).

\section{Risk of bias}

\begin{tabular}{|c|c|c|}
\hline Bias & Authors' judgement & Support for judgement \\
\hline $\begin{array}{l}\text { Random sequence genera- } \\
\text { tion (selection bias) }\end{array}$ & Low risk & $\begin{array}{l}\text { "Randomised... using a permuted block design (block size } 6 \text { ) to ensure ap- } \\
\text { proximately equal distribution of patients according to their race/ethnici- } \\
\text { ty" (Field 2010, p. 65). }\end{array}$ \\
\hline $\begin{array}{l}\text { Allocation concealment } \\
\text { (selection bias) }\end{array}$ & Low risk & $\begin{array}{l}\text { "Study clinicians were blinded to patient randomisation prior to completion } \\
\text { of baseline assessment. Treatment assignment was generated offsite and was } \\
\text { provided to study clinicians in sealed opaque envelopes" (Roudsari 2009, p. } \\
\text { 287). }\end{array}$ \\
\hline $\begin{array}{l}\text { Blinding of treatment } \\
\text { providers }\end{array}$ & High risk & $\begin{array}{l}\text { Although study clinicians were blinded to patient randomisation prior to com- } \\
\text { pletion of the baseline assessment, they then had contact with both arms } \\
\text { (Field 2010, p. 65). }\end{array}$ \\
\hline Blinding of participants & High risk & No reported attempt to blind participants. \\
\hline $\begin{array}{l}\text { Blinding of outcome as- } \\
\text { sessment (detection bias) } \\
\text { All outcomes }\end{array}$ & Low risk & $\begin{array}{l}\text { "Research staff blind to treatment assignment conducted follow-up assess- } \\
\text { ments" (Field 2010, p. 66). }\end{array}$ \\
\hline $\begin{array}{l}\text { Incomplete outcome data } \\
\text { (attrition bias) } \\
\text { All outcomes }\end{array}$ & High risk & Loss to follow-up $>30 \%$. \\
\hline $\begin{array}{l}\text { Selective reporting (re- } \\
\text { porting bias) }\end{array}$ & High risk & $\begin{array}{l}\text { Authors specified typical quantity consumed as a primary outcome but did not } \\
\text { report these data. }\end{array}$ \\
\hline
\end{tabular}

Fleming 1997

Methods Parallel RCT: brief physician advice versus health booklet control.

ITT: only in 1 sub analysis paper.

Participants

Setting: USA.

Participants: patients with regularly scheduled physician appointments, aged 18 to 65 years, consuming $>14$ drinks per week for men and $>11$ drinks per week ( 1 drink $=8 \mathrm{~g}$ ) for women; screened by health screening survey provided by reception personnel containing four sets of parallel questions on exercise, smoking, weight and alcohol use; excluded if pregnant, under 18 , over 65 , had attended an alcohol treatment program in previous year, reported symptoms of alcohol withdrawal in previous year, advice in previous three months from GP to change alcohol use, consumption $>50$ drinks per week, reported symptoms of suicide. 
Fleming 1997 (Continued)

Number randomised = 774; (following numbers are for those assessed): $62 \%$ male; $92 \%$ White, $1 \%$ Hispanic, $4 \%$ African American, $3 \%$ other; $41 \%$ high school or less, $40 \%$ some college, $20 \%$ college degree or more.

At baseline: mean consumption in previous seven days $=19.0$ drinks; number of binge drinking episodes (defined as $>5$ drinks for men or $>4$ drinks for women on one occasion) in previous 30 days $=5.5$; binge drinkers in previous 30 days $=78 \%$; excessive drinkers (defined as $>20$ drinks per week for men or $>13$ drinks per week for women) in previous 7 days $=43 \%$.

Intervention group ( $\mathrm{N}=392)$ received booklet on general health issues, and scheduled to see their per-
sonal physician for two 15 minute advice sessions (one brief intervention and one reinforcement ses-
sion) one month apart, and a workbook containing feedback regarding current health behaviours, re-
view of prevalence of problem drinking, adverse effects of alcohol, worksheet on drinking cues, drink-
ing agreement and diary cards (based on MRC trial). Participants received a follow-up telephone call
from the clinic nurse two weeks after each meeting with GP.
Control group $(\mathrm{N}=382)$ received a health booklet on general health issues, instructed to address
health concerns in their usual manner.

\begin{tabular}{ll}
\hline Outcomes & Mean drinks in previous seven days; binge drinking (defined as $>5$ drinks for men or $>4$ drinks for \\
women on one occasion); excessive drinking (defined as $>20$ drinks per week for men or $>13$ drinks per \\
week for women); assessed at 6 and 12 months (further paper gives 48 month data); health care utili- \\
sation (hospital days and emergency department visits), changes in health status (smoking status, de- \\
pression, motor vehicle crashes, unintentional injuries).
\end{tabular}

Funding source

This work was supported by grant AA 08512-01A from the National Institutes of Health, National Institute on Alcohol Abuse and Alcoholism, and was assisted by the Wisconsin Research Network, Madison, and the Wisconsin Institute of Family Medicine, Milwaukee.

\begin{tabular}{ll}
\hline Declaration of interests & Not reported. \\
\hline Notes & TrEAT trial \\
& Participants paid USD 50, practices paid USD 300. \\
& Loss to follow-up: \\
& Intervention group $=39 / 392(10 \%)$. \\
& Control group $=12 / 382(3 \%)$. \\
& Separate papers on 48 month data; cost-benefit analysis; subgroup analysis of women of childbearing \\
& age; subgroup analysis of young adults. \\
\hline
\end{tabular}

\section{Risk of bias}

\begin{tabular}{|c|c|c|}
\hline Bias & Authors' judgement & Support for judgement \\
\hline $\begin{array}{l}\text { Random sequence genera- } \\
\text { tion (selection bias) }\end{array}$ & Low risk & Computer generated random sequence (p. 1040). \\
\hline $\begin{array}{l}\text { Allocation concealment } \\
\text { (selection bias) }\end{array}$ & Low risk & Physicians were not told which of their patients were in control group. \\
\hline $\begin{array}{l}\text { Blinding of treatment } \\
\text { providers }\end{array}$ & Low risk & $\begin{array}{l}\text { Researchers carried out baseline assessment; physicians (treatment providers) } \\
\text { only saw the intervention participants and were not told which patients were } \\
\text { in the control group, therefore little chance of contamination. }\end{array}$ \\
\hline Blinding of participants & Low risk & $\begin{array}{l}\text { "The survey was designed as a general lifestyle questionnaire to... minimise } \\
\text { the intervention effect of the alcohol questions" (p. 1040). }\end{array}$ \\
\hline $\begin{array}{l}\text { Blinding of outcome as- } \\
\text { sessment (detection bias) } \\
\text { All outcomes }\end{array}$ & Low risk & $\begin{array}{l}\text { Follow-up included telephone interview by researcher not assigned to sub- } \\
\text { ject's clinic (p. 1040). }\end{array}$ \\
\hline
\end{tabular}


Fleming 1997 (Continued)

Incomplete outcome data Unclear risk Loss to follow-up 10\% in intervention group and 3\% in control group. (attrition bias)

All outcomes

Selective reporting (re- Low risk Outcomes specified in methods were reported.
porting bias)

\section{Fleming 1999}

\section{Methods}

Parallel RCT: physician delivered counselling versus health booklet.

ITT: yes.
Setting: USA, primary care clinic.

Participants: patients $>65$ years with regularly scheduled appointments at community based primary health care clinics; consuming $>11$ drinks for men or $>8$ drinks ( 1 drink $=8 \mathrm{~g}$ ) per week for women, or $\geq 2$ positive responses to CAGE, or binge drinking (defined as $\geq 4$ drinks per occasion for men two or more times in the last three months, or $\geq 3$ drinks per occasion for women); screened using modified Health Screening Survey; baseline assessment 30 minute face-to-face interview in primary care clinic conducted by trained researcher; excluded if attendance at an alcohol treatment programme or reported symptoms of alcohol withdrawal in the last year, or physician advice received in previous three months to change alcohol use, or consumption > 50 drinks per week, or reported thoughts of suicide. Number randomised $=158 ; 66 \%$ male; age range $=65$ to 75 years; $26 \%$ college educated At baseline: mean weekly alcohol consumption = 16.0 drinks; mean binge drinking episodes (defined as $\geq 4$ drinks per occasion for men or $\geq 3$ for women) in previous 30 days $=3.7$; binge drinkers in previous 30 days $=44.9 \%$; excessive drinkers (defined as $>20$ drinks per week for men and $>13$ for women) in previous seven days $=29.7 \%$.

Interventions Intervention group $(\mathrm{N}=87)$ received general health booklet, scheduled to see their personal physicians for two 10 to 15 minute sessions one month apart (1 brief intervention, 1 reinforcement session) received follow-up phone call from nurse two weeks after each session and a workbook containing feedback on patients health behaviours, review of problem drinking prevalence, reasons for drinking, adverse consequences of alcohol, drinking agreement, drink diary cards. Used same protocols as Medical Research Council trial and Project TrEAT

Control group $(\mathrm{N}=71)$ received a general health booklet only.

Outcomes

Mean drinks in previous seven days; binge drinking episodes (defined as $>4$ drinks per occasion for men or $>3$ for women) in previous 30 days; percentage of participants binge drinking in previous 30 days; percentage of participants drinking excessively (defined as $>20$ drinks per week for men and $>13$ for women) in previous seven days.

Assessed at 3, 6, 12 months.

Funding source

This work was supported by NIAA grant 3R01 AA08512-0351, the American Academy of Family Physicians, and the Dean Foundation for Health Research and Education.
Notes GOAL trial

Physicians paid USD 250.

Loss to follow-up:

Intervention group: 9/87 (9\%).

Control group: $4 / 71(6 \%)$.

\section{Risk of bias}


Fleming 1999 (Continued)

\begin{tabular}{lll} 
Bias & Authors' judgement & Support for judgement \\
\hline $\begin{array}{l}\text { Random sequence genera- } \\
\text { tion (selection bias) }\end{array}$ & Unclear risk & Not reported. \\
\hline $\begin{array}{l}\text { Allocation concealment } \\
\text { (selection bias) }\end{array}$ & Low risk & Physicians were not told which of their patients were in control group (p. 379). \\
\hline
\end{tabular}

\begin{tabular}{|c|c|c|}
\hline $\begin{array}{l}\text { Blinding of treatment } \\
\text { providers }\end{array}$ & Low risk & $\begin{array}{l}\text { Researchers carried out baseline assessment; physicians (treatment providers) } \\
\text { only saw the intervention participants and were not told which patients were } \\
\text { in the control group, therefore little chance of contamination. }\end{array}$ \\
\hline Blinding of participants & Low risk & $\begin{array}{l}\text { Patients completed a modified Health Screening Survey with alcohol ques- } \\
\text { tions embedded. }\end{array}$ \\
\hline $\begin{array}{l}\text { Blinding of outcome as- } \\
\text { sessment (detection bias) } \\
\text { All outcomes }\end{array}$ & Low risk & $\begin{array}{l}\text { Follow-up telephone interviews done by physician not linked to patient's clinic } \\
\text { (p. 379). }\end{array}$ \\
\hline $\begin{array}{l}\text { Incomplete outcome data } \\
\text { (attrition bias) } \\
\text { All outcomes }\end{array}$ & Low risk & Loss to follow-up is reported with reasons. \\
\hline $\begin{array}{l}\text { Selective reporting (re- } \\
\text { porting bias) }\end{array}$ & Low risk & Outcomes specified in methods are reported. \\
\hline
\end{tabular}

Fleming 2004

Methods Parallel RCT: brief primary care clinician advice versus usual care.

ITT: yes.

Participants

Setting: USA, primary care clinics.

Participants: Aged 30 to 60 years who were on medication for diabetes or hypertension with CDT level $>2.5 \%$, or $\geq 50$ drinks in the previous 30 days for men or $\geq 30$ for women; identified by patient database search, screened by medical records review and telephone interview; baseline interview conducted at clinic participating in the study excluded if current symptoms of alcohol withdrawal, or participation in alcohol treatment programme in previous 12 months; recruited from existing study of \%CDT test in 8 primary care clinics.

Number randomised $=151 ; 45 \%$ male; mean age $=48.7$ years; $88 \%$ white, $8 \%$ black, $4 \%$ other; high school or less $=41 \%$, college degree $=21 \%$, technical degree $=18 \%$, advanced degree $=19 \%$.

At baseline: current alcohol abuse $=7.3 \%$, current alcohol dependence $=9.9 \%$, mean drinks in previous 30 days $=33.2$, percentage heavy drinkers (defined as $\geq 30$ drinks in previous 30 days for men or $\geq 25$ for women) $=39.1 \%$, mean frequency of binge drinking (defined as $\geq 5$ drinks in one occasion for men or $\geq$ 4 for women) in previous 30 days $=2.6$.

Interventions

Intervention group ( $\mathrm{N}=81$ ) received two 15 minute sessions (one month apart) from nurse practitioners or physician assistants and two five minute follow-up phone calls from the office nurse. Sessions (based on TrEAT) followed a scripted workbook reviewing prevalence of problem drinking, adverse effects of alcohol, \%CDT test result, drinking diary cards and a drinking agreement in the form of a prescription.

Control group $(\mathrm{N}=70)$ received a general health booklet and were told by the researcher to contact the physician with any health concerns.

Outcomes

Mean percentage of heavy drinkers, mean drinks in previous 30 days, mean frequency of binge drinking, proportion of subjects who reduced \%CDT. 
Fleming 2004 (Continued)

Assessed at two months, four months and 12 months with change scores reported.

Funding source This study was funded by Axis Shield (CT-C0003), by the National Institute on Alcohol Abuse and Alcoholism (R01 AA8512-03) and by grants from the Department of Family Medicine, University of Wisconsin. [Axis Shield: "A pioneering organisation focused on the development and manufacturing of important and innovative in vitro diagnostic tests for use in clinical laboratories"].

\begin{tabular}{ll}
\hline Declaration of interests & Not reported. \\
\hline Notes & Loss to follow-up at 12 months: \\
& Intervention group: $11 / 92(12 \%)$. \\
& Control group: $5 / 75(7 \%)$. \\
\hline
\end{tabular}

\section{Risk of bias}

\begin{tabular}{|c|c|c|}
\hline Bias & Authors' judgement & Support for judgement \\
\hline $\begin{array}{l}\text { Random sequence genera- } \\
\text { tion (selection bias) }\end{array}$ & Unclear risk & Method of sequence generation not reported. \\
\hline $\begin{array}{l}\text { Allocation concealment } \\
\text { (selection bias) }\end{array}$ & Unclear risk & Allocation concealment not reported. \\
\hline $\begin{array}{l}\text { Blinding of treatment } \\
\text { providers }\end{array}$ & Low risk & $\begin{array}{l}\text { Nurse practitioners or physician assistants carried out the brief intervention } \\
\text { but had no contact with control patients, so little chance of contamination. }\end{array}$ \\
\hline Blinding of participants & High risk & Participants not blinded (p. 632). \\
\hline $\begin{array}{l}\text { Blinding of outcome as- } \\
\text { sessment (detection bias) } \\
\text { All outcomes }\end{array}$ & Low risk & Data were collected by a researcher blind to group assignment (p. 632). \\
\hline $\begin{array}{l}\text { Incomplete outcome data } \\
\text { (attrition bias) } \\
\text { All outcomes }\end{array}$ & Unclear risk & Loss to follow-up is reported but not reasons. \\
\hline $\begin{array}{l}\text { Selective reporting (re- } \\
\text { porting bias) }\end{array}$ & Low risk & Outcomes specified in methods are reported. \\
\hline
\end{tabular}

Fleming 2010

\begin{tabular}{ll}
\hline Methods & Parallel RCT: brief intervention versus health booklet. \\
& ITT: yes. \\
\hline Participants & Setting: USA, college primary care clinics. \\
& Participants: $\geq 18$ years, presenting at student health centre and reporting $>50$ drinks or $\geq 8$ heavy \\
drinking episodes in previous 28 days ( $\geq 5$ standard $14 \mathrm{~g}$ drinks) for men, or $>40$ drinks or $\geq 6$ heavy \\
drinking episodes ( $\geq 4$ standard $14 \mathrm{~g}$ drinks) for women in the previous 28 days, screened with gener- \\
al lifestyle questionnaire containing alcohol consumption questions, received 30 to 45 minutes assess- \\
ment; excluded if pregnant, or had attended an alcohol-treatment program in the previous year, or re- \\
ported symptoms of alcohol withdrawal in the last 12 months, or received advice from their physician \\
in the previous three months to change their alcohol use, or drank more than 200 drinks in the previous \\
28 days, or reported symptoms of suicide.
\end{tabular}


Fleming 2010 (Continued)

Number randomised $=986 ; 49 \%$ male; mean age 21 years; $91 \%$ White; $19 \%$ freshman, $17 \%$ sophomore, $22 \%$ junior, $26 \%$ senior, $16 \%$ graduate.

Baseline characteristics for total sample not reported.

Interventions

BI group ( $N=493$ ) received two 15 to 20 minute face to face brief intervention sessions one month apart from a trained physician or nurse practitioner. The first reviewed the participant's current health habits and put self-reported alcohol use at the baseline in a normative context of peer drinking rates and consequences, and examined the subject's expectancies of alcohol use. In addition, the clinician discussed the subject's peak BAC and its consequences, pointed to the financial costs associated with abusive drinking and estimated alcohol calories consumed while drinking. The clinician facilitated the subject's contemplation of his/her life goals and how they would be affected by changes in alcohol use. The student's readiness to change was evaluated and a plan to reduce alcohol consumption was formulated. Subjects were offered drinking cards as a way to self-monitor drinking rates. In addition, three work sheets titled 'Identify Reasons to Make Drinking Changes,' 'Strategies to Success' and 'Alcohol and Decision-Making' were offered to students to consider at home. The second visit reviewed drinking since the first visit and discussed work sheets taken home after the first intervention. The clinician explored the subject's discrepancy between goals and drinking behaviour and ambivalence about drinking change, and focused on harms reduction and alternatives to drinking. The student and the clinician agreed on goals for alcohol use, general health and career. Ways to reward oneself for cutting down on drinking were discussed. Participants received a follow-up phone call or email two weeks after the first visit and one month after the second visit. $88 \%$ completed all four parts, $8 \%$ received one physician vii sit, $4 \%$ received no physician intervention.

Control group ( $N=493$ ) received the same health booklet as the intervention group, plus usual care.

Outcomes

Mean drinks in previous 28 days, mean heavy drinking days in previous 28 days, mean drinking days in previous 28 days, percentage of subjects with at least one hospitalisation or emergency department visit or urgent care visit or admission to local detoxification unit in previous six months, mean RAPI score (Rutgers Alcohol Problem Index).

Assessed at 6 and 12 months.

\section{Funding source \\ This research was supported by National Institute on Alcohol Abuse and Alcoholism grant R01 AA014685-01 (Michael F. Fleming, principal investigator); the Child and Family Research Institute, Van- couver, British Columbia, Canada (Elizabeth M. Saewyc, principal investigator); the Michael Smith Foundation for Health Research (Elizabeth M. Saewyc, principal investigator); and the Institute for Population and Public Health, Canadian Institutes for Health Research grant CPP 86374 (Elizabeth M. Saewyc, chair in Applied Public Health).}

\section{Declaration of interests Not reported.}

Notes

CHIPs (College Health Intervention Projects) study.

USD 200 for completing the required procedures.

Loss to follow-up: $96 \%$ completed either six month or 12 month follow-up; $88 \%$ completed both.

\section{Risk of bias}

\begin{tabular}{lll}
\hline Bias & Authors' judgement & Support for judgement \\
\hline $\begin{array}{l}\text { Random sequence genera- } \\
\text { tion (selection bias) }\end{array}$ & Low risk & $\begin{array}{l}\text { Randomised using a computer-generated allocation method (separately for } \\
\text { men and women) (p. 26). }\end{array}$ \\
\hline $\begin{array}{l}\text { Allocation concealment } \\
\text { (selection bias) }\end{array}$ & Low risk & $\begin{array}{l}\text { Each clinician had control and experimental participants in his or her practice } \\
\text { with no identifiers available to recognise controls. }\end{array}$ \\
\hline
\end{tabular}


Fleming 2010 (Continued)

Blinding of treatment Low risk Researchers carried out baseline assessment; physicians (treatment providers) providers only saw the intervention participants and were not told which patients were in the control group, therefore little chance of contamination.

$\begin{array}{ll}\text { Blinding of participants Low risk } & \text { "The health screening survey was designed as a general lifestyle questionnaire } \\ \text { to increase student acceptance of the research procedures and to minimize } & \\ \text { the intervention effect of the alcohol questions" (p. 26). }\end{array}$

\begin{tabular}{|c|c|c|}
\hline $\begin{array}{l}\text { Blinding of outcome as- } \\
\text { sessment (detection bias) }\end{array}$ & Low risk & $\begin{array}{l}\text { Follow-up was carried out by researchers not assigned to the students' clinic, } \\
\text { and they were blinded to group status (p. } 26) \text {. }\end{array}$ \\
\hline
\end{tabular}

All outcomes

Incomplete outcome data Low risk Loss to follow-up is reported with reasons.
(attrition bias)

All outcomes

Selective reporting (re- Low risk

porting bias)

Outcomes specified in methods are reported.

Heather 1987

Methods Parallel RCT: Drinking Reasonably And Moderately with Self control scheme (DRAMS) versus simple advice versus non-intervention control group.

ITT: unclear.

Participants Setting: Scotland, urban teaching primary care practices.

Participants: Aged 18 to 65 years with weekly alcohol consumption $>35$ units for men or $>20$ units for women ( 1 unit $=8 \mathrm{~g}$ ), or clinical suspicion by GP of dependence; screened by health questionnaire with alcohol consumption questions embedded. Patients with high consumption or provoking clinical suspicion were given a 10-question DRAMS medical questionnaire by GP from which any positive response indicated eligibility; excluded if the Brief Edinburgh Alcohol Dependence Schedule showed evidence of late dependence, had known liver disease or severe mental illness, were receiving antidepressant medication, were of subnormal intelligence, were dependent on opiate drugs or were pregnant. Number randomised $=104 ; 75 \%$ men; mean age $=36.4$ years (range 18 to $64, S D=12.2$ ) At baseline: mean consumption in previous month $=194.4$ units; mean Michigan alcoholism score $=7.2$ $(\mathrm{SD}=5.9)$.

Interventions

\begin{abstract}
DRAMS group ( $\mathrm{N}=34$ ): DRAMS kit contained a four-page introductory leaflet for GPs, a patient record card for recording patient details, results of blood tests, self-monitored alcohol consumption and a medical questionnaire with a checklist of ten medical complications, adverse social consequences and signs of physical dependence, a two week self-monitoring drinking diary card for use by patient, a 59 page self-help book, a pocket-sized and abbreviated version of the a self-help manual for controlled drinking. Responses to 10 -item medical questionnaire were entered on the medical record card. The patient was handed the drinking diary card and asked to fill it in honestly, a follow-up consultation in two weeks was arranged. At follow-up the results of the blood tests and the drinking diary card were reviewed with the patient and if the existence of a drinking problem was confirmed, the doctor advised the patient to try to control the amount consumed. The patient was then introduced to the self help book and encouraged to decide on a realistic plan of action based on measures suggested in the book and using further diary sheets. Additional appointments were made at which the patients medical condition and progress at cutting down were reviewed, using the results of further blood tests Advice group $(\mathrm{N}=32)$ : were informed that their drinking could be harmful and were given strong advice to cut down from GP but no specific targets given and no follow-up consultations regarding their alcohol problem were arranged.
\end{abstract}


Heather 1987 (Continued)

Control group ( $\mathrm{N}=38$ ): doctor explained that the study would involve a blood test and an assessment interview, but made no specific reference to treatment or drinking and arranged no follow-up consultations in connection with their alcohol problem.

\begin{tabular}{ll}
\hline Outcomes & $\begin{array}{l}\text { Units of alcohol consumed in previous month, units of alcohol consumed in heaviest month of the pre- } \\
\text { vious six; control of drinking problems factor score; GGT and mean corpuscular volume, collaterals (in- } \\
\text { dividual known to the patient) reports of patients change in drinking. } \\
\text { Assessed at } 6 \text { months. }\end{array}$ \\
\hline Funding source & Not reported. \\
\hline Declaration of interests & Not reported. \\
\hline Notes & $\begin{array}{l}\text { DRAMS trial } \\
\text { Loss to follow-up: } \\
\text { DRAMS group: } 5 / 34(15 \%) . \\
\text { Advice group: } 2 / 32(6 \%) . \\
\text { Control group: } 6 / 38(16 \%) .\end{array}$ \\
\hline
\end{tabular}

\section{Risk of bias}

Bias Authors' judgement Support for judgement

Random sequence genera- Unclear risk Unclear how randomisation sequence was generated.
tion (selection bias)

tion (selection bias)

\begin{tabular}{lll}
\hline $\begin{array}{l}\text { Allocation concealment } \\
\text { (selection bias) }\end{array}$ & Low risk & Unclear how allocation was concealed. \\
\hline $\begin{array}{l}\text { Blinding of treatment } \\
\text { providers }\end{array}$ & High risk & Treatment providers not blinded (p. 359). \\
\hline Blinding of participants & High risk & $\begin{array}{l}\text { Patients were screened with a general health questionnaire but were told that } \\
\text { the study was about the way people's drinking changes over time (p. 359). }\end{array}$
\end{tabular}

Blinding of outcome as- Low risk The follow-up interviewers were blind to patients' study groups (p. 359).
sessment (detection bias) All outcomes

Incomplete outcome data Low risk Loss to follow-up completely recorded with reasons.
(attrition bias)

All outcomes

Selective reporting (re- Low risk $\quad$ Outcomes specified in methods are reported.
porting bias)

\section{Helstrom 2014}

\begin{tabular}{ll} 
Methods & Parallel RCT: telephone care management and standard care versus standard care. \\
& ITT: no. \\
\hline Participants & Setting: USA, primary care clinic. \\
& $\begin{array}{l}\text { Participants: those who endorsed heavy drinking over the past week ( }>21 \text { drinks for men and }>14 \\
\text { drinks per week for women or for men over the age of } 65), \text { or any episodes of binge drinking, and had }\end{array}$ \\
\hline
\end{tabular}


Helstrom 2014 (Continued)

adequate hearing to participate in scheduled telephone assessments. Screened by AUDIT-C; excluded if they reported active suicidal ideation, or had received specialised addiction treatment during the three months prior, or exhibited symptoms of alcohol dependence or repeated use of illicit drugs in the last year, or experienced current delusions or hallucinations, or had current symptoms of post-traumatic stress disorder (PTSD), or a history of mania.

Number randomised $=146 ; 98 \%$ male, mean age $=57$ years, $55 \%$ white, $37.4 \%$ employed .

At baseline: mean drinks per day $=3.2(S D=2.4)$, drinking days per week $=6$, drinks per drinking day $=$ 5.1 , binge days per month $=10(\mathrm{SD}=9.9)$.

Interventions

Telephone Care Management group (TCM, N =68) received standard care and a TCM session at three, six and nine months. The TCM intervention was based on a treatment manual developed during a pilot phase of this study and includes elements of motivational enhancement, decisional balance, education about alcohol misuse, and development of an individualised behaviour change plan. TCM is consistent with the stepped care model. Behavioural health specialists, two nurses trained in motivational approaches to substance use and brief interventions for addictions, maintained regularly scheduled telephone contact to develop a treatment plan, monitor treatment effectiveness and adverse effects, assess and encourage treatment adherence, and offer support and education. The content of individual sessions included alcohol use monitoring, support and education, and individualised education about at-risk drinking and information about common comorbidities (e.g., depressive symptoms). The TCM manual also includes the use of an addiction management algorithm, that is, a telephone adaptation of a brief intervention developed in previous studies. The algorithm provides guidelines for clinical decision making regarding referral to specialty addictions treatment when needed (e.g. following a significant increase in alcohol use) and close collaboration with the patient's physician. Workbooks logging treatment goals and progress were mailed to participants after each session.

Standard care (SC, $N=71$ ) group received information and brief advice about the risks associated with alcohol misuse and suggestions to decrease alcohol use. Also received a letter informing them of recommended drinking limits and a description of standard drinks, as is standard practice for all patients endorsing heavy drinking during the assessment.

Outcomes

Drinks per day, number of days drinking, drinks per drinking day, binges per month, problems due to alcohol (SIP), motivation to change.

Assessed at 4, 8 and12 months.

\begin{tabular}{ll}
\hline Funding source & Not reported. \\
\hline Declaration of interests & The authors declare no conflict of interest. \\
\hline Notes & $\begin{array}{l}\text { Loss to follow up not reported by arm. Seven could not be contacted following baseline or withdrew } \\
\text { from the study. }\end{array}$
\end{tabular}

\section{Risk of bias}

\section{Bias \\ Authors' judgement Support for judgement}

Random sequence genera- Unclear risk Method of sequence generation not reported. tion (selection bias)

\begin{tabular}{lll}
\hline $\begin{array}{l}\text { Allocation concealment } \\
\text { (selection bias) }\end{array}$ & Unclear risk & Not described. \\
\hline $\begin{array}{l}\text { Blinding of treatment } \\
\text { providers }\end{array}$ & Low risk & $\begin{array}{l}\text { Interventionist only had contact with intervention group, so low chance of } \\
\text { contamination between groups. The primary care doctor had contact with } \\
\text { both groups but was supposed to give the same advice to both, so this did not } \\
\text { affect risk of bias. }\end{array}$ \\
\hline
\end{tabular}

Blinding of participants High risk Not blinded; no reported attempt to reduce bias.


Helstrom 2014 (Continued)

Blinding of outcome as- Unclear risk Not blinded; no reported attempt to reduce bias. sessment (detection bias)

All outcomes

\begin{tabular}{lll}
$\begin{array}{l}\text { Incomplete outcome data } \\
\text { (attrition bias) } \\
\text { All outcomes }\end{array}$ & Unclear risk & $\begin{array}{l}\text { Loss to follow-up not described by arm and only reasons given were "unable to } \\
\text { follow-up or withdrew". }\end{array}$ \\
\hline $\begin{array}{l}\text { Selective reporting (re- } \\
\text { porting bias) }\end{array}$ & Low risk & Outcomes specified in methods are reported. \\
\hline
\end{tabular}

Huas 2002

\begin{tabular}{l} 
Methods $\begin{array}{l}\text { Cluster RCT: brief intervention versus usual care, average cluster size }=4.8 . \\
\text { ITT: unclear. }\end{array}$ \\
\hline
\end{tabular}

Petting: France, general practice.
Participants: aged 18 to 65 years who were consuming $>28$ glasses per week and on $\geq 5$ days per week;
screened by MAST and declared consumption of alcohol; excluded if MAST $\geq 3$, or history of alcohol de-
pendence, or in treatment for alcohol problems.
Number randomised $=541 ; 100 \%$ male; mean age $=51.8$ years.

$\begin{array}{ll}\text { Interventions } & \text { Intervention group (number not reported) received } 10 \text { minutes intervention focused on reducing alco- } \\ \text { hol consumption to }<28 \text { glasses per week. Patients with physical or biological symptoms were invited } \\ \text { back every three months, otherwise they returned at one year. } \\ \text { Control group (number not reported) received usual care. }\end{array}$

\begin{tabular}{ll}
\hline Outcomes & Mean drinks per week. \\
& Assessed at 1 year. \\
\hline Funding source & $\begin{array}{l}\text { Etude realise grace a un contrat CNAM-INSERM, et au soutien des laboratoires Liphia. [Study completed } \\
\text { through a CNAM-INSERM contract, and support of Liphia laboratories. CNAM=National Conservatory of } \\
\text { Arts and Trades; INSERM = National Institute of Health and Medical Research]. }\end{array}$ \\
\hline Declaration of interests & Not reported. \\
\hline Notes & Number of participants assessed $=419$, associated with 88 physicians.
\end{tabular}

\section{Risk of bias}

\begin{tabular}{lll}
\hline Bias & Authors' judgement & Support for judgement \\
\hline $\begin{array}{l}\text { Random sequence genera- } \\
\text { tion (selection bias) }\end{array}$ & Unclear risk & Not reported. \\
\hline $\begin{array}{l}\text { Allocation concealment } \\
\text { (selection bias) }\end{array}$ & Low risk & Cluster randomised. \\
\hline $\begin{array}{l}\text { Blinding of treatment } \\
\text { providers }\end{array}$ & Unclear risk & Not blinded; no reported attempt to reduce bias. \\
\hline Blinding of participants & High risk & Not blinded; no reported attempt to reduce bias. \\
\hline
\end{tabular}


Huas 2002 (Continued)

Blinding of outcome as- Unclear risk Not reported. sessment (detection bias)

All outcomes

\begin{tabular}{lll}
$\begin{array}{l}\text { Incomplete outcome data } \\
\text { (attrition bias) }\end{array}$ & Low risk & Loss to follow-up reported with reasons. \\
All outcomes & & \\
\hline $\begin{array}{l}\text { Selective reporting (re- } \\
\text { porting bias) }\end{array}$ & Low risk & Outcomes specified in methods are reported.
\end{tabular}

porting bias)

Israel 1996

Methods Parallel RCT: Cognitive behavioural counselling (extended) versus brief advice (control). ITT: no.

Participants Setting: Canada, primary care practices.

Participants: drawn from those attending clinic who answered positively to at least one of four trauma questions and consumed $\geq 90$ drinks in previous four weeks (average $>3$ drinks per day), or consumed $\geq 5$ drinks per day for $\geq 8$ days in previous four weeks, or CAGE $\geq 2$; screened by trauma questionnaire followed by alcohol consumption questionnaire followed by CAGE questionnaire; excluded if severe physical dependence on alcohol, or serum gamma glutamyl transferase (GGT) activity $>2$ standard deviations above the mean, or treatment for emotional or psychiatric problems, or regular attendance at Alcoholics Anonymous, or current substance abuse (other than alcohol).

Number randomised $=105$; age range $=30$ to 60 years.

At baseline (for those assessed): mean alcohol consumption in previous four weeks = 145.2 drinks; serum GGT $=56.9 \mathrm{U} / \mathrm{l}$.

Interventions

Brief counselling group (number not reported) received a pamphlet with guidelines for achieving abstinence or acceptable drinking, were counselled on cognitive behavioural techniques (30 minutes) to achieve abstinence or sensible drinking as their goal. Acceptable drinking was the consumption of 12 drinks per week as a maximum, provided it did not exceed four drinks (three for women) on any single day and provided that not more than one drink was consumed in one hour. Patients in this group were asked to be alcohol-free when retiring at night. Patients were given reactive strips to detect alcohol in saliva when retiring, and asked to keep records of alcohol consumption and presence or absence of alcohol in saliva on retiring. They were advised of changes in their GGT values, and the significance of the test in relation to alcohol consumption was explained. Cognitive behavioural counselling techniques were those developed by Sanchez-Craig et al for self-referred problem drinkers and were delivered by a nurse ratione recruited for study. Patients also received one 20 minute session every two months for one year, during which patients were retested for GGT before each visit and were informed of any change in values. The nurse further reviewed the strategy to achieve the patient's goal. Participants were informed of their new GGT values and their significance at each session Advice group (number not reported) received advice to reduce their consumption and were handed a pamphlet with guidelines for achieving abstinence or acceptable drinking. They were also informed of their GGT values, and the significance of the test in relation to alcohol consumption was explained.

Outcomes Mean alcohol consumption in previous four weeks; serum GGT; psychosocial problems.

Assessed at 12 months.

Declaration of interests Not reported.

Notes Loss to follow-up not recorded by treatment arm, $30 \%$ overall.


Israel 1996 (Continued)

Missing data: gender, number randomised to each arm, baseline data for all randomised participants: requested, not available.

\section{Risk of bias}

\begin{tabular}{|c|c|c|}
\hline Bias & Authors' judgement & Support for judgement \\
\hline $\begin{array}{l}\text { Random sequence genera- } \\
\text { tion (selection bias) }\end{array}$ & Low risk & Independent process. \\
\hline $\begin{array}{l}\text { Allocation concealment } \\
\text { (selection bias) }\end{array}$ & High risk & "Nurse opened a sealed envelope" (p. 1445). \\
\hline $\begin{array}{l}\text { Blinding of treatment } \\
\text { providers }\end{array}$ & High risk & Provider not blinded. \\
\hline Blinding of participants & Low risk & $\begin{array}{l}\text { Screening and baseline questionnaires were broad and not focused on alcohol } \\
\text { (p. 1445). }\end{array}$ \\
\hline $\begin{array}{l}\text { Blinding of outcome as- } \\
\text { sessment (detection bias) } \\
\text { All outcomes }\end{array}$ & Low risk & $\begin{array}{l}\text { Follow-up questionnaires were administered "by a research assistant who was } \\
\text { not aware of group assignment" (p. 1445). }\end{array}$ \\
\hline $\begin{array}{l}\text { Incomplete outcome data } \\
\text { (attrition bias) } \\
\text { All outcomes }\end{array}$ & Unclear risk & Loss to follow-up not reported by treatment arm $>30 \%$ overall. \\
\hline $\begin{array}{l}\text { Selective reporting (re- } \\
\text { porting bias) }\end{array}$ & Low risk & Outcomes specified in methods are reported. \\
\hline
\end{tabular}

Kaner 2013

Methods Cluster RCT: patient information leaflet (PIL) versus PIL plus brief advice (BA) versus PIL plus BA plus brief lifestyle counselling (BLC), average target cluster size 31.

ITT: yes.

Participants Setting: UK, primary care practices.

Participants: $\geq 18$ years, alert and oriented, resident within 20 miles of the practice, and able to understand English sufficiently to complete study questionnaires, screened with FAST (Fast Alcohol Screening Test) $\geq 3$ or positive M-SASQ (Modified Single Alcohol Screening Question); excluded if already involved in an alcohol research study, or specifically seeking help for alcohol problems, or severely injured or unwell, or had a serious mental health problem, or were grossly intoxicated, or had no fixed abode.

Number randomised = 34 clusters, 756 patients; $62 \%$ male; mean age 45 years; $92 \%$ White; $55 \%$ education post 16 years; $34 \%$ degree or equivalent professional qualification.

At baseline: mean AUDIT $=12.7$.

Interventions

The interventions were cumulative.

PIL group ( $N=251$, all received) received simple feedback on their screening outcome and a 16 page patient information leaflet ('How much is too much?') describing the effects of alcohol on health and well being, showing the number of units contained in popular alcoholic drinks, and listing two internet help sites, local alcohol treatment agencies, and details of a national Drinkline number. 
Kaner 2013 (Continued)

BA group ( $N=251,250$ received) received PIL plus five minutes of structured brief advice from practice staff based on the 'How much is too much?' BI programme. In addition to providing specific details about the health and social consequences of hazardous and harmful drinking, patients were shown a sex-specific graph, which indicated that their drinking exceeded that of most of the population, and a list of benefits that would result from reduced drinking. Thereafter, patients were taken through a menu of techniques to help reduce drinking and asked to consider a personal target for an achievable reduction in drinking.

BLC group ( $N=254,143$ received) received PIL plus $B A$ and were asked to make an appointment for a follow-up consultation within two weeks, which comprised a 20 minute session of brief lifestyle counselling from practice staff based on a condensed form of motivational interviewing called health behaviour change. The patients first described their typical drinking day and then rated the importance of changing their drinking and their confidence about changing their drinking on a ten point scale (where a higher number indicated greater importance or confidence and vice versa). The practitioner then worked with these ratings to establish why they were at the current level and how they might be increased to a higher point before eliciting both pros and cons of drinking and finally working through a six step plan to help reduce drinking levels.

Outcomes

Proportions of participants with negative AUDIT < 8 at six months; mean AUDIT scores, experience of alcohol related problems (alcohol problems questionnaire), health utility (EQ-5D), satisfaction, service utilisation, and patients' motivation to change drinking behaviour (readiness to change) as measured by a modified readiness ruler at 12 months.

Assessed at 6 and 12 months.

Funding source

EK was part funded by Fuse the Centre for Translational Research in Public Health. Fuse is a UKCRC Public Health Research Centre of Excellence, and funding comes from the British Heart Foundation, Cancer Research UK, Economic and Social Research Council, Medical Research Council, and the National Institute for Health Research. This study was funded by the Department of Health.

Declaration of interests

All authors had financial support from the Department of Health in England (Alcohol Policy Unit) for the submitted work; no financial relationships with any organisations that might have an interest in the submitted work in the previous three years; no other relationships or activities that could appear to have influenced the submitted work.

Notes SIPS trial.

Practices received GBP 3000 (staged). Screening and brief intervention was incentivised as GBP 1 per participant screened (EUR 1.26 or USD 1.85, all conversions at 2008 exchange rates), GBP 8 per brief advice, and GBP 32 per brief lifestyle counselling.

Participants received GBP 10 voucher after baseline assessment and at each follow-up interview.

Loss to follow-up:

BLC group: 51/254 (20\%).

BA group: 46/251 (18\%).

PIL group: 61/251 (24\%).

We contacted the authors, who supplied missing data.

\section{Risk of bias}

\begin{tabular}{lll}
\hline Bias & Authors' judgement & Support for judgement \\
\hline $\begin{array}{l}\text { Random sequence genera- } \\
\text { tion (selection bias) }\end{array}$ & Low risk & "Secure remote randomisation service" (p. 2). \\
\hline $\begin{array}{l}\text { Allocation concealment } \\
\text { (selection bias) }\end{array}$ & Low risk & $\begin{array}{l}\text { Cluster randomised so all patients in each practice received the same inter- } \\
\text { vention. }\end{array}$ \\
\hline \hline
\end{tabular}

Effectiveness of brief alcohol interventions in primary care populations (Review) 
Kaner 2013 (Continued)

$\begin{array}{ll}\begin{array}{l}\text { Blinding of treatment } \\ \text { providers }\end{array} & \text { Low risk } \\ & \text { one arm, so risk of contamination low. }\end{array}$

Blinding of participants High risk $\quad \begin{aligned} & \text { Screening was by alcohol tools; control group received a leaflet specifically } \\ & \text { about drinking }\end{aligned}$
about drinking.

\begin{tabular}{lll}
\hline $\begin{array}{l}\text { Blinding of outcome as- } \\
\text { sessment (detection bias) } \\
\text { All outcomes }\end{array}$ & Low risk & $\begin{array}{l}\text { Researchers who were blinded to allocated intervention contacted the partici- } \\
\text { pants (p. 3). }\end{array}$ \\
\hline $\begin{array}{l}\text { Incomplete outcome data } \\
\begin{array}{l}\text { attrition bias) } \\
\text { All outcomes }\end{array}\end{array}$ & Low risk & $\begin{array}{l}\text { To assess the impact of missing data on the primary outcome, we carried out } \\
\text { multiple imputation using the ICE procedure in STATA. }\end{array}$ \\
\hline $\begin{array}{l}\text { Selective reporting (re- } \\
\text { porting bias) }\end{array}$ & Unclear risk & $\begin{array}{l}\text { Protocol specifies proportion of patients drinking within recommended levels; } \\
\text { outcome paper says negative AUDIT. }\end{array}$ \\
\hline
\end{tabular}

\section{Kunz 2004}

Methods $\quad$ Parallel RCT: brief intervention versus health information pack.
ITT: unclear.

Setting: USA, emergency department.
Participants
previous 12 months; excluded if they received alcohol counselling in previous year, or signs of cognitive
impairment, or physically unable to take part as a consequence of medical treatment, or in police cus-
tody.
Number randomised = 294; (following data are for those assessed), $81 \%$ male; mean age $=41.7$ years;
$70 \%$ African American, $30 \%$ Hispanic; $44 \%$ high school or more education
At baseline (for those assessed): mean weekly consumption in previous three months $=34.1$ drinks;
binge drinkers in previous three months (defined as $>6$ drinks on one occasion for men and $>4$ for
women) $=92 \% ;$ mean AUDIT score $=20.1$; injured as a result of drinking in previous three months $=$
27\%.

Interventions Intervention group $(\mathrm{N}=151)$ received action plans from researchers according to their self-reported levels of readiness to change: seek more information about drinking, think more about negative consequences of drinking, or lower their drinking per day, per week and per occasion. Participants received a copy of their action plan, a packet of health information and a reminder about a follow-up session. Control group $(\mathrm{N}=143)$ received the packet of health information only.

\begin{tabular}{|c|c|}
\hline Outcomes & $\begin{array}{l}\text { Mean weekly alcohol consumption; percentage binge drinkers in previous month, AUDIT score. } \\
\text { Assessed at } 3 \text { months. }\end{array}$ \\
\hline Funding source & $\begin{array}{l}\text { Research for this study was supported by grants R01 AA13167 and U24 AA11899 from the National Insti- } \\
\text { tute of Alcohol Abuse and Alcoholism (NIAAA) and the National Center for Minority Health Disparities, } \\
\text { National Institutes of Health. }\end{array}$ \\
\hline Declaration of interests & Not reported. \\
\hline Notes & $\begin{array}{l}\text { Participants received USD } 10 \text { for baseline and USD } 20 \text { for follow-up. } \\
\text { Loss to follow-up: } \\
\text { Intervention group: } 61 / 151(40 \%) \text {. } \\
\text { Control group: } 39 / 143(27 \%) \text {. } \\
\text { Missing data: baseline data for all randomised participants: requested, no reply. }\end{array}$ \\
\hline
\end{tabular}


Screening, baseline and follow-up questionnaires were not masked as in TrEAT (Fleming 1997) and GOAL (Fleming 1999) trials (participant blinding).

\section{Risk of bias}

\begin{tabular}{lll}
\hline Bias & Authors' judgement & Support for judgement \\
\hline $\begin{array}{l}\text { Random sequence genera- } \\
\text { tion (selection bias) }\end{array}$ & Unclear risk & No information available on sequence generation. \\
\hline $\begin{array}{l}\text { Allocation concealment } \\
\text { (selection bias) }\end{array}$ & Unclear risk & Not reported. \\
\hline $\begin{array}{l}\text { Blinding of treatment } \\
\text { providers }\end{array}$ & High risk & Treatment providers not blinded. \\
\hline
\end{tabular}

\begin{tabular}{lll}
\hline Blinding of participants & High risk & Screening, baseline an follow-up questionnaires were not masked (p. 365). \\
\hline $\begin{array}{l}\text { Blinding of outcome as- } \\
\text { sessment (detection bias) } \\
\begin{array}{l}\text { All outcomes } \\
\text { Incomplete outcome data }\end{array}\end{array}$ & Low risk & $\begin{array}{l}\text { Patients assessed initially by one health promotion advocate were re-inter- } \\
\text { viewed by another at 3 month follow-up (p. 365). }\end{array}$ \\
$\begin{array}{l}\text { (attrition bias) } \\
\text { All outcomes }\end{array}$ & Data (baseline and follow-up) reported only for those not lost to follow-up. \\
\hline
\end{tabular}

Selective reporting (re- Low risk Outcomes specified in methods were reported.

porting bias)

\section{L'Engle 2014}

Methods

Parallel RCT: brief intervention versus equal attention nutrition control.

ITT: yes.
Setting: Kenya, drop-in centres (DIC) for AIDS, Population, Health, and Integrated Assistance (APHIA) II project.

Participants: women who self-reported being female sex workers, were registered as an APHIA program participant, aged $\geq 18$ years, lived in Mombasa and planned to reside there for the next 12 months, moderate risk drinkers defined as those who scored 7 to 19 on AUDIT, had a laboratory-confirmed negative result for gonorrhoea, chlamydia, and trichomoniasis at enrolment; excluded if < 7 on AUDIT.

Number randomised $=818$.

Baseline characteristics not reported for whole population.

Interventions

Intervention group ( $\mathrm{N}=410$ ) received one-on-one sessions lasting 20 minutes on average from nurse counsellors; based on the WHO Brief Intervention for Alcohol Use and contained elements of stages of change and social cognitive health behaviour change theories. Motivational interviewing techniques, focused on goal-setting and increasing self-efficacy for changing behaviour, the provision of positive feedback and encouragement for change, and use of counselling noted and noting stage of change for alcohol reduction were essential intervention elements. In the first counselling session that occurred at the enrolment visit, all participants were presented with their AUDIT screening results. Sessions then included discussion of risks and consequences from drinking, soliciting participants' commitment to reduce drinking, identifying the goal of reduced drinking or abstinence, developing a habit-breaking plan, discussing high-risk situations and coping strategies, and providing feedback and encouragement. Nurse counsellors used a flip chart that included locally-designed illustrations such as physiolog-

Effectiveness of brief alcohol interventions in primary care populations (Review)

Copyright @ 2018 The Cochrane Collaboration. Published by John Wiley \& Sons, Ltd. 
L'Engle 2014 (Continued)

ical consequences of alcohol use and depictions of risky situations relevant to female sex workers, and recorded notes from each counselling session on a data, assessment, and plan form, to track discussions across sessions and record the date for the next session.

Equal attention nutrition control group $(\mathrm{N}=408)$ received monthly 20-minute sessions from the nurse counsellors, based on Kenyan National Guidelines on nutrition and HIV/AIDS. Sessions included assessment of women's nutritional status, addressed nutritional needs for women and their children and other key groups including people living with HIV and/or taking antiretroviral medication, and included development and monitoring of a nutrition care plan.

\begin{tabular}{ll}
\hline Outcomes & AUDIT and behavioural interview. \\
& Assessed at 6 and12 months. \\
\hline Funding source & $\begin{array}{l}\text { Supported by the Public Health Evaluation (PHE) component of the President's Emergency Plan for } \\
\text { AIDS Relief (PEPFAR), PHE \#KE09.0235. Funding was provided through the US Agency for International } \\
\text { Development (USAID), under the terms of AID-623-A-11-00007. }\end{array}$ \\
\hline Declaration of interests & The authors have no conflicts of interest to disclose. \\
\hline Notes & Loss to follow-up: \\
& Intervention group: $37 / 410$ (9\%). \\
& Control group: $29 / 408$ (7\%). \\
No direct payment but could receive condoms.
\end{tabular}

\section{Risk of bias}

\begin{tabular}{|c|c|c|}
\hline Bias & Authors' judgement & Support for judgement \\
\hline $\begin{array}{l}\text { Random sequence genera- } \\
\text { tion (selection bias) }\end{array}$ & Low risk & $\begin{array}{l}\text { "A statistician not otherwise involved in the study generated the randomiza- } \\
\text { tion sequences using the random function RANUNI in SAS" (p. 447). }\end{array}$ \\
\hline $\begin{array}{l}\text { Allocation concealment } \\
\text { (selection bias) }\end{array}$ & Low risk & $\begin{array}{l}\text { Statistician produced written assignments sealed in individual tamper-evident } \\
\text { opaque envelopes. "The envelopes were fully protected until the site coordi- } \\
\text { nator confirmed the prospective participants' eligibility, obtained written in- } \\
\text { formed consent, and collected all baseline data" (p. 447). }\end{array}$ \\
\hline $\begin{array}{l}\text { Blinding of treatment } \\
\text { providers }\end{array}$ & High risk & $\begin{array}{l}\text { "Given the nature of the intervention, study participants and site staff could } \\
\text { not be masked to treatment allocation" (p. 447). }\end{array}$ \\
\hline Blinding of participants & High risk & $\begin{array}{l}\text { "Given the nature of the intervention, study participants and site staff could } \\
\text { not be masked to treatment allocation" (p. 447). }\end{array}$ \\
\hline $\begin{array}{l}\text { Blinding of outcome as- } \\
\text { sessment (detection bias) } \\
\text { All outcomes }\end{array}$ & Low risk & $\begin{array}{l}\text { Study investigators and analysts were masked until data handling and analysis } \\
\text { decisions were finalized (p. 447). }\end{array}$ \\
\hline $\begin{array}{l}\text { Incomplete outcome data } \\
\text { (attrition bias) } \\
\text { All outcomes }\end{array}$ & Unclear risk & Loss to follow-up reported; only reason given was "missed appointment". \\
\hline $\begin{array}{l}\text { Selective reporting (re- } \\
\text { porting bias) }\end{array}$ & Unclear risk & $\begin{array}{l}\text { Had intended to report AUDIT at all time points but do not. They explain that } \\
\text { this is because of overlaps in reporting due to time frame component of AU- } \\
\text { DIT. Therefore alcohol frequency and binge frequency responses from inter- } \\
\text { views are reported instead. }\end{array}$ \\
\hline
\end{tabular}


Lane 2008

Methods Parallel RCT: brief intervention versus screening only control.

ITT: yes.

Participants Setting: Australia, public sexual health clinic.

Participants: Aged $>16$ years, $\geq 8$ on AUDIT, or AUDIT-3 $=3$ or 4 ; excluded if they had a language or literacy problem, mental health problem or were too sick to participate.

Number randomised $=184$.

Baseline AUDIT score: 8-12 = 99 (54\%), 13-19 = 58 (31\%), $\geq 20=27(15 \%)$.

Interventions Brief intervention group $(\mathrm{N}=87)$ received 5 to 10 minutes advice, guided by the Drink-less handy card.

Control group $(\mathrm{N}=97)$ received screening only (AUDIT and basic demographical information).

Outcomes

AUDIT score, questions relating to any changes in alcohol consumption, having any recent treatment for alcohol problems, and recall and acceptability of being asked about alcohol and getting advice from a research nurse at their visit to the clinic.

Assessed at 3 months.

Funding source The Drug and Alcohol Council, New South Wales Health, provided funding for the study. The funding body had no part in the conduct or design of the design.

\begin{tabular}{ll}
\hline Declaration of interests & Competing interests: none. \\
\hline Notes & Loss to follow-up: \\
& Brief intervention group: $21 / 87(24 \%)$. \\
& Control group: $30 / 97(31 \%)$. \\
\hline
\end{tabular}

\section{Risk of bias}

\begin{tabular}{|c|c|c|}
\hline Bias & Authors' judgement & Support for judgement \\
\hline $\begin{array}{l}\text { Random sequence genera- } \\
\text { tion (selection bias) }\end{array}$ & Unclear risk & Method of sequence generation not reported. \\
\hline $\begin{array}{l}\text { Allocation concealment } \\
\text { (selection bias) }\end{array}$ & Unclear risk & Pre-coded consent forms in sealed envelopes, but not opaque or numbered. \\
\hline $\begin{array}{l}\text { Blinding of treatment } \\
\text { providers }\end{array}$ & High risk & Not blinded. \\
\hline Blinding of participants & High risk & Not blinded. \\
\hline $\begin{array}{l}\text { Blinding of outcome as- } \\
\text { sessment (detection bias) } \\
\text { All outcomes }\end{array}$ & Low risk & $\begin{array}{l}\text { Follow-up data were directly entered into SPSS v.15 by the telephone inter- } \\
\text { viewer who was blind to group status. }\end{array}$ \\
\hline $\begin{array}{l}\text { Incomplete outcome data } \\
\text { (attrition bias) } \\
\text { All outcomes }\end{array}$ & Unclear risk & Loss to follow-up reported but no reasons. \\
\hline
\end{tabular}


Lane 2008 (Continued)

Selective reporting (re- Low risk Outcomes specified in methods are reported. porting bias)

Lock 2006

Methods

Cluster randomised controlled trial: brief intervention versus standard advice, average cluster size $=2$.

ITT: yes.

Participants Setting: UK, general practice.

Participants: Aged $\geq 16$ years with AUDIT score $\geq 8$ for men or $\geq 7$ for women; excluded if current major physical or psychiatric illness, or severely alcohol dependent, or severely brain damaged or mentally impaired.

Number randomised $=127 ; 50 \%$ male; mean age $=44.1$ years; $72 \%$ employed, $5 \%$ unemployed, $15 \%$ retired, $3 \%$ students; $3 \%$ primary school, $6 \%$ some secondary school, $47 \%$ completed secondary school, $21 \%$ technical or trade certificate, $23 \%$ university or tertiary education.

At baseline: mean weekly units consumed = 24.6; mean AUDIT score $=10.5$.

Interventions

Intervention group ( $\mathrm{N}=67$ ) received 5 to 10 minute intervention using the 'drink-less' protocol. This involved structured advice including: standard drink units, recommended low-risk consumption levels, benefits of cutting down drinking, tips on helping patients reduce consumption, advice on how to set goals, determine action and review progress. Also received a self-help booklet/diary to take away. Control group $(\mathrm{N}=60)$ received standard treatment comprising nurses advice on cutting down drinking and UK Government Health Education Authority leaflet entitled 'Think About Drink', which contained daily benchmark guides for adult men and women and basic advice on alcohol.

Outcomes $\quad$ AUDIT score, mean drinks per drinking day, mean units per week, Drinking Problems Index, SF-12 physical health, health related quality of life measured by the SF-12.

Assessed at 6 and 12 months.

Funding source $\quad$ Funding for this project was provided by an NHS Executive (Northern \& Yorkshire) Research and Development Regionally Commissioned Project Grant.

Declaration of interests Not reported.

Notes Loss to follow-up at 12 months:

Intervention group: $31 / 67(46.2 \%)$.

Control group: $18 / 60(30.0 \%)$.

Number of patients assessed $=78$ in $40 \mathrm{GP}$ practices.

\section{Risk of bias}

\begin{tabular}{lll}
\hline Bias & Authors' judgement & Support for judgement \\
\hline $\begin{array}{l}\text { Random sequence genera- } \\
\text { tion (selection bias) }\end{array}$ & Low risk & Computer generated allocation (p. 428). \\
\hline $\begin{array}{l}\text { Allocation concealment } \\
\text { (selection bias) }\end{array}$ & Low risk & $\begin{array}{l}\text { Randomisation was carried out by a member of the team not involved in re- } \\
\text { cruitment or training, all patients in each practice received the same interven- } \\
\text { tion (p. 428). }\end{array}$ \\
\hline $\begin{array}{l}\text { Blinding of treatment } \\
\text { providers }\end{array}$ & Low risk & Cluster randomised so that treatment providers interacted with only one arm. \\
\hline
\end{tabular}


Lock 2006 (Continued)

Blinding of participants High risk Patients knew that alcohol advice was being evaluated (p. 429).

$\begin{array}{ll}\begin{array}{l}\text { Blinding of outcome as- } \\ \text { sessment (detection bias) }\end{array} & \text { Low risk }\end{array} \quad \begin{aligned} & \text { Outcome measurement was done by researchers who were blind to patient's } \\ & \text { study group (p. 429). }\end{aligned}$

All outcomes

Incomplete outcome data High risk Loss to follow-up $>30 \%$.
(attrition bias)
All outcomes

Selective reporting (re- Low risk Outcomes specified in methods are reported.
porting bias)

porting bias)

Longabaugh 2001

Methods Parallel RCT: brief intervention versus brief intervention plus booster versus standard care.

ITT: yes.

Participants Setting: USA, emergency department.

Participants: English or Spanish speaking, living less than one hour from hospital, aged $\geq 18$ years, presenting to emergency department with an injury that did not require hospitalisation; either breath alcohol positive ( $B A C \geq 0.003 \mathrm{mg} / \mathrm{dl}$ ) in emergency department, or reported having ingested alcohol in six hours previous to injury, or AUDIT $\geq 8$; excluded if homeless, or under arrest, or psychiatric disorders, or previous diagnosis of alcohol dependence or abuse

Number randomised $=539 ; 78 \%$ male; mean age $=27$ years $(S D=9) ; 72 \%$ white, $14 \%$ Latino $/$ Hispanic, $10 \%$ black, $<1 \%$ Asian, $<1 \%$ Native American, $3 \%$ other; $72 \%$ employed

At baseline: AUDIT = 12.8; DrInC lifetime negative consequences score = 15.6; mean self-reported alcohol-related injuries in previous year $=1.6$.

BI group ( $N=182$ ) received brief intervention by specially trained clinician: one 40-60 minute session based on motivational interviewing. Began with open-ended questions about the patient's injury and a possible connection between injury and alcohol use. If the patient assessed said that there was no connection between the present injury and alcohol use, the interventionist broadened the focus to include negative effects the patient had identified on the DrinC as attributed to drinking. The interventionist listened reflectively, provided affirmations, brief summaries and elicited self-motivational statements. To increase awareness of the pros and cons of the target behaviour, patients were assisted in assessing how their alcohol use compared with a national sample, how much money they spent on alcohol, how many calories they consume because of alcohol use, and positive and negative consequences that may be related to their alcohol use. Patients were assisted in determining whether or not they wanted to change any behaviours and, if so, which behaviours they wished to target. In regard to the target behaviour chosen, patients filled out a decisional balance form indicating the pros and cons of change. Last, with the assistance of the interventionist, the patient completed a change worksheet that listed: (1) "The changes I want to make are"; (2) "The most important reasons why I want to make these changes are"; (3) "The steps I plan to take are"; (4) "The ways other people can help me are"; (5) "I will know my plan is working if" and; (6) "Some things that could interfere with my plan are." The patient was given a copy of the change plan at the end of the session.

BIB group $(N=169)$ received brief intervention (as above) plus a booster session with specially trained clinician 7 to 10 days after BI. Based on motivational interviewing. Participants were encouraged to discuss post-discharge experiences, particularly in regard to the change plan they had made in the first session. Then they were provided with additional information about their use of alcohol in an effort to help strengthen the change plan. Based upon reported post-discharge experiences and discussion during the booster session, patients could alter change plans to reflect their experience since the first session. 
Longabaugh 2001 (Continued)

SC group ( $N=188$ ) received the customary care that they otherwise would have received in the absence of the research protocol. This consisted of treatment for their injury by the emergency department staff.

\begin{tabular}{|c|c|c|}
\hline Outcomes & \multicolumn{2}{|c|}{$\begin{array}{l}\text { Number of heavy drinking days per week; alcohol related injuries; negative consequences from drink- } \\
\text { ing (DrlnC). }\end{array}$} \\
\hline & \multicolumn{2}{|l|}{ Assessed at 1 year. } \\
\hline Funding source & \multicolumn{2}{|c|}{$\begin{array}{l}\text { This study was funded by National Institute on Alcohol Abuse and Alcoholism grant } 5 \text { R01 AA09835; } \\
\text { Richard Longabaugh Principal Investigator. }\end{array}$} \\
\hline Declaration of interests & \multicolumn{2}{|l|}{ Not reported. } \\
\hline Notes & \multicolumn{2}{|c|}{ Loss to follow-up not reported by arm. } \\
\hline \multicolumn{3}{|l|}{ Risk of bias } \\
\hline Bias & Authors' judgement & Support for judgement \\
\hline $\begin{array}{l}\text { Random sequence genera- } \\
\text { tion (selection bias) }\end{array}$ & Unclear risk & Unclear how randomisation sequence was generated. \\
\hline $\begin{array}{l}\text { Allocation concealment } \\
\text { (selection bias) }\end{array}$ & High risk & $\begin{array}{l}\text { Interventionist opened a sealed envelope that revealed treatment assignment } \\
\text { (p. 807). }\end{array}$ \\
\hline $\begin{array}{l}\text { Blinding of treatment } \\
\text { providers }\end{array}$ & High risk & Not blinded. \\
\hline Blinding of participants & High risk & Not blinded. \\
\hline $\begin{array}{l}\text { Blinding of outcome as- } \\
\text { sessment (detection bias) } \\
\text { All outcomes }\end{array}$ & Low risk & $\begin{array}{l}\text { All data were collected by independent research assistants who were blind to } \\
\text { patient treatment assignment (p. 807). }\end{array}$ \\
\hline $\begin{array}{l}\text { Incomplete outcome data } \\
\text { (attrition bias) } \\
\text { All outcomes }\end{array}$ & Unclear risk & Loss to follow-up not reported per arm. \\
\hline $\begin{array}{l}\text { Selective reporting (re- } \\
\text { porting bias) }\end{array}$ & Low risk & Outcomes specified in methods are reported. \\
\hline
\end{tabular}

Maisto 2001

\begin{tabular}{ll}
\hline Methods & Parallel RCT: brief advice versus motivational enhancement versus standard care. \\
& ITT: unclear. \\
\hline Participants & Setting: USA, primary care clinics. \\
& Participants: Aged $\geq 21$ yrs with $\geq 8$ on AUDIT, or $\geq 16$ standard drinks per week for men or $\geq 12$ for \\
& women ( 1 standard drink $=0.6$ oz ethanol = $14 \mathrm{~g})$; screened by a lifestyle survey containing general \\
& health, stress and alcohol-specific questions including AUDIT; excluded if other drug abuse or depen- \\
& dence, or alcohol withdrawal for previous year, or participation in substance abuse treatment in last \\
& year, or unstable psychiatric status and life expectancy $<2$ years, or having an active malignancy with \\
the exception of non melanoma skin cancer.
\end{tabular}


Maisto 2001 (Continued)

Number randomised $=301 ; 70 \%$ men; mean age $=45.6$ years; $77 \%$ white, $22 \%$ black, $1 \%$ other; $89 \%$ at least high school; $60 \%$ employed.

At baseline (for previous 30 days): mean days abstinent $=16.3$; mean drinks $=75.3$; mean number of days consumed one to six drinks = 10.0; mean drinks per drinking day = 5.7; mean Alcohol Dependence Scale score $=5.2$.

Interventions

Brief advice group ( $N=100$ ) received one 10 to 15 minute session from a trained interventionist giving feedback from baseline results and implications for participant's drinking, and advice on goal for reducing or stopping drinking, and a booklet on the effects of alcohol. In this condition, interventionists were trained to focus on delivering feedback to the participant and guiding selection of a drinking goal. Motivational enhancement group ( $\mathrm{N}=101$ ) received one 30 to 45 minute session, focused on delivery of feedback of the baseline assessment data and the setting of alcohol use goals, and two 15 to 20 minute 'booster' sessions after two and six weeks, which were designed to provide a formal check-up on the participant's progress, from a trained interventionist. Throughout ME sessions, the interventionist used empathy, reflective listening and other techniques to enhance the participant's motivation to change their alcohol use and the participant was encouraged to elaborate and discuss his or her thoughts related to alcohol use and its consequences. The participant was given considerable freedom and time to discuss and select drinking goals. They received the same booklet on the effects of alcohol after the first session.

Standard care group $(\mathrm{N}=100)$ received no intervention from research interventionists but, as in all other conditions, selected data (the AUDIT score, if positive; alcohol consumption, if high risk; systolic blood pressure if $\geq 200$; diastolic blood pressure if $\geq 100$; GGT levels at least five times higher than normal; blood glucose if 350 or higher) from baseline assessments was forwarded to GP who was not discouraged from acting. The inclusion of items on health-related habits other than drinking allowed for the feedback to be places in a more general health context. Physicians did not receive any instructions about use of interventions for the participant's alcohol use.

Outcomes Mean days abstinent; mean drinks; mean days consumed one to six drinks; mean drinks per drinking day.

Assessed at 1, 3, 6, 9 and 12 months.

Funding source

This research was supported by National Institute on Alcohol Abuse and Alcoholism grant AA1029. Dr Joseph Conigliaro is supported by an Advanced Career Development Award from the Department of Veterans Affairs (VA) HSR\&D Service (CD-97324-A) and by a Robert Wood Johnson Foundation Generalist Physician Faculty Scholar Award (\#0315000). Dr Conigliaro is also a core member of the VISN-4 Mental Illness Research, Education and Clinical Center and the Pittsburgh Geriatric Research, Education and Clinical Center. Dr Kraemer is supported by a Mentored Clinical Scientist Development Award from the National Institute of Alcohol Abuse and Alcoholism (5K01-AA00235).

\begin{tabular}{|c|c|c|}
\hline Declaration of interests & \multicolumn{2}{|l|}{ Not reported. } \\
\hline Notes & \multicolumn{2}{|c|}{$\begin{array}{l}\text { ELM trial } \\
\text { Loss to follow-up: } \\
\text { Brief advice group: } 26 / 100 \text { (26\%). } \\
\text { Motivational enhancement group: } 28 / 101 \text { (28\%). } \\
\text { Standard care group: } 15 / 100 \text { (15\%). } \\
\text { Separate paper on elderly as subgroup. }\end{array}$} \\
\hline \multicolumn{3}{|l|}{ Risk of bias } \\
\hline Bias & Authors' judgement & Support for judgement \\
\hline $\begin{array}{l}\text { Random sequence genera- } \\
\text { tion (selection bias) }\end{array}$ & Low risk & Project coordinator used random numbers table (p. 606). \\
\hline $\begin{array}{l}\text { Allocation concealment } \\
\text { (selection bias) }\end{array}$ & Low risk & $\begin{array}{l}\text { The schedule was kept in an envelope in a locked drawer and was used only by } \\
\text { the project coordinator (p. 606). }\end{array}$ \\
\hline
\end{tabular}


Maisto 2001 (Continued)

Blinding of treatment Unclear risk Physicians saw control patients and interventionists administered intervenproviders tions so no risk of contamination, but physicians were forwarded details of AUDIT score (if positive) and alcohol consumption (if high) and were not discouraged from advising patients.

\begin{tabular}{lll}
\hline Blinding of participants & High risk & Not blinded. Completed AUDIT for screening therefore alcohol focus clear. \\
\hline $\begin{array}{ll}\text { Blinding of outcome as- } \\
\text { sessment (detection bias) }\end{array}$ & Unclear risk & Not clear whether outcome assessor was blinded. \\
All outcomes &
\end{tabular}

Incomplete outcome data Unclear risk Loss to follow-up reported but not reasons.
(attrition bias)

All outcomes

Selective reporting (re- Low risk Outcomes specified in methods are reported.
porting bias)

McDevitt-Murphy 2014

Methods Parallel RCT: personalised drinking feedback plus motivational interviewing versus feedback only.
ITT: unclear.

Participants Setting: USA, Veterans Affairs Medical Centre primary care clinic.

Participants: combat veterans who screened positive on AUDIT for hazardous drinking; excluded if they had schizophrenia or were in residential substance abuse treatment.

Number randomised $=68 ; 91.2 \%$ male, mean age $=32.31$ years $($ SD 8.84$) ; 64.7 \%$ White, $27.9 \%$ Black.
Motivational interviewing and personalised drinking feedback (PDF) group $(N=35)$ received PDF in a one hour session where the clinician proceeded through the pages of a PDF packet and used the material to engage the veteran in a motivational interview-style discussion about the content. The session concluded with the clinician querying the impact of this information and engaging the veteran in collaborative goal-setting. The personalised drinking feedback included: deployment related phenomena (personalised feedback about combat experiences and post-deployment adjustment, PTSD and depression, personalised feedback about veterans own symptoms); coping (general information about coping styles, feedback about veteran's own typical coping style); substance misuse; normative feedback based on age-and gender-based norms; psycho-education and personalised feedback about blood alcohol content, binge drinking and risks associated with veteran's own drinking, personal risk factors for alcohol dependence; PTSD-alcohol misuse, information about the "vicious cycle" relationship between PTSD-related symptoms and alcohol misuse, included personalised information about the veteran's motives for drinking.

Feedback only group $(\mathrm{N}=33$ ) received detailed (PDF) packets, provided in written format with $30 \mathrm{~min}$ utes to read followed by a chance to ask questions.

\section{Outcomes}

Mean drinks per week, mean drinking days per week, past month binge days, drinks per drinking day (from TLFB), recent consequences of alcohol use using DrlnC.

Assessed at 6 weeks and 6 months.
This work was conducted with support from National Institute of Alcohol Abuse and Alcoholism Grant K23AA016120 to Meghan E McDevitt-Murphy, and with support from the Office of Research and Development, 
McDevitt-Murphy 2014 (Continued)

Memphis Veterans Affairs Medical Center, and the Tennessee Board of Regents, through the Center for Applied Psychological Research.

\begin{tabular}{ll}
\hline Declaration of interests & Not reported. \\
\hline Notes & Loss to follow up: \\
& MI \& PDF group: $3 / 35(8.5 \%)$. \\
& FO group: $2 / 33(6 \%)$. \\
& Payment: USD 50 for baseline, USD 25 for each follow-up.
\end{tabular}

\section{Risk of bias}

\begin{tabular}{|c|c|c|}
\hline Bias & Authors' judgement & Support for judgement \\
\hline $\begin{array}{l}\text { Random sequence genera- } \\
\text { tion (selection bias) }\end{array}$ & Unclear risk & Method of sequence generation not reported. \\
\hline $\begin{array}{l}\text { Allocation concealment } \\
\text { (selection bias) }\end{array}$ & Unclear risk & Not reported. \\
\hline $\begin{array}{l}\text { Blinding of treatment } \\
\text { providers }\end{array}$ & High risk & Not blinded. \\
\hline Blinding of participants & High risk & Not blinded. \\
\hline $\begin{array}{l}\text { Blinding of outcome as- } \\
\text { sessment (detection bias) } \\
\text { All outcomes }\end{array}$ & Unclear risk & Not reported. \\
\hline $\begin{array}{l}\text { Incomplete outcome data } \\
\text { (attrition bias) } \\
\text { All outcomes }\end{array}$ & Unclear risk & Loss to follow-up reported but no reasons. \\
\hline $\begin{array}{l}\text { Selective reporting (re- } \\
\text { porting bias) }\end{array}$ & Low risk & Outcomes specified in methods are reported. \\
\hline
\end{tabular}

\section{McIntosh 1997}

Methods Parallel RCT: brief physician advice versus physician delivered cognitive behavioural strategies versus nurse delivered cognitive behavioural strategies.

ITT: unclear.

Petting: Canada, family practice clinic.
Participants: aged $>15$ years who had consumed $\geq 4$ standard drinks on any day in the previous month,
or responded positively to $\geq 1$ CAGE question.
Number randomised $=159 ; 52 \%$ male; mean age $=31.1$ years; $50 \%$ employed full time, $16 \%$ employed
part time, $34 \%$ unemployed.

Interventions

Group $1(\mathrm{~N}=40)$ received two 30 minute sessions two weeks apart from a physician (not their own) using cognitive behavioural strategies and giving advice on sensible drinking, helping participants understand the function of alcohol within their daily activities, and developing a plan and drinking goals. At the first session they received booklets containing this information and diary sheets to record drinking. 
McIntosh 1997 (Continued)

Group $2(N=66)$ received the same intervention and materials as group 1 but from a nurse ratione rather than a physician.

Group $3(\mathrm{~N}=53)$ received five minutes of advice from their own family physician based on the patient's initial self-reports of drinking; physicians gave specific information on a standard drink, the limits of moderation, sensible drinking, and avoiding risky situations. Possible connections between drinking and the health concerns that prompted the office visit were identified. This advice was reinforced with a handout.

\begin{tabular}{|c|c|}
\hline Outcomes & $\begin{array}{l}\text { Mean monthly quantity frequency of drinking; problem/problem free drinker (participants were de- } \\
\text { scribed as problem free if they had no more than one of: insomnia, headache, nausea, cramps, di- } \\
\text { arrhoea, palpitations, shakiness, sweats, poor memory, poor concentration, mood or personality } \\
\text { changes and feeling sluggish). } \\
\text { Assessed at 3, } 6 \text { and12 months. }\end{array}$ \\
\hline Funding source & $\begin{array}{l}\text { This project was funded by the National Health Research and Development Program, Project no } \\
6603-1355-\text { DA. We acknowledge the support of the Drug Dependency Services Division, Department of } \\
\text { Health, and the Cape Breton Regional Hospital in Sydney, Nova Scotia. }\end{array}$ \\
\hline Declaration of interests & Not reported. \\
\hline Notes & $\begin{array}{l}\text { Loss to follow-up: not reported by arm; } 1 / 159(1 \%) \text { at } 3 \text { months, } 11 / 159(7 \%) \text { at } 6 \text { months, } 16 / 159(10 \%) \\
\text { at } 12 \text { months overall. } \\
\text { Group } 1 \text { and group } 2 \text { are aggregated in our analysis as they are an identical intervention. }\end{array}$ \\
\hline
\end{tabular}

\section{Risk of bias}

\begin{tabular}{|c|c|c|}
\hline Bias & Authors' judgement & Support for judgement \\
\hline $\begin{array}{l}\text { Random sequence genera- } \\
\text { tion (selection bias) }\end{array}$ & Unclear risk & Method of sequence generation not reported. \\
\hline $\begin{array}{l}\text { Allocation concealment } \\
\text { (selection bias) }\end{array}$ & Unclear risk & Not reported. \\
\hline $\begin{array}{l}\text { Blinding of treatment } \\
\text { providers }\end{array}$ & Unclear risk & $\begin{array}{l}\text { Not blinded but each treatment provider delivered only one kind of interven- } \\
\text { tion therefore limited chance of contamination. }\end{array}$ \\
\hline Blinding of participants & High risk & Not blinded. \\
\hline $\begin{array}{l}\text { Blinding of outcome as- } \\
\text { sessment (detection bias) } \\
\text { All outcomes }\end{array}$ & Unclear risk & Not reported. \\
\hline $\begin{array}{l}\text { Incomplete outcome data } \\
\text { (attrition bias) } \\
\text { All outcomes }\end{array}$ & Unclear risk & Loss-to follow-up reported as $10 \%$ overall and not by study arm. \\
\hline $\begin{array}{l}\text { Selective reporting (re- } \\
\text { porting bias) }\end{array}$ & Low risk & Outcomes specified in methods are reported. \\
\hline
\end{tabular}

Mello 2008

Methods Parallel RCT: brief telephone intervention versus standard care.

ITT: yes. 
Mello 2008 (Continued)

Participants
Setting: USA, screened in emergency department, intervention delivered at home via telephone.

Participants: aged $\geq 18$ years who were non-critically injured (in the first year only motor crash victims but after that all injured patients), discharged to home, had a telephone, English-speaking, using alcohol at risky levels (defined as NIAAA quantity frequency guidelines, either $>14$ drinks per week for men ( $>7$ for women) or $\geq 5$ drinks per occasion for men ( $\geq 4$ for women) screened by research assistant using a health survey during ED visit; excluded if suicidal or in police custody.

Number randomised $=285 ; 61 \%$ male; $72 \%$ White, $87 \%$ non-Hispanic; $75 \%$ employed.

Baseline data not reported for total sample.
BI group ( $N=140$ ) received 30 minute scripted brief intervention delivered by telephone within five days of emergency department visit by trained counsellors, which aimed to mobilise the participant's own resources to bring about changes needed to reduce alcohol-related risky behaviours. The counsellor's role is to be reflective, to provide an atmosphere that will support and enhance the participant's motivation for change and that will lead the participant to initiate and persist in behavioural change efforts. Two weeks later, they received an additional 15 minute brief intervention booster session. $69 \%$ of BI participants received booster.

SC group $(N=145)$ received no study interventions.
Outcomes Mean change in AUDIT score, binge drinking, impaired driving measures - assessed at three months.

Difference in AUDIT-C, alcohol related injuries, differences in DrInC (Drinkers Inventory of Consequences) score - assessed at 12 months.
The study was funded by the Centers for Disease Control and Prevention's (CDC's) National Center for Injury Prevention and Control (R49/CCR1232280; Mello, principal investigator).

\begin{tabular}{ll}
\hline Declaration of interests & None (says all conflicts must be r \\
\hline Notes & DIAL study. \\
& Participants received a total of USD \\
& Loss to follow-up at three months: \\
& BI group: $10 / 140(7 \%)$. \\
& SC group: $2 / 145(1 \%)$. \\
& Loss to follow-up at 12 months: \\
& BI group: $18 / 140(13 \%)$. \\
& SC group: $18 / 145(12 \%)$.
\end{tabular}

\section{Risk of bias}

\begin{tabular}{lll}
\hline Bias & Authors' judgement & Support for judgement \\
\hline $\begin{array}{l}\text { Random sequence genera- } \\
\text { tion (selection bias) }\end{array}$ & Low risk & $\begin{array}{l}\text { "Participants were randomised by computer assignment to either treatment } \\
\text { or standard care group" (p. 45). }\end{array}$ \\
\hline $\begin{array}{l}\text { Allocation concealment } \\
\text { (selection bias) }\end{array}$ & Unclear risk & $\begin{array}{l}\text { Research staff opened an envelope that contained allocation assignment (p. } \\
45) .\end{array}$ \\
\hline $\begin{array}{l}\text { Blinding of treatment } \\
\text { providers }\end{array}$ & High risk & $\begin{array}{l}\text { Not blinded and contamination risk is high because treatment provider talks } \\
\text { to all participants on the phone. }\end{array}$ \\
\hline
\end{tabular}


Mello 2008 (Continued)

Blinding of participants High risk All patients received briefing that the intervention is about alcohol use and driving behaviours.

Blinding of outcome as- Low risk sessment (detection bias)

All outcomes
All data was collected by a research assistant blinded to treatment condition (p. 45).

Incomplete outcome data Unclear risk Loss to follow-up reported but not reasons.
(attrition bias)

(attrition bias)

Selective reporting (re- Low risk Outcomes specified in methods are reported.

porting bias)

\section{Mertens 2014}

Methods Parallel RCT: brief motivational intervention plus referral list versus usual care plus referral list.

ITT: no.

Setting: South Africa, primary health care clinic.
Participants
drug use with a single question: "In the past year how many times have you had three or more drinks
on one occasion" (for women) or "In the past year, how many times have you had five or more drinks on
one occasion" (for men); excluded if too ill to participate or no phone.
Number randomised = 403; (in assessed population) mean age = 21 years; $49 \%$ black, $51 \%$ mixed race;
$8 \%$ education grade six or less, $79 \%$ some high school, $13 \%$ completed high school, $74 \%$ unemployed.

Interventions $\quad$ BMI group $(\mathrm{N}=206)$ received brief motivational intervention for alcohol and drug misuse at the Cape

Town Drug Counselling Center (CTDCC). The training manual was Rollnick's Health Behavior Change: A Guide for Practitioners (Rollnick et al 1999). Average intervention length was 10 minutes plus referral resource list for drinking and drug use.

Usual Care group ( $\mathrm{N}=197$ ) received minimally enhanced usual care plus resource list.

Outcomes ASSIST score, prevalence of at risk use of alcohol, cannabis, methamphetamine, sedatives, methaqualone and heavy drinking.

Assessed at 3 months.

Funding source $\quad$ Funded by the National Institute on Drug Abuse R21DA022557.

Declaration of interests Conflict of interest statement: none declared.

Notes
Loss to follow-up:
Usual Care group: $24 / 197(12.2 \%)$.
Payment: voucher for cell phone time or a local supermarket, worth ZAR 50 (approximately USD 6).

\section{Risk of bias}

Bias Authors' judgement Support for judgement


Mertens 2014 (Continued)

Random sequence genera- Unclear risk Method of sequence generation not described. tion (selection bias)

\begin{tabular}{lll}
\hline $\begin{array}{l}\text { Allocation concealment } \\
\text { (selection bias) }\end{array}$ & Unclear risk & Sealed envelope but not described as numbered or opaque (p. 431). \\
\hline $\begin{array}{l}\text { Blinding of treatment } \\
\text { providers }\end{array}$ & High risk & Not blinded. \\
\hline Blinding of participants & High risk & Not blinded. \\
\hline $\begin{array}{l}\text { Blinding of outcome as- } \\
\text { sessment (detection bias) } \\
\text { All outcomes }\end{array}$ & Low risk & $\begin{array}{l}\text { "Research interviewers conducting follow-up were blinded to randomisation } \\
\text { status" (p. 431). }\end{array}$ \\
\hline
\end{tabular}

Incomplete outcome data Unclear risk Loss to follow-up reported but only reason given is "unable to be contacted". (attrition bias)

All outcomes

Selective reporting (re- Low risk Outcomes specified in methods are reported.

porting bias)

Monti 2007

Methods Parallel RCT: motivational intervention plus feedback plus booster versus feedback only.

ITT: unclear.

Participants

Setting: USA, emergency department.

Participants: aged 18 to 24 years who were treated in level I trauma centre and (a) had a blood alcohol concentration (BAC) greater than $0.01 \%$ according to a biochemical test, or (b) reported drinking alcohol in the six hours prior to the event that caused their visit, or (c) scored $\geq 8$ on AUDIT; screened with mini-mental status examination to assess readiness for consent and assessment; excluded if they did not speak English, had a self-inflicted injury or were in police custody.

Number randomised $=198 ; 68 \%$ male; mean age of total sample not reported; $65 \%$ White, $13 \%$ Hispanic, $6 \%$ Black, $2 \%$ Asian, $2 \%$ American Indian, $12 \%$ Other or multiple race.

Baseline characteristics for total sample not reported.

Interventions

MI group ( $N=98$ ) received 30 to 45 minutes motivational interviewing in the emergency department from counsellors which incorporated open-ended exploration, personalised feedback, support for selfefficacy and discussion about patients' alcohol use and associated risky behaviours. Session components included establishing rapport, assessing motivation for change, enhancing motivation and establishing goals for change. A worksheet was used to outline the patient's reasons for change and barriers to change. A graphic personalised feedback report was derived from the baseline assessments and included normative information about consumption, summaries of the patient's alcohol-related consequences and indicators of risk, and was discussed in the MI session to enhance motivation. If the patient was interested in discussing change, a goal worksheet containing reduction and cessation strategies was used to facilitate this process. Patients received copies of the worksheets and feedback report, and handouts about alcohol risks and local treatment facilities. The one month booster (20 minutes) started with an assessment ( 30 day TLFB) of the patient's past-month drinking. The counsellor then reviewed the patient's goals from the first session and inquired about progress. Goals were adjusted or new goals set. For the three month booster (25-30 minutes), patients completed a short assessment battery of alcohol consumption and problem measures described above. A new feedback sheet about the patient's recent behavior relative to their baseline report was generated and reviewed, and a copy 
Monti 2007 (Continued)

mailed to the patient. Progress toward goals since the first booster was reviewed and new goals were generated and discussed.

FO group ( $N=100$ ) received the same baseline assessment and computer-generated personalised feedback report as those in $\mathrm{Ml}$, and counsellors spent one to three minutes introducing the report as providing information about how much the patients drink and what happens when they drink, and how they compare to others their age. Conversation with the counsellor was minimal, but any questions or concerns were addressed appropriately. Patients received the same handouts as in MI. At the three month assessment participants were mailed a new feedback sheet.

\begin{tabular}{|c|c|}
\hline Outcomes & $\begin{array}{l}\text { Mean days drinking in past month, mean heavy drinking days in past month, mean drinks per week in } \\
\text { past month, RAPI (Rutgers Alcohol Problem Index) score, number of alcohol related injuries in the past } \\
\text { year. } \\
\text { Assessed at } 6 \text { and } 12 \text { months. }\end{array}$ \\
\hline Funding source & $\begin{array}{l}\text { This investigation was supported by research grant AA09892 from the National Institute on Alcohol } \\
\text { Abuse and Alcoholism and by a Department of Veterans Affairs Senior Career Research Scientist Award } \\
\text { to Peter M Monti. }\end{array}$ \\
\hline Declaration of interests & Not reported. \\
\hline Notes & $\begin{array}{l}\text { USD } 25 \text { gift certificate for participating at baseline, USD } 15 \text { cash for } 1 \text { month booster, USD } 30 \text { for three } \\
\text { month booster, } \$ 40 \text { each for six and } 12 \text { month follow-ups, } \$ 30 \text { bonus if all follow-ups were completed } \\
\text { within one month of due date. } \\
\text { Loss to follow-up: } \\
\text { MI group: } 19 / 98(19 \%) \text {. } \\
\text { FO group: } 14 / 100(14 \%) \text {. }\end{array}$ \\
\hline
\end{tabular}

\section{Risk of bias}

\begin{tabular}{|c|c|c|}
\hline Bias & Authors' judgement & Support for judgement \\
\hline $\begin{array}{l}\text { Random sequence genera- } \\
\text { tion (selection bias) }\end{array}$ & Low risk & $\begin{array}{l}\text { Randomisation was carried out by the project coordinator using a random } \\
\text { numbers table (p. 1235). }\end{array}$ \\
\hline $\begin{array}{l}\text { Allocation concealment } \\
\text { (selection bias) }\end{array}$ & Unclear risk & Implementation of randomisation sequence unclear. \\
\hline $\begin{array}{l}\text { Blinding of treatment } \\
\text { providers }\end{array}$ & High risk & Not blinded. \\
\hline Blinding of participants & High risk & Not blinded. \\
\hline $\begin{array}{l}\text { Blinding of outcome as- } \\
\text { sessment (detection bias) } \\
\text { All outcomes }\end{array}$ & Low risk & $\begin{array}{l}\text { Research assistants conducting follow-up were blind to intervention condition } \\
\text { (p. 1235). }\end{array}$ \\
\hline $\begin{array}{l}\text { Incomplete outcome data } \\
\text { (attrition bias) } \\
\text { All outcomes }\end{array}$ & Unclear risk & Loss to follow-up reported but not reasons. \\
\hline $\begin{array}{l}\text { Selective reporting (re- } \\
\text { porting bias) }\end{array}$ & Low risk & Outcomes specified in methods are reported. \\
\hline
\end{tabular}


Moore 2011

\begin{tabular}{l} 
Methods $\begin{array}{l}\text { Parallel RCT: brief intervention versus general health booklet. } \\
\text { ITT: yes. }\end{array}$ \\
\hline
\end{tabular}

Participants

Setting: USA, primary care clinics.

Participants: $\geq 55$ years, English or Spanish speaking, presenting for any reason to participating clinicians and reporting consumption of at least one alcoholic drink in the previous week; screened with the Comorbidity Alcohol Risk Evaluation Tool (CARET); excluded if they could not hear the screening questions, were too ill to participate or had received treatment for an alcohol use disorder in the prior three months.

Number randomised $=631 ; 71 \%$ male; mean age $=68.4$ years, age range 55 to 89 years; $88 \%$ White, $9 \%$ Hispanic, $3 \%$ Other ethnicity; $23 \%$ high school or less, $31 \%$ some college, $46 \%$ college degree or more; $74 \%$ retired or homemaker, $26 \%$ employed full or part time At baseline: mean 15.2 drinks in previous seven days; $34 \%$ had a heavy drinking day in previous seven days ( $\geq 4$ drinks per day); $24 \%$ binge drinkers ( $\geq 4$ drinks per occasion).

Interventions

Intervention group $(\mathrm{N}=310)$ received one session of one to five minutes from the primary care provider, followed by three sessions of 40 minutes, 20 minutes and 20 minutes respectively from a health educator. At the baseline visit, the research assistant informed intervention group participants that the study focused on healthy drinking behaviours and they were asked to sign a second informed consent form describing additional procedures. Before seeing the primary care practitioner (PCP), the research assistant handed each participant a personalised report and drinking diary to keep track of alcohol use. A similar version of the report was given to the PCP. The reports outlined participants' alcohol-associated risks identified by the CARET (e.g. drinking two drinks daily and taking a sedative) and potential consequences (e.g. increased sedation and falls). The PCP gave the participant oral and written advice (in prescription-style format on an alcohol education booklet). At two, four and eight weeks after the baseline visit, a health educator called participants to provide additional feedback and counselling using motivational interviewing techniques to help reduce alcohol consumption.

Control group $(\mathrm{N}=321)$ received a health information booklet outlining recommended behaviours for alcohol use, nutrition, exercise, medication use and smoking. Research assistants encouraged participants to read the booklet and discuss it with their PCPs.

Outcomes Per cent scoring one to seven on CARET, per cent with one or more heavy drinking days in past seven days, number of drinks in past seven days, CARET risk score range.

Assessed at 3 and 12 months.

Funding source

This study was supported by R01 AA013937, K23 AA00270, and K24 AA15957 (awarded to Dr Moore) from the National Institute of Alcohol Abuse and Alcoholism, P30AG021684 from the National Institute on Aging (Dr Moore), P30MH082760 from the National Institute of Mental Health (Dr Tang), the Medical Student Training in Aging Program, funded by the National Institute on Aging (T35 AG026736), and the John A. Hartford Foundation (Ms Gill and Ms Chen), Special Fellowship in Advanced Geriatrics, Veterans Affairs Greater Los Angeles Healthcare System (Dr Lin). Data management activities were supported by the UCLA Claude Pepper Older Americans Independence Center funded by the National Institute on Aging (P30AG028748). The sponsor provided financial support for the study only and had no role in the design and conduct of the study; the collection, management, analysis and interpretation of the study; or in the preparation, review or approval of the manuscript.

Declaration of interests Declarations of interest: none.

Notes Healthy Living As You Age (HLAYA) trial; elderly drinkers.

Loss to follow-up at 3 months:

Intervention group: $64 / 310$ (21\%).

Control group: $12 / 321(4 \%)$.

Loss to follow-up at 12 months:

Intervention group: $88 / 310$ (28\%). 
Moore 2011 (Continued)

Control group: 22/321 (7\%).

\section{Risk of bias}

\begin{tabular}{|c|c|c|}
\hline Bias & Authors' judgement & Support for judgement \\
\hline $\begin{array}{l}\text { Random sequence genera- } \\
\text { tion (selection bias) }\end{array}$ & Low risk & $\begin{array}{l}\text { Assignment information was prepared "at the study coordinating center using } \\
\text { a computer-generated set of random numbers" (p. 113). }\end{array}$ \\
\hline $\begin{array}{l}\text { Allocation concealment } \\
\text { (selection bias) }\end{array}$ & Low risk & $\begin{array}{l}\text { "Research assistants used consecutively numbered, sealed opaque en- } \\
\text { velopes" (p. 113). }\end{array}$ \\
\hline $\begin{array}{l}\text { Blinding of treatment } \\
\text { providers }\end{array}$ & Low risk & $\begin{array}{l}\text { Treatment providers were not involved in randomisation or allocation and } \\
\text { were alerted only when they had intervention patient (although they had ap- } \\
\text { pointments with all participants). }\end{array}$ \\
\hline Blinding of participants & Low risk & $\begin{array}{l}\text { "To mask the true purpose of the study to potential participants before ran- } \\
\text { domisation occurred, questions on seat belt use, exercise, diet and smoking } \\
\text { were asked" (p. 114). }\end{array}$ \\
\hline $\begin{array}{l}\text { Blinding of outcome as- } \\
\text { sessment (detection bias) } \\
\text { All outcomes }\end{array}$ & Low risk & $\begin{array}{l}\text { "Research assistants, blinded to treatment allocation, conducted all baseline } \\
\text { and follow-up outcome assessments" (p. 114). }\end{array}$ \\
\hline $\begin{array}{l}\text { Incomplete outcome data } \\
\text { (attrition bias) } \\
\text { All outcomes }\end{array}$ & Unclear risk & $\begin{array}{l}\text { Loss to follow-up reported with reasons, but large difference between control } \\
\text { and intervention group. }\end{array}$ \\
\hline $\begin{array}{l}\text { Selective reporting (re- } \\
\text { porting bias) }\end{array}$ & High risk & $\begin{array}{l}\text { Mentions re-administering the } 7 \text {-day alcohol timeline follow-back, questions } \\
\text { on self-rated health status, ability to perform strenuous activities (p. 114) but } \\
\text { does not report in results. }\end{array}$ \\
\hline
\end{tabular}

Noknoy 2010

Methods Parallel RCT: motivational enhancement therapy versus usual care.

ITT: unclear.

Participants Setting: Thailand, primary care clinics.

Participants: 18 to 65 years presenting to primary care clinic and self-completing AUDIT $\geq 8$; excluded if alcohol-dependent (according to DSM-IV criteria, as applied by a physician), or history of any liver disease, or history of regular alcohol drinking starting early in the morning, or recent consumption of extremely high amounts per day (> $120 \mathrm{~g}$ for men or $>80 \mathrm{~g}$ for women), or neurological disease and psychiatric disorders, or pregnant.

Number randomised $=117 ; 91 \%$ male; mean age $=37$ years; $52 \%$ primary school or less, $25 \%$ secondary school, $7 \%$ graduate or higher, $16 \%$ unknown.

At baseline: mean 6.39 drinks per drinking day or 15.15 drinks per week during the previous month; mean 4.75 drinks per drinking day or 11.92 drinks per week during the previous week; mean AUDIT = $17.4 ; 59 \%$ and $43 \%$ of participants had hazardous drinking behaviour (men $>4$ drinks per day, women $>$ 3 drinks per day) during the previous month and week respectively.

Interventions

Motivational Enhancement Therapy (MET) group ( $N=59)$ received three 15 minute sessions of MET from a trained nurse according to project MATCH protocol (a project which aimed to match participant characteristics to their treatment), starting with an evaluation of the patient's ability to change his drinking habits according to the stage of change. For participants in the pre-contemplation stage, the 
Noknoy 2010 (Continued)

main technique was feedback, using reflection and questioning skills to elicit self-motivational statements. If change was contemplated, the study nurse would work with the participant's ambivalence using a pros and cons technique. If in the determination stage, options on how to reduce drinking behaviour were provided. At the same time, an empathic counselling style and encouragement of the participant's self-efficacy were used to support change in drinking behaviour. Subsequently, each participant's readiness to change drinking behaviour was assessed. If in the determination stage, options on how to reduce drinking behaviour were provided. Participants were then asked to commit themselves to try and change their behaviour and to negotiate appropriate goals. A plan was made with measurable goals in changing drinking behaviour during the action phase. Relapse prevention procedures were used during the maintenance phase.

Control group $(\mathrm{N}=58)$ received usual care (not detailed).

$\begin{array}{ll}\text { Outcomes } & \text { Mean number of drinks per drinking day during previous week, per cent of participants engaging in } \\ \text { hazardous drinking (men }>4 \text {, women }>3 \text { drinks) per drinking day during previous week, mean number } \\ \text { of drinks per week during previous week, per cent of participants engaging in hazardous drinking per } \\ \text { week during the previous week, mean number of binge drinking episodes during previous week, mean } \\ \text { number of times drunk during previous month, GGT. }\end{array}$

Assessed at 6 weeks (i.e. at time of last interview), 3, 6 months.

\begin{tabular}{ll}
\hline Funding source & This research was supported by grants from the Thai Health Promotion Foundation. \\
\hline Declaration of interests & Not reported. \\
\hline Notes & Loss to follow-up: \\
& MET group: $3 / 59(5 \%)$. \\
& Control group: $7 / 58(12 \%)$. \\
\hline
\end{tabular}

\section{Risk of bias}

\begin{tabular}{|c|c|c|}
\hline Bias & Authors' judgement & Support for judgement \\
\hline $\begin{array}{l}\text { Random sequence genera- } \\
\text { tion (selection bias) }\end{array}$ & Low risk & $\begin{array}{l}\text { "Randomisation... was carried out... using a standard randomisation table" (p. } \\
\text { 264). }\end{array}$ \\
\hline $\begin{array}{l}\text { Allocation concealment } \\
\text { (selection bias) }\end{array}$ & Unclear risk & $\begin{array}{l}\text { "Randomisation codes were distributed to each PCU in sealed envelopes" (p. } \\
\text { 264). }\end{array}$ \\
\hline $\begin{array}{l}\text { Blinding of treatment } \\
\text { providers }\end{array}$ & Low risk & $\begin{array}{l}\text { Control group complete assessment only and nurse interventionist saw only } \\
\text { intervention group so no risk of contamination. }\end{array}$ \\
\hline Blinding of participants & Low risk & $\begin{array}{l}\text { Subjects randomised into the control condition "were told that the trial fo- } \\
\text { cused on health behaviours, which included questions on smoking, exercise, } \\
\text { eating behaviour, weight and alcohol use" (p. 265). }\end{array}$ \\
\hline $\begin{array}{l}\text { Blinding of outcome as- } \\
\text { sessment (detection bias) } \\
\text { All outcomes }\end{array}$ & Low risk & $\begin{array}{l}\text { "The study interviewers at follow-up visits were not aware of the assignment } \\
\text { allocation of the study participants" (p. 265). }\end{array}$ \\
\hline $\begin{array}{l}\text { Incomplete outcome data } \\
\text { (attrition bias) } \\
\text { All outcomes }\end{array}$ & Unclear risk & Loss to follow-up reported but not reasons. \\
\hline $\begin{array}{l}\text { Selective reporting (re- } \\
\text { porting bias) }\end{array}$ & Low risk & Outcomes specified in methods are reported. \\
\hline
\end{tabular}


Ockene 1999

Methods

Cluster RCT: special intervention versus usual care, average cluster size $=111$. ITT: yes.

Participants

Setting: USA, primary care centres.

Participants: 21 to 70 years consuming $>12$ standard drinks per week or $\geq 5$ standard drinks on $\geq 1$ occasion in previous month for men, or $>9$ standard drinks per week or $\geq 4$ standard drinks on $\geq 1$ occasion in previous month for women ( 1 standard drink $=12.8 \mathrm{~g}$ alcohol); screened by Health Habits Survey with embedded CAGE; excluded if pregnant, or planning to move away from the area within one year, or did not have telephone, or already participating in alcohol intervention programme, or psychiatric disorder.

Number randomised $=530 ; 64.7 \%$ male; mean age $=43.9$ years; $94.6 \%$ White, $5.4 \%$ non-white; less than high school level $=8.6 \%$, high school graduate or some college $=51.0 \%$, college graduate or more $=$ $40.4 \%$.

At baseline: mean drinks per week $=17.8$.

\section{Interventions}

SI group $(\mathrm{N}=274)$ participants were told that at their next regularly scheduled appointment their providers probably would discuss one of the health issues that was asked about in their lifestyle interview. They were given the same booklet as the UC participants. The SI providers received 2.5 hours training in the patient-centred alcohol intervention program during which the change in orientation required to work with high-risk drinkers (where the goal may be reduction in drinking) vs alcohol dependent patients (where the goal is abstinence) was emphasised. The SI providers were asked to carry out the brief 5 to 10 minute patient centred alcohol counselling sequence at the time of a regular visit with patients identified as high-risk drinkers. Counselling focused on the number of drinks per week, binge drinking, or both, depending on the participant's problem area(s). The SI providers were instructed to request that the patient set a follow-up visit to review progress. The SI office sites also had a limited office support system designed to assist the busy primary care provider in carrying out the intervention. Although implemented by Project Health RAs, the system was designed to be incorporated easily into usual office procedures and includes the RA affixing the following to the chart of the high risk drinker: the lifestyle interview summary sheet, which reports the participant's alcohol history (drinks per week, history of binge drinking, family history of alcohol abuse); the intervention algorithm to remind the physician of the counselling sequence taught in the training sessions; patient education materials in the form of the tip sheets for the providers' use with patients.

UC group $(\mathrm{N}=256)$ received a health booklet that included advice on general health issues and were told to address any health questions with their providers. The UC providers were encouraged to identify and intervene with patients with alcohol-related issues to whatever extent they thought appropriate. All providers were encouraged to attend the weekly conference series in which the approach to the patient with alcohol problems was presented biannually as part of a two year curriculum.
Mean drinks per week, mean binge drinking episodes (defined as $>5$ drinks on one occasion for men and $>4$ for women), change in weekly drinking levels and binge drinking episodes.

Assessed at 6 and 12 months.

This project was supported by grant 5-R01-AA09153 from the National Institute on Alcohol Abuse and Alcoholism.

Declaration of interests The authors have not been engaged in any financial or personal conflicts of interests as a result of the research described in this manuscript.

Notes HEALTH trial

Loss to follow-up:

SI group: 39/274 (14\%).

UC group: $46 / 256(18 \%)$.

Number of participants assessed $=445$ in 4 practice sites.

12 month outcome data reported in separate paper, but baseline data for all randomised participants reported only in Ockene 1999. 
Ockene 1999 (Continued)

Risk of bias

\begin{tabular}{|c|c|c|}
\hline Bias & Authors' judgement & Support for judgement \\
\hline $\begin{array}{l}\text { Random sequence genera- } \\
\text { tion (selection bias) }\end{array}$ & Low risk & $\begin{array}{l}\text { Sequence generated using random number generator in SA statistical soft- } \\
\text { ware (p. 2199). }\end{array}$ \\
\hline $\begin{array}{l}\text { Allocation concealment } \\
\text { (selection bias) }\end{array}$ & Low risk & $\begin{array}{l}\text { Cluster randomised so all patients in a practice received the same interven- } \\
\text { tion. }\end{array}$ \\
\hline $\begin{array}{l}\text { Blinding of treatment } \\
\text { providers }\end{array}$ & Low risk & Cluster randomised so treatment providers only interacted with one arm. \\
\hline Blinding of participants & Low risk & $\begin{array}{l}\text { Alcohol questions were embedded with other health-related questions to min- } \\
\text { imise the intervention effect of the alcohol questions (p. 2199). }\end{array}$ \\
\hline $\begin{array}{l}\text { Blinding of outcome as- } \\
\text { sessment (detection bias) } \\
\text { All outcomes }\end{array}$ & Low risk & Follow-up interviews were conducted by blinded RAs (p. 2199). \\
\hline $\begin{array}{l}\text { Incomplete outcome data } \\
\text { (attrition bias) } \\
\text { All outcomes }\end{array}$ & Low risk & $\begin{array}{l}\text { Loss to follow up similar across both groups and reasons reported (only re- } \\
\text { fused or not available). }\end{array}$ \\
\hline $\begin{array}{l}\text { Selective reporting (re- } \\
\text { porting bias) }\end{array}$ & Low risk & Outcomes specified in methods are reported. \\
\hline
\end{tabular}

Richmond 1995

Methods Parallel RCT: alcohol screen versus minimal intervention versus no intervention versus no assessment

Participants Setting: Australia, general practice.

Participants: 18 to 70 years consuming $>35$ standard drinks per week for men or 21 for women;

Screened by MAST and Ph (physical dependence on alcohol) score; no exclusion criteria listed Number randomised $=378 ; 57 \%$ male; mean age $=37.7$ years; $74 \%$ employed; $67 \%$ beyond secondary school.

At baseline: mean weekly consumption $=36.8$ units.

Interventions

Alcohol screen (AS) group ( $\mathrm{N}=96$ ) received five consultations: 1 ) five minutes where patients were given self-help manual and day diary to monitor their consumption; 2) one week later, patients had a 15 to 20 minute consultation where a personalised approach to patient education using a flip-over unit displaying 12 pictorial and text prompts was used, and patients were counselled about recommended limits, problems associated with excessive drinking, alternate activities; 3 ) one month later, patients had 5 to 25 minute consultation to reinforce and support new drinking habits; 4) and 5) were both five minute sessions for further support.

Minimal intervention ( $\mathrm{MI}$ ) group ( $\mathrm{N}=96)$ received five minutes brief advice and self-help manual. No intervention $(\mathrm{NI})$ group $(\mathrm{N}=93)$ received no intervention.

No assessment $(\mathrm{NA})$ group $(\mathrm{N}=93)$ received no intervention and no assessments (for comparison with $\mathrm{NI}$ group to test whether the assessments make a difference).

Outcomes Mean weekly consumption; mean quantity-frequency consumption; GGT.

Assessed at 6 and 12 months. 
Richmond 1995 (Continued)

Funding source

The study was funded by the Drug and Alcohol Research and Education Committee of the Department of Health, Housing, Local Government and Community Services as part of the National Campaign Against Drug Abuse and by the National Health and Medical Research Council.

\begin{tabular}{ll}
\hline Declaration of interests & Not reported. \\
\hline Notes & Alcohol screen trial \\
& Loss to follow-up: \\
& AS group: $32 / 96(33 \%)$. \\
& Ml group: $26 / 96(27 \%)$. \\
& Nl group: $30 / 93(32 \%)$. \\
& (NA group was not assessed at 1 year). \\
\hline
\end{tabular}

\section{Risk of bias}

\begin{tabular}{|c|c|c|}
\hline Bias & Authors' judgement & Support for judgement \\
\hline $\begin{array}{l}\text { Random sequence genera- } \\
\text { tion (selection bias) }\end{array}$ & Unclear risk & $\begin{array}{l}\text { Patients were not randomly assigned but allocated to one of the four study } \\
\text { groups in weekly blocks, the order of blocks being randomly determined for } \\
\text { each GP (p. 121). }\end{array}$ \\
\hline $\begin{array}{l}\text { Allocation concealment } \\
\text { (selection bias) }\end{array}$ & Unclear risk & Method of allocation concealment unclear. \\
\hline $\begin{array}{l}\text { Blinding of treatment } \\
\text { providers }\end{array}$ & High risk & GPs delivered both Alcoholscreen and minimal intervention. \\
\hline Blinding of participants & Low risk & $\begin{array}{l}\text { Alcohol questions were disguised among questions relating to weight, smok- } \\
\text { ing and exercise. Study was described to patients as being about lifestyles. }\end{array}$ \\
\hline $\begin{array}{l}\text { Blinding of outcome as- } \\
\text { sessment (detection bias) } \\
\text { All outcomes }\end{array}$ & Low risk & $\begin{array}{l}\text { "Follow-up assessment was carried out at } 6 \text { and } 12 \text { months... by a research as- } \\
\text { sistant blind to study group" (p. 121). }\end{array}$ \\
\hline $\begin{array}{l}\text { Incomplete outcome data } \\
\text { (attrition bias) } \\
\text { All outcomes }\end{array}$ & High risk & Loss to follow-up $>30 \%$. \\
\hline
\end{tabular}

Selective reporting (re- Low risk Outcomes specified in methods are reported.

porting bias)

\section{Rodríguez 2003}

Methods
Parallel RCT: brief intervention versus minimal intervention.
ITT: yes.

Participants

Setting: Spain, emergency department.

Participants: Aged $>18$ years, had been involved in a traffic crash in previous six hours and BAC $\geq 0.2 \mathrm{~g} /$ $\mathrm{L}$; excluded if unable to speak Spanish, non-resident, very severe medical, psychiatric or social conditions; acute intoxication, patient not sober at discharge; screened by alcohol-on-site saliva test.

Number randomised $=85 ; 88 \%$ male; median age $=26$ years.

Baseline AUDIT-C = 4.9.

Interventions

BI group ( $N=40$ ) received 15 to 20 minute intervention based on FRAMES, model of change and motivational interviewing, and an information leaflet. 
Rodríguez 2003 (Continued)

MI group $(\mathrm{N}=45)$ received five minute empathic advice and the same information leaflet.

Outcomes AUDIT-C positive or negative, percentage participants who reduced consumption, percentage reduction in hazardous drinkers.

Assessed at one year.

Funding source Esta investigacion esta parcialment subvencionada por el Fondo de Investigaciones Sanitarias (01/0903) y por el Sevei Catala de Transit [This research was partially funded by the Health Research Fund (01/0903) and by the Catalan traffic service].

\begin{tabular}{ll}
\hline Declaration of interests & Not reported. \\
\hline Notes & Loss to follow-up: \\
& Bl group: $12 / 40(30 \%)$. \\
& MI group: $16 / 45(36 \%)$. \\
& Not included in meta-analysis due to unusable outcome data - discussed narratively.
\end{tabular}

\section{Risk of bias}

\begin{tabular}{|c|c|c|}
\hline Bias & Authors' judgement & Support for judgement \\
\hline $\begin{array}{l}\text { Random sequence genera- } \\
\text { tion (selection bias) }\end{array}$ & Unclear risk & Randomly distributed by weeks (p. 193). \\
\hline $\begin{array}{l}\text { Allocation concealment } \\
\text { (selection bias) }\end{array}$ & High risk & Randomly distributed by weeks; predictable sequence. \\
\hline $\begin{array}{l}\text { Blinding of treatment } \\
\text { providers }\end{array}$ & High risk & Not blinded. \\
\hline Blinding of participants & High risk & Not blinded. \\
\hline $\begin{array}{l}\text { Blinding of outcome as- } \\
\text { sessment (detection bias) } \\
\text { All outcomes }\end{array}$ & Low risk & Follow-ups were performed blind by phone. \\
\hline $\begin{array}{l}\text { Incomplete outcome data } \\
\text { (attrition bias) } \\
\text { All outcomes }\end{array}$ & High risk & Loss to follow-up $30 \%$. \\
\hline $\begin{array}{l}\text { Selective reporting (re- } \\
\text { porting bias) }\end{array}$ & Low risk & Outcomes specified in methods are reported. \\
\hline
\end{tabular}

Romelsjö 1989

\begin{tabular}{ll}
\hline Methods & Parallel RCT: brief intervention versus brief advice. \\
ITT: unclear.
\end{tabular}


Romelsjö 1989 (Continued)

three years, or other substance abuse in previous three years, or ongoing treatment or need for treatment for a mental disorder, or severe somatic disease, or other potential causes of elevated GGT. Number randomised $=83 ; 84 \%$ male; mean age $=46.3$ years (range $=21$ to 64 years); $86 \%$ employed. At baseline: GGT $=2.0$ Ukat/l; daily alcohol consumption $=29.1 \mathrm{~g} 100 \%$ ethanol; 'problems index' $=$ 11.3 .

Interventions Intervention group ( $\mathrm{N}=41$ ) were advised by their $\mathrm{GP}$ to cut down their alcohol consumption by the next visit, and if this seemed difficult, to abstain from alcohol. Elevated GGT values and changes in GGT over time were used in discussion with patients in a biofeedback approach. Patients were asked to visit the laboratory again so that the new GGT values were at the GP's disposal at the visit. The GP treated other conditions when necessary, and tried to get a good picture of the patient's social and psychological condition and to give support. The time interval between visits was according to the GP's judgement. The mean number of visits to the GP was about three.

Control group ( $\mathrm{N}=42$ ) were told by their general practitioner that they should cut down on alcohol consumption and that a follow-up examination was planned for approximately one year later. They had earlier been informed by the nurse that their alcohol consumption was elevated or, by letter, that their GGT was elevated.

Outcomes Change in GGT; change in self-reported alcohol consumption; change in a combined measure of alcohol problems 'problem index'.

Assessed at one year.

Funding source

This work was supported by a grant from the Swedish Ministry of Health and Social Affairs, the Commission for Social Research (Project No D84/212:1) and by the Stockholm County Council.

\begin{tabular}{ll}
\hline Declaration of interests & Not reported. \\
\hline Notes & Loss to follow-up: \\
& Intervention group $=5 / 41(12 \%)$. \\
& Control group $=6 / 42(14 \%)$. \\
\hline
\end{tabular}

\section{Risk of bias}

\begin{tabular}{lll}
\hline Bias & Authors' judgement & Support for judgement \\
\hline $\begin{array}{ll}\text { Random sequence genera- } \\
\text { tion (selection bias) }\end{array}$ & Unclear risk & $\begin{array}{l}\text { "Randomisation was performed by the project leader according to a randomi- } \\
\text { sation scheme unknown to the GPs; each patient was randomised to reach an } \\
\text { equal number of patients from each group per GP... distribution for all GPs was } \\
\text { considered... then the total distribution was considered... if this distribution } \\
\text { was equal, ultimately the choice was made by coin flipping" (p. 1320). }\end{array}$ \\
\hline
\end{tabular}

\begin{tabular}{lll}
\hline $\begin{array}{l}\text { Allocation concealment } \\
\text { (selection bias) }\end{array}$ & Low risk & $\begin{array}{l}\text { Allocation sent in a closed envelope to the GP, which was opened only after } \\
\text { the first visit. The rationale for this, which worked well, was that the attitude or } \\
\text { behaviour of the GP towards the patient should not be affected by knowledge } \\
\text { of allocation (p. 1320). }\end{array}$ \\
\hline $\begin{array}{l}\text { Blinding of treatment } \\
\text { providers }\end{array}$ & High risk & Not blinded. \\
\hline Blinding of participants & Low risk & $\begin{array}{l}\text { It was attempted to conduct the interviews as a rather open talk on health and } \\
\text { social questions; alcohol questions were embedded in other health-related } \\
\text { questions (p. 1320). }\end{array}$ \\
\hline
\end{tabular}

Blinding of outcome as- Low risk Outcome assessment was carried out in a lab.


Romelsjö 1989 (Continued)

Incomplete outcome data Unclear risk Loss to follow-up reported but only reasons are "drop-out". (attrition bias)

All outcomes

Selective reporting (re- Low risk Outcomes specified in methods are reported.
porting bias)

\section{Rubio 2010}

Methods Parallel RCT: brief intervention plus health leaflet versus health leaflet.

ITT: yes.

Participants Setting: Spain, primary care clinic.

Participants: 18 to 65 years, AUDIT $=8$ to 15 or reported binge drinking (men $\geq 5$ and women $\geq 4$ standard drinks per occasion one or more times in the past month); screened with AUDIT; excluded if alcohol dependent (AUDIT > 15), or refused to take part, or pregnant, or planning to move out of the area within the year, or no telephone, or already participating in an alcohol intervention program, or Axis I psychiatric disorder that prevented participation (according to physician's judgement).

Number randomised $=752 ; 65 \%$ male; mean age of total sample not reported; $88 \%$ employed, $4 \%$ unemployed, $8 \%$ homemaker; $58 \%$ high school or less, $38 \%$ some college, $4 \%$ college degree or more.

Baseline data not reported for total sample.

Interventions

BI group ( $N=371$ ) received two 10 to 15 minute counselling sessions four weeks apart from the primary care physician using a scripted workbook, which included a review of alcohol-related health effects, a pie chart displaying the frequency of different types of at-risk drinkers, a list of methods for cutting down drinking, a treatment contract, and cognitive behavioural exercises. An office nurse contacted the patients two and eight weeks after the initial counselling sessions to reinforce the face-to-face sessions. Participants also received the same booklet as the control group.

Control group $(\mathrm{N}=381)$ received a booklet on general health issues and were instructed to address any health concerns in their usual manner.

\section{Outcomes}

Mean number of binge drinking episodes in the last 30 days, mean number of drinks in previous seven days, mean number of participants binge drinking in last 30 days, mean number of participants reporting excessive drinking in the previous seven days (> 18 drinks per week for men and > 13 for women); all reported separately by gender.

Assessed at 12 months.

Funding source $\quad$ Funding: This research was supported by Grants FCM/03 and FCM/04 (Fundacion Cerebro y Mente) and Instituto de Salud Carlos III, Centro de Investigación en Red de Salud Mental, CIBERSAM.

Declaration of interests Conflict of Interest: none of the authors have any conflicts of interest associated with the work presented in this manuscript.

Notes $\quad$ Loss to follow-up:

BI group: 31/371 (8\%).

Control group: $47 / 381(12 \%)$.

\section{Risk of bias}


Rubio 2010 (Continued)

$\begin{array}{ll}\begin{array}{l}\text { Random sequence genera- } \\ \text { tion (selection bias) }\end{array} & \text { Low risk } \\ \end{array}$

Allocation concealment Unclear risk Implementation of sequence not reported.

(selection bias)

\begin{tabular}{lll}
\hline $\begin{array}{l}\text { Blinding of treatment } \\
\text { providers }\end{array}$ & High risk & Not blinded. \\
\hline Blinding of participants & High risk & Not blinded. Screened by AUDIT. \\
\hline $\begin{array}{l}\text { Blinding of outcome as- } \\
\text { sessment (detection bias) } \\
\begin{array}{l}\text { All outcomes } \\
\hline\end{array}\end{array}$ & Low risk & Conducted by blinded researchers not assigned to the subject's clinic (p. 73). \\
\hline
\end{tabular}

Incomplete outcome data Low risk Loss to follow-up reported with reasons.

(attrition bias)

All outcomes

Selective reporting (re- Low risk Outcomes specified in methods are reported.

porting bias)

\section{Schaus 2009}

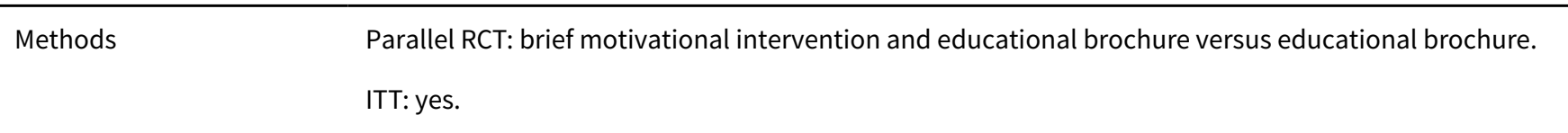

Participants

Setting: USA, university primary care centre.

Participants: students $\geq 18$ years who reported drinking $\geq 5$ (for men) or $\geq 4$ (for women) drinks containing alcohol in a row on at least one occasion during the past two weeks, screened with an 11-item health questionnaire including quantity frequency alcohol question; excluded if pregnant, or planning to leave the university within 12 months, or already enrolled in an alcohol or drug treatment program, or had consumed more than 200 drinks in the past 30 days, or had a BAC greater than 0.35 on any day within the past 30 days.

Number randomised $=363 ; 48 \%$ male; mean age not reported for total sample; $77 \%$ White, $5 \%$ Black, $11 \%$ Hispanic, $2 \%$ Asian, $1 \%$ American Indian or Alaskan Native, $3 \%$ Other, $1 \%$ prefer not to respond; $26 \%$ freshman, $21 \%$ sophomore, $28 \%$ junior, $17 \%$ senior, $8 \%$ graduate/post baccalaureate.

At baseline: mean number of days drinking in past 30 days $=8.6$, number of days episodic (5/4) drinking $=5.2$, mean $B A C=0.08$, mean peak $B A C=0.15$.

Interventions

BMI group ( $N=181,174$ completed intervention) received two 20-minute BMI sessions from health centre staff (physicians, physician assistants, nurses) combining patient-centred MI techniques and cognitive-behavioural skills training, and written individual normative feedback based on the participant's baseline assessment. The focus of the first BMI session was to establish rapport between the participant and the provider by focusing on positive lifestyle concerns of the patient. The second session maintained the student-centred focus of $\mathrm{MI}$ and stressed the alcohol skills training components of the BASICS program. At completion of the second BMI session, participants received the participant feedback document for future reference, along with an alcohol prevention educational brochure entitled 'Drinking: What's Normal, What's Not'.

Control group ( $\mathrm{N}=182$ ) received the brochure only.

Outcomes

Mean typical BAC, mean peak BAC, mean number of drinks per sitting, mean number of drinks per week, mean number of times drunk in a typical week, mean peak number of drinks in a sitting, mean 
Schaus 2009 (Continued)

number of days heavy episodic drinking (met 5/4) in month, mean RAPI (Rutgers Alcohol Problem Index) score; all in previous 30 days.

Assessed at 3, 6, 9 and 12 months.

\begin{tabular}{ll}
\hline Funding source & $\begin{array}{l}\text { This research was supported by National Institute on Alcohol Abuse and Alcoholism grants } 1 \text { U18 } \\
\text { AA015673-01 and U01 AA14741. }\end{array}$ \\
\hline Declaration of interests & Not reported. \\
\hline Notes & USD 30 at baseline, USD 10 each at three, six, nine months; USD 40 at 12 months. \\
& Loss to follow-up at 12 months: \\
BMI: $70 / 181(39 \%)$. \\
Control: $57 / 182(31 \%)$.
\end{tabular}

\section{Risk of bias}

\begin{tabular}{|c|c|c|}
\hline Bias & Authors' judgement & Support for judgement \\
\hline $\begin{array}{l}\text { Random sequence genera- } \\
\text { tion (selection bias) }\end{array}$ & Low risk & $\begin{array}{l}\text { Subjects were block randomised using SPSS to either the control or the inter- } \\
\text { vention group, where the order of the interventions varied randomly within } \\
\text { each block (p. 132). }\end{array}$ \\
\hline $\begin{array}{l}\text { Allocation concealment } \\
\text { (selection bias) }\end{array}$ & Unclear risk & $\begin{array}{l}\text { "The group assignment was placed into a sealed envelope by the data manag- } \\
\text { er and was not available to those recruiting subjects until after informed con- } \\
\text { sent was obtained" (p. 132). }\end{array}$ \\
\hline $\begin{array}{l}\text { Blinding of treatment } \\
\text { providers }\end{array}$ & Low risk & $\begin{array}{l}\text { Control groups were allocated to health providers who received no training in } \\
\text { BI (a different group of people to those who administered brief intervention), } \\
\text { so no chance of cross-contamination. }\end{array}$ \\
\hline Blinding of participants & Unclear risk & $\begin{array}{l}\text { Participants filled in a healthy lifestyle questionnaire as well as alcohol ques- } \\
\text { tions at screening, but all participants received an alcohol-related educational } \\
\text { brochure (p. 132). }\end{array}$ \\
\hline $\begin{array}{l}\text { Blinding of outcome as- } \\
\text { sessment (detection bias) } \\
\text { All outcomes }\end{array}$ & Unclear risk & $\begin{array}{l}\text { Participants completed follow-up documents online; unclear whether data as- } \\
\text { sessors could see group allocation. }\end{array}$ \\
\hline $\begin{array}{l}\text { Incomplete outcome data } \\
\text { (attrition bias) } \\
\text { All outcomes }\end{array}$ & High risk & Loss to follow-up $>30 \%$. \\
\hline $\begin{array}{l}\text { Selective reporting (re- } \\
\text { porting bias) }\end{array}$ & Low risk & Measures stated in the methods were reported in the results. \\
\hline
\end{tabular}

\section{Scott 1990}

\begin{tabular}{ll}
\hline Methods & Parallel RCT: brief intervention versus control. \\
ITT: yes.
\end{tabular}

\begin{tabular}{ll}
\hline Participants & Setting: England, general practice. \\
& $\begin{array}{l}\text { Participants: } 17 \text { to } 69 \text { years, consuming }>350 \mathrm{~g} \text { alcohol for men and }>168 \mathrm{~g} \text { for women in previous } \\
\text { week; screened by Health Survey Questionnaire including quantity frequency measure of alcohol; }\end{array}$ \\
\hline
\end{tabular}


Scott 1990 (Continued)

excluded if consumption > $1050 \mathrm{~g} /$ week for men or $560 \mathrm{~g} /$ week for women, or previous advice to cut down during the previous year.

Number randomised $=226 ; 68 \%$ male; mean age $=44.7$ years.

At baseline: mean alcohol consumption for previous week (from interview) $=526 \mathrm{~g}$ for men, $293 \mathrm{~g}$ for women; mean quantity frequency drinking for previous week (from HSQ) $=439 \mathrm{~g}$ for men, $247 \mathrm{~g}$ for women; binge drinkers $=43 \%$ for men (defined as consumption of $140 \mathrm{~g}$ on at least two occasions in previous three months), $18 \%$ for women (defined as consumption of $>14$ units on at least two occasions in previous three months).

Interventions

Intervention group ( $\mathrm{N}=113$ ) asked at the end of the assessment interview to make an appointment with their own general practitioner. Advice lasted ten minutes and consisted of feedback of the assessment interview and results of blood tests, information on the risks of excessive drinking, information on the benefits of drinking less, information on how the patient's weekly alcohol consumption compared with that of the general population using a histogram, and advice to reduce alcohol consumption to below four units per week. Advice was supplemented with a self-help booklet (the 'Cut Down on Drinking' booklet) designed for the study.

Control group $(\mathrm{N}=113$ ) received no advice from their general practitioner, except at their own request.

\begin{tabular}{ll}
\hline Outcomes & Change in weekly alcohol consumption. \\
& Assessed at one year. \\
\hline Funding source & $\begin{array}{l}\text { The pilot study was supported by the Alcohol and Education Research Council and the main study by } \\
\text { the Mental Health Foundation. }\end{array}$ \\
\hline Declaration of interests & Not reported. \\
\hline Notes & $\begin{array}{l}\text { 'Cut Down on Drinking' trial. } \\
\text { Loss to follow-up: } \\
\text { Intervention group }=33 / 113(29 \%) . \\
\text { Control group }=43 / 113(38 \%) .\end{array}$ \\
\hline
\end{tabular}

\section{Risk of bias}

\begin{tabular}{|c|c|c|}
\hline Bias & Authors' judgement & Support for judgement \\
\hline $\begin{array}{l}\text { Random sequence genera- } \\
\text { tion (selection bias) }\end{array}$ & Low risk & Random numbers table used to randomise patients (p. 891). \\
\hline $\begin{array}{l}\text { Allocation concealment } \\
\text { (selection bias) }\end{array}$ & Low risk & $\begin{array}{l}\text { Allocated at assessment interview before making an appointment with doctor } \\
\text { (p. 891). }\end{array}$ \\
\hline $\begin{array}{l}\text { Blinding of treatment } \\
\text { providers }\end{array}$ & Low risk & $\begin{array}{l}\text { Researcher carried out baseline assessment and only intervention patients } \\
\text { were asked to make an appointment with GP so low risk of contamination be- } \\
\text { tween groups. }\end{array}$ \\
\hline Blinding of participants & Low risk & $\begin{array}{l}\text { No mention was made that the assessment interview was about alcohol con- } \\
\text { sumption, and alcohol questions were embedded amongst other health-relat- } \\
\text { ed questions. }\end{array}$ \\
\hline $\begin{array}{l}\text { Blinding of outcome as- } \\
\text { sessment (detection bias) } \\
\text { All outcomes }\end{array}$ & Low risk & Follow-up interview done by a researcher blinded to patient allocation. \\
\hline $\begin{array}{l}\text { Incomplete outcome data } \\
\text { (attrition bias) } \\
\text { All outcomes }\end{array}$ & High risk & Loss to follow-up $>30 \%$. \\
\hline
\end{tabular}


Scott 1990 (Continued)

Selective reporting (re- Low risk Outcomes specified in methods are reported. porting bias)

Segatto 2011

Methods

Parallel RCT: motivational intervention and educational brochure versus educational brochure only.

ITT: no.

Participants Setting: Brazil, emergency room (ER).

Participants: Aged 16 to 25 years, admitted to ER up to six hours after last alcohol use, permanent residents in Uberlandia, able to read and understand consent forms, screened with multiple choice questionnaire; excluded if no permanent address in the city, or unable to interview, or psychotic or mental disorder, or cognitive damage, or under arrest, or undergoing treatment at addiction care centres, or refusal to participate (due to physical pain, fatigue or lack of interest), or alcohol use $>6$ hours prior to ER visit.

Number randomised $=175 ; 90 \%$ male; mean age $=21.8$ years; $71 \%$ Caucasian; $1 \%$ illiterate, $49 \%$ junior high, $47 \%$ senior high, $3 \%$ university or college.

Interventions

MI group ( $N=87$ ) received one 45-minute motivational interview from a trained senior psychologist, followed by a three-page educational brochure on risks of alcohol consumption and possible ways or tips to consider reduction or to avoid problems related to alcohol abuse.

EB group $(\mathrm{N}=88)$ received the same educational brochure plus maximum five minute discussion with trained junior psychologist researchers.

\begin{tabular}{ll}
\hline Outcomes & $\begin{array}{l}\text { Mean number of days of alcohol use, mean number of days of light use (one to four units/day), both in } \\
\text { previous three months. } \\
\text { Assessed at } 90 \text { days. }\end{array}$ \\
\hline Funding source & Not reported. \\
\hline Declaration of interests & Not reported. \\
\hline Notes & Loss to follow-up: \\
MI group: $13 / 87(15 \%)$. \\
EB group: $13 / 88(15 \%)$.
\end{tabular}

\section{Risk of bias}

\begin{tabular}{lll}
\hline Bias & Authors' judgement & Support for judgement \\
\hline $\begin{array}{l}\text { Random sequence genera- } \\
\text { tion (selection bias) }\end{array}$ & Low risk & "A lottery system was employed" (p. 227). \\
\hline $\begin{array}{l}\text { Allocation concealment } \\
\text { (selection bias) }\end{array}$ & Low risk & $\begin{array}{l}\text { The lottery system was performed "by ER personnel not linked to the clinical } \\
\text { trial in order to avoid selection bias" (p. 227). }\end{array}$ \\
\hline $\begin{array}{l}\text { Blinding of treatment } \\
\text { providers }\end{array}$ & Low risk & $\begin{array}{l}\text { One psychologist was responsible for administering intervention and different } \\
\text { researchers were responsible for screening and "control" condition, therefore } \\
\text { no chance of cross-contamination. }\end{array}$ \\
\hline
\end{tabular}


Segatto 2011 (Continued)

Blinding of participants L Low risk $\quad$ "Patients were blinded to the intervention applied" (p. 228).

$\begin{array}{ll}\begin{array}{l}\text { Blinding of outcome as- } \\ \text { sessment (detection bias) }\end{array} & \text { High risk }\end{array} \quad \begin{aligned} & \text { "The person who conducted the follow-up was not a baseline recruiter or in- } \\ & \text { terventionist, nor was intervention condition masked" (p. 228). }\end{aligned}$

All outcomes

Incomplete outcome data Low risk Loss to follow-up reported with reasons.
(attrition bias)

All outcomes

Selective reporting (re- Low risk Outcomes specified in methods are reported.
porting bias)

porting bias)

\section{Senft 1997}

Methods $\quad$ Parallel RCT: brief intervention versus usual care.

ITT: yes.
Participants Setting: USA, primary care clinics.
Participants: $\geq 21$ years, total AUDIT score $=8$ to 21 , or sum of AUDIT frequency \& quantity item scores $\geq$ 5 , or $\geq 6$ drinks (defined as 10 oz beer or 4 oz wine or 1 oz liquor) per occasion at least weekly; screened by questionnaire including AUDIT; excluded if pregnant.
Number randomised $=516 ; 71 \%$ male; mean age $=42.4$ years; $82 \%$ white, $18 \%$ non-white; some college or more $=59.5 \%$.
At baseline: mean AUDIT score $=10.6$; mean weekly drinking days $=3.4$; mean drinks per drinking day $=$ 4.9; binge drinkers (defined as $\geq 6$ drinks per occasion at least weekly) $=28 \%$.

Interventions

Intervention group $(\mathrm{N}=260)$ received a 30 -second message from the primary care clinician and a 15minute session with a health counsellor immediately following the medical visit. Clinicians included primary care physicians, nurse practitioners, and physicians' assistants. Screeners cued clinicians to deliver a brief message, based on the following script, to patients in their exam rooms: "Thank you for filling out the AUDIT questionnaire. I'm concerned that your drinking may pose a risk to your health. I recommend that you consider cutting down on your drinking and l'd like you to meet briefly with the health counsellor today after our visit". Health counsellors were trained in principles of motivational interviewing. Components of the counselling session included: gathering additional information about the quantity and frequency of the subject's alcohol use and giving feedback by comparison to national norms; explaining the acute and chronic effects of alcohol use and teaching the patient ways to estimate blood alcohol level; recommending no more than three drinks daily for men, no more than two drinks daily for women, and no alcohol on at least two days per week. Abstinence was mentioned as the only sure method of eliminating health risks from alcohol and "zero" alcohol was recommended for driving; suggesting some options to help achieve lower-risk drinking. If the patient was receptive, a low-risk drinking plan was created, building the patient's confidence that he or she could succeed. All intervention group patients, whether or not they agreed to the counselling session, were offered a packet of printed materials.

Control group $(\mathrm{N}=256)$ received usual care only.

Outcomes Number of standard drinks or total standard ethanol content units in previous three months; drinking
pattern (steady, episodic, or combination); peak blood alcohol concentration.

Assessed at 6 and 12 months.

$\begin{array}{ll}\text { Funding source } & \text { This research was supported by grant number R01 AA08976 from the National Institute on Alcohol } \\ \text { Abuse and Alcoholism. }\end{array}$
This research was suppor
Abuse and Alcoholism.

Declaration of interests Not reported. 
Senft 1997 (Continued)

Notes
Loss to follow-up:

Intervention group: 64/260 (25\%).

Control group: $41 / 256$ (16\%).

This study did not exclude participants told by their GP to avoid alcohol.

\section{Risk of bias}

\begin{tabular}{|c|c|c|}
\hline Bias & Authors' judgement & Support for judgement \\
\hline $\begin{array}{l}\text { Random sequence genera- } \\
\text { tion (selection bias) }\end{array}$ & Unclear risk & Sequence generation not reported. \\
\hline $\begin{array}{l}\text { Allocation concealment } \\
\text { (selection bias) }\end{array}$ & Unclear risk & Method of allocation concealment not reported. \\
\hline $\begin{array}{l}\text { Blinding of treatment } \\
\text { providers }\end{array}$ & High risk & $\begin{array}{l}\text { GPs saw all participants and delivered a } 30 \text { second message giving advice to } \\
\text { cut down to intervention group. }\end{array}$ \\
\hline Blinding of participants & High risk & No reported attempt to blind participants. \\
\hline $\begin{array}{l}\text { Blinding of outcome as- } \\
\text { sessment (detection bias) } \\
\text { All outcomes }\end{array}$ & Low risk & $\begin{array}{l}\text { Follow-up telephone interviews done by interviewers who were unaware of } \\
\text { subjects' study group status (p. 465). }\end{array}$ \\
\hline $\begin{array}{l}\text { Incomplete outcome data } \\
\text { (attrition bias) } \\
\text { All outcomes }\end{array}$ & Unclear risk & Loss to follow-up reported but no reasons. \\
\hline $\begin{array}{l}\text { Selective reporting (re- } \\
\text { porting bias) }\end{array}$ & Low risk & Outcomes specified in methods are reported. \\
\hline
\end{tabular}

\section{Seppa 1992}

$\begin{array}{ll}\text { Methods } & \text { Parallel RCT: brief intervention versus control. } \\ \text { ITT: unclear. }\end{array}$

ITT: unclear.

Setting: Finland, general practice.
Participants
mo Modified Michigan Alcoholism Screening Test and macrocytosis for which no other aetiology was
found, medical history giving clues to alcohol abuse or an alcohol-induced increase in serum gamma
glutamyltransferase $(\mathrm{GGT})(\geq 50 \mathrm{U} / \mathrm{L})$ were taken into account
Number randomised $=178 ; 79 \%$ male; mean age $=53.2$ years.
At baseline: mean $\mathrm{MCV}=101.6 \mathrm{fl} ; \mathrm{GGT}=145.4 \mathrm{U} / \mathrm{L}$.

Interventions

Intervention group ( $\mathrm{N}=92$ ) were asked to visit the doctor $(\mathrm{GP})$ at intervals of three months for one year to monitor their MCV value and long-term alcohol consumption. The sessions were brief: the patients were asked about their alcohol consumption, were informed about the results of their blood test, and encouraged to minimise consumption.

Control group $(\mathrm{N}=86)$ received no intervention, but were invited by mail to contact their doctor one year later.

Outcomes Self-report of whether alcohol consumption was reduced; patient history for past year; MCV values. Assessed at 12 months. 
Seppa 1992 (Continued)

\begin{tabular}{ll} 
Funding source & Not reported. \\
\hline Declaration of interests & Not reported. \\
\hline Notes & $\begin{array}{l}\text { Loss to follow-up: } \\
\text { Intervention group }=51 / 92(55 \%) . \\
\end{array}$ \\
& Control group $=32 / 86(37 \%)$.
\end{tabular}

\title{
Risk of bias
}

\begin{tabular}{lll}
\hline Bias & Authors' judgement & Support for judgement \\
\hline $\begin{array}{l}\text { Random sequence genera- } \\
\text { tion (selection bias) }\end{array}$ & Unclear risk & No information on how sequence was generated. \\
\hline $\begin{array}{l}\text { Allocation concealment } \\
\text { (selection bias) }\end{array}$ & Unclear risk & No information on concealment of allocation. \\
\hline $\begin{array}{l}\text { Blinding of treatment } \\
\text { providers }\end{array}$ & High risk & Doctors saw patients from both arms. \\
\hline $\begin{array}{l}\text { Blinding of participants } \\
\text { Blinding of outcome as- } \\
\text { sessment (detection bias) }\end{array}$ & High risk & No reported attempt to blind participants. \\
$\begin{array}{l}\text { All outcomes } \\
\begin{array}{l}\text { Incomplete outcome data } \\
\text { (attrition bias) } \\
\text { All outcomes }\end{array}\end{array}$ High risk & No information available on blinding. \\
\hline $\begin{array}{l}\text { Selective reporting (re- } \\
\text { porting bias) }\end{array}$ & Low risk & Loss to follow-up > 30\%. \\
\hline
\end{tabular}

Soderstrom 2007

Methods $\quad$ Parallel RCT: brief personalised motivational intervention versus brief information and advice.

ITT: yes.

Participants

\begin{abstract}
Setting: USA, Shock Trauma Centre.
Participants: $\geq 18$ years and English speaking, with intact cognition and hospital length of stay $\geq 12$ hours, reporting (1) any positive response to an item of the CAGE questionnaire, or (2) drinking two or more times per week with total weekly drinking of eight or more drinks for women and 15 or more drinks for men, or (3) drinking two to four times a month or less with typical daily consumption of four or more drinks for women and five or more drinks for men, or (4) drinking six or more drinks on one occasion, weekly, daily or almost daily, screened with CAGE and AUDIT; excluded if unstable contact information, or legal issues (i.e. probation or parole), or a severe alcohol use problem considered inappropriate for a brief intervention, or a severe drug use problem.
\end{abstract}

Number randomised $=497 ; 85 \%$ male; mean age of total sample not reported; $63 \%$ White.

Baseline characteristics of total sample not reported.

Interventions

Personalised motivational intervention (PMI) group $(N=250)$ received (i) a 15 to 20 minute motivational interview from trained clinical psychology doctoral graduates who explored information obtained in 
the intake interview to help the subject evaluate his or her drinking patterns, assess motivations and barriers to change, explore motivation to modify drinking behaviours and support any initiative to reduce or eliminate excessive drinking; (ii) a personalised feedback letter that summarised participant intake data and provided feedback based on responses to the questionnaires regarding problem dimensions, as well as stage of change, decisional balance, self-efficacy, risk taking, stress and social support with some recommended actions, sent within one week of the subject's discharge; (iii) a phone call (duration not reported) from same interventionist after several days to reinforce the interview and discuss the letter, where attempts were made to elicit a specific change plan (according to the participant's stage of change) regarding drinking behavior; (iv) a further phone call (duration not reported) four weeks after trauma centre discharge, where the same interventionist checked the change plan, reassessed motivation, discussed problem solving difficulties and barriers, supported self efficacy and reinforced the need and motivation to modify drinking behaviour.

Brief information and advice (BIA) group ( $N=247$ ) received (i) advice (duration not reported) from trained clinical psychology doctoral graduates to reduce their drinking to reduce future risk of injury; (ii) a two-page handout that described causes of injury, the role of alcohol and injury, definition of a drink, types of drinkers, alcohol consumption in the United States, alcohol-related problems, and tips on how to reduce drinking or receive help; (iii) a phone call (duration not reported) two weeks after discharge from the same interventionist asking how they were doing, if they had a chance to read the handout and if they had any questions.

\begin{tabular}{ll}
\hline Outcomes & $\begin{array}{l}\text { Mean number of drinks, mean number of binges, both within the last } 90 \text { days. } \\
\text { Assessed at } 6 \text { and } 12 \text { months. }\end{array}$ \\
\hline Funding source & Supported by the National Institute on Alcoholic Abuse and Alcoholism (grant 2 R01 AA09050-04A2). \\
\hline Declaration of interests & Not reported. \\
\hline Notes & Extended versus brief. \\
& Loss to follow-up at 12 months for outcome 1: $249(50 \%)$ in total (unclear per arm). \\
& Loss to follow-up at 12 months for outcome 2: $248(50 \%)$ in total. \\
& We contacted the authors, who supplied missing data.
\end{tabular}

\section{Risk of bias}

\begin{tabular}{lll}
\hline Bias & Authors' judgement & Support for judgement \\
\hline $\begin{array}{l}\text { Random sequence genera- } \\
\text { tion (selection bias) }\end{array}$ & Unclear risk & Generation of randomisation sequence not reported. \\
\hline $\begin{array}{l}\text { Allocation concealment } \\
\text { (selection bias) }\end{array}$ & Unclear risk & $\begin{array}{l}\text { "After the intake was completed the intervention specialist opened a sealed } \\
\text { envelope which indicated the subject's group assignment" (p. 1103). }\end{array}$ \\
\hline $\begin{array}{l}\text { Blinding of treatment } \\
\text { providers }\end{array}$ & High risk & $\begin{array}{l}\text { Not blinded and delivered both arms of trial therefore increased chance of } \\
\text { contamination. }\end{array}$ \\
\hline $\begin{array}{l}\text { Blinding of participants } \\
\text { Blinding of outcome as- } \\
\begin{array}{l}\text { sessment (detection bias) } \\
\text { All outcomes }\end{array}\end{array}$ & High risk & Not blinded. Screening tools alcohol focused. \\
\hline $\begin{array}{l}\text { Incomplete outcome data } \\
\text { (attrition bias) } \\
\text { All outcomes }\end{array}$ & High risk & Unclear whether outcome assessor was blind to group allocation. \\
\hline
\end{tabular}


Soderstrom 2007 (Continued)

Selective reporting (re- Unclear risk $\quad$ Primary outcome not specified and not all measures listed in the methods are porting bias) reported in the results.

Sommers 2006

Methods $\quad$ Parallel RCT: brief counselling versus simple advice versus usual care.

ITT: unclear.

\begin{abstract}
Participants Setting: USA, level 1 trauma centres.
Participants: 18 to 45 years, English speaking with intact cognition, hospitalised within 24 hours of an injury after a motor vehicle crash, $\mathrm{BAC} \geq 10 \mathrm{mg} / \mathrm{dL}$, potential for discharge from hospital to home within four weeks after entry into the study; screened by daily review of the emergency department (ED) or trauma service admitting logs; excluded if they had attended an alcohol treatment program in the past year, or evidenced signs and symptoms of alcohol withdrawal, or had received advice from their health care provider in the past three months to reduce their alcohol use, or drank more than $150 \mathrm{~g}$ of alcohol (12 standard drinks) per day, or scored $\geq 2$ on any or all of the three alcohol-dependence items on AUDIT.
\end{abstract}

Number randomised $=187 ; 78 \%$ male; mean age $=29.03$ years; $89 \%$ White.

At baseline: mean $B A C=165.18 \mathrm{mg} / \mathrm{dL}$.

Interventions

$\mathrm{BC}$ group ( $\mathrm{N}=63$ ) received (i) 20 minute brief counselling based on WHO model, TrEAT, FRAMES and reflective listening, using a printed self-help manual, from a nurse clinician hired for the study, on alcohol consumption and its consequences, recommended drinking limits, feedback about the participant's drinking behaviours to make the connection between drinking and the injury, pros and cons of changing drinking behaviours and how the participant's life might be different with a change in drinking, a realistic drinking agreement was negotiated based on the discussion; (ii) a 20 minute booster phone call by the same interventionist one month after discharge to review the agreement, explore risky situations, and devise coping mechanisms, drinking goals were re-negotiated.

SA group ( $N=68$ ) received (i) five minutes of feedback, using a printed self-help manual, from a nurse clinician hired for the study, that they were drinking in ways that put their health at risk and advice about current health behaviours and adverse effects of alcohol. The most important part of the simple advice intervention was to discuss "low risk" drinking and to review the menu of alternative choices: abstinence or cutting back to low risk drinking; (ii) a five minute booster phone call by the same interventionist one month after discharge, repeating the same information.

Control group ( $\mathrm{N}=56)$ : no details reported.

Outcomes Mean BAC, mean number of standard drinks in previous month, number of binges in previous month.

Assessed at 3, 6 and 12 months.

Funding source $\quad$ Funded by the Centers for Disease Control and Prevention, National Center for Injury Control and Prevention, R49/CCR-510153.

Declaration of interests Not reported.

Notes Loss to follow-up at 12 months:

BC group: 26/63 (41\%).

SA group: $39 / 68$ (57\%).

Control group: 22/56 (39\%). 
Sommers 2006 (Continued)

Risk of bias

\begin{tabular}{|c|c|c|}
\hline Bias & Authors' judgement & Support for judgement \\
\hline $\begin{array}{l}\text { Random sequence genera- } \\
\text { tion (selection bias) }\end{array}$ & Unclear risk & Not described. \\
\hline $\begin{array}{l}\text { Allocation concealment } \\
\text { (selection bias) }\end{array}$ & Unclear risk & Not described. \\
\hline $\begin{array}{l}\text { Blinding of treatment } \\
\text { providers }\end{array}$ & Unclear risk & Unclear if individual nurse clinicians delivered all arms. \\
\hline Blinding of participants & High risk & Not blinded. \\
\hline $\begin{array}{l}\text { Blinding of outcome as- } \\
\text { sessment (detection bias) } \\
\text { All outcomes }\end{array}$ & Low risk & $\begin{array}{l}\text { "Interviewers were blinded to participant condition during follow-up inter- } \\
\text { views" (p. 525). }\end{array}$ \\
\hline $\begin{array}{l}\text { Incomplete outcome data } \\
\text { (attrition bias) } \\
\text { All outcomes }\end{array}$ & High risk & Loss to follow-up $>30 \%$. \\
\hline $\begin{array}{l}\text { Selective reporting (re- } \\
\text { porting bias) }\end{array}$ & Low risk & Outcomes specified in methods are reported. \\
\hline
\end{tabular}

Sommers 2013

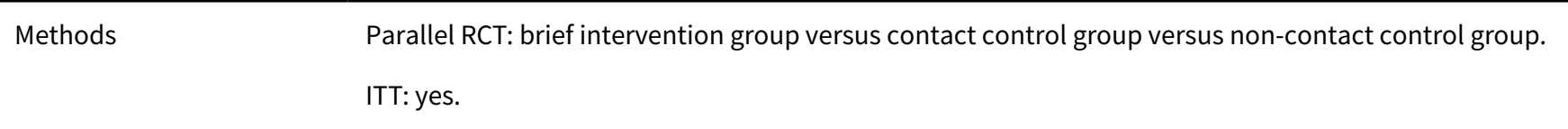

Participants

Setting: USA, emergency department.

Participants: Aged 18 to 44 years admitted to emergency department between 8 am and 2am on randomly selected days, drove a motor vehicle two days per week, screened positive on two risky driving and two hazardous drinking items in the three minute screen (at least two of the following in the past month: four standard alcoholic drinks on a typical drinking day, five drinks per occasion for women and six for men, 11 drinks per week for women and 14 for men); excluded if no identifiable residence or contact phone number, or were under arrest at the time of emergency department visit, or were unable to participate in an English language screen due to language or cognitive barriers, or were admitted to the hospital as an inpatient, or had a history of daily alcohol use suggesting alcohol dependence on AUDIT.

Number randomised $=476 ; 70 \%$ male; age range $=23$ to 34.5 years; $62 \%$ non-White; $57 \%$ employed fulltime, $17 \%$ employed part-time, $26 \%$ unemployed; $17 \%$ less than high school, $38 \%$ high school graduate, $45 \%$ more than high school.

Baseline data not reported for total sample.

Interventions

BI group ( $N=150$ ) received (i) a 20 minute SBIRT intervention from a nurse clinician employed for the study, based on FRAMES and reflective listening, on both reducing risky driving practices and reducing alcohol (a drinking typology - dependent, heavy, and low-risk drinkers), the early consequences of heavy drinking, and tips to cut down on drinking. They received written feedback adapted from the TrEAT protocol on their risky driving and hazardous alcohol behaviours, and the interventionist discussed pros and cons of behaviours and negotiated a contract for change; (ii) a 20 minute booster telephone call 10 to 14 days after discharge the interventionist discussed and renegotiated the contract. 
Sommers 2013 (Continued)

CC group ( $N=162$ ) received same 20 minute assessment as BIG group but no intervention.

NC group $(\mathrm{N}=164)$ received no assessment or intervention.

Outcomes Number of participants drinking $\geq 5$ drinks per drinking day in previous three months, median maximum number of drinks within six hour period, median number of drinks in a typical week, median number of drinks in a typical day, number of participants having $\geq 1$ binge per month, number of participants with AUDIT > 10; also driving-related outcomes.

Assessed at 3, 6, 9 and 12 months.

Funding source This work was funded by a grant (R49/CCR-523225) from the National Center for Injury Prevention and Control, Centers for Disease Control and Prevention (PI:MSS).

\begin{tabular}{|c|c|}
\hline Declaration of interests & Not reported. \\
\hline \multirow[t]{7}{*}{ Notes } & An SBIRT study. \\
\hline & $\begin{array}{l}\text { USD } 20 \text { at enrolment; USD } 20 \text { for baseline, three, six, nine month interviews, USD } 40 \text { for } 12 \text { month inter- } \\
\text { view. }\end{array}$ \\
\hline & Loss to follow-up: \\
\hline & BIG group: 53/150 (35\%). \\
\hline & CCG group: 53/162 (33\%). \\
\hline & NCG group: 43/164 (26\%). \\
\hline & We contacted the authors, who supplied missing data. \\
\hline
\end{tabular}

\section{Risk of bias}

\begin{tabular}{|c|c|c|}
\hline Bias & Authors' judgement & Support for judgement \\
\hline $\begin{array}{l}\text { Random sequence genera- } \\
\text { tion (selection bias) }\end{array}$ & Low risk & Randomisation by computer software (p. 1754). \\
\hline $\begin{array}{l}\text { Allocation concealment } \\
\text { (selection bias) }\end{array}$ & Low risk & $\begin{array}{l}\text { "Enrolment packets of the same size and thickness were placed in opaque en- } \\
\text { velopes, sealed and locked in a drawer in consecutive order by participant } \\
\text { number" (p. 1754). }\end{array}$ \\
\hline $\begin{array}{l}\text { Blinding of treatment } \\
\text { providers }\end{array}$ & High risk & $\begin{array}{l}\text { The assessment, brief intervention, and booster intervention were delivered } \\
\text { by } 4 \text { nurse clinicians employed by the study team; i.e. treatment providers had } \\
\text { contact with all participants. }\end{array}$ \\
\hline Blinding of participants & High risk & No reported attempt to blind participants. \\
\hline $\begin{array}{l}\text { Blinding of outcome as- } \\
\text { sessment (detection bias) } \\
\text { All outcomes }\end{array}$ & Low risk & "Interviewers were blinded to condition during follow-up interviews" (p. 1755) \\
\hline $\begin{array}{l}\text { Incomplete outcome data } \\
\text { (attrition bias) } \\
\text { All outcomes }\end{array}$ & High risk & Loss to follow-up $>30 \%$ overall. \\
\hline $\begin{array}{l}\text { Selective reporting (re- } \\
\text { porting bias) }\end{array}$ & Low risk & Outcomes specified in methods were reported. \\
\hline
\end{tabular}


Spirito 2004

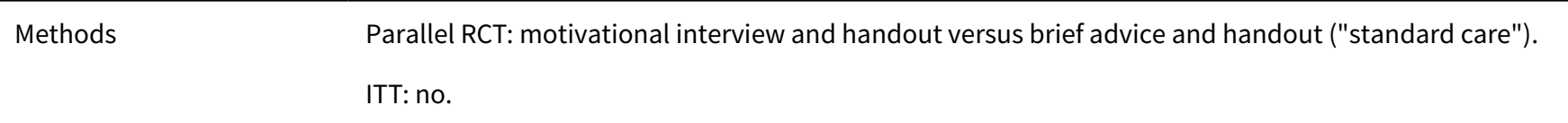

Participants Setting: USA, emergency department.

Participants: 13 to 17 years and English speaking, presenting to emergency department with evidence of alcohol in blood, breath, or saliva, or reported drinking alcohol in the six hours before the injury that required treatment in the emergency department, assessment 45 minutes, received intervention once $\mathrm{BAC}<0.1$ and/or they could pass mental state examination; excluded if suicidal, or in police custody, or had suffered serious traumatic injury requiring admission.

Number randomised $=152 ; 64 \%$ male; mean age $=15.6$ years; $72 \%$ White, $7 \%$ African American, $3 \%$ Asian/East Indian, 17\% Hispanic, 1\% Native American; 28\% middle school, 57\% high school, 3\% high school graduate or equivalent, $12 \%$ dropped out or expelled.

Baseline data not reported for total sample.

Interventions

MI group ( $N=78$ ) received (i) handout on avoiding drinking and driving; (ii) list of substance abuse treatment referral services; (iii) personalised feedback sheet; (iv) information sheets on negative effects of alcohol; (v) 35 to 45 minute motivational interview with study researchers trained in MI. MI protocol included the following six components: (1) emphasis on personal responsibility for change and that any decisions made about changing their drinking would be up to them; (2) exploration of motivation for drinking and review of potential negative consequences; (3) personalised normative assessment feedback about their pattern of alcohol use and risks; (4) imagining their future if they continued to drink the same way versus if they decided to make a change in their drinking behaviour; (5) establishing goals with regard to drinking; and (6) anticipating barriers to accomplishing the goals. In addition to being empathic and avoiding argumentation, the interventionists made an effort to develop a discrepancy between the teen's current drinking behavior and current and longer-term goals, and to support the teen's sense of self-efficacy about making changes. They recommended follow-up with primary care provider.

SC group ( $N=74$ ) received (i) the same handout on avoiding drinking and driving; (ii) list of substance abuse treatment referral services (iii) five minute brief advice session from emergency department physicians advising participants to stop drinking. They recommended follow-up with primary care provider.

\section{Outcomes}

Mean days per month drinking, mean drinks per occasion, mean days per month binging ( $\geq 5$ drinks per occasion), mean number of alcohol-related injuries, percentage reporting alcohol-related problems.

Assessed at 3, 6 and 12 months.

\begin{tabular}{ll}
\hline Funding source & Supported by grant number AA09892 from the National Institute on Alcohol Abuse and Alcoholism. \\
\hline Declaration of interests & Not reported. \\
\hline Notes & USD 20 gift certificate on completion of intervention, USD 10 at three months, USD 15 at six months, \\
& USD 25 at 12 months. \\
& Only received intervention if well enough to be discharged. \\
& Loss to follow-up: \\
& MI group: $14 / 78(18 \%)$. \\
& SC group: $14 / 74(19 \%)$.
\end{tabular}

\section{Risk of bias}


Spirito 2004 (Continued)

$\begin{array}{ll}\begin{array}{l}\text { Random sequence genera- } \\ \text { tion (selection bias) }\end{array} & \begin{array}{l}\text { Used a random numbers table but randomisation took place after baseline as- } \\ \text { sessment (p. 397). }\end{array}\end{array}$

\begin{tabular}{|c|c|c|}
\hline $\begin{array}{l}\text { Allocation concealment } \\
\text { (selection bias) }\end{array}$ & Unclear risk & Not reported. \\
\hline $\begin{array}{l}\text { Blinding of treatment } \\
\text { providers }\end{array}$ & High risk & Research interventionist delivers both arms. \\
\hline Blinding of participants & High risk & No reported attempt to blind participants. \\
\hline $\begin{array}{l}\text { Blinding of outcome as- } \\
\text { sessment (detection bias) } \\
\text { All outcomes }\end{array}$ & Low risk & "Research assistants... were blind to treatment group assignment" (p. 398). \\
\hline $\begin{array}{l}\text { Incomplete outcome data } \\
\text { (attrition bias) } \\
\text { All outcomes }\end{array}$ & Unclear risk & Loss to follow-up reported but not reasons. \\
\hline $\begin{array}{l}\text { Selective reporting (re- } \\
\text { porting bias) }\end{array}$ & Unclear risk & $\begin{array}{l}\text { Two items from the ADQ were very highly correlated so they only reported one } \\
\text { of them. }\end{array}$ \\
\hline
\end{tabular}

Spirito 2011

$\begin{array}{ll}\text { Methods } & \begin{array}{l}\text { Parallel RCT: individual motivational interview versus individual motivational interview and family } \\ \text { check up. }\end{array}\end{array}$

ITT: not reported.

Participants Setting: USA, emergency department.

Participants: Aged 13 to 17 years, English or Spanish speaking, presenting to urban level 1 trauma centre with positive BAC using blood, breath or saliva, or self-reported drinking in six hours previous to emergency department visit, approached only when $\mathrm{BAC}<0.1 \%$ or they passed a mental status examination; screened by BAC or self-reported drinking within six hours of visit (Adolescent Drinking Questionnaire); excluded if suicidal, or had experienced serious traumatic injury.

Number randomised $=125 ; 46 \%$ male; mean age of total sample not reported; $66 \%$ White, $2 \%$ Black, $2 \%$ Asian American or East Indian, 28\% Hispanic, 2\% mixed race.

At baseline: mean days per month drinking $=3.4$, mean drinks per occasion $=5.3$, mean days per month drinking high volume $(\geq 5$ drinks per occasion $)=2.6$.

Interventions

IMI group ( $N=63$ ) received (i) 45 to 60 minute interview from interventionists with masters degrees in counselling and psychology that included an emphasis on personal responsibility, exploration of motivation for drinking and review of potential negative consequences, personalised normative assessment feedback, establishing goals regarding drinking, and anticipating barriers to accomplishing goals, such as peer pressure to drink. In addition to being empathic and avoiding argumentation, the interventionists made an effort to develop a discrepancy between the adolescent's current drinking and longer-term goals and to support the adolescent's sense of self-efficacy. (ii) Participants' parents were given follow-up information regarding substance use treatment services and received monthly booster brochures on parenting.

IMI + FCU group ( $\mathrm{N}=62$ randomised, 50 received intervention) received their intervention from interventionists with masters degrees in counselling and psychology: (i) the same 45 to 60 minute interview (participant only). (ii) Additionally, the family received a one hour videotaped family assessment task (called "FAsTask6"), which consists of the parent(s) and the adolescent discussing family beliefs regarding alcohol, marijuana, cigarette, other drug use and other topics, such as curfew. All FAsTask 
Spirito 2011 (Continued)

videos were coded separately by the treatment provider and a second rater to provide information to be used in the feedback session. (iii) A week after the family completed the FAsTask, parents received one hour feedback (self-assessment, support and clarification, feedback, and development of a plan for change) derived from the FAsTask and from self-report measures that assessed family stress, parent substance use, and beliefs regarding substance use. Parent motivation for change, change options, and specific steps for making positive changes in family relationships and parenting were discussed, including potential barriers to change. (iv) Participants' parents were given the same follow-up information regarding substance use treatment services and received monthly booster brochures on parenting.

Outcomes

Mean days per month drinking, mean drinks per occasion, mean days per month with high volume drinking ( $\geq 5$ drinks per occasion), number of participants reporting high volume drinking ( $\geq 5$ drinks per occasion); all for previous three months.

Assessed at 3, 6 and 12 months.

Funding source

This study was supported by grant AA013385 from the National Institute on Alcohol Abuse and Alcoholism. The study sponsor (the National Institutes of Health) had no role in (1) the study design; (2) the collection, analysis, and interpretation of data; (3) the writing of the report; and (4) the decision to submit the paper for publication.

\begin{tabular}{ll}
\hline Declaration of interests & Financial Disclosure: none reported. \\
\hline Notes & Brief intervention vs extended intervention \\
& USD 20 gift certificate for adolescent for IMI completion; USD 50 for parents for FCU completion \\
& Loss to follow-up at 12 months: \\
& IMI group: $16 / 63(25 \%)$. \\
& IMI + FCU group: $26 / 62(42 \%)$.
\end{tabular}

\section{Risk of bias}

\begin{tabular}{|c|c|c|}
\hline Bias & Authors' judgement & Support for judgement \\
\hline $\begin{array}{l}\text { Random sequence genera- } \\
\text { tion (selection bias) }\end{array}$ & Unclear risk & $\begin{array}{l}\text { Patients were randomly assigned but method of sequence generation not re- } \\
\text { ported. }\end{array}$ \\
\hline $\begin{array}{l}\text { Allocation concealment } \\
\text { (selection bias) }\end{array}$ & Unclear risk & $\begin{array}{l}\text { "Patients were then randomly assigned ... based on condition assignments } \\
\text { contained in sealed envelopes" (p. 270). }\end{array}$ \\
\hline $\begin{array}{l}\text { Blinding of treatment } \\
\text { providers }\end{array}$ & Low risk & $\begin{array}{l}\text { Both arms receive initial intervention (so no contamination) and then booster } \\
\text { is a separate visit which comprises a discussion between the family. }\end{array}$ \\
\hline Blinding of participants & Low risk & $\begin{array}{l}\text { Both arms receive initial intervention so no differential knowledge of interven- } \\
\text { tion between the groups. }\end{array}$ \\
\hline $\begin{array}{l}\text { Blinding of outcome as- } \\
\text { sessment (detection bias) } \\
\text { All outcomes }\end{array}$ & Low risk & "Research assistants... were masked to treatment group assignment" (p. 270). \\
\hline $\begin{array}{l}\text { Incomplete outcome data } \\
\text { (attrition bias) } \\
\text { All outcomes }\end{array}$ & High risk & Loss to follow-up > $30 \%$ overall. \\
\hline $\begin{array}{l}\text { Selective reporting (re- } \\
\text { porting bias) }\end{array}$ & Unclear risk & $\begin{array}{l}\text { Prespecified "feeling drunk" outcome was highly correlated with "high volume } \\
\text { drinking days" so former was omitted from results. }\end{array}$ \\
\hline
\end{tabular}




Methods Parallel RCT: brief intervention versus usual care.

ITT: unclear.
Participants Setting: Australia, emergency department.
Participants: 12 to 19 years, presenting to emergency department with involvement of alcohol or other drug use, screening "via the hospital ED information system and by liaison with medical staff" (no more details provided); no exclusion criteria specified.
Number randomised $=127 ; 55 \%$ male; mean age $=16.7$ years; $83 \%$ born in Australia; $17 \%$ in full time work.
Baseline characteristics not reported for total sample.

Interventions

Bl group $(N=60)$ received (i) an interview (duration not reported) with a named counsellor (researcher, social worker or health worker), aimed at facilitating attendance at a community AOD treatment agency. They identified and discussed negative consequences of alcohol/drug use, impediments to reduce negative consequences and high risk (trigger) situations; offered advice about appropriate services that were available in his/her local area and the type of intervention that would be offered by the external agency. Possible impediments to treatment were discussed with the adolescent (e.g. need for a counsellor of the same gender). (ii) Participants received a reminder telephone call prior to attending their appointment.

UC group $(\mathrm{N}=67)$ received "usual hospital care" (details not specified).

Outcomes

Attendance at community treatment agency by four months (reported at 4 and 12 months), hazardous alcohol use (AUDIT-3 $\geq 5$ for men or $\geq 4$ for women) at 12 months only, GHQ-12, FAD (family assessment device) scores.

Assessed at 4 and 12 months.

Funding source This study was funded by Healthway, the West Australian Health Promotion Foundation. The Alcohol Education and Rehabilitation Foundation funded the collection of ED data and subsequent analyses.

\begin{tabular}{ll}
\hline Declaration of interests & Not reported. \\
\hline Notes & Loss to follow-up at 12 months: \\
& Bl group: $22 / 60(37 \%)$. \\
& UC group: $18 / 67(27 \%)$. \\
& We contacted the authors, who supplied missing data. \\
\hline
\end{tabular}

\section{Risk of bias}

\begin{tabular}{lll}
\hline Bias & Authors' judgement & Support for judgement \\
\hline $\begin{array}{l}\text { Random sequence genera- } \\
\text { tion (selection bias) }\end{array}$ & Low risk & Computer generated randomisation codes (p. 366). \\
\hline $\begin{array}{l}\text { Allocation concealment } \\
\text { (selection bias) }\end{array}$ & Unclear risk & "Codes were held in numbered, sealed envelopes by the interviewer" (p. 366). \\
\hline $\begin{array}{l}\text { Blinding of treatment } \\
\text { providers }\end{array}$ & Unclear risk & Unclear whether interventionist researcher had contact with both groups. \\
\hline
\end{tabular}


Tait 2004 (Continued)

\begin{tabular}{lll} 
Blinding of participants & High risk & Not blinded. \\
\hline $\begin{array}{l}\text { Blinding of outcome as- } \\
\text { sessment (detection bias) } \\
\text { All outcomes }\end{array}$ & Unclear risk & Not reported. \\
\hline $\begin{array}{l}\text { Incomplete outcome data } \\
\text { (attrition bias) }\end{array}$ & High risk & Loss to follow-up > 30\% overall. \\
All outcomes & &
\end{tabular}

Selective reporting (re- Low risk Outcomes specified in methods are reported.
porting bias)

porting bias)

Tomson 1998

$\begin{array}{ll}\text { Methods } & \text { RCT: brief intervention versus usual care. } \\ \text { ITT: unclear. }\end{array}$

ITT: unclear.

Petting: Sweden, general practice health centre.
Participants: 25 to 54 years with GGT > 0.89 microkatals/L; screened by health check including GGT; ex-
cluded if chronic alcoholic.

Number randomised $=222$.

The following data is for $\mathrm{N}=75$, who were not excluded and then were followed up: $81 \%$ male; mean age $=45.2$ years; $73 \%$ blue collar, $27 \%$ white collar.

At baseline: mean weekly consumption given at baseline only for intervention group $=337 \mathrm{~g}$; mean SGGT $=1.7$ microkatals/L.

Interventions

Intervention group $(\mathrm{N}=100)$ had an appointment with a nurse to establish whether the laboratory finding could be explained by excess alcohol intake. The nurse had experience from outpatient care of alcoholics and made a 'general lifestyle and health survey interview'. The assessment also included selfreported alcohol consumption and the CAGE questionnaire. Patients responding "yes" to two or more of the four questions were classified as positive. The nurse discussed those with an unclear elevation of GGT with the GP, who sometimes recommended further examination and:or laboratory investigations. Participants classified as high consumers of alcohol ( 280 and $210 \mathrm{~g} 100 \%$ alcohol per week for men and women, respectively) were offered two more consultations with the nurse during the intervention year. The consultations focused on lifestyle in general and alcohol consumption in particular. Factors that facilitated or made controlled drinking more difficult were discussed in an empathic way. GGT was used as a biochemical feedback at follow-up.

Control group ( $\mathrm{N}=122$ ) recommended an appointment with the GP. The participants were asked about diseases and ongoing medication. They were told that the most common reasons for an elevated GGT had to do with eating and drinking habits and drug use. They were asked about their own thoughts concerning the reason for their elevated GGT. When the spontaneous response was that their alcohol consumption was a plausible explanation, the GP accepted this without comment. In the other cases the GP also made a clinical and an extended laboratory investigation. Those classified as high consumers were not given any advice about how to reduce their drinking, but were told that a follow-up was planned in one to two years.

Outcomes

GGT measured at one and two years. Data about sickness allowance days one year before, during, and one year after the intervention, and notations in the social services records were collected. The number of visits to the health centre for reasons other than alcohol intervention (intervention group), days of hospital care, and deaths up to two years after intervention were followed.

Assessed at one and two years. 
Tomson 1998 (Continued)

Declaration of interests Not reported.

\begin{tabular}{ll}
\hline Notes & Loss to follow-up: \\
& Intervention group: $70 / 100(70 \%)$. \\
& Control group: $77 / 122(63 \%)$. \\
& Randomisation $(\mathrm{n}=222)$ then assessment \& exclusion (leaving $\mathrm{n}=75$ who actually had the intervention \\
& or control sessions).
\end{tabular}

\section{Risk of bias}

\begin{tabular}{lll}
\hline Bias & Authors' judgement & Support for judgement \\
\hline $\begin{array}{l}\text { Random sequence genera- } \\
\text { tion (selection bias) }\end{array}$ & High risk & Date of birth used for randomisation (as reported in Kristensen 1983). \\
\hline $\begin{array}{l}\text { Allocation concealment } \\
\text { (selection bias) }\end{array}$ & Unclear risk & No information on how allocation was concealed. \\
\hline $\begin{array}{l}\text { Blinding of treatment } \\
\text { providers }\end{array}$ & Low risk & $\begin{array}{l}\text { Different treatment providers interacted with the different arms (nurse for in- } \\
\text { tervention group, doctor for control group: "the GP was anxious not to use the } \\
\text { consultation with the control group as an intervention but to try to rule out an } \\
\text { elevated GGT due to a serious disease" - p. 189). }\end{array}$ \\
\hline
\end{tabular}

\begin{tabular}{ll}
\hline Blinding of participants Low risk & $\begin{array}{l}\text { Recruitment letter to participants does not discuss alcohol as a reason for at- } \\
\text { tendance but just that elevated blood test needed a follow-up. }\end{array}$
\end{tabular}

\begin{tabular}{lll}
\hline $\begin{array}{l}\text { Blinding of outcome as- } \\
\text { sessment (detection bias) } \\
\text { All outcomes }\end{array}$ & Unclear risk & Not clear whether outcom \\
\hline $\begin{array}{l}\text { Incomplete outcome data } \\
\text { (attrition bias) }\end{array}$ & High risk & Loss to follow-up $>30 \%$. \\
All outcomes & &
\end{tabular}

\begin{tabular}{l}
\hline $\begin{array}{l}\text { Selective reporting (re- } \\
\text { porting bias) }\end{array}$ \\
\hline
\end{tabular}

\section{Wallace 1988}

$\begin{array}{ll}\text { Methods } & \text { RCT: brief intervention versus control. } \\ \text { ITT: unclear. }\end{array}$
Participants
Setting: UK, general practice.
Participants: 17 to 69 years, had consumed $\geq 35$ units of alcohol in previous week for men and 21 units for women, or had $\geq 2$ post ive CAGE responses; screened by self-administered health survey question- naire including quantity/frequency scale and modified CAGE; excluded if serious illness, or received medical advice about drinking in the previous year, or requested help from nurse with drinking, or GGT $>150 \mathrm{IU} / \mathrm{L}$.
Number randomised $=909 ; 71 \%$ male; mean age $=42.4$ years .
At baseline: alcohol consumption for previous week (from interview) $=55.0$ units; alcohol consumption according to questionnaire (quantity/frequency) $=44.1$ units; $G G T=23.0 \mathrm{IU} / \mathrm{L}$.

Interventions

Intervention group $(\mathrm{N}=450)$ contacted by their general practitioner and asked to attend for a brief interview. After an assessment interview about the pattern and amount of alcohol consumption and evidence of alcohol related problems and dependence (obtained by using the brief Edinburgh alcohol de- 
Wallace 1988 (Continued)

pendence scale), patients were shown a histogram based on figures from a national survey of drinking habits to illustrate how their weekly consumption compared with that of the general population. Advice was given about the potential harmful effects of their current level of alcohol consumption, backed with the information booklet 'That's the Limit'. Men were advised to drink not more than $18 \mathrm{U} /$ week and women not more than $9 \mathrm{U} /$ week. Where there was evidence of dependence on alcohol general, practitioners were encouraged to advise abstinence.

Patients were given a drinking diary, the front cover of which was a facsimile of an EClO prescription with the words "Cut Down on your Drinking!" The last page contained a guide to the alcohol content (in $U$ ) of a range of drinks. An initial follow up appointment one month later was offered to all patients; subsequent appointments at 4, 7 and 10 months were at the discretion of the general practitioner. During these sessions, the patient's drinking diary was reviewed and feedback given on the results of blood tests indicating evidence of damage due to alcohol

Control group $(\mathrm{N}=459)$ received no advice from their general practitioner about drinking except at their own request or if there was evidence that their alcohol consumption had already resulted in substantially impaired liver function (y-glutamyltransferase activity exceeding $150 \mathrm{IU} / \mathrm{L}$ ).

Outcomes

Stated alcohol consumption in the seven days before interview; consumption as assessed by the health survey questionnaire; changes in the values of laboratory indicators of alcohol consumption.

Assessed at 6 and 12 months.

Funding source

The study was generously supported by grants from the Alcohol and Education Research Council, the Brewers' Society, the Medical Council on Alcoholism, the Medical Research Council, and Merck Sharp and Dohme Ltd.

\begin{tabular}{ll}
\hline Declaration of interests & Not reported. \\
\hline Notes & Loss to follow-up: \\
& Intervention group: $87 / 450(19 \%)$ \\
& Control group: $74 / 459(16 \%)$.
\end{tabular}

\section{Risk of bias}

\begin{tabular}{|c|c|c|}
\hline Bias & Authors' judgement & Support for judgement \\
\hline $\begin{array}{l}\text { Random sequence genera- } \\
\text { tion (selection bias) }\end{array}$ & Unclear risk & Method of sequence generation not reported. \\
\hline $\begin{array}{l}\text { Allocation concealment } \\
\text { (selection bias) }\end{array}$ & Unclear risk & Not reported. \\
\hline $\begin{array}{l}\text { Blinding of treatment } \\
\text { providers }\end{array}$ & Low risk & $\begin{array}{l}\text { GPs only interviewed intervention participants and were not involved in re- } \\
\text { cruitment or baseline assessment. }\end{array}$ \\
\hline Blinding of participants & Low risk & $\begin{array}{l}\text { Recruitment and screening described as "lifestyle and health survey inter- } \\
\text { view" (p. 664). }\end{array}$ \\
\hline $\begin{array}{l}\text { Blinding of outcome as- } \\
\text { sessment (detection bias) } \\
\text { All outcomes }\end{array}$ & Low risk & Nurse conducting interviews were unaware of patient allocation (p. 664). \\
\hline $\begin{array}{l}\text { Incomplete outcome data } \\
\text { (attrition bias) } \\
\text { All outcomes }\end{array}$ & Low risk & Loss to follow-up reported with reasons. \\
\hline $\begin{array}{l}\text { Selective reporting (re- } \\
\text { porting bias) }\end{array}$ & Low risk & Outcomes specified in methods are reported. \\
\hline
\end{tabular}


Walton 2010

Methods

Parallel RCT: computer-administered brief intervention versus therapist-administered brief intervention versus brochure on alcohol and violence.

ITT: unclear.

Participants Setting: USA, emergency department.

Participants: 14 to 18 years, presenting to emergency department for medical illness or injury with normal vital signs (including trauma patients after initial stabilisation), reporting past-year alcohol consumption and aggressive behaviour; screened with computerised self-complete survey plus AUDIT-C, CRAFFT and Problem Oriented Screening Instrument for Teenagers (POSIT); excluded if victim of acute sexual assault, or displaying suicidal ideation, or altered mental status precluded consent, or medical instability (i.e. abnormal vital signs).

Number randomised $=726 ; 44 \%$ male; mean age 16.8 years; $56 \%$ African American, $39 \%$ White, $7 \%$ Hispanic, $5 \%$ Other ethnicity; $10 \%$ dropped out of school.

At baseline: $52 \%$ past year binge drinking ( $\geq 5$ drinks), $48 \%$ AUDIT-C $=>3,45 \%$ POSIT alcohol score $\geq 2$.

Interventions

Computer-administered brief intervention ( $C B I)$ group $(N=237)$ had one session (median 29 minutes) on an interactive multimedia computer program developed for the study and viewed on tablet laptops with touch screens and audio delivered through headphones, to ensure participant privacy. Therapist-administered brief intervention (TBI) group $(\mathrm{N}=254)$ received one session (median 37 minutes) from a research therapist who utilised a tablet laptop to provide personalised feedback from the screening and baseline surveys as well as age- and sex-specific normative information. Adolescents completed computerised checklists identifying reasons to stay away from drinking and fighting. Using a preprogrammed algorithm, the computer selected a set of role-play scenarios based on the participant's risk behaviours, and the therapist guided the participant.

Control group ( $\mathrm{N}=235$ ) received a brochure containing information on alcohol and violence with community resources including phone numbers.

Outcomes Per cent with AUDIT-C $\geq 3$, per cent binge drinking ( $\geq 5$ drinks per occasion), per cent with POSIT (Problem Oriented Screening Instrument for Teenagers) $\geq 2$.

Assessed at 3, 6 and 12 months.

Funding source

This project was supported by National Institute on Alcohol Abuse and Alcoholism (NIAAA) grant 014889.

Declaration of interests Not reported.

Notes

\author{
SafERteens study; teenagers \\ Loss to follow-up at three months: \\ CBI group: 32/237 (14\%). \\ TBI group: $39 / 254$ (15\%). \\ Control group: 29/235 (12\%). \\ Loss to follow-up at six months: \\ CBI group: 28/237 (12\%). \\ TBI group: 45/254 (18\%). \\ Control group: $27 / 235$ (11\%). \\ Loss to follow-up at 12 months: \\ CBI group: 36/237 (15\%). \\ TBI group: 50/254 (20\%). \\ Control group: 33/235 (14\%).
}

Payment: USD 1 for screening; USD 20 for baseline assessment; USD 25 for three month assessment; USD 30 for six month assessment; USD 35 for 12 month assessment; USD 111 in total. 
Walton 2010 (Continued)

We contacted the authors, who supplied missing data.

\section{Risk of bias}

\begin{tabular}{|c|c|c|}
\hline Bias & Authors' judgement & Support for judgement \\
\hline $\begin{array}{l}\text { Random sequence genera- } \\
\text { tion (selection bias) }\end{array}$ & Low risk & Randomisation was based on computer-generated algorithm (p. 528). \\
\hline $\begin{array}{l}\text { Allocation concealment } \\
\text { (selection bias) }\end{array}$ & Unclear risk & Used "numbered sealed envelopes" (p. 528). \\
\hline $\begin{array}{l}\text { Blinding of treatment } \\
\text { providers }\end{array}$ & High risk & Not blinded. \\
\hline Blinding of participants & Low risk & $\begin{array}{l}\text { "Participants were blinded to condition assignment until after the baseline as- } \\
\text { sessment" (p. 528). }\end{array}$ \\
\hline $\begin{array}{l}\text { Blinding of outcome as- } \\
\text { sessment (detection bias) } \\
\text { All outcomes }\end{array}$ & Low risk & "Follow-up staff were blinded to baseline condition assignment" (p. 528). \\
\hline $\begin{array}{l}\text { Incomplete outcome data } \\
\text { (attrition bias) } \\
\text { All outcomes }\end{array}$ & Low risk & Loss to follow-up reported with reasons. \\
\hline
\end{tabular}

Selective reporting (re- Low risk Outcomes specified in methods are reported.

porting bias)

\section{Watson 2013}

Methods RCT: stepped care versus minimal intervention.

ITT: yes.

Participants Setting: England and Scotland, general practices.

Participants: Aged $\geq 55$ years, scored $\geq 8$ on AUDIT, provided contact details on the screening form, were residing in a stable place of residence, lived within commutable distance of the primary care centre; excluded if they had received treatment for substance use, excluding nicotine, in the previous 90 days, were already seeking help for alcohol use, had any outstanding legal issues likely to lead to imprisonment, suffered from severe mental or physical illness likely to preclude active participation in treatment or follow-up.

Number randomised $=529 ; 80.3 \%$ male; mean age $=62.83$ years $(S D=5.83) ; 35.3 \%$ employed, $52.3 \%$ retired, $1.4 \%$ home worker, $0.2 \%$ student, $2.7 \%$ seeking work; $63.3 \%$ continued education after school, $41.8 \%$ degree or equivalent qualification.

At baseline: mean drinks per day $=3.39(\mathrm{SD}=2.21)$, mean AUDIT-C score $=8.26(\mathrm{SD}=2.22)$, mean drinking problems index score $=2.86(\mathrm{SD}=3.12)$.

Interventions

Stepped care $(N=266)$ consisted of three consecutive steps, in which progression between steps was dependent upon the outcome of each previous step.

Step 1: one 20 minute session of behavioural change counselling (based on motivational interviewing) was delivered by the practice/research nurse. The counselling was protocol guided. Four weeks after randomisation, the participant was contacted by the nurse and a short telephone assessment was made regarding the participant's alcohol consumption in the previous four weeks using the extend- 
Watson 2013 (Continued)

ed AUDIT-Consumption (three item) (AUDIT-C). If the participant was still consuming alcohol at hazardous levels, a referral was made to step 2 of the intervention.

Step 2: MET intervention by a trained therapist in the primary care environment. Three weekly 40 minute sessions; protocol guided; addressed six basic principles of increasing motivation for change. Four weeks after the final MET session, the nurse contacted the participant and a short telephone assessment was made regarding the participant's alcohol consumption in the previous four weeks using the extended AUDIT-C. If the participant was still consuming alcohol at hazardous levels, a referral was to be made to step 3 of the intervention.

Step 3: a referral to the local specialist alcohol services to receive specialist intervention including, as necessary, detoxification, inpatient care, outpatient counselling, group therapy, relapse prevention treatment or medication.

Minimal intervention group ( $N=263$ ) received a five minute brief advice intervention with the practice nurse or research nurse involving feedback of the results of the screening and discussion regarding the health consequences of continued hazardous alcohol consumption. The participant also received a brief self-help booklet, 'Safer drinking - a self help guide', outlining the consequences of excessive alcohol consumption and providing information on sources of help for drinking problems locally and nationally.

Outcomes $\quad$ Mean drinks per day, AUDIT-C score, drinking problems index.

Assessed at 6 and 12 months.

\begin{tabular}{ll}
\hline Funding source & The research reported [here] was funded by the HTA programme as project number 06/304/142. \\
\hline Declaration of interests & Declared competing interests of authors: none. \\
\hline Notes & Loss to follow-up: \\
& Stepped Care group: $31 / 266(12 \%)$. \\
& Minimal intervention: $35 / 263(13 \%)$.
\end{tabular}

\section{Risk of bias}

\begin{tabular}{lll}
\hline Bias & Authors' judgement & Support for judgement \\
\hline $\begin{array}{l}\text { Random sequence genera- } \\
\text { tion (selection bias) }\end{array}$ & Low risk & $\begin{array}{l}\text { "The generation of the randomisation sequence and subsequent treatment al- } \\
\text { location were performed by an independent, secure, remote, telephone ran- } \\
\text { domisation service based at the University of York" (p. 7). }\end{array}$ \\
\hline $\begin{array}{l}\text { Allocation concealment } \\
\text { (selection bias) }\end{array}$ & Low risk & $\begin{array}{l}\text { "The generation of the randomisation sequence and subsequent treatment al- } \\
\text { location were performed by an independent, secure, remote, telephone ran- } \\
\text { domisation service based at the University of York" (p. } 7) .\end{array}$ \\
\hline $\begin{array}{l}\text { Blinding of treatment } \\
\text { providers }\end{array}$ & High risk & $\begin{array}{l}\text { "Owing to the nature of the intervention and the pragmatic aim of the evalua- } \\
\text { tion, treatment allocation, once determined, was not concealed from the par- } \\
\text { ticipant or the professional delivering the intervention (p. 7). }\end{array}$ \\
\hline $\begin{array}{l}\text { Blinding of participants } \\
\text { High risk }\end{array}$ & $\begin{array}{l}\text { "Owing to the nature of the intervention and the pragmatic aim of the evalua- } \\
\text { tion, treatment allocation, once determined, was not concealed from the par- } \\
\text { ticipant or the professional delivering the intervention" (p. 7). }\end{array}$ \\
\hline
\end{tabular}

Blinding of outcome as- Unclear risk Participants self-completed postal questionnaires.

sessment (detection bias)

All outcomes 
Watson 2013 (Continued)

Incomplete outcome data Unclear risk Loss to follow-up is reported but not reasons. (attrition bias)

All outcomes

Selective reporting (re- Low risk Outcomes specified in methods are reported.
porting bias)

\section{Woolard 2013}

Methods $\quad$ Parallel RCT: brief intervention versus standard care.

ITT: yes.

Participants Setting: USA, emergency department.

Participants: $\geq 18$ years, reported alcohol use in the prior month and marijuana use in the prior year; screened by the Wellness questionnaire; excluded if they were admitted to the hospital, or in treatment for substance use or psychiatric disorders, or were not English speaking, or were in police custody or were unable to consent or too medically unstable to participate in the research.

Number randomised $=515 ; 83.4 \%$ male; $68 \%$ White, $17 \%$ Hispanic.

Interventions

BI group $(\mathrm{N}=249$ ) received two counselling sessions based on the principles of $\mathrm{MI}$ as described by Miller and Rollnick (2002) and the MATCH MET treatment manual. The first BI session lasted between 20 and 60 minutes, and the second 15 to 40 minutes. The goal of the first brief intervention session was to engage the participant in reflection upon the pros and cons of alcohol and marijuana use. The intervention included: feedback; emphasis on personal responsibility for change; advice with permission; a menu of alternative change options; an empathic interventionist style; and fostering patient self-efficacy. The interventionist provided direct feedback concerning the participant's alcohol and marijuana use compared to community norms. The participant and interventionist developed a change plan that addressed changes the participant wanted to make, usually focused on reduction of substance use. If the participant was not ready to change substance use, the interventionist worked with the participant to increase motivation for change. The interventionists discussed with participants the pros and cons of alcohol and marijuana use and also explored their conjoint use, and the effect that conjoint use had on the reported pros and cons. The focus of the second BI session was to review and reinforce the change plan for those who had one, or to increase motivation for change and create a change plan with those who had not made a change plan in the first session.

Standard care group $(\mathrm{N}=266$ ) received routine emergency care for their presenting medical complaint during and after completing the baseline assessment. All study participants were offered information on local treatment resources for substance misuse either following the BI or after the baseline assessment for the SC group.

Outcomes

Days alcohol use in past 30 days, days alcohol binge use in past 30 days, alcohol negative consequences.

Assessed at 3 and 12 months.

Funding source

This study was supported by grant funding from NIAAA (1R01AA13709-01A1).

Declaration of interests There are no conflicts of interest by any author.

Notes

Payment: USD 25 for baseline and three month assessments and USD 50 for 12 month assessments.

Loss to follow up:

Brief intervention group: 43/249 (17\%). 
Woolard 2013 (Continued)

SC group: $46 / 266$ (17\%).

\section{Risk of bias}

\begin{tabular}{|c|c|c|}
\hline Bias & Authors' judgement & Support for judgement \\
\hline $\begin{array}{l}\text { Random sequence genera- } \\
\text { tion (selection bias) }\end{array}$ & Unclear risk & Method of sequence generation not described. \\
\hline $\begin{array}{l}\text { Allocation concealment } \\
\text { (selection bias) }\end{array}$ & Unclear risk & Closed envelopes but does not specify numbered or opaque (p. 1734). \\
\hline $\begin{array}{l}\text { Blinding of treatment } \\
\text { providers }\end{array}$ & Low risk & $\begin{array}{l}\text { Interventionist only delivered one style of intervention and did not come into } \\
\text { contact with control participants. }\end{array}$ \\
\hline Blinding of participants & Low risk & "Participants were not informed of the hypotheses being tested" (p. 1734). \\
\hline $\begin{array}{l}\text { Blinding of outcome as- } \\
\text { sessment (detection bias) } \\
\text { All outcomes }\end{array}$ & Low risk & RAs "blinded to the participant's original treatment condition" (p. 1734). \\
\hline $\begin{array}{l}\text { Incomplete outcome data } \\
\text { (attrition bias) } \\
\text { All outcomes }\end{array}$ & Unclear risk & Loss to follow-up reported but not reasons. \\
\hline $\begin{array}{l}\text { Selective reporting (re- } \\
\text { porting bias) }\end{array}$ & Low risk & Outcomes specified in methods are reported. \\
\hline
\end{tabular}

AA: Alcoholics Anonymous

ADM-related days: services for conditions related to alcohol, drugs or mental health

ALT: alanine aminotransferase

AST: aspartate aminotransferase

AUDIT: Alcohol Use Disorders Identification Test

AUDIT-C: Alcohol Use Disorders Identification Test Consumption, a brief version of AUDIT

BAC: blood alcohol contentCAGE: Cut down, Annoyed, Guilty, Eye-opener, an alcohol screening tool

CDT: Carbohydrate-deficient transferrin, a blood test used to detect heavy alcohol use

CRAFFT: Car, Relax, Alone, Forget, Friends, Trouble, an alcohol screening tool

DRInC: drinker inventory of consequences

FRAMES: Feedback, Responsibility (of the drinker for change), Advice, Menu of options, Empathy (from interventionist), Self efficacy (from the drinker)

GGT: gamma-glutamyltransferase

GP: general practitioner

ITT: intention-to-treat

IMI: individual motivational interview

MALT: Munich alcoholism test

MCV: mean corpuscular volume, part of a blood count

MI: motivational interview

NIAAA: National Institute on Alcohol Abuse and Alcoholism (USA)

PAT: Paddington Alcohol Test, an alcohol screening tool

RA: research assistant

RAPS: Remorse, Amnesia, Perform, Starter, an alcohol screening tool

$\mathrm{RCT}$ : randomised controlled trial

SBIRT: screening, brief intervention and referral to treatment

SC: stepped care

TLFB: Timeline Followback, a method of self-assessing alcohol consumption

WHO: World health Organization 
Characteristics of excluded studies [ordered by study ID]

\begin{tabular}{|c|c|}
\hline Study & Reason for exclusion \\
\hline Academic ED SBIRT 2007 & Participants in both arms received the interventions sequentially rather than in parallel. \\
\hline Ameratunga 2011 & Not a conversation-based intervention. \\
\hline Apodaca 2007 & Not a brief intervention; the face-to-face element was an explanation of the written materials. \\
\hline Areesantichai 2010 & Participants were not recruited from primary care. \\
\hline Areesantichai 2013 & Participants were not recruited from primary care. \\
\hline Babor 1996 & Some participants were not recruited from primary care: unable to separate outcome data. \\
\hline Baker 2014 & Participants were not recruited from primary care. \\
\hline Ball 2007 & Participants were not recruited from primary care. \\
\hline Boekeloo 2004 & Not a conversation-based intervention. \\
\hline Ceperich 2011 & Participants were not recruited from primary care. \\
\hline Chander 2015 & Participants were not recruited from primary care. \\
\hline Chang 1997 & Comparator was alcohol treatment referral (previously included study, Kaner 2007). \\
\hline Field 2014 & $\begin{array}{l}\text { A large proportion of participants were dependent drinkers and had been admitted to the trauma } \\
\text { centre. }\end{array}$ \\
\hline Gentilello 1999 & $\begin{array}{l}\text { Participants were inpatients; excluded if discharged within } 24 \text { hours (previously included study, } \\
\text { Kaner 2007). }\end{array}$ \\
\hline Gwadz 2008 & Participants were not recruited from primary care. \\
\hline Haller 2014 & Intervention was practitioner training. \\
\hline Hansen 2012 & Not a conversation-based intervention. \\
\hline Hansen 2012a & Participants were not recruited from primary care. \\
\hline Hansson 2007 & Participants were not recruited from primary care. \\
\hline Hilbink 2012 & Not a brief intervention. \\
\hline Houry 2011 & Not a conversation-based intervention. \\
\hline Hyman 2007 & Implementation trial. \\
\hline Ingersoll 2013 & Participants were not recruited from primary care. \\
\hline Ivanets 1991 & Some participants were not recruited from primary care: unable to separate outcome data. \\
\hline Jessop 2008 & Not a conversation-based intervention. \\
\hline Kristenson 1983 & Participants were not recruited from primary care. \\
\hline
\end{tabular}




\begin{tabular}{|c|c|}
\hline Study & Reason for exclusion \\
\hline Kulesza 2013 & Participants were not recruited from primary care. \\
\hline Lang 2007 & Not an RCT. \\
\hline Maheswaran 1992 & Participants were not recruited from primary care. \\
\hline Massey 2015 & Neither arm was conversation only. \\
\hline McDevitt-Murphy 2015 & Comparator arm was not eligible - active intervention. \\
\hline Mezzani 2007 & Implementation trial. \\
\hline Milner 2010 & Not an RCT. \\
\hline Monti 1999 & A screening tool was not used to recruit participants. \\
\hline Nayak 2015 & Outcomes are presented only by readiness to change scores. \\
\hline Nilssen 1991 & Participants were not recruited from primary care. \\
\hline Pal 2007 & Participants were not recruited from primary care. \\
\hline Palm 2016 & Participants were not screened before randomisation; trial contained non-risky drinkers. \\
\hline Rhodes 2015 & Not all participants were risky drinkers. \\
\hline Shetty 2011 & $\begin{array}{l}\text { Participants were not recruited from primary care - they attended a clinic for follow-up care at a } \\
\text { level } 1 \text { trauma centre. }\end{array}$ \\
\hline Sterling 2017 & Not all participants were risky drinkers. \\
\hline Toft 2009 & Participants were not recruited from primary care. \\
\hline UKATT 2005 & Participants were not recruited from primary care. \\
\hline Walton 2015a & Only admitted inpatients were screened and recruited. \\
\hline Worden 2011 & Participants were not recruited from primary care. \\
\hline Wutzke 2002 & Some participants were not recruited from primary care: unable to separate outcome data. \\
\hline
\end{tabular}

Characteristics of studies awaiting assessment [ordered by study ID]

Arnaud 2017

\begin{tabular}{ll}
\hline Methods & Cluster RCT \\
\hline Participants & $\begin{array}{l}\text { Setting: Germany; children under } 18 \text { years who presented to emergency departments of paediatric } \\
\text { hospitals with alcohol intoxication }\end{array}$ \\
\hline Interventions & $\begin{array}{l}\text { Single session brief motivational intervention (manual-based, delivered by staff external to hospi- } \\
\text { tal) with telephone booster after six weeks, plus carer consultation }\end{array}$ \\
\hline
\end{tabular}


Arnaud 2017 (Continued)

Outcomes
Frequency of binge drinking, number of alcoholic drinks on a typical occasion, and alcohol-related problems using the brief Rutgers Alcohol Problem Index; measured at three and six months

Notes

\section{Cherpitel 2016}

\begin{tabular}{ll}
\hline Methods & Parallel design RCT \\
\hline Participants & $\begin{array}{l}\text { Setting: USA, participants were those aged } 18 \text { to } 30 \text { years who presented to the emergency depart- } \\
\text { ment, self-identified as of Mexican origin, reported consuming } 15 \text { (men) or } 8 \text { (women) drinks/week, } \\
\text { or } 5 \text { (men) or } 4 \text { (women) drinks/occasion in previous } 28 \text { days }\end{array}$ \\
\hline Interventions & Promotores (peer health promotion advocates) delivered brief negotiation interview (20 minutes) \\
\hline Outcomes & $\begin{array}{l}\text { Mean days binge drinking, mean drinking days/week, mean drinks/drinking day; measured at } 3 \text { and } \\
12 \text { months }\end{array}$ \\
\hline
\end{tabular}

Notes

\section{Crawford 2015}

\begin{tabular}{ll}
\hline Methods & Parallel design RCT \\
\hline Participants & $\begin{array}{l}\text { Setting: UK, adults aged } 19 \text { years or over presenting to (primary care) sexual health clinic and re- } \\
\text { porting excessive consumption - } 8 \text { (men) or } 6 \text { (women) drinks on a single occasion more than } \\
\text { monthly }\end{array}$
\end{tabular}

Brief advice ( 2 to 3 minutes) from the treating clinician plus offer of an appointment with an alco-
hol health worker, who delivered a FRAMES brief intervention for up to 30 minutes

\begin{tabular}{ll}
\hline Outcomes & Mean weekly alcohol consumption measured at six months \\
\hline Notes & $\begin{array}{l}\text { Project SHEAR (Sexual Health and Excessive } \\
\text { Alcohol: Randomised trial) }\end{array}$ \\
\hline
\end{tabular}

Diaz Gomez 2017

\begin{tabular}{ll}
\hline Methods & Parallel design RCT \\
\hline Participants & Setting: France, participants aged 16 to 24 years presenting to emergency department \\
\hline Interventions & Brief motivational intervention (duration uncertain) \\
\hline Outcomes & Mean number of drinks, measured at 3 months \\
\hline Notes & \\
\hline
\end{tabular}


Mello 2016

\begin{tabular}{ll}
\hline Methods & Parallel design RCT \\
\hline Participants & $\begin{array}{l}\text { Setting: USA, adults aged } 18 \text { years or over presenting to emergency department and reporting } \\
\text { moderate or high-risk alcohol consumption (ASSIST score } 11 \text { or greater) }\end{array}$ \\
\hline Interventions & Telephone-based brief motivational interviewing, median 40 minutes, maximum of 3 calls \\
\hline Outcomes & $\begin{array}{l}\text { Frequency of binge drinking, mean number of drinks/week, maximum number of drinks/occasion; } \\
\text { all in previous } 30 \text { days; measured at } 12 \text { months }\end{array}$ \\
\hline Notes & Project ReDIAL \\
\hline
\end{tabular}

Monti 2015

\begin{tabular}{ll}
\hline Methods & Parallel design RCT \\
\hline Participants & $\begin{array}{l}\text { Setting: USA, participants aged } 18 \text { to } 65 \text { years who received treatment in emergency department } \\
\text { and screened for harmful alcohol use and risky sexual behaviour }\end{array}$ \\
\hline Interventions & Brief motivational intervention \\
\hline Outcomes & Mean number of heavy drinking days, mean drinks/week; measured at 3, 6 and 9 months \\
\hline Notes & \\
\hline
\end{tabular}

Nadkarni 2017

\begin{tabular}{ll}
\hline Methods & Parallel design RCT \\
\hline Participants & $\begin{array}{l}\text { Setting: India, men aged } 18 \text { to } 65 \text { years presenting to primary health care clinic who scored } 12 \text { to } 19 \\
\text { on AUDIT }\end{array}$ \\
\hline Interventions & $\begin{array}{l}\text { Counselling for Alcohol Problems (CAP); a manual intervention delivered over a maximum of four } \\
\text { sessions of } 30 \text { to } 45 \text { minutes duration (i.e. an extended intervention by the definition of this review) }\end{array}$ \\
\hline
\end{tabular}

\section{Outcomes}

Remission (AUDIT score > 8), mean drinks/day, per cent days abstinent, per cent days heavy drinking; measured at three months

\section{Notes}

\section{Walton 2015}

\begin{tabular}{ll}
\hline Methods & Parallel design RCT \\
\hline Participants & $\begin{array}{l}\text { Setting: USA, participants aged } 14 \text { to } 20 \text { years presenting to emergency department who screened } \\
\text { positive for risky drinking on AUDIT }\end{array}$ \\
\hline Interventions & $\begin{array}{l}\text { Motivational interviewing based brief intervention delivered by therapist (there is also a comput- } \\
\text { er-delivered and a control arm) }\end{array}$ \\
\hline
\end{tabular}


Walton 2015 (Continued)

Outcomes

Notes
Alcohol consumption (conference abstract gives no more detail of type of consumption), measured at three months

ASSIST: Alcohol, Smoking and Substance Involvement Screening Test

AUDIT: Alcohol Use Disorders Identification Test

FRAMES: Feedback, Responsibility (of the drinker for change), Advice, Menu of options, Empathy (from interventionist), Self efficacy (from the drinker)

Characteristics of ongoing studies [ordered by study ID]

\section{ISRCTN13832949}

Trial name or title

Development and evaluation of the efficacy of a brief motivational intervention among young adults admitted in the emergency room while being alcohol intoxicated

\begin{tabular}{ll}
\hline Methods & Parallel design RCT \\
\hline Participants & $\begin{array}{l}\text { Setting: Switzerland, adults aged } 18 \text { to } 35 \text { years attending the emergency room with alcohol intoxi- } \\
\text { cation }\end{array}$ \\
\hline Interventions & Brief motivational intervention \\
\hline Outcomes & Heavy drinking days in the last month \\
\hline Starting date & 1 December 2016 \\
\hline Contact information & Dr Jacques Gaume \\
& Lausanne University Hospital \\
& Avenue de Beaumont 21 bis - P2, Lausanne 1011 Switzerland
\end{tabular}

Notes

\section{ISRCTN45300218}

\begin{tabular}{ll}
\hline Trial name or title & SIPS Junior \\
\hline Methods & Parallel design RCT \\
\hline Participants & Setting: UK, adolescents (14 to 17 years) attending emergency department \\
\hline Interventions & $\begin{array}{l}\text { Smart phone or web-based electronic brief intervention or face-to-face personalised feedback } \\
\text { Control group will receive treatment according to the injury that brought them to the emergency } \\
\text { department }\end{array}$ \\
\hline Outcomes & Total alcohol consumption in previous 28 days \\
\hline Starting date & March 2014 \\
\hline Contact information & S.coulton@kent.ac.uk \\
\hline
\end{tabular}


ISRCTN45300218 (Continued)

Notes

RBR-65262C

\begin{tabular}{ll}
\hline Trial name or title & Brief intervention for hazardous and harmful women's alcohol consumption \\
\hline Methods & Parallel design RCT \\
\hline Participants & $\begin{array}{l}\text { Setting: Brazil, women (aged over } 18 \text { years) presenting to primary health care clinic who are } \\
\text { screened as having risky or harmful alcohol consumption }\end{array}$ \\
\hline Interventions & Brief alcohol intervention - two sessions of 20 to 30 minutes each \\
\hline Outcomes & AUDIT score change \\
\hline Starting date & 1 June 2017 \\
\hline Contact information & Talita Dutra Ponce, talitadp@usp.br \\
\hline Notes & \\
\hline
\end{tabular}

AUDIT: Alcohol Use Disorders Identification Test

\section{DATA AND ANALYSES}

\section{Comparison 1. Brief intervention versus control}

\begin{tabular}{|c|c|c|c|c|}
\hline Outcome or subgroup title & No. of studies & $\begin{array}{l}\text { No. of partici- } \\
\text { pants }\end{array}$ & Statistical method & Effect size \\
\hline $\begin{array}{l}1 \text { Quantity of drinking (g/week) at } 12 \\
\text { months }\end{array}$ & 34 & 15197 & $\begin{array}{l}\text { Mean Difference (IV, Ran- } \\
\text { dom, } 95 \% \mathrm{CI} \text { ) }\end{array}$ & $\begin{array}{l}-20.08[-28.36 \\
-11.81]\end{array}$ \\
\hline $\begin{array}{l}2 \text { Quantity of drinking (g/week) at } 12 \\
\text { months, restricted to trials at low risk } \\
\text { of bias due to allocation concealment }\end{array}$ & 19 & 8856 & $\begin{array}{l}\text { Mean Difference (IV, Ran- } \\
\text { dom, } 95 \% \mathrm{CI} \text { ) }\end{array}$ & $\begin{array}{l}-19.98[-30.45 \\
-9.51]\end{array}$ \\
\hline $\begin{array}{l}3 \text { Quantity of drinking (g/week) at } 12 \\
\text { months, restricted to trials at low risk } \\
\text { of bias due to attrition }\end{array}$ & 19 & 8496 & $\begin{array}{l}\text { Mean Difference (IV, Ran- } \\
\text { dom, } 95 \% \mathrm{CI} \text { ) }\end{array}$ & $\begin{array}{l}-20.69[-31.78 \\
-9.60]\end{array}$ \\
\hline $\begin{array}{l}4 \text { Quantity of drinking (g/week) at } 12 \\
\text { months, with imputation of unknown } \\
\text { standard deviations }\end{array}$ & 39 & 17514 & $\begin{array}{l}\text { Mean Difference (IV, Ran- } \\
\text { dom, } 95 \% \mathrm{CI} \text { ) }\end{array}$ & $\begin{array}{l}-19.35[-26.90 \\
-11.80]\end{array}$ \\
\hline $\begin{array}{l}5 \text { Quantity of drinking (g/week) at } 12 \\
\text { months, subgrouped by cluster/indi- } \\
\text { vidual randomisation }\end{array}$ & 34 & 15197 & $\begin{array}{l}\text { Mean Difference (IV, Ran- } \\
\text { dom, } 95 \% \mathrm{CI} \text { ) }\end{array}$ & $\begin{array}{l}-20.08[-28.36 \\
-11.81]\end{array}$ \\
\hline 5.1 Cluster-randomised & 6 & 2588 & $\begin{array}{l}\text { Mean Difference (IV, Ran- } \\
\text { dom, } 95 \% \mathrm{CI} \text { ) }\end{array}$ & $\begin{array}{l}-25.30[-42.69, \\
-7.91]\end{array}$ \\
\hline
\end{tabular}




\begin{tabular}{|c|c|c|c|c|}
\hline Outcome or subgroup title & No. of studies & $\begin{array}{l}\text { No. of partici- } \\
\text { pants }\end{array}$ & Statistical method & Effect size \\
\hline 5.2 Individually randomised & 28 & 12609 & $\begin{array}{l}\text { Mean Difference (IV, Ran- } \\
\text { dom, } 95 \% \mathrm{CI} \text { ) }\end{array}$ & $\begin{array}{l}-18.77[-28.01 \\
-9.53]\end{array}$ \\
\hline $\begin{array}{l}6 \text { Quantity of drinking (g/week) at } 12 \\
\text { months, subgrouped by cluster/indi- } \\
\text { vidual randomisation, varying imput- } \\
\text { ed ICC }\end{array}$ & 34 & 15197 & $\begin{array}{l}\text { Mean Difference (IV, Ran- } \\
\text { dom, } 95 \% \mathrm{CI} \text { ) }\end{array}$ & $\begin{array}{l}-19.41[-27.59 \\
-11.22]\end{array}$ \\
\hline 6.1 Cluster-randomised & 6 & 2588 & $\begin{array}{l}\text { Mean Difference (IV, Ran- } \\
\text { dom, } 95 \% \mathrm{CI} \text { ) }\end{array}$ & $\begin{array}{l}-20.32[-33.50 \\
-7.14]\end{array}$ \\
\hline 6.2 Individually randomised & 28 & 12609 & $\begin{array}{l}\text { Mean Difference (IV, Ran- } \\
\text { dom, } 95 \% \mathrm{CI} \text { ) }\end{array}$ & $\begin{array}{l}-18.77[-28.01 \\
-9.53]\end{array}$ \\
\hline $\begin{array}{l}7 \text { Quantity of drinking (g/week) at } 12 \\
\text { months, subgrouped by gender }\end{array}$ & 11 & 4836 & $\begin{array}{l}\text { Mean Difference (IV, Ran- } \\
\text { dom, } 95 \% \mathrm{CI} \text { ) }\end{array}$ & $\begin{array}{l}-37.42[-54.39 \\
-20.45]\end{array}$ \\
\hline 7.1 Men & 11 & 3486 & $\begin{array}{l}\text { Mean Difference (IV, Ran- } \\
\text { dom, 95\% CI) }\end{array}$ & $\begin{array}{l}-42.21[-64.53 \\
-19.89]\end{array}$ \\
\hline 7.2 Women & 7 & 1350 & $\begin{array}{l}\text { Mean Difference (IV, Ran- } \\
\text { dom, 95\% CI) }\end{array}$ & $\begin{array}{l}-30.27[-58.99 \\
-1.55]\end{array}$ \\
\hline $\begin{array}{l}8 \text { Quantity of drinking (g/week) at } 12 \\
\text { months, subgrouped by gender, ex- } \\
\text { cluding trials of men only }\end{array}$ & 7 & 4036 & $\begin{array}{l}\text { Mean Difference (IV, Ran- } \\
\text { dom, } 95 \% \mathrm{CI} \text { ) }\end{array}$ & $\begin{array}{l}-33.12[-51.47 \\
-14.76]\end{array}$ \\
\hline 8.1 Men & 7 & 2686 & $\begin{array}{l}\text { Mean Difference (IV, Ran- } \\
\text { dom, } 95 \% \mathrm{CI} \text { ) }\end{array}$ & $\begin{array}{l}-35.16[-60.51 \\
-9.80]\end{array}$ \\
\hline 8.2 Women & 7 & 1350 & $\begin{array}{l}\text { Mean Difference (IV, Ran- } \\
\text { dom, } 95 \% \mathrm{Cl} \text { ) }\end{array}$ & $\begin{array}{l}-30.27[-58.99 \\
-1.55]\end{array}$ \\
\hline $\begin{array}{l}9 \text { Quantity of drinking (g/week) at } \\
12 \text { months, subgrouped by adoles- } \\
\text { cents/young adults only versus other }\end{array}$ & 34 & 15197 & $\begin{array}{l}\text { Mean Difference (IV, Ran- } \\
\text { dom, } 95 \% \mathrm{CI} \text { ) }\end{array}$ & $\begin{array}{l}-20.08[-28.36 \\
-11.81]\end{array}$ \\
\hline 9.1 Adolescents/young adults only & 3 & 1638 & $\begin{array}{l}\text { Mean Difference (IV, Ran- } \\
\text { dom, } 95 \% \mathrm{CI} \text { ) }\end{array}$ & $-7.09[-17.18,2.99]$ \\
\hline 9.2 Other trials & 31 & 13559 & $\begin{array}{l}\text { Mean Difference (IV, Ran- } \\
\text { dom, } 95 \% \mathrm{CI} \text { ) }\end{array}$ & $\begin{array}{l}-22.79[-32.42 \\
-13.16]\end{array}$ \\
\hline $\begin{array}{l}10 \text { Quantity of drinking (g/week) at } 12 \\
\text { months, subgrouped by general prac- } \\
\text { tice/emergency setting }\end{array}$ & 34 & 15197 & $\begin{array}{l}\text { Mean Difference (IV, Ran- } \\
\text { dom, } 95 \% \mathrm{CI} \text { ) }\end{array}$ & $\begin{array}{l}-20.08[-28.36 \\
-11.81]\end{array}$ \\
\hline 10.1 General practice setting & 24 & 8811 & $\begin{array}{l}\text { Mean Difference (IV, Ran- } \\
\text { dom, } 95 \% \mathrm{CI} \text { ) }\end{array}$ & $\begin{array}{l}-25.69[-37.30 \\
-14.08]\end{array}$ \\
\hline 10.2 Emergency care setting & 10 & 6386 & $\begin{array}{l}\text { Mean Difference (IV, Ran- } \\
\text { dom, } 95 \% \mathrm{CI} \text { ) }\end{array}$ & $-9.73[-17.52,-1.93]$ \\
\hline
\end{tabular}




\begin{tabular}{|c|c|c|c|c|}
\hline Outcome or subgroup title & No. of studies & $\begin{array}{l}\text { No. of partici- } \\
\text { pants }\end{array}$ & Statistical method & Effect size \\
\hline $\begin{array}{l}11 \text { Quantity of drinking (g/wk) at } 12 \\
\text { months, subgrouped by intervention } \\
\text { modality (advice versus counselling) }\end{array}$ & 32 & 13780 & $\begin{array}{l}\text { Mean Difference (IV, Ran- } \\
\text { dom, } 95 \% \mathrm{CI} \text { ) }\end{array}$ & $\begin{array}{l}-21.01[-30.06 \\
-11.96]\end{array}$ \\
\hline 11.1 Advice-based & 20 & 8243 & $\begin{array}{l}\text { Mean Difference (IV, Ran- } \\
\text { dom, } 95 \% \mathrm{CI} \text { ) }\end{array}$ & $\begin{array}{l}-32.68[-45.75 \\
-19.60]\end{array}$ \\
\hline 11.2 Counselling-based & 12 & 5537 & $\begin{array}{l}\text { Mean Difference (IV, Ran- } \\
\text { dom, } 95 \% \mathrm{CI} \text { ) }\end{array}$ & $-0.17[-2.96,2.61]$ \\
\hline $\begin{array}{l}12 \text { Quantity of drinking (g/week) at } 12 \\
\text { months, subgrouped by type of con- } \\
\text { trol }\end{array}$ & 34 & 15197 & $\begin{array}{l}\text { Mean Difference (IV, Ran- } \\
\text { dom, } 95 \% \mathrm{CI} \text { ) }\end{array}$ & $\begin{array}{l}-20.08[-28.36 \\
-11.81]\end{array}$ \\
\hline 12.1 No alcohol content & 18 & 8606 & $\begin{array}{l}\text { Mean Difference (IV, Ran- } \\
\text { dom, } 95 \% \mathrm{CI} \text { ) }\end{array}$ & $\begin{array}{l}-24.41[-36.47 \\
-12.35]\end{array}$ \\
\hline 12.2 Some alcohol content & 16 & 6591 & $\begin{array}{l}\text { Mean Difference (IV, Ran- } \\
\text { dom, } 95 \% \mathrm{CI} \text { ) }\end{array}$ & $\begin{array}{l}-12.80[-22.93 \\
-2.66]\end{array}$ \\
\hline $\begin{array}{l}13 \text { Quantity of drinking (g/week), sub- } \\
\text { grouped by length of follow-up }\end{array}$ & 38 & & $\begin{array}{l}\text { Mean Difference (IV, Ran- } \\
\text { dom, } 95 \% \mathrm{CI} \text { ) }\end{array}$ & Subtotals only \\
\hline 13.1 At 6 months & 21 & 10313 & $\begin{array}{l}\text { Mean Difference (IV, Ran- } \\
\text { dom, } 95 \% \mathrm{Cl} \text { ) }\end{array}$ & $\begin{array}{l}-21.56[-31.56 \\
-11.55]\end{array}$ \\
\hline 13.2 At 8 to 9 months & 2 & 352 & $\begin{array}{l}\text { Mean Difference (IV, Ran- } \\
\text { dom, } 95 \% \mathrm{CI} \text { ) }\end{array}$ & $-15.70[-34.19,2.79]$ \\
\hline 13.3 At 12 months & 34 & 15197 & $\begin{array}{l}\text { Mean Difference (IV, Ran- } \\
\text { dom, } 95 \% \mathrm{CI} \text { ) }\end{array}$ & $\begin{array}{l}-20.08[-28.36 \\
-11.81]\end{array}$ \\
\hline 13.4 At 36 months & 1 & 277 & $\begin{array}{l}\text { Mean Difference (IV, Ran- } \\
\text { dom, } 95 \% \mathrm{CI} \text { ) }\end{array}$ & $-6.11[-79.55,67.33]$ \\
\hline $\begin{array}{l}14 \text { Quantity of drinking (g/week), sub- } \\
\text { grouped by length of follow-up ( } 6 \text { and } \\
12 \text { months) and restricted to trials } \\
\text { with information at both times }\end{array}$ & 18 & & $\begin{array}{l}\text { Mean Difference (IV, Ran- } \\
\text { dom, } 95 \% \mathrm{CI} \text { ) }\end{array}$ & Subtotals only \\
\hline 14.1 At 6 months & 18 & 9739 & $\begin{array}{l}\text { Mean Difference (IV, Ran- } \\
\text { dom, } 95 \% \mathrm{CI} \text { ) }\end{array}$ & $\begin{array}{l}-21.28[-31.82 \\
-10.75]\end{array}$ \\
\hline 14.2 At 12 months & 18 & 9645 & $\begin{array}{l}\text { Mean Difference (IV, Ran- } \\
\text { dom, } 95 \% \mathrm{CI} \text { ) }\end{array}$ & $\begin{array}{l}-22.25[-34.04 \\
-10.47]\end{array}$ \\
\hline $\begin{array}{l}15 \text { Quantity of drinking (g/week) at } \\
12 \text { months, subgrouped by effective- } \\
\text { ness/efficacy }\end{array}$ & 34 & 15197 & $\begin{array}{l}\text { Mean Difference (IV, Ran- } \\
\text { dom, } 95 \% \mathrm{CI} \text { ) }\end{array}$ & $\begin{array}{l}-20.08[-28.36 \\
-11.81]\end{array}$ \\
\hline 15.1 Effectiveness trials & 16 & 7091 & $\begin{array}{l}\text { Mean Difference (IV, Ran- } \\
\text { dom, } 95 \% \mathrm{CI} \text { ) }\end{array}$ & $\begin{array}{l}-27.06[-41.49 \\
-12.63]\end{array}$ \\
\hline 15.2 Efficacy trials & 18 & 8106 & $\begin{array}{l}\text { Mean Difference (IV, Ran- } \\
\text { dom, } 95 \% \mathrm{CI} \text { ) }\end{array}$ & $\begin{array}{l}-14.37[-23.97 \\
-4.76]\end{array}$ \\
\hline
\end{tabular}




\begin{tabular}{|c|c|c|c|c|}
\hline Outcome or subgroup title & No. of studies & $\begin{array}{l}\text { No. of partici- } \\
\text { pants }\end{array}$ & Statistical method & Effect size \\
\hline $\begin{array}{l}16 \text { Frequency of binge drinking (num- } \\
\text { ber binges/week) at } 12 \text { months }\end{array}$ & 15 & 6946 & $\begin{array}{l}\text { Mean Difference (IV, Ran- } \\
\text { dom, } 95 \% \mathrm{CI} \text { ) }\end{array}$ & $-0.08[-0.14,-0.02]$ \\
\hline $\begin{array}{l}17 \text { Frequency of drinking (number } \\
\text { binges/week), subgrouped by length } \\
\text { of follow-up ( } 6 \text { \& } 12 \text { months) and re- } \\
\text { stricted to trials with information at } \\
\text { both times }\end{array}$ & 9 & & $\begin{array}{l}\text { Mean Difference (IV, Ran- } \\
\text { dom, } 95 \% \mathrm{CI})\end{array}$ & Subtotals only \\
\hline 17.1 At 6 months & 9 & 4354 & $\begin{array}{l}\text { Mean Difference (IV, Ran- } \\
\text { dom, } 95 \% \mathrm{CI} \text { ) }\end{array}$ & $-0.15[-0.22,-0.08]$ \\
\hline 17.2 At 12 months & 9 & 4333 & $\begin{array}{l}\text { Mean Difference (IV, Ran- } \\
\text { dom, } 95 \% \mathrm{CI} \text { ) }\end{array}$ & $-0.12[-0.23,-0.02]$ \\
\hline $\begin{array}{l}18 \text { Frequency of drinking (number } \\
\text { days drinking/week) at } 12 \text { months }\end{array}$ & 11 & 5469 & $\begin{array}{l}\text { Mean Difference (IV, Ran- } \\
\text { dom, } 95 \% \mathrm{CI})\end{array}$ & $-0.13[-0.23,-0.04]$ \\
\hline $\begin{array}{l}19 \text { Frequency of drinking (number } \\
\text { days drinking/week), subgrouped by } \\
\text { length of follow-up ( } 6 \text { \& } 12 \text { months) } \\
\text { and restricted to trials with informa- } \\
\text { tion at both times }\end{array}$ & 6 & & $\begin{array}{l}\text { Mean Difference (IV, Ran- } \\
\text { dom, } 95 \% \mathrm{CI})\end{array}$ & Subtotals only \\
\hline 19.1 At 6 months & 6 & 3637 & $\begin{array}{l}\text { Mean Difference (IV, Ran- } \\
\text { dom, } 95 \% \mathrm{CI} \text { ) }\end{array}$ & $-0.12[-0.24,0.00]$ \\
\hline 19.2 At 12 months & 6 & 3658 & $\begin{array}{l}\text { Mean Difference (IV, Ran- } \\
\text { dom, } 95 \% \mathrm{CI} \text { ) }\end{array}$ & $-0.16[-0.28,-0.04]$ \\
\hline $\begin{array}{l}20 \text { Intensity of drinking (g/drinking } \\
\text { day) at } 12 \text { months }\end{array}$ & 10 & 3128 & $\begin{array}{l}\text { Mean Difference (IV, Ran- } \\
\text { dom, } 95 \% \mathrm{CI} \text { ) }\end{array}$ & $-0.18[-3.09,2.73]$ \\
\hline 21 Heavy drinkers at 12 months & 18 & 7623 & $\begin{array}{l}\text { Risk Difference (M-H, Ran- } \\
\text { dom, } 95 \% \mathrm{Cl})\end{array}$ & $-0.09[-0.13,-0.04]$ \\
\hline 22 Binge drinkers at 12 months & 10 & 4456 & $\begin{array}{l}\text { Risk Difference (M-H, Ran- } \\
\text { dom, } 95 \% \mathrm{Cl})\end{array}$ & $-0.07[-0.12,-0.02]$ \\
\hline $\begin{array}{l}23 \text { Laboratory markers - GGT (IU/L) at } \\
12 \text { months }\end{array}$ & 3 & 1166 & $\begin{array}{l}\text { Mean Difference (IV, Ran- } \\
\text { dom, } 95 \% \mathrm{CI} \text { ) }\end{array}$ & $-0.89[-3.86,2.08]$ \\
\hline $\begin{array}{l}24 \text { Laboratory markers - GGT (IU/L) at } \\
12 \text { months, subgrouped by gender }\end{array}$ & 2 & 1094 & $\begin{array}{l}\text { Mean Difference (IV, Ran- } \\
\text { dom, } 95 \% \mathrm{CI} \text { ) }\end{array}$ & $-0.03[-2.52,2.46]$ \\
\hline 24.1 Men & 2 & 764 & $\begin{array}{l}\text { Mean Difference (IV, Ran- } \\
\text { dom, } 95 \% \mathrm{CI} \text { ) }\end{array}$ & $-2.08[-6.10,1.95]$ \\
\hline 24.2 Women & 2 & 330 & $\begin{array}{l}\text { Mean Difference (IV, Ran- } \\
\text { dom, } 95 \% \mathrm{CI} \text { ) }\end{array}$ & $1.23[-1.94,4.40]$ \\
\hline
\end{tabular}




\section{Analysis 1.1. Comparison 1 Brief intervention versus control, Outcome 1 Quantity of drinking (g/week) at 12 months.}

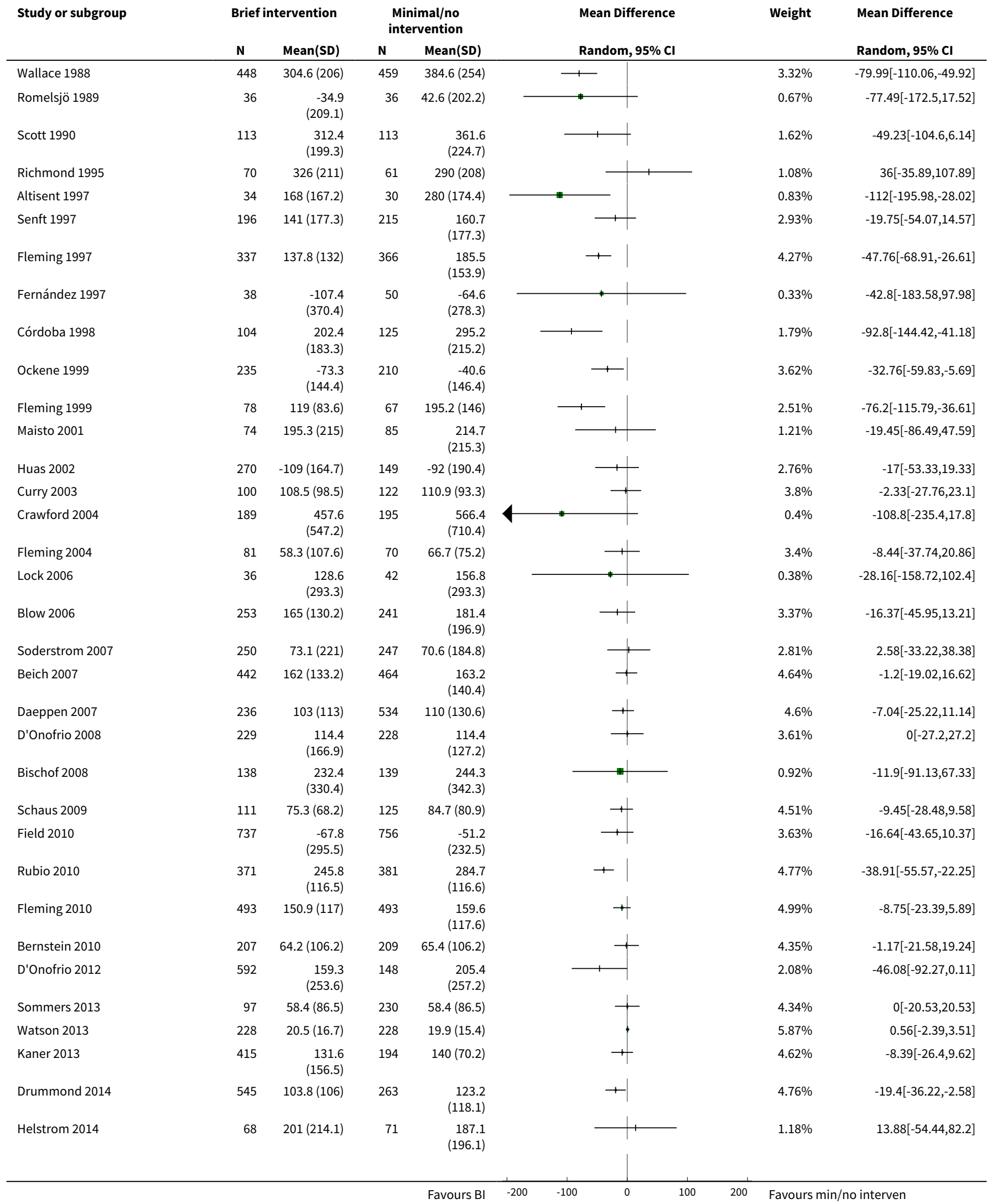




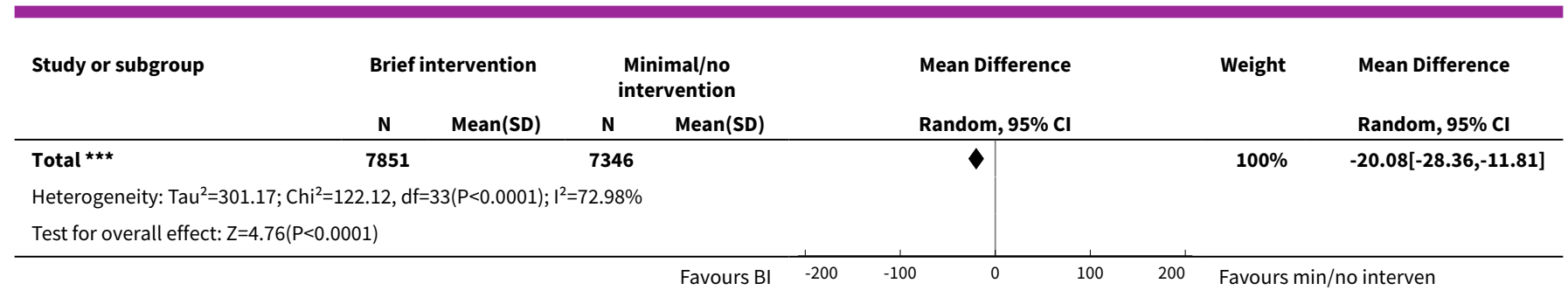

\section{Analysis 1.2. Comparison 1 Brief intervention versus control, Outcome 2 Quantity of drinking ( $\mathrm{g} /$ week) at 12 months, restricted to trials at low risk of bias due to allocation concealment.}

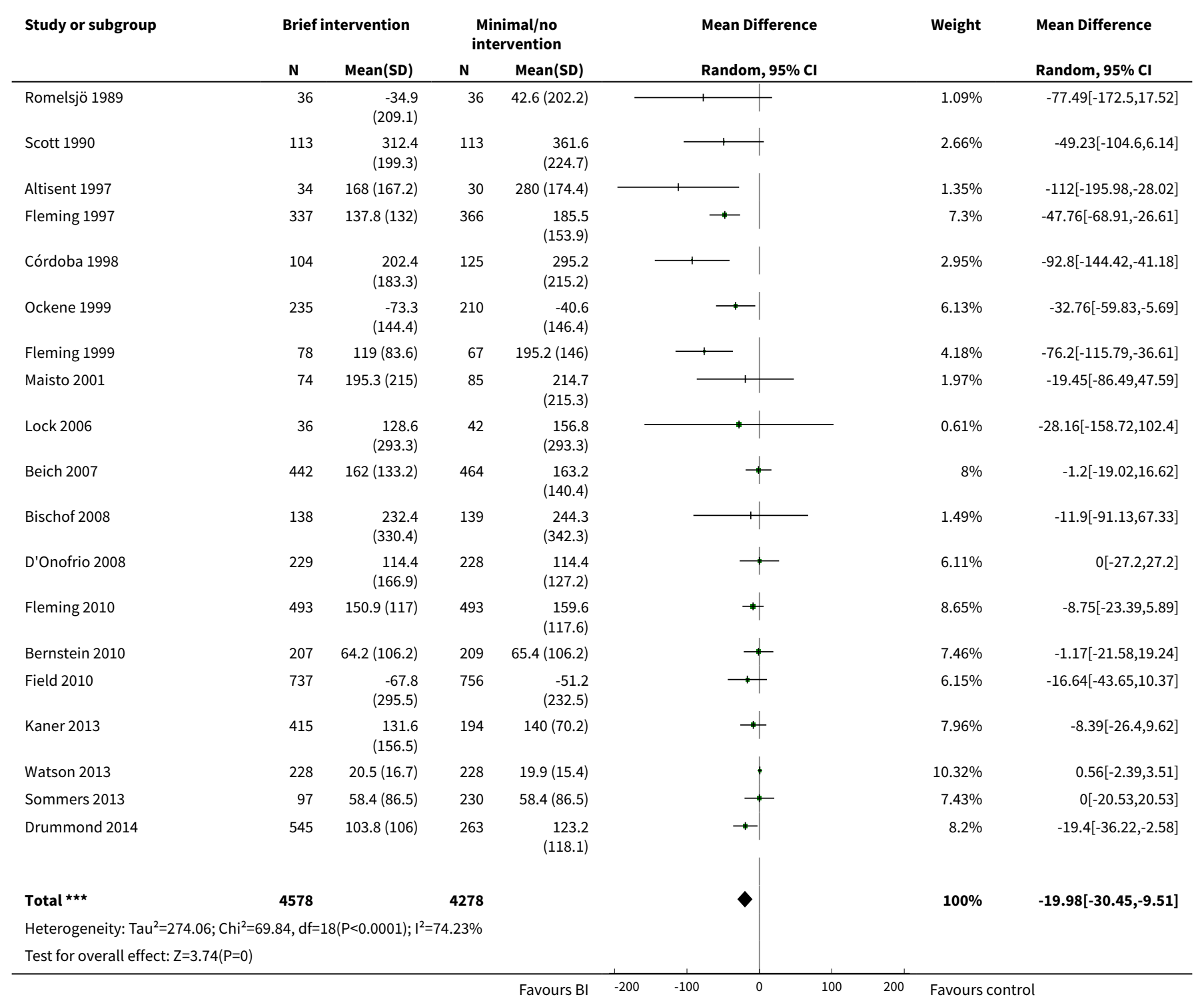


Analysis 1.3. Comparison 1 Brief intervention versus control, Outcome 3 Quantity of drinking ( $\mathrm{g} /$ week) at 12 months, restricted to trials at low risk of bias due to attrition.

\begin{tabular}{|c|c|c|c|c|c|c|c|}
\hline \multirow{3}{*}{$\begin{array}{l}\text { Study or subgroup } \\
\text { Wallace } 1988\end{array}$} & \multicolumn{2}{|c|}{ Brief intervention } & \multicolumn{2}{|c|}{$\begin{array}{c}\text { Minimal/no } \\
\text { intervention }\end{array}$} & \multirow{2}{*}{$\begin{array}{l}\text { Mean Difference } \\
\text { Random, } 95 \% \mathrm{Cl}\end{array}$} & \multirow[t]{2}{*}{ Weight } & \multirow{2}{*}{$\begin{array}{l}\text { Mean Difference } \\
\text { Random, 95\% CI }\end{array}$} \\
\hline & \multirow{2}{*}{$\frac{\mathbf{N}}{448}$} & \multirow{2}{*}{$\begin{array}{l}\text { Mean(SD) } \\
304.6(206)\end{array}$} & \multirow{2}{*}{$\frac{\mathbf{N}}{459}$} & \multirow{2}{*}{$\begin{array}{l}\text { Mean(SD) } \\
384.6(254)\end{array}$} & & & \\
\hline & & & & & $\longrightarrow$ & $5.34 \%$ & $-79.99[-110.06,-49.92]$ \\
\hline Romelsjö 1989 & 36 & $\begin{array}{r}-34.9 \\
(209.1)\end{array}$ & 36 & $42.6(202.2)$ & + & $1.18 \%$ & $-77.49[-172.5,17.52]$ \\
\hline Senft 1997 & 196 & $141(177.3)$ & 215 & $\begin{array}{r}160.7 \\
(177.3)\end{array}$ & 1 & $4.77 \%$ & $-19.75[-54.07,14.57]$ \\
\hline Ockene 1999 & 235 & $\begin{array}{r}-73.3 \\
(144.4)\end{array}$ & 210 & $\begin{array}{r}-40.6 \\
(146.4)\end{array}$ & $\longrightarrow$ & $5.77 \%$ & $-32.76[-59.83,-5.69]$ \\
\hline Fleming 1999 & 78 & $119(83.6)$ & 67 & $195.2(146)$ & + & $4.15 \%$ & $-76.2[-115.79,-36.61]$ \\
\hline Maisto 2001 & 74 & $195.3(215)$ & 85 & $\begin{array}{r}214.7 \\
(215.3)\end{array}$ & $\ldots$ & $2.09 \%$ & $-19.45[-86.49,47.59]$ \\
\hline Huas 2002 & 270 & $-109(164.7)$ & 149 & $-92(190.4)$ & $\longrightarrow$ & $4.52 \%$ & $-17[-53.33,19.33]$ \\
\hline Fleming 2004 & 81 & $58.3(107.6)$ & 70 & $66.7(75.2)$ & - & $5.45 \%$ & $-8.44[-37.74,20.86]$ \\
\hline Daeppen 2007 & 236 & $103(113)$ & 534 & $110(130.6)$ & - & $7.11 \%$ & $-7.04[-25.22,11.14]$ \\
\hline D'Onofrio 2008 & 229 & $\begin{array}{r}114.4 \\
(166.9)\end{array}$ & 228 & $\begin{array}{r}114.4 \\
(127.2)\end{array}$ & & $5.75 \%$ & $0[-27.2,27.2]$ \\
\hline Bischof 2008 & 138 & $\begin{array}{r}232.4 \\
(330.4)\end{array}$ & 139 & $\begin{array}{r}244.3 \\
(342.3)\end{array}$ & 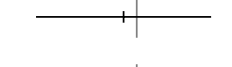 & $1.6 \%$ & $-11.9[-91.13,67.33]$ \\
\hline Rubio 2010 & 371 & $\begin{array}{r}245.8 \\
(116.5)\end{array}$ & 381 & $\begin{array}{r}284.7 \\
(116.6)\end{array}$ & $\rightarrow$ & $7.33 \%$ & $-38.91[-55.57,-22.25]$ \\
\hline Bernstein 2010 & 207 & $64.2(106.2)$ & 209 & $65.4(106.2)$ & $\longrightarrow$ & $6.77 \%$ & $-1.17[-21.58,19.24]$ \\
\hline Fleming 2010 & 493 & $150.9(117)$ & 493 & $\begin{array}{r}159.6 \\
(117.6)\end{array}$ & $\rightarrow$ & $7.62 \%$ & $-8.75[-23.39,5.89]$ \\
\hline Kaner 2013 & 415 & $\begin{array}{r}131.6 \\
(156.5)\end{array}$ & 194 & $140(70.2)$ & $\rightarrow$ & $7.13 \%$ & $-8.39[-26.4,9.62]$ \\
\hline Watson 2013 & 228 & $20.5(16.7)$ & 228 & $19.9(15.4)$ & 申 & $8.73 \%$ & $0.56[-2.39,3.51]$ \\
\hline Helstrom 2014 & 68 & $201(214.1)$ & 71 & $\begin{array}{r}187.1 \\
(196.1)\end{array}$ & & $2.03 \%$ & $13.88[-54.44,82.2]$ \\
\hline Total $\star \star \star$ & 4240 & & 4256 & & $\diamond$ & $100 \%$ & $-20.69[-31.78,-9.6]$ \\
\hline \multicolumn{8}{|c|}{ Heterogeneity: $\operatorname{Tau}^{2}=364.47 ; \mathrm{Chi}^{2}=89.12, \mathrm{df}=18(\mathrm{P}<0.0001) ; \mathrm{I}^{2}=79.8 \%$} \\
\hline Test for overall effec & & & & & & & \\
\hline
\end{tabular}

Analysis 1.4. Comparison 1 Brief intervention versus control, Outcome 4 Quantity of drinking (g/week) at 12 months, with imputation of unknown standard deviations.

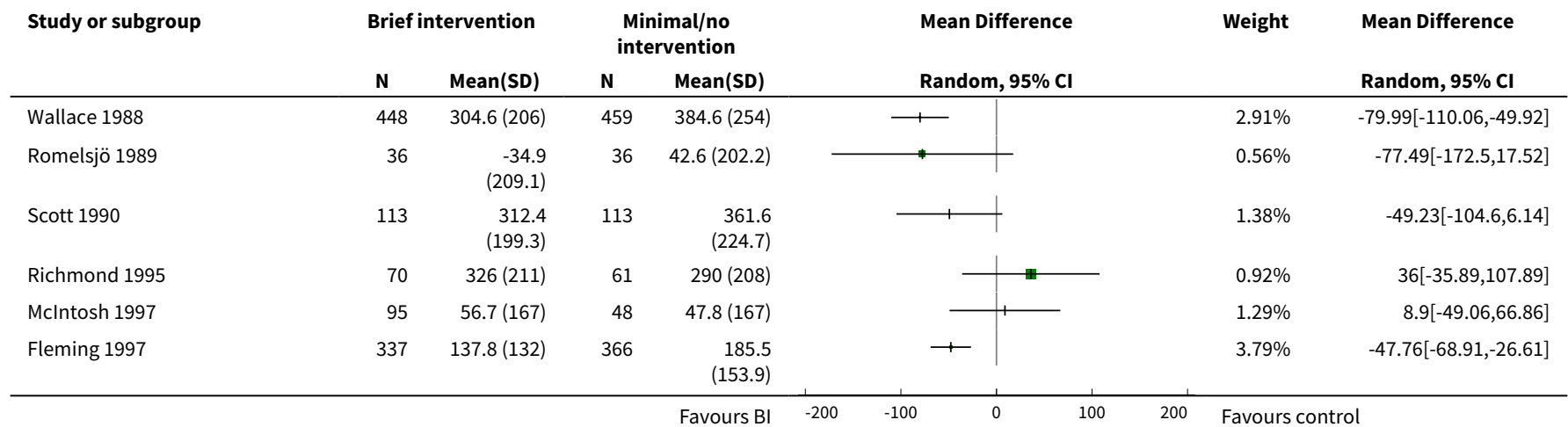




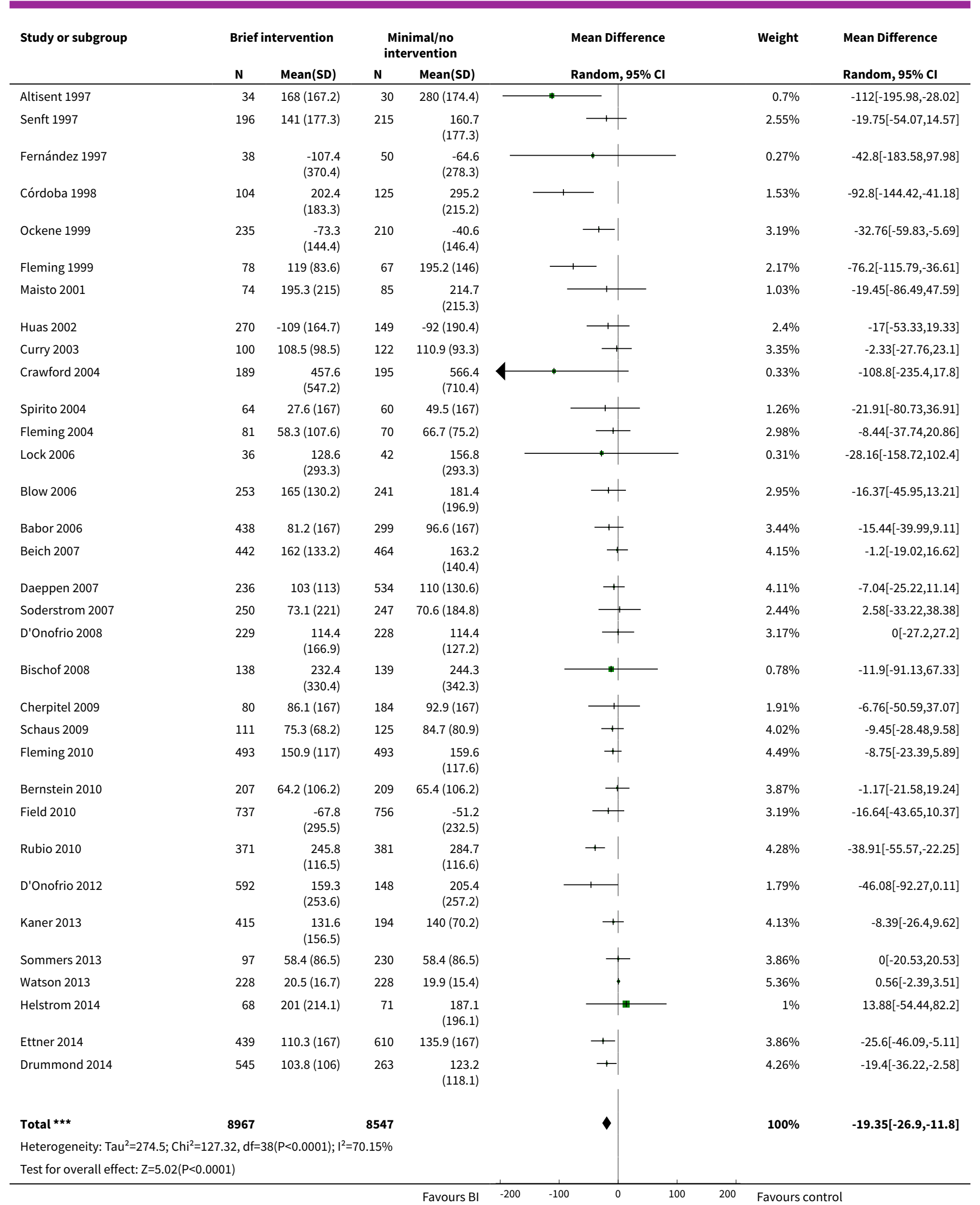


Analysis 1.5. Comparison 1 Brief intervention versus control, Outcome 5 Quantity of drinking ( $\mathrm{g} /$ week) at 12 months, subgrouped by cluster/individual randomisation.

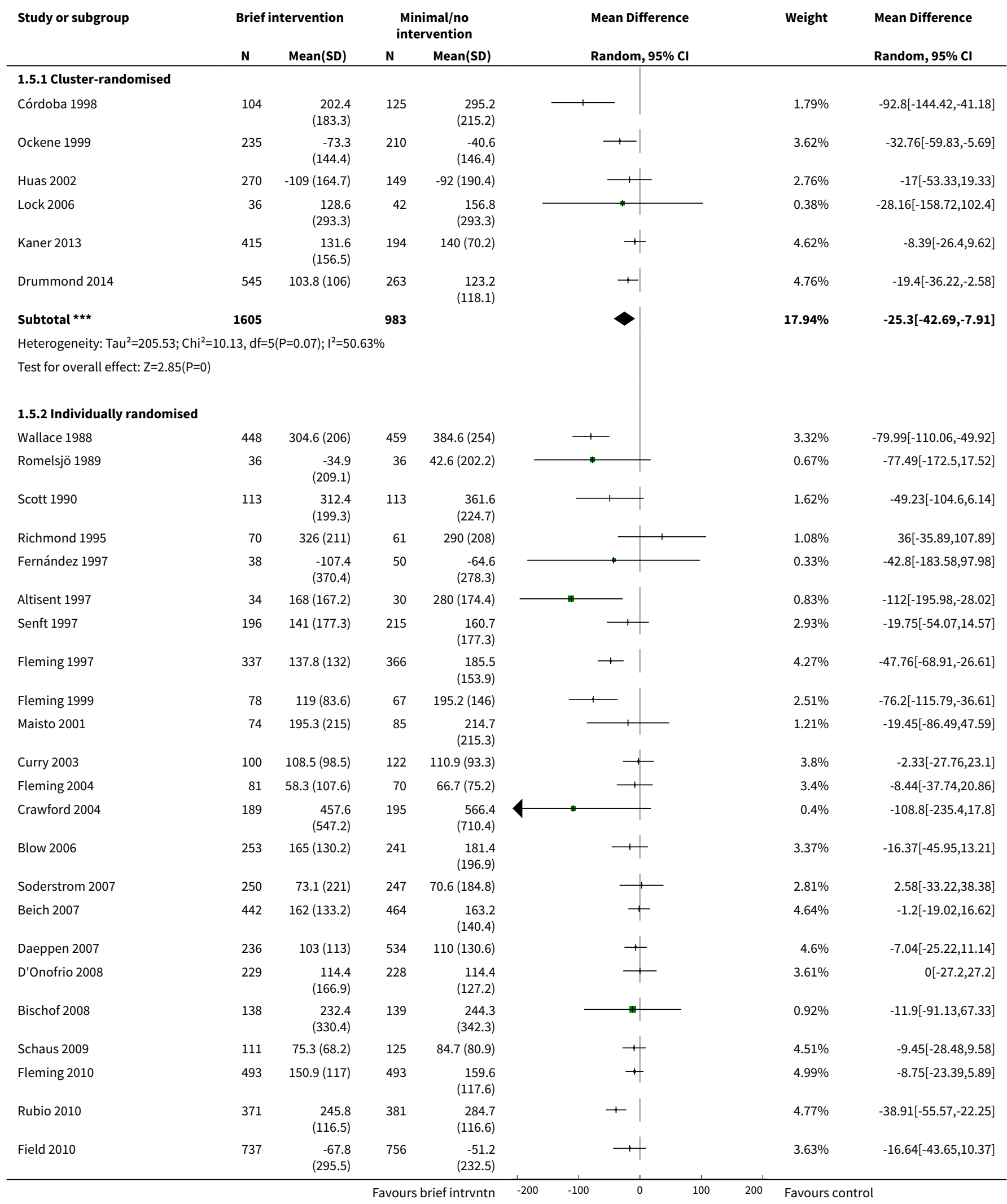




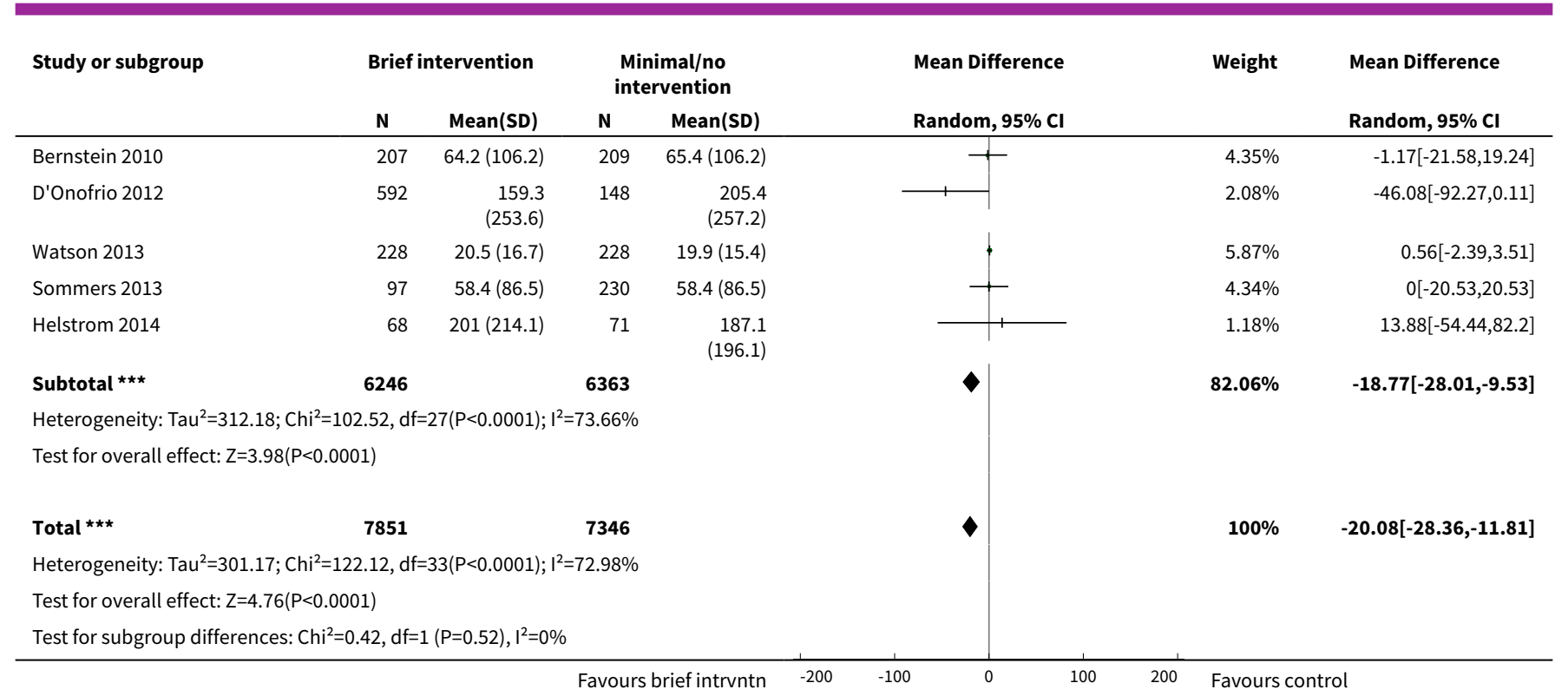

Analysis 1.6. Comparison 1 Brief intervention versus control, Outcome 6 Quantity of drinking (g/week) at 12 months, subgrouped by cluster/individual randomisation, varying imputed ICC.

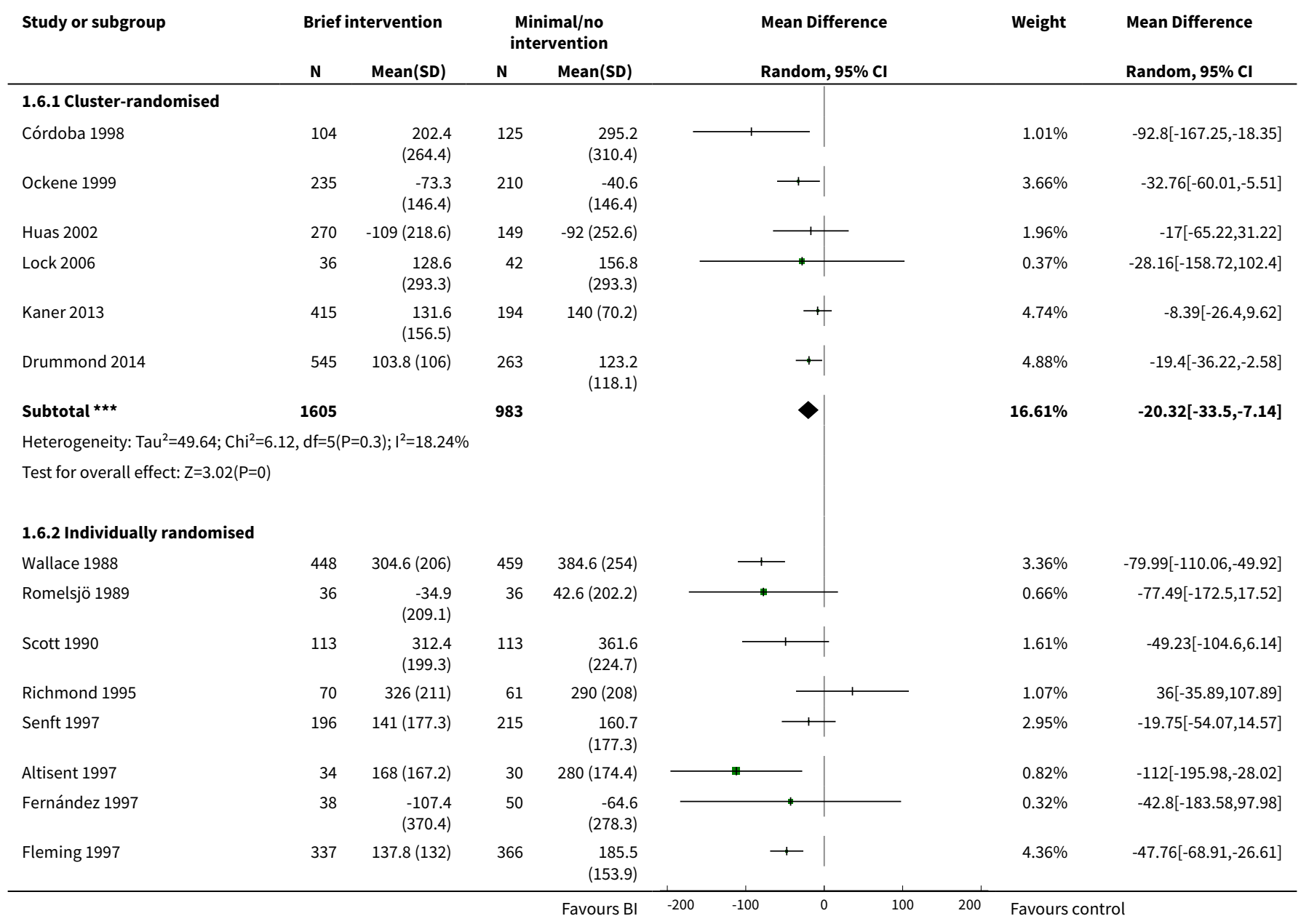




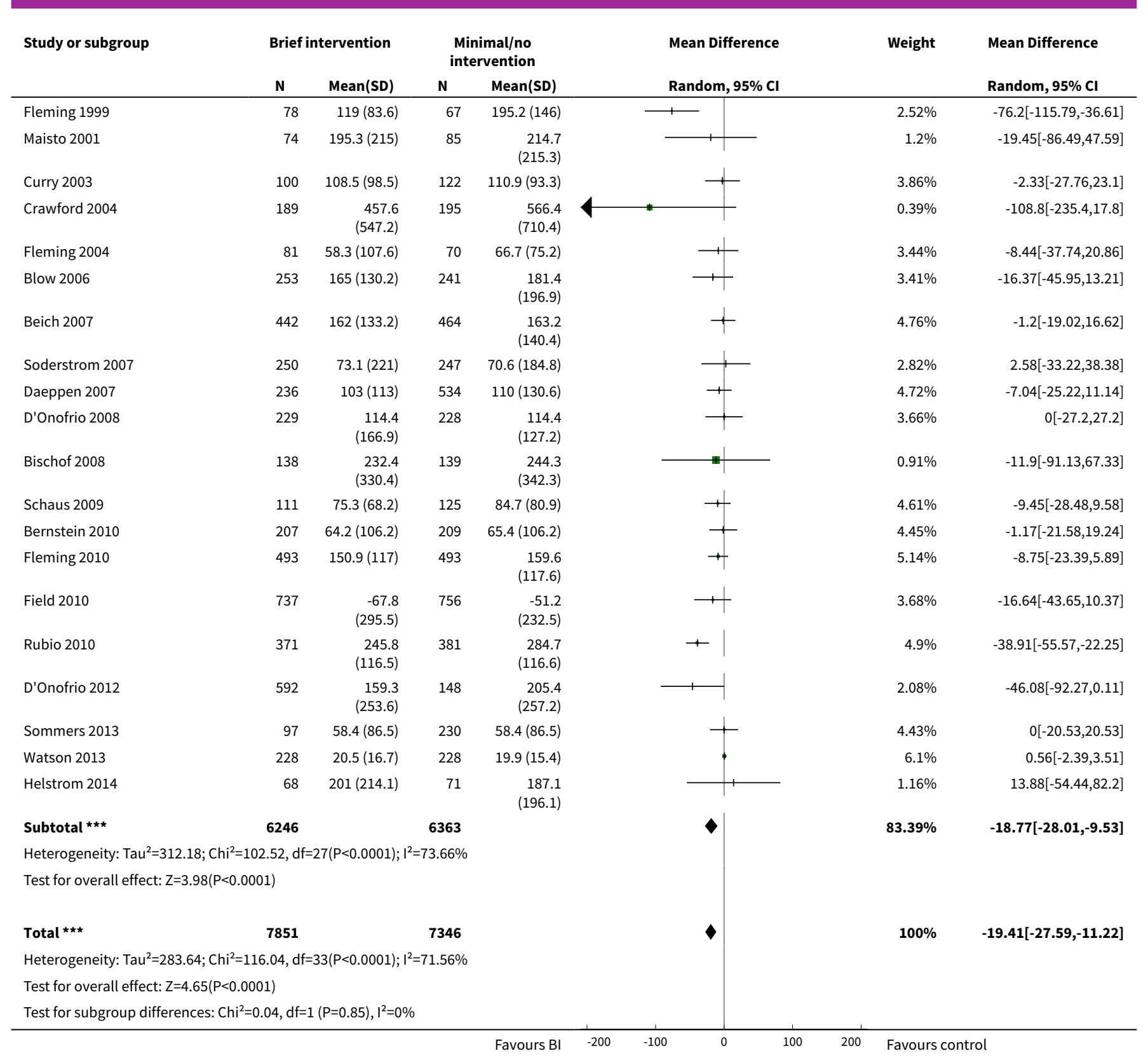

\section{Analysis 1.7. Comparison 1 Brief intervention versus control, Outcome 7 Quantity of drinking (g/week) at 12 months, subgrouped by gender.}

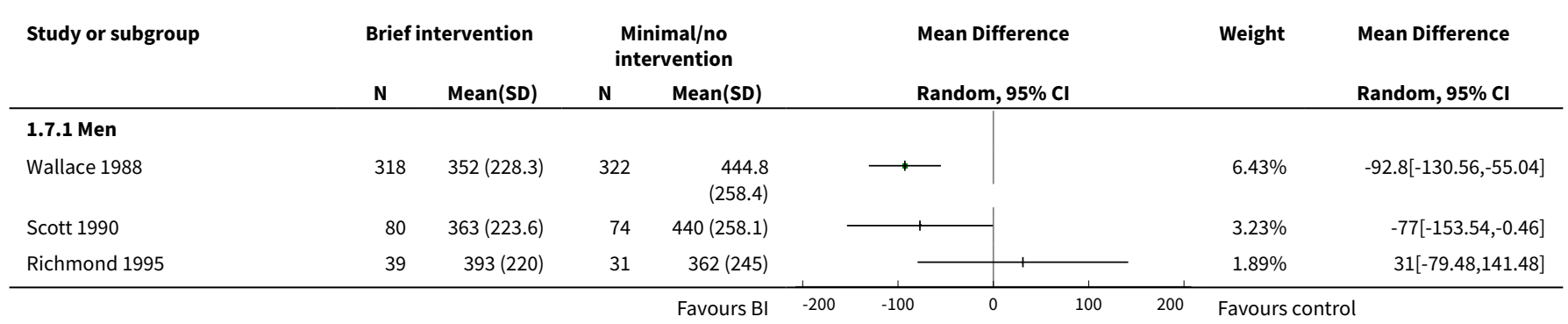




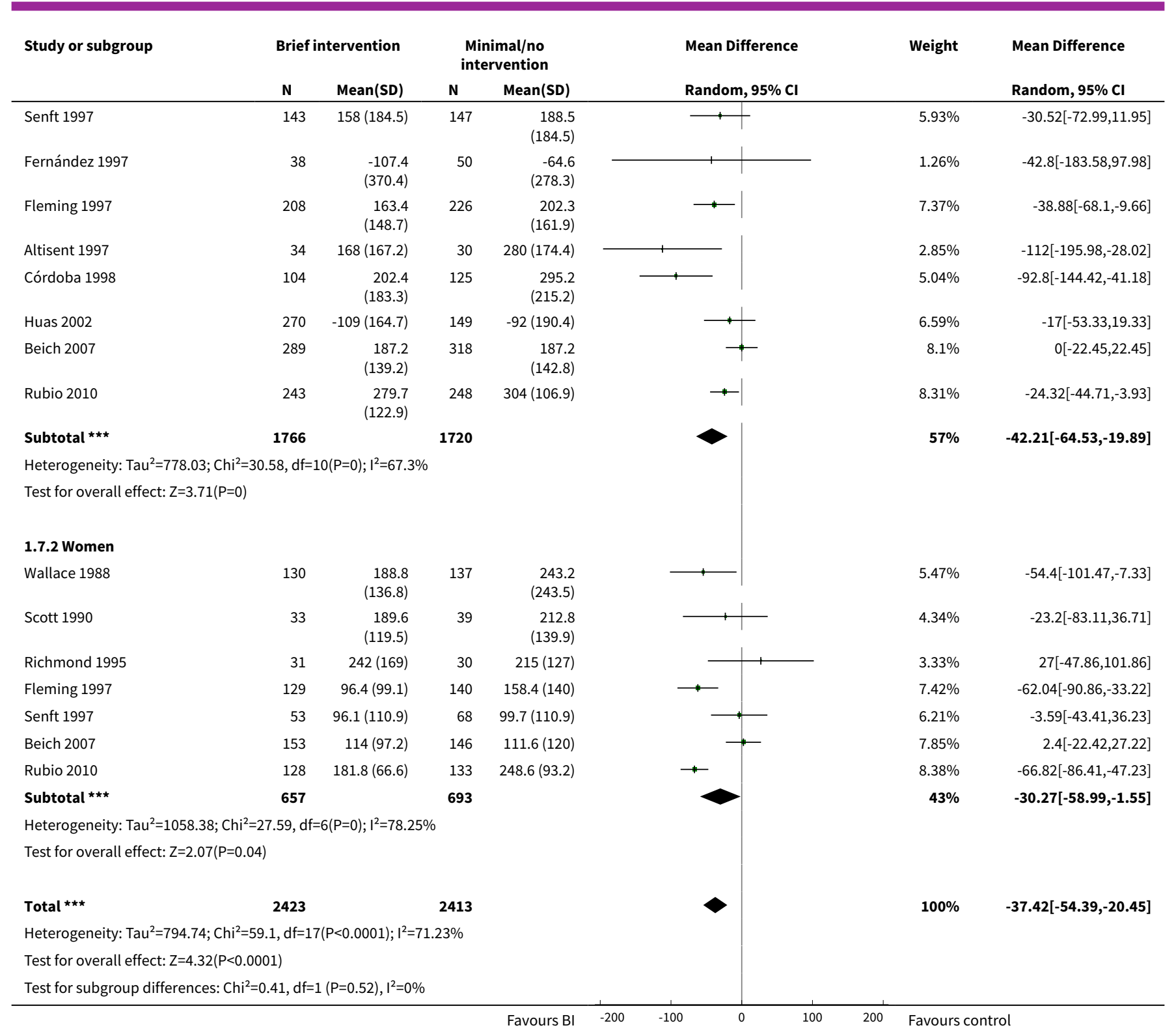

Analysis 1.8. Comparison 1 Brief intervention versus control, Outcome 8 Quantity of drinking (g/week) at 12 months, subgrouped by gender, excluding trials of men only.

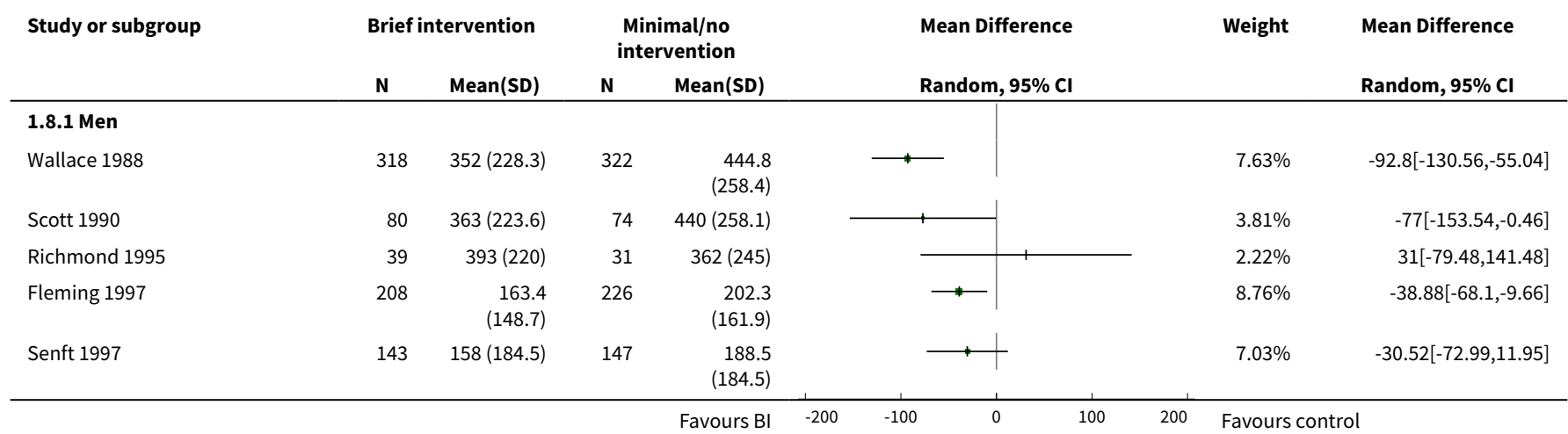




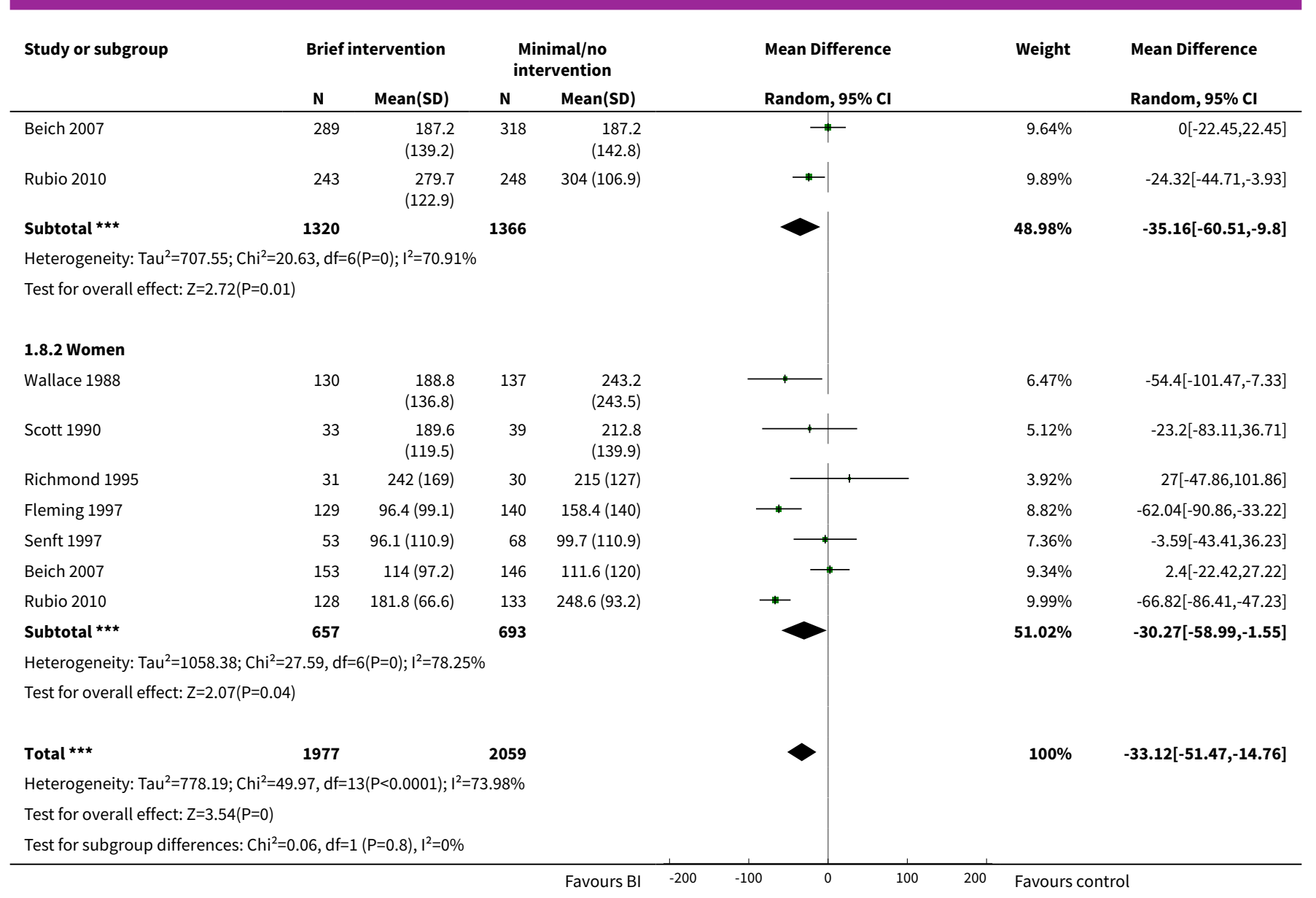

Analysis 1.9. Comparison 1 Brief intervention versus control, Outcome 9 Quantity of drinking (g/week) at 12 months, subgrouped by adolescents/young adults only versus other.

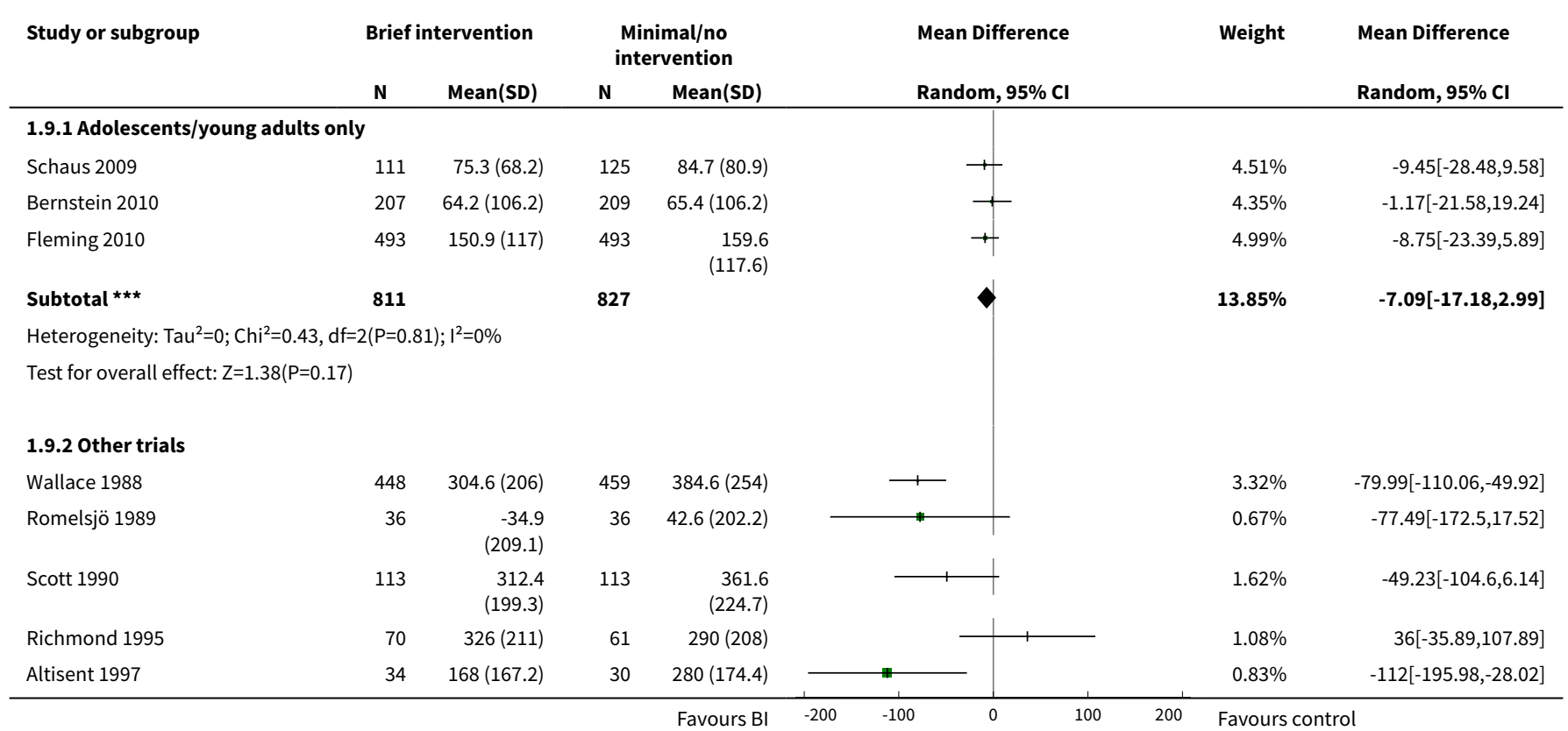




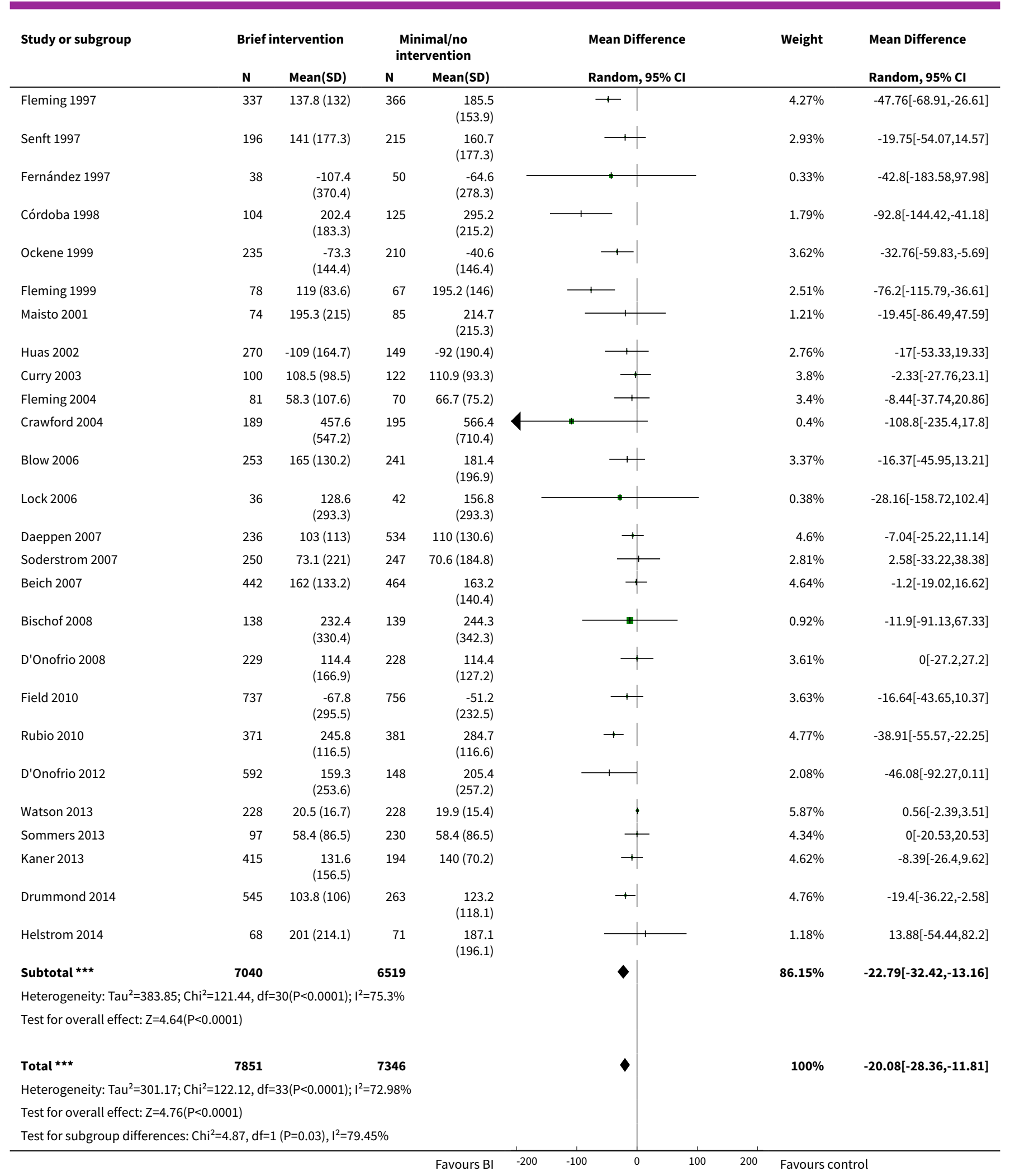


Analysis 1.10. Comparison 1 Brief intervention versus control, Outcome 10 Quantity of drinking (g/week) at 12 months, subgrouped by general practice/emergency setting.

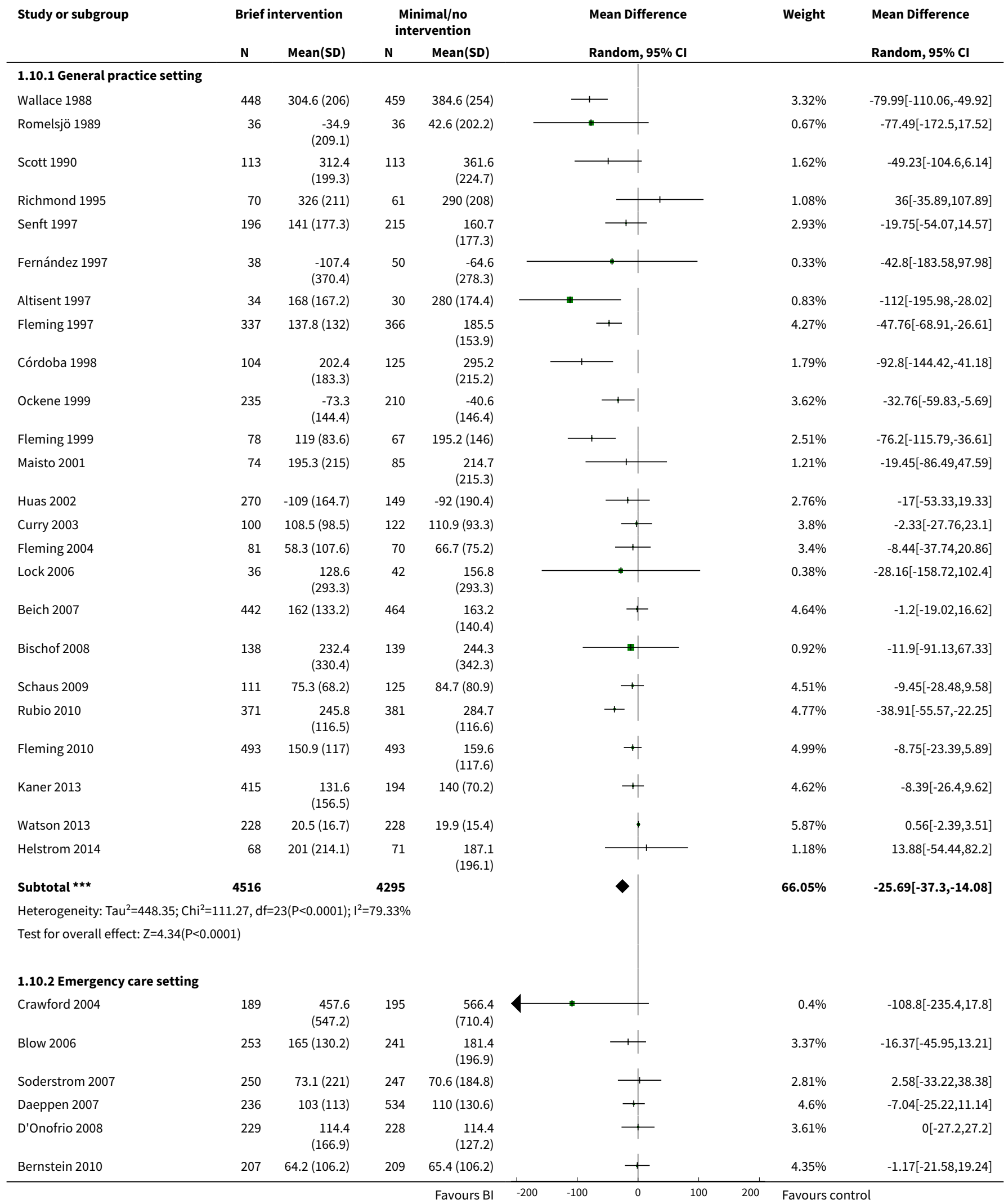




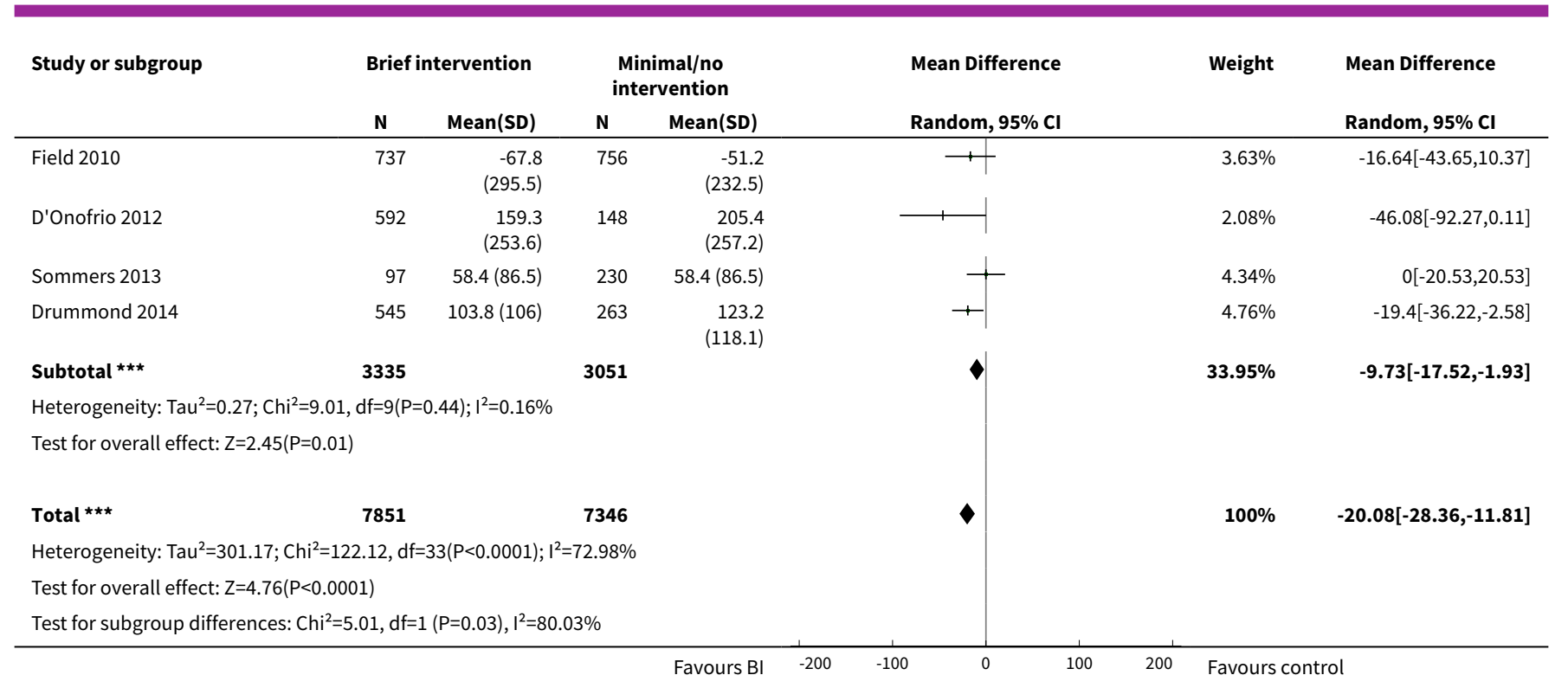

\section{Analysis 1.11. Comparison 1 Brief intervention versus control, Outcome 11 Quantity of drinking (g/wk) at 12 months, subgrouped by intervention modality (advice versus counselling).}

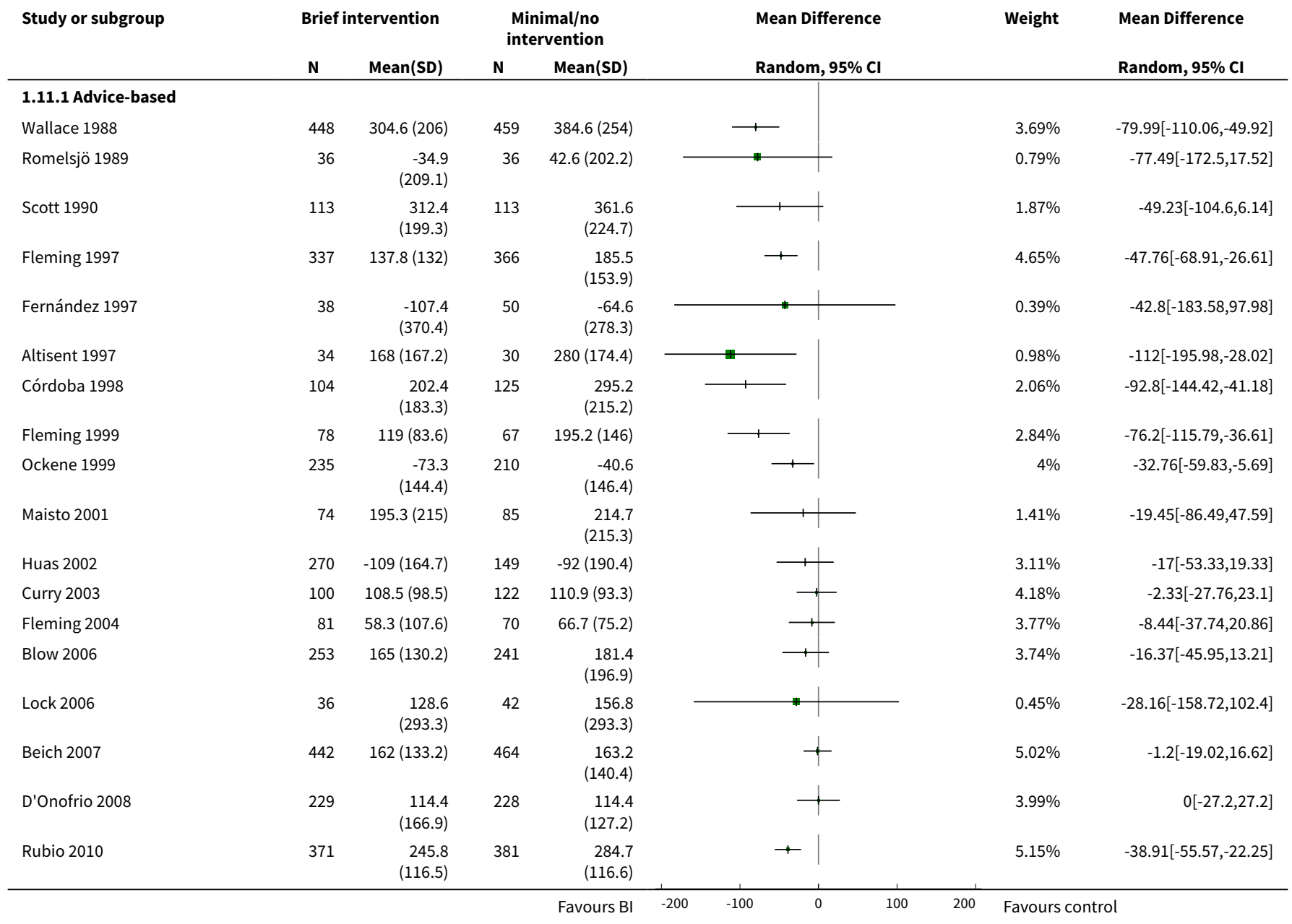




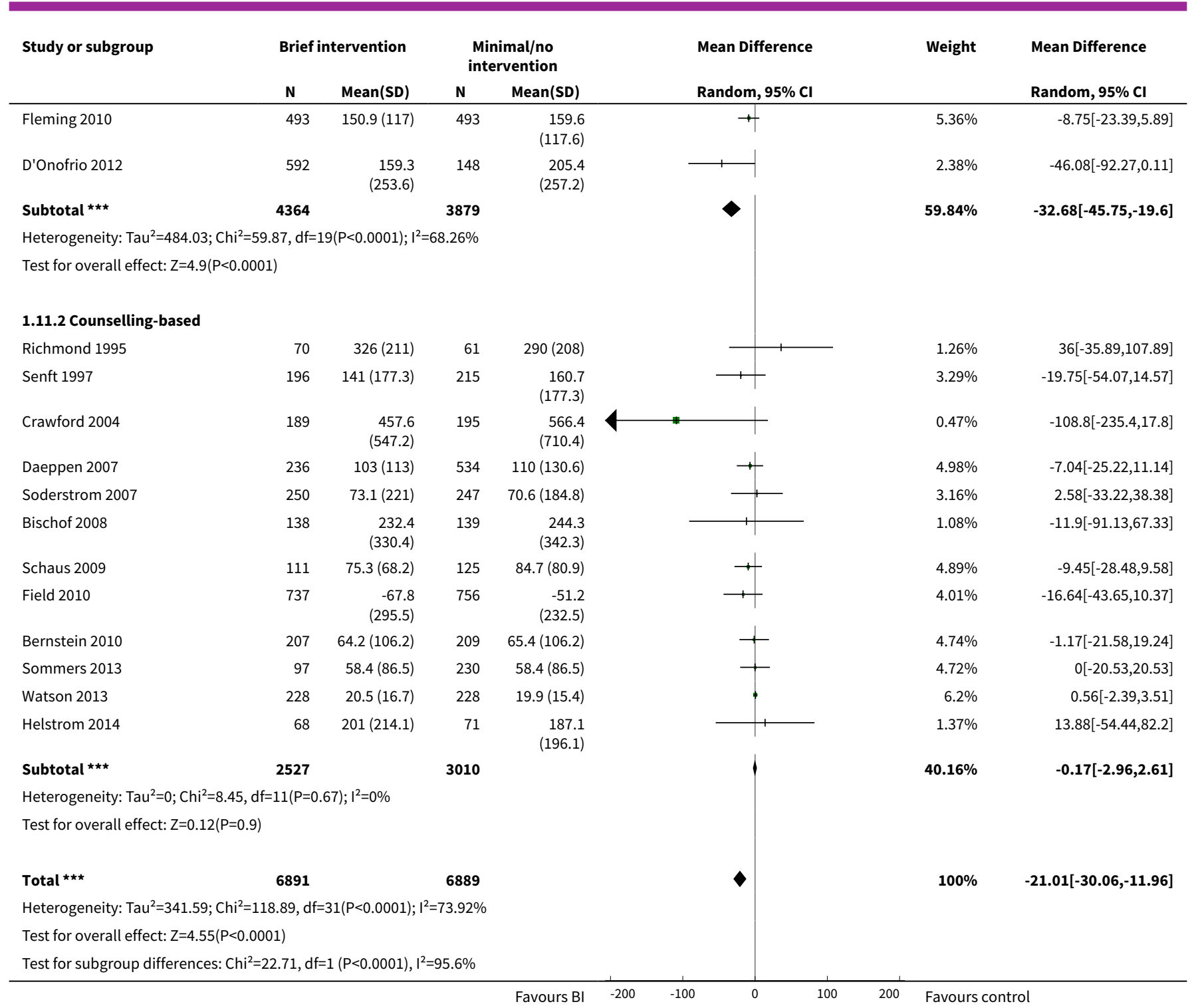

Analysis 1.12. Comparison 1 Brief intervention versus control, Outcome 12 Quantity of drinking ( $\mathrm{g} /$ week) at 12 months, subgrouped by type of control.

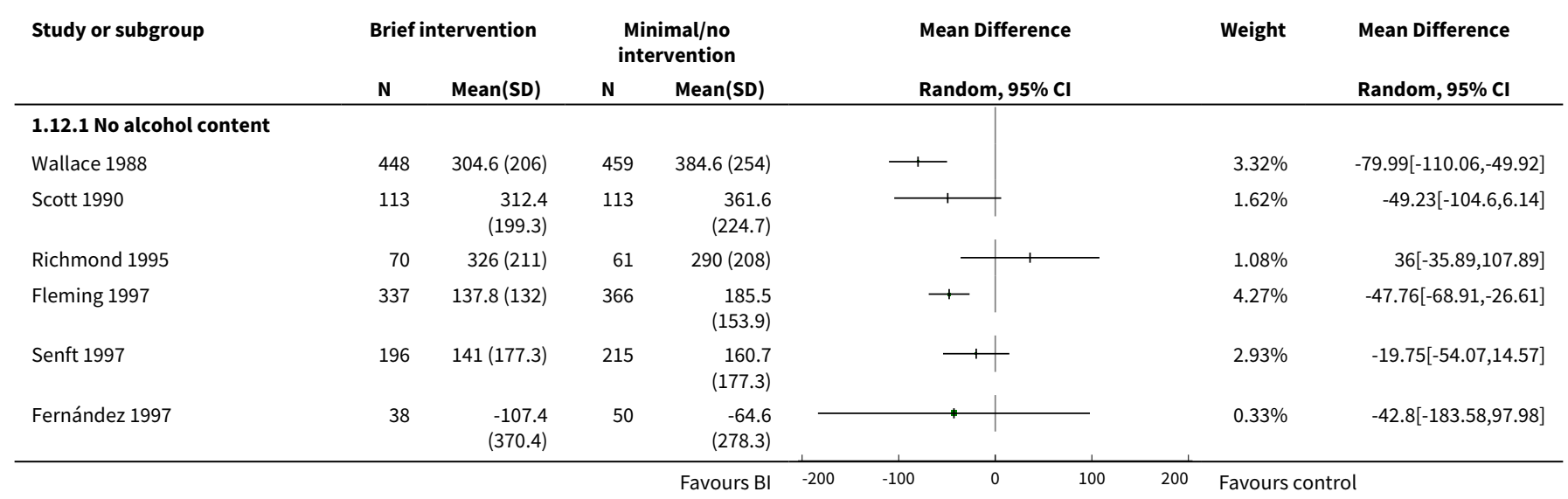




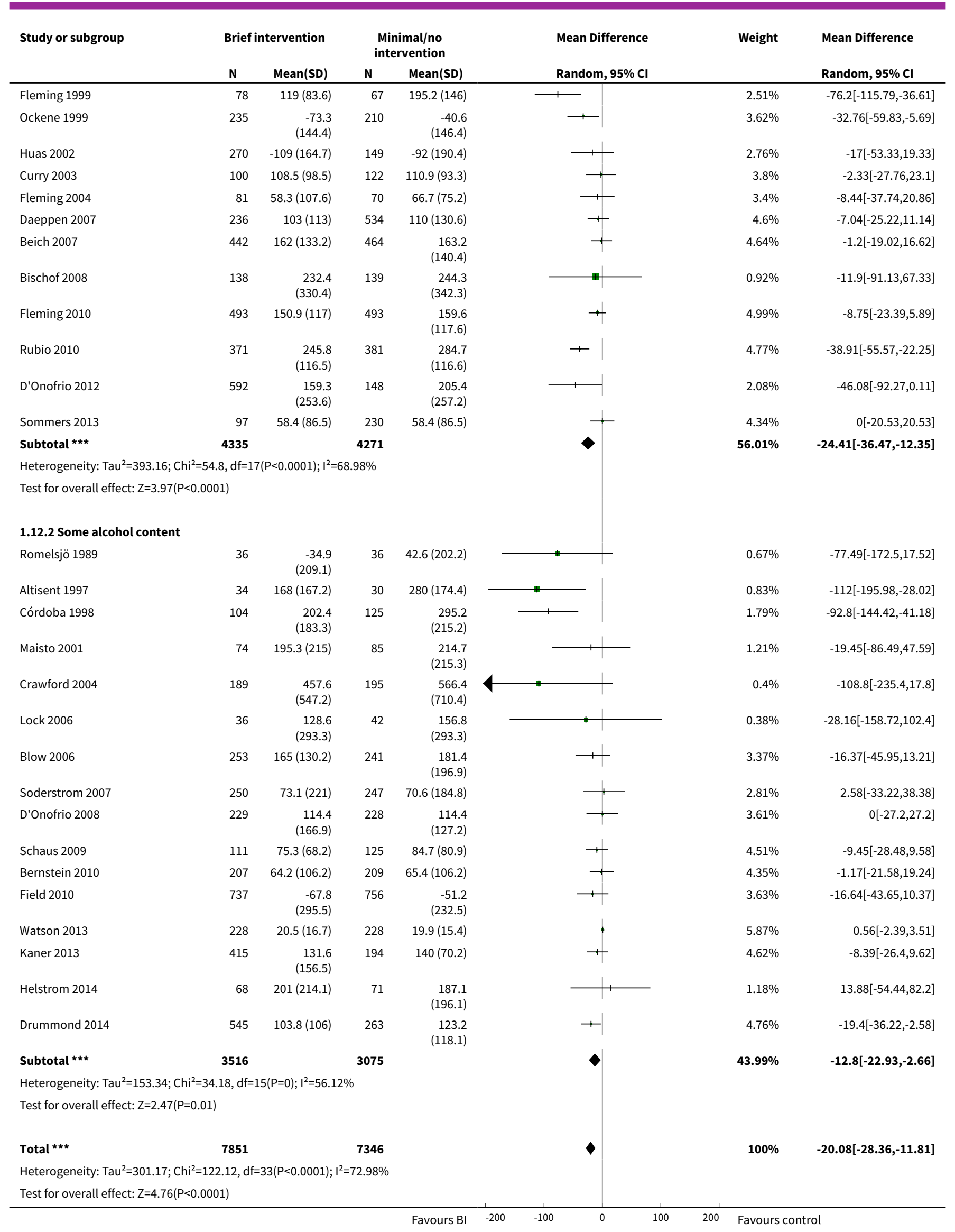




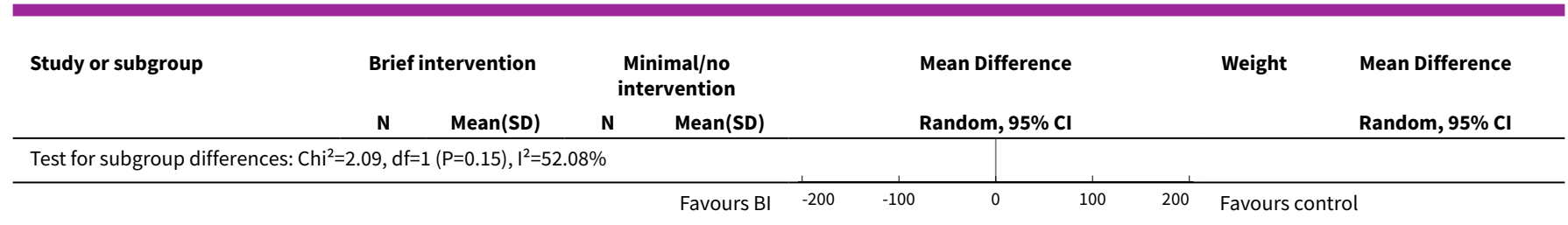

\section{Analysis 1.13. Comparison 1 Brief intervention versus control, Outcome 13 Quantity of drinking (g/week), subgrouped by length of follow-up.}

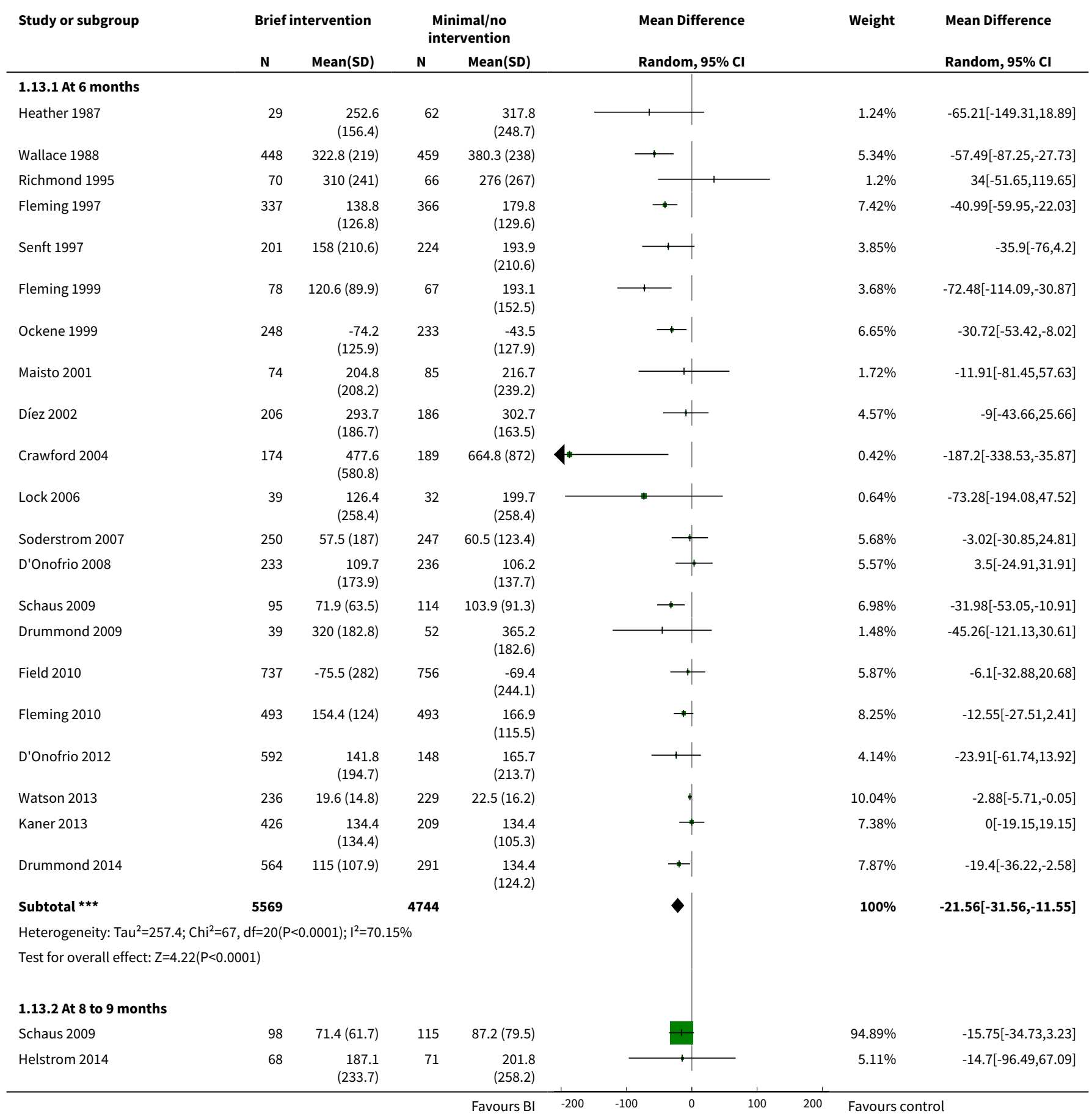




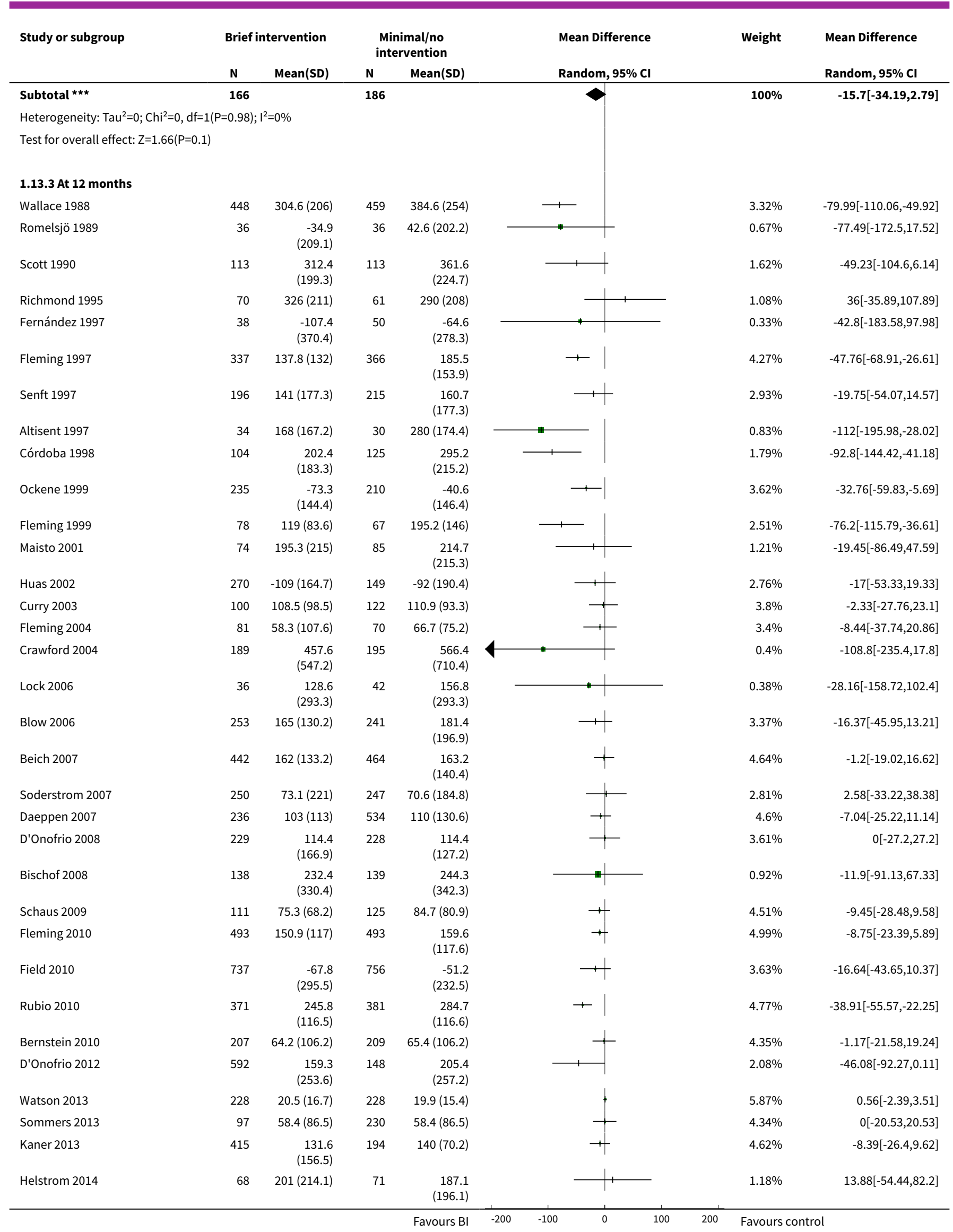




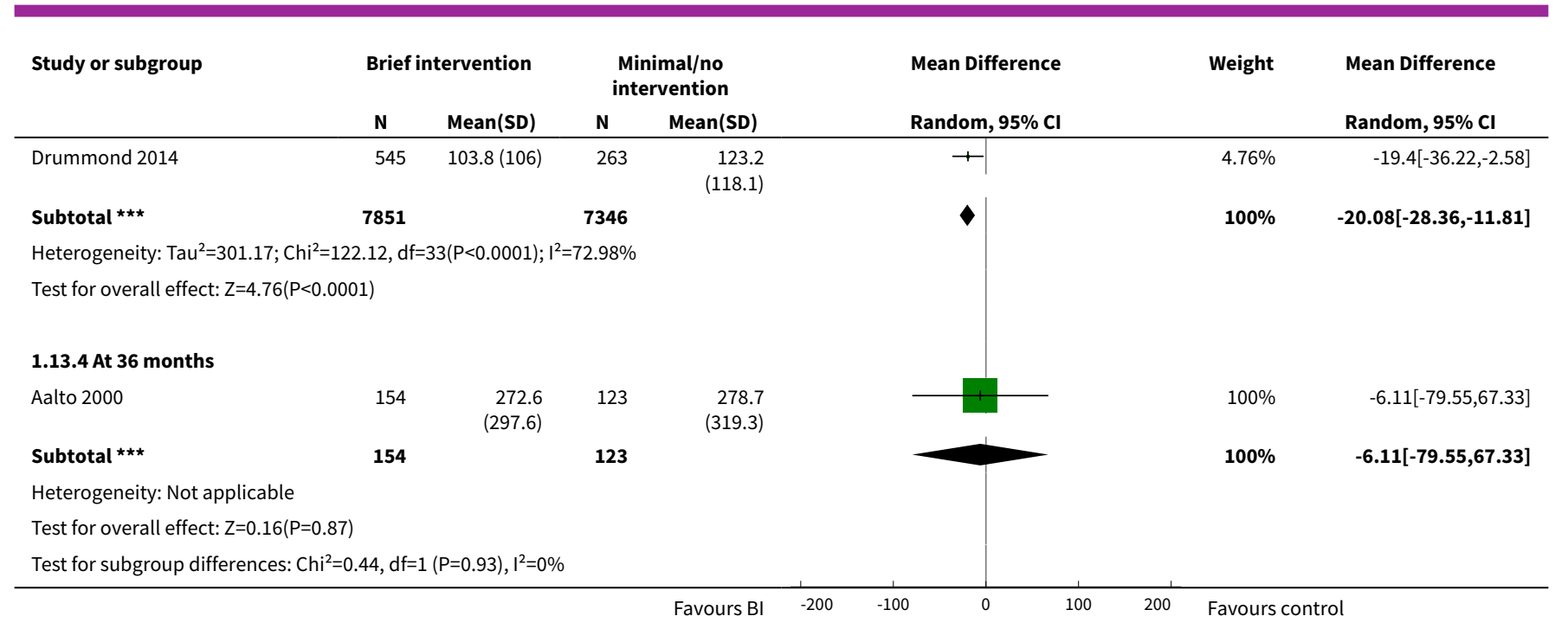

Analysis 1.14. Comparison 1 Brief intervention versus control, Outcome 14 Quantity of drinking (g/week), subgrouped by length of follow-up ( 6 and 12 months) and restricted to trials with information at both times.

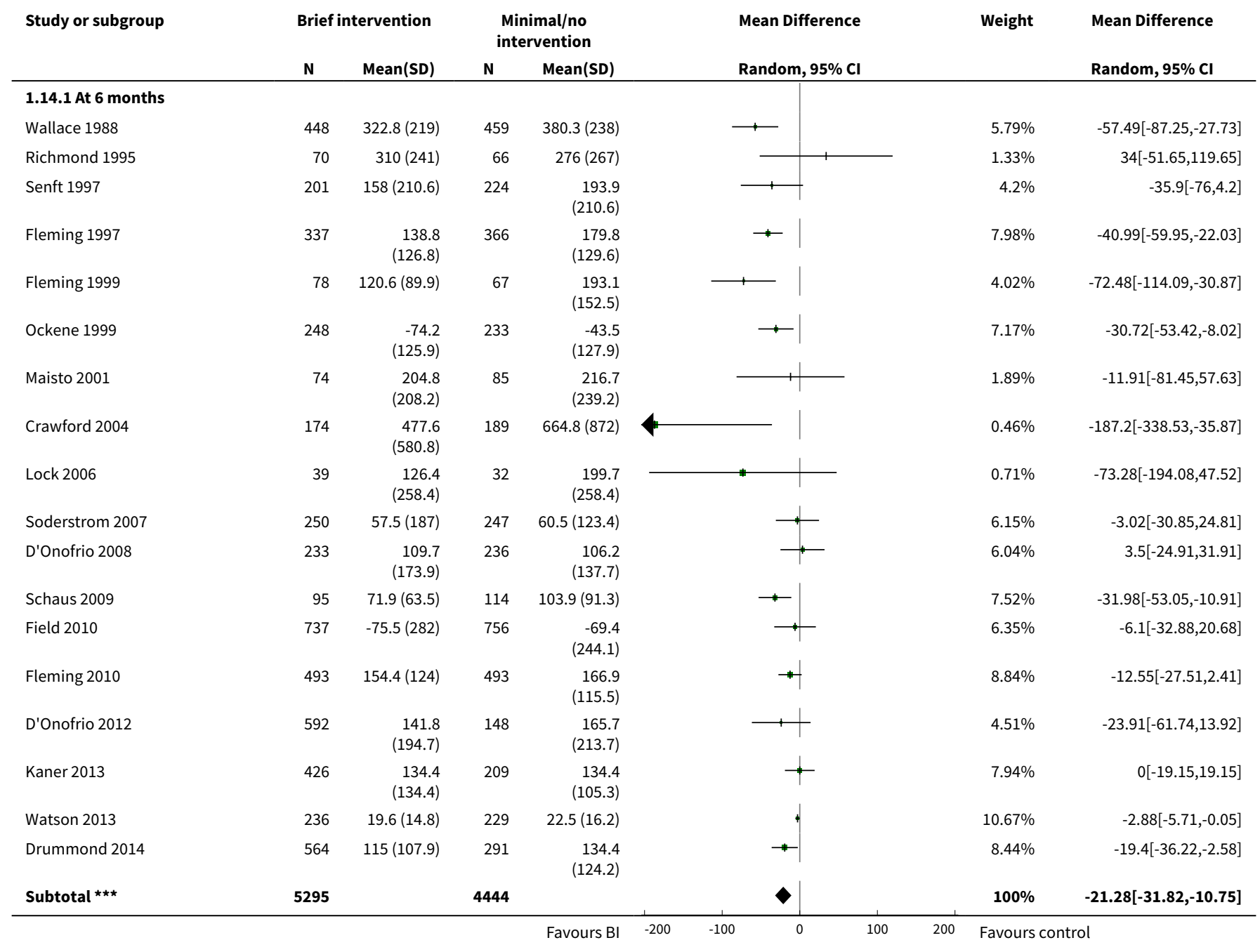




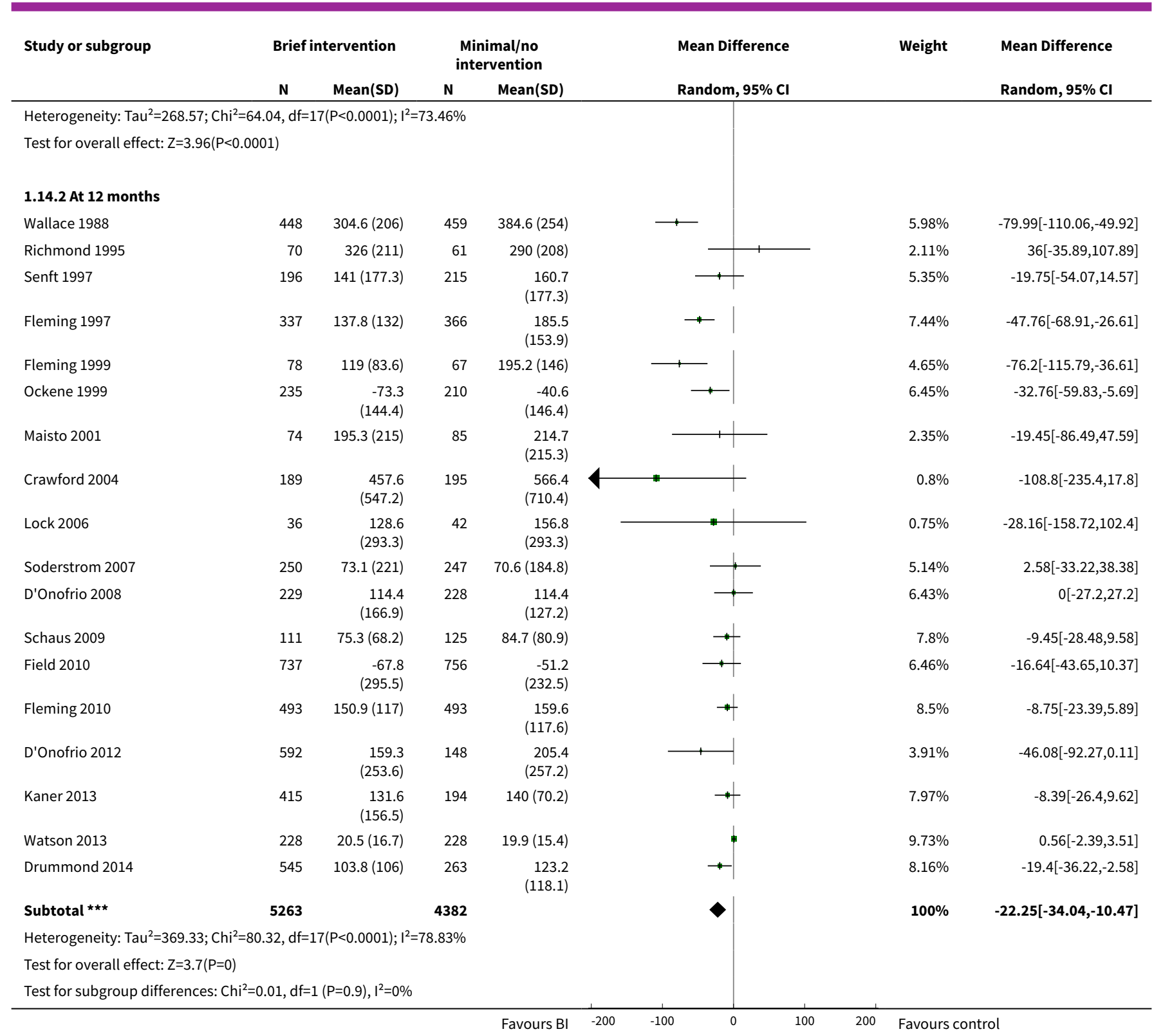

Analysis 1.15. Comparison 1 Brief intervention versus control, Outcome 15 Quantity of drinking (g/week) at 12 months, subgrouped by effectiveness/efficacy.

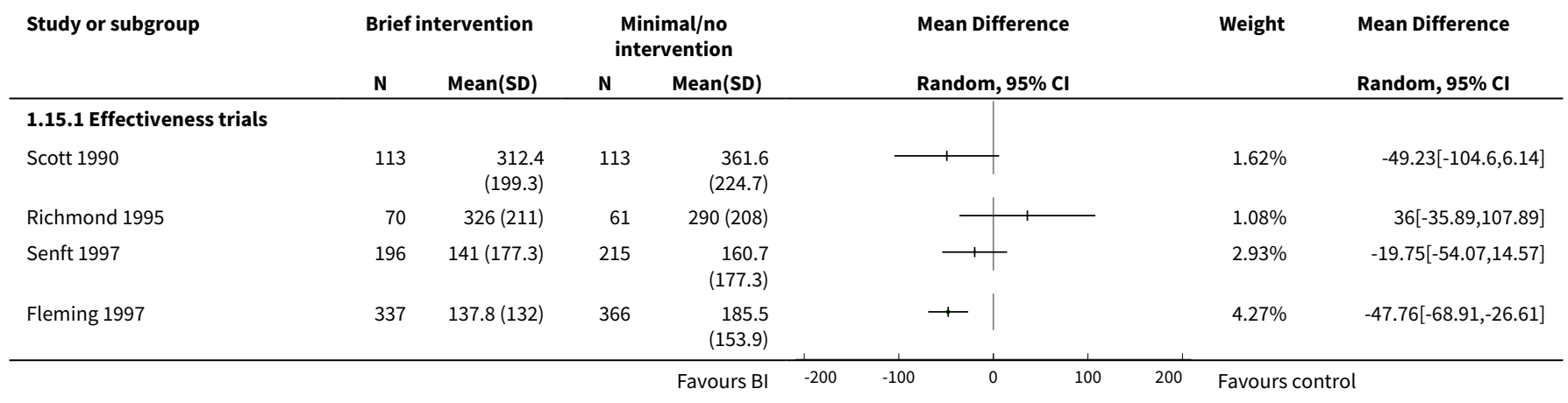




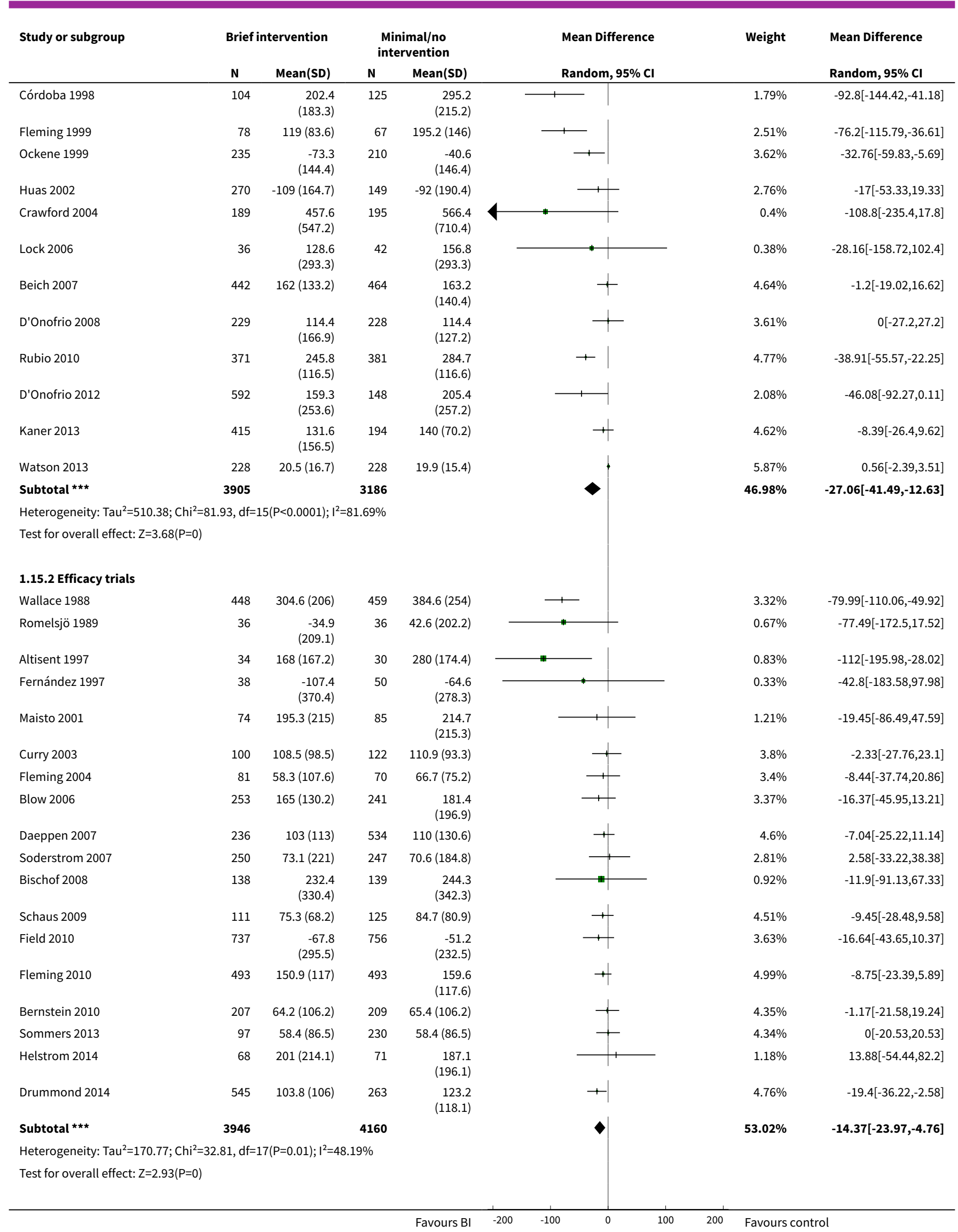




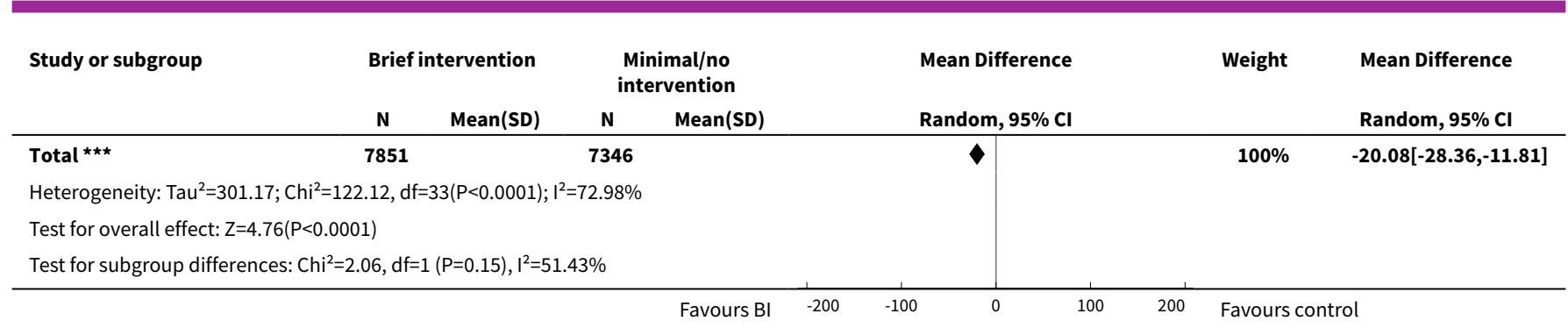

\section{Analysis 1.16. Comparison 1 Brief intervention versus control, Outcome 16 Frequency of binge drinking (number binges/week) at 12 months.}

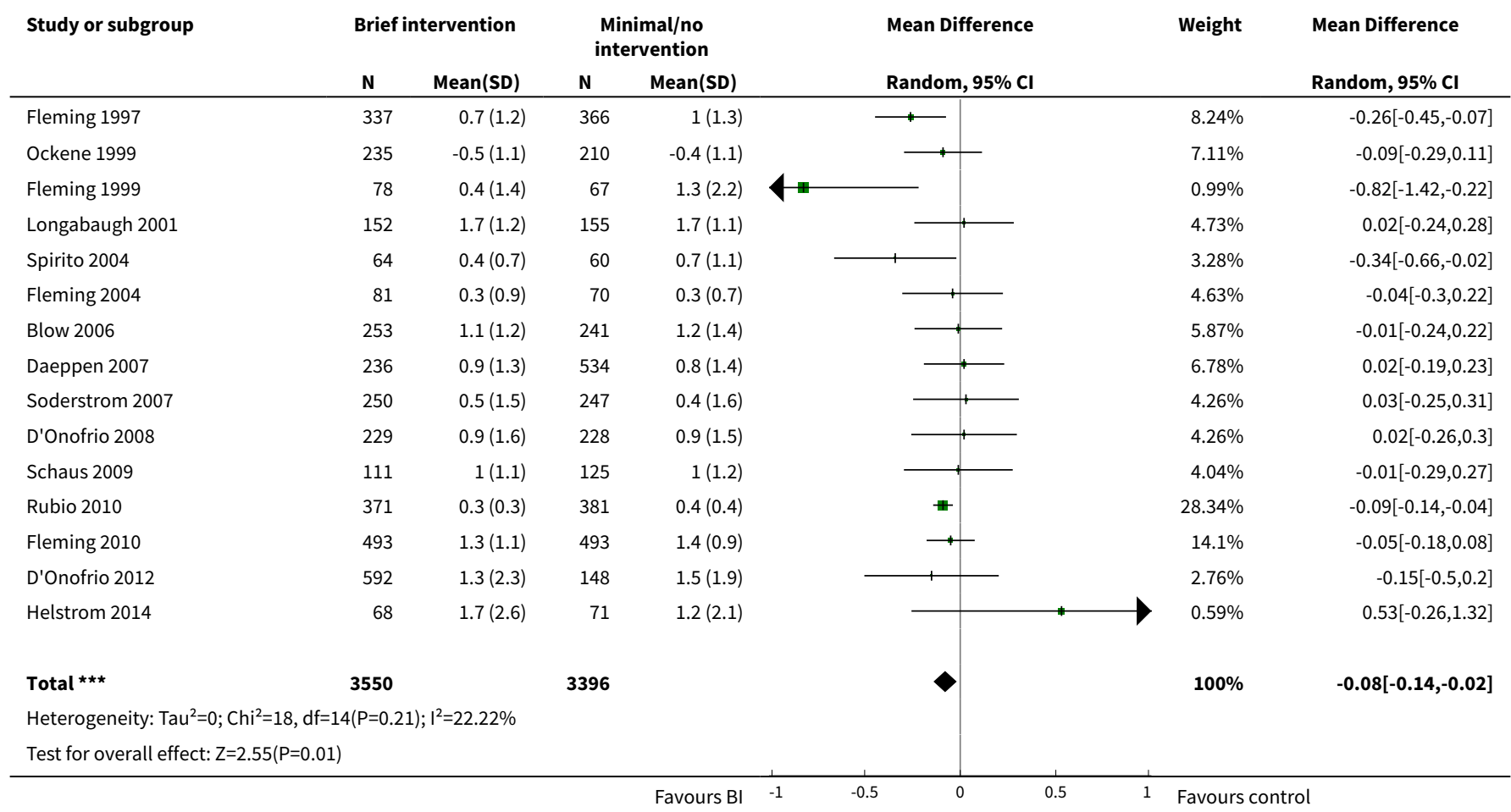

Analysis 1.17. Comparison 1 Brief intervention versus control, Outcome 17 Frequency of drinking (number binges/ week), subgrouped by length of follow-up ( 6 \& 12 months) and restricted to trials with information at both times.

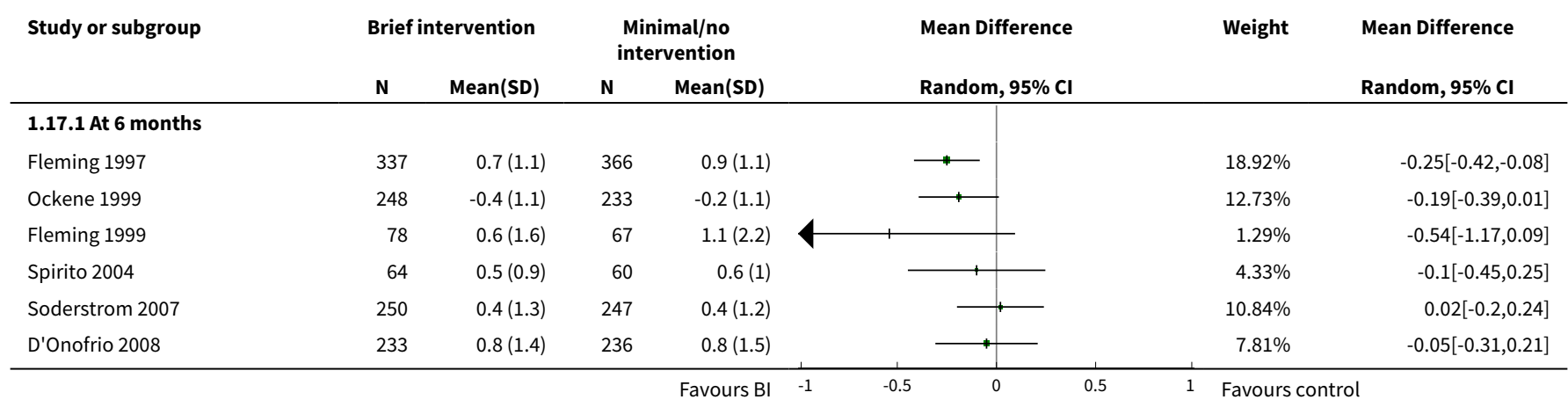




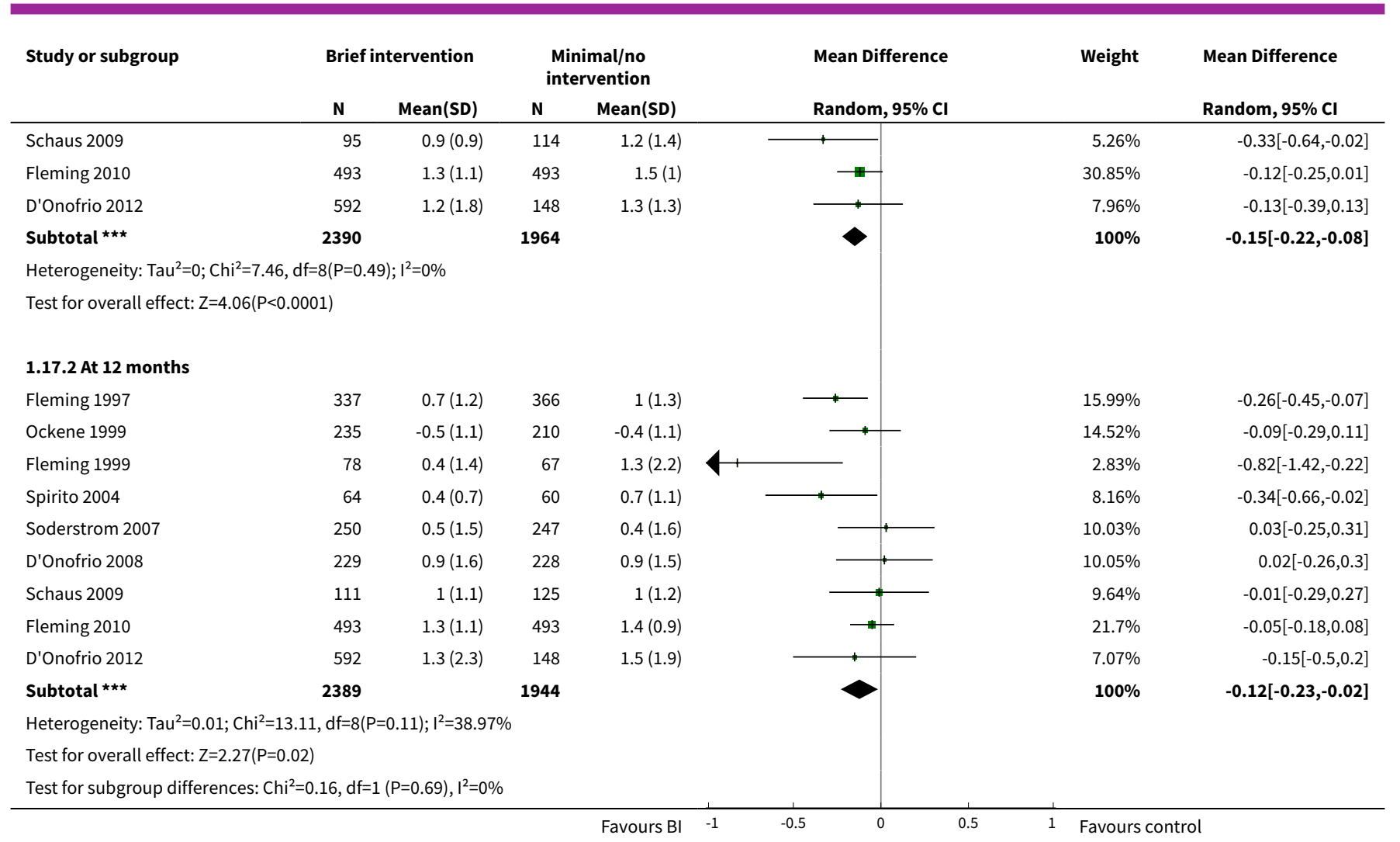

\section{Analysis 1.18. Comparison 1 Brief intervention versus control, Outcome 18 Frequency of drinking (number days drinking/week) at 12 months.}

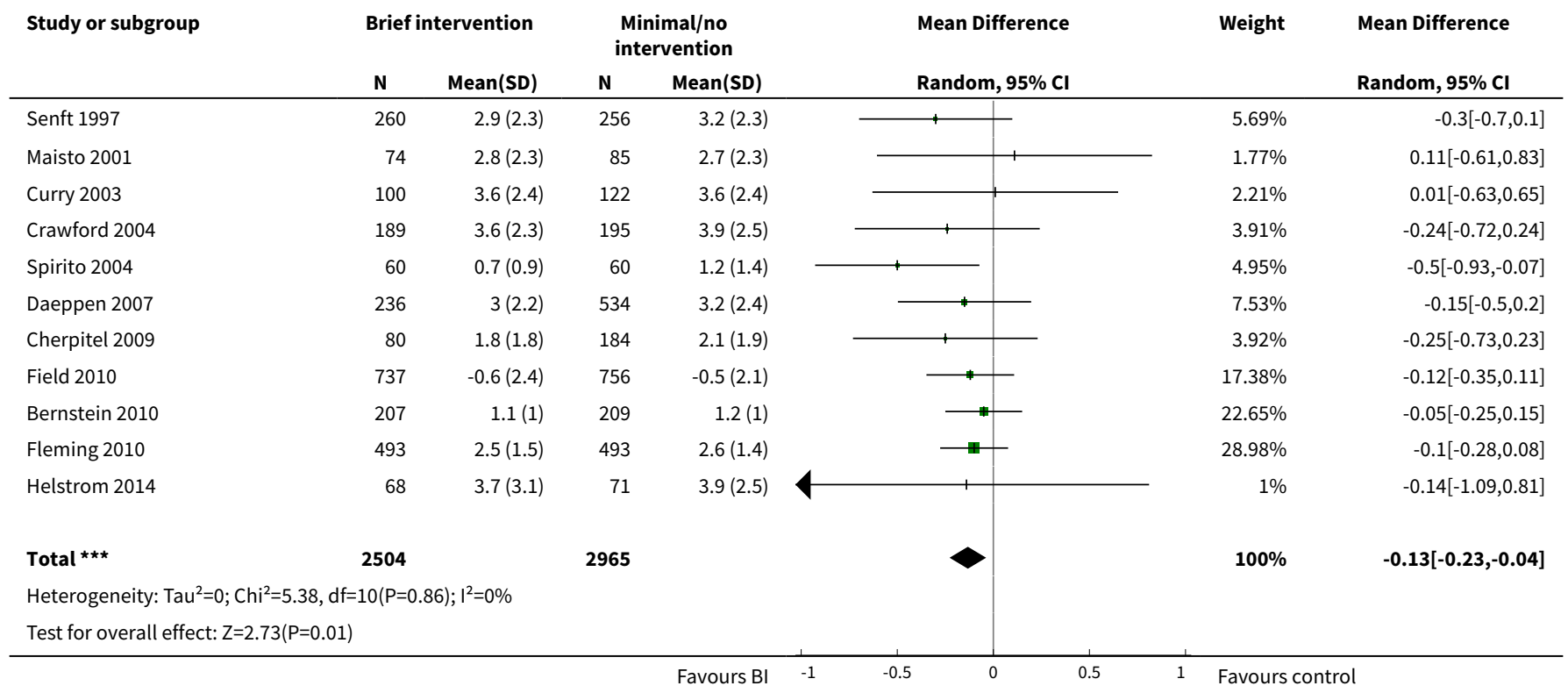


Analysis 1.19. Comparison 1 Brief intervention versus control, Outcome 19

Frequency of drinking (number days drinking/week), subgrouped by length of follow-up (6 \& 12 months) and restricted to trials with information at both times.

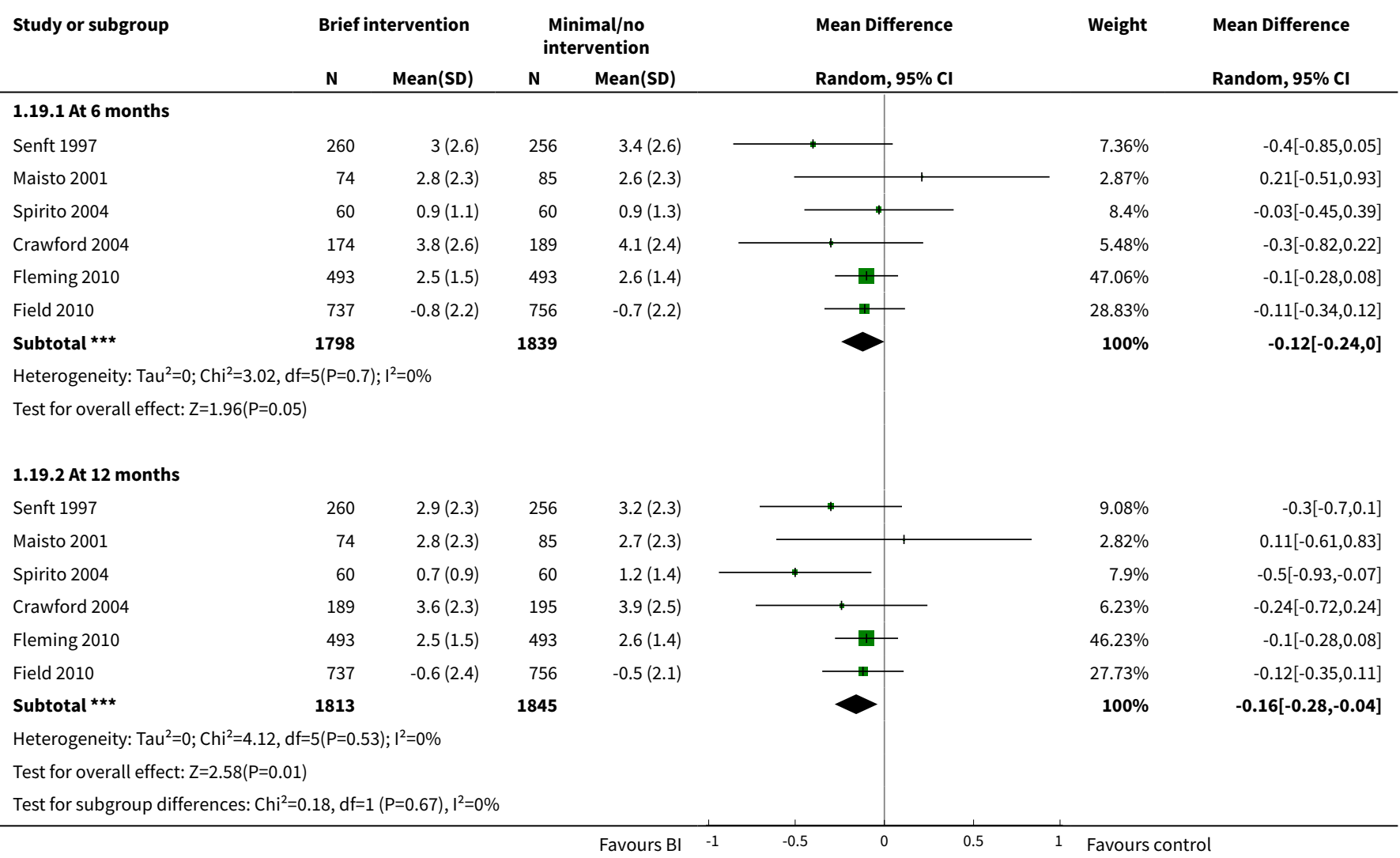

Analysis 1.20. Comparison 1 Brief intervention versus control, Outcome 20 Intensity of drinking (g/drinking day) at 12 months.

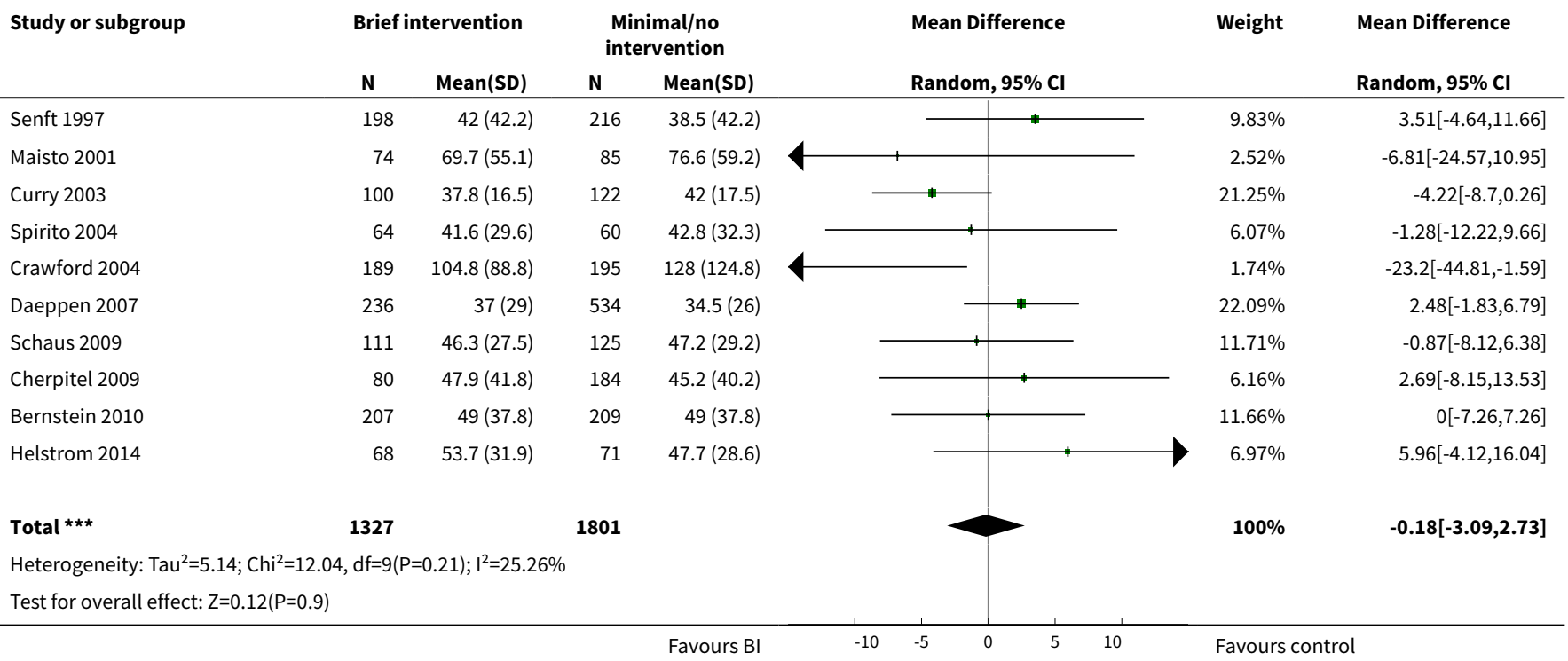


Analysis 1.21. Comparison 1 Brief intervention versus control, Outcome 21 Heavy drinkers at 12 months.

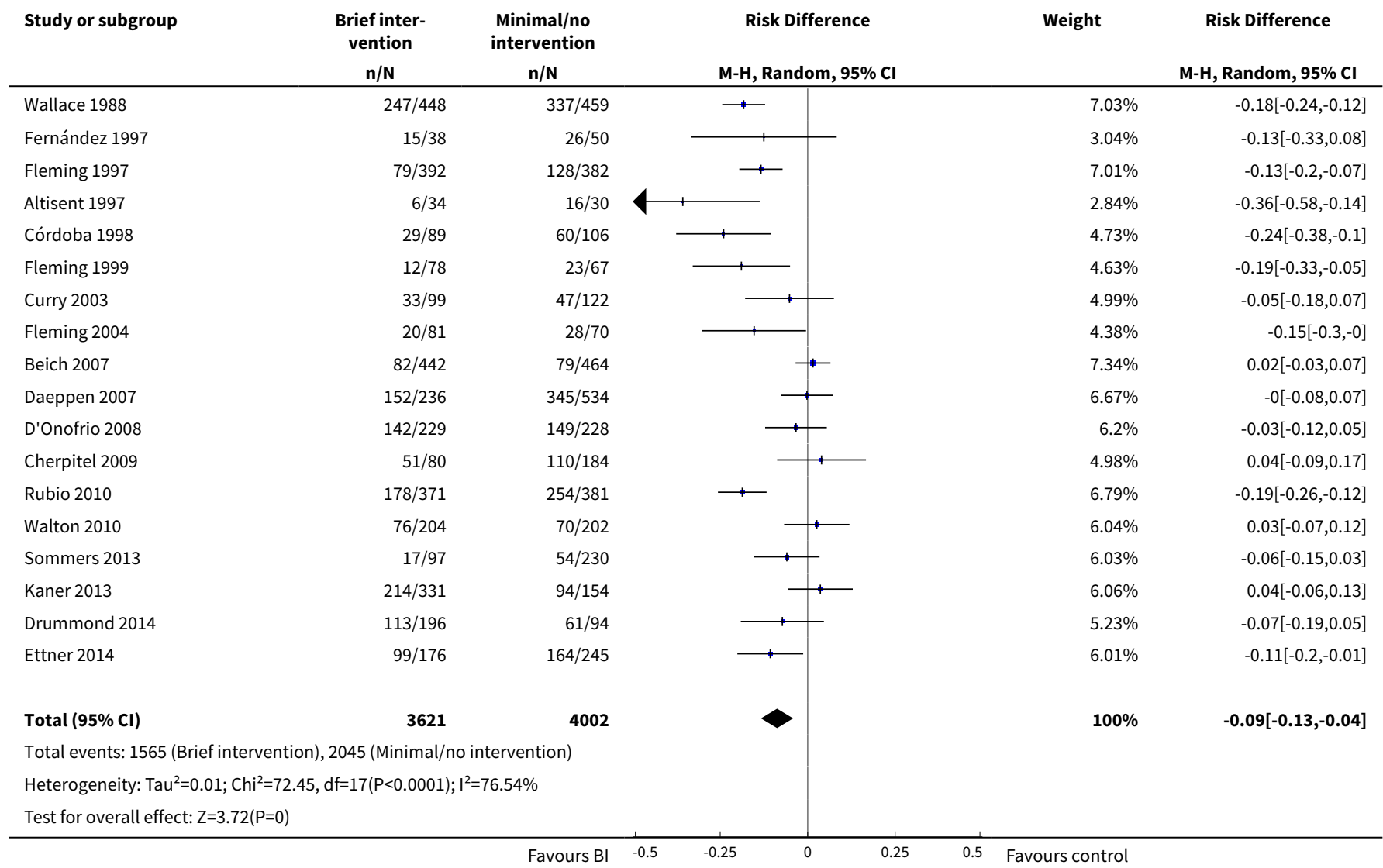

Analysis 1.22. Comparison 1 Brief intervention versus control, Outcome 22 Binge drinkers at 12 months.

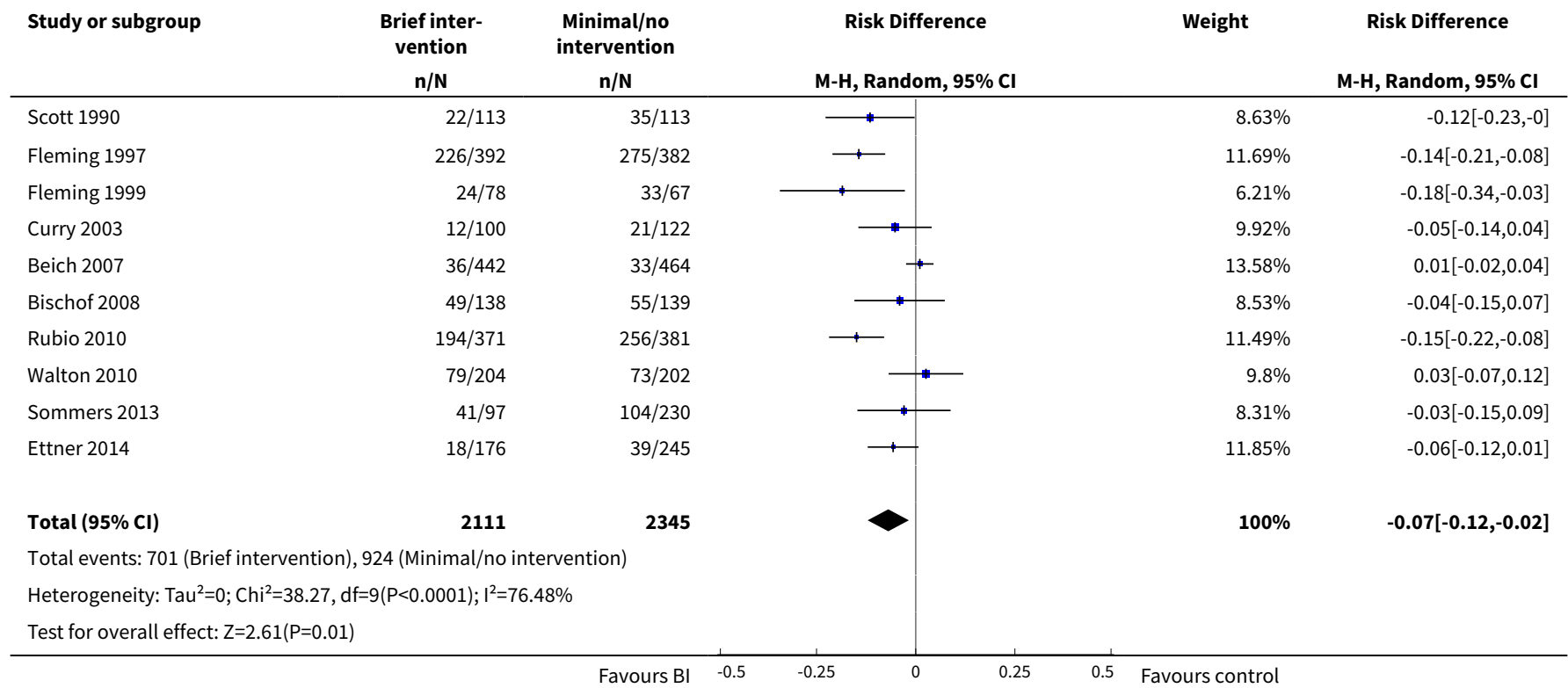




\section{Analysis 1.23. Comparison 1 Brief intervention versus control, Outcome 23 Laboratory markers - GGT (IU/L) at 12 months.}

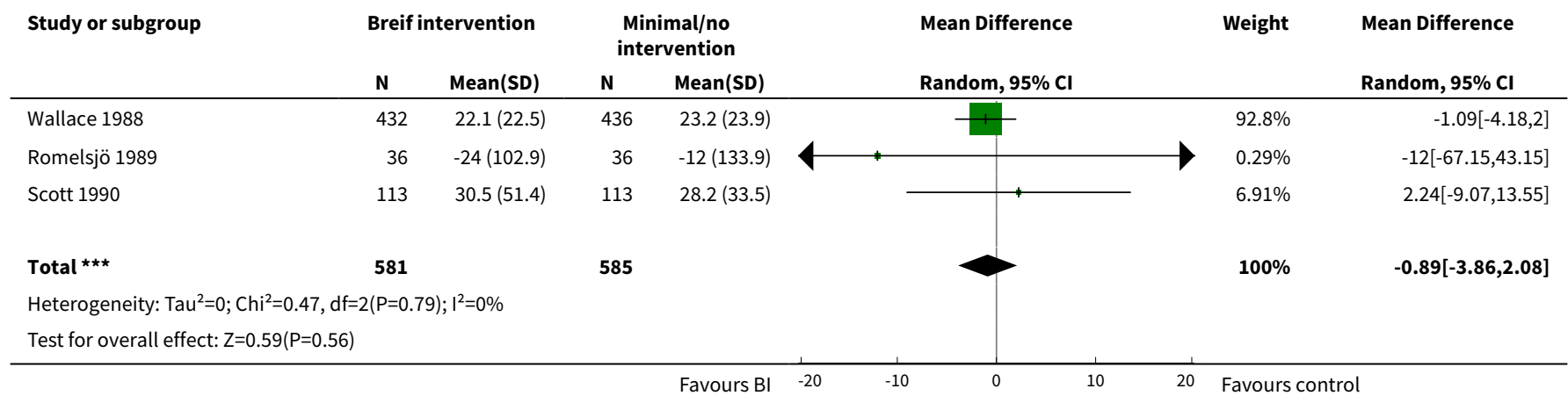

Analysis 1.24. Comparison 1 Brief intervention versus control, Outcome 24 Laboratory markers - GGT (IU/L) at 12 months, subgrouped by gender.

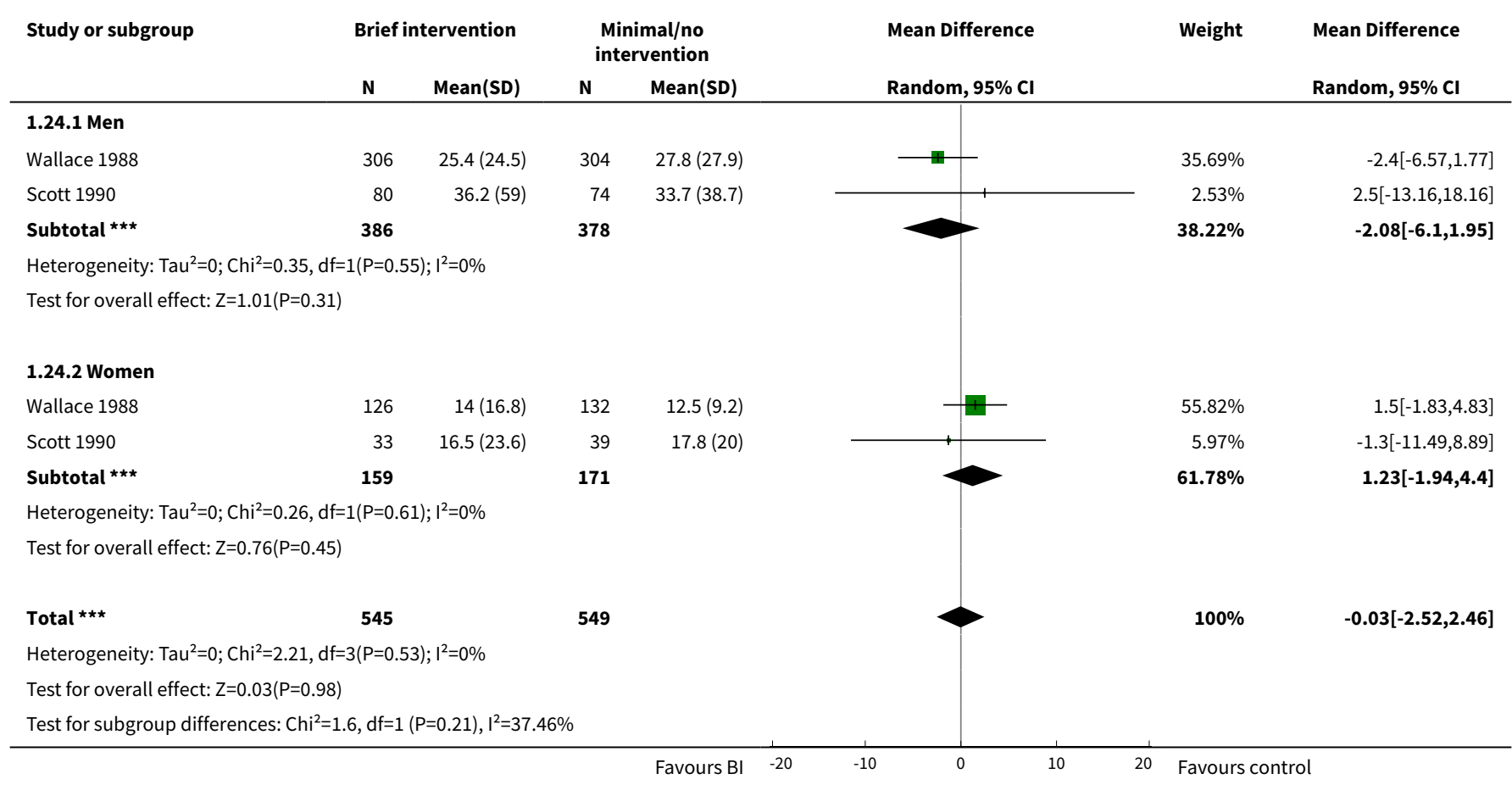

\section{Comparison 2. Extended intervention versus minimal or no intervention}

\begin{tabular}{lllll}
\hline Outcome or subgroup title & No. of studies & $\begin{array}{l}\text { No. of partici- } \\
\text { pants }\end{array}$ & Statistical method & Effect size \\
\hline $\begin{array}{l}1 \text { Quantity of drinking (g/week) at } 12 \\
\text { months }\end{array}$ & 6 & 1296 & $\begin{array}{l}\text { Mean Difference (IV, Random, } \\
95 \% \text { Cl) }\end{array}$ & $\begin{array}{l}-19.50[-40.47, \\
1.48]\end{array}$ \\
\hline
\end{tabular}




\begin{tabular}{|c|c|c|c|c|}
\hline Outcome or subgroup title & No. of studies & $\begin{array}{l}\text { No. of partici- } \\
\text { pants }\end{array}$ & Statistical method & Effect size \\
\hline $\begin{array}{l}2 \text { Frequency of binge drinking (num- } \\
\text { ber binges/week) at } 12 \text { months }\end{array}$ & 2 & 456 & $\begin{array}{l}\text { Mean Difference (IV, Random, } \\
95 \% \mathrm{CI} \text { ) }\end{array}$ & $-0.08[-0.28,0.12]$ \\
\hline $\begin{array}{l}3 \text { Frequency of drinking (number } \\
\text { days drinking/week) at } 12 \text { months }\end{array}$ & 2 & 319 & $\begin{array}{l}\text { Mean Difference (IV, Random, } \\
95 \% \mathrm{CI} \text { ) }\end{array}$ & $\begin{array}{l}-0.45[-0.81 \\
-0.09]\end{array}$ \\
\hline $\begin{array}{l}4 \text { Intensity of drinking (g/drinking } \\
\text { day) at } 12 \text { months }\end{array}$ & 1 & & $\begin{array}{l}\text { Mean Difference (IV, Random, } \\
95 \% \mathrm{CI})\end{array}$ & Subtotals only \\
\hline 5 Heavy drinkers at 12 months & 1 & & $\begin{array}{l}\text { Risk Difference (M-H, Random, } \\
95 \% \mathrm{Cl})\end{array}$ & Subtotals only \\
\hline 6 Binge drinkers at 12 months & 2 & 777 & $\begin{array}{l}\text { Risk Difference (M-H, Random, } \\
95 \% \mathrm{Cl})\end{array}$ & $-0.02[-0.07,0.03]$ \\
\hline $\begin{array}{l}7 \text { Laboratory markers - GGT (IU/L) at } \\
12 \text { months }\end{array}$ & 1 & & $\begin{array}{l}\text { Mean Difference (IV, Random, } \\
95 \% \mathrm{CI} \text { ) }\end{array}$ & Subtotals only \\
\hline
\end{tabular}

\section{Analysis 2.1. Comparison 2 Extended intervention versus minimal or no intervention, Outcome 1 Quantity of drinking (g/week) at 12 months.}

\begin{tabular}{|c|c|c|c|c|c|c|c|c|}
\hline \multirow{3}{*}{$\begin{array}{l}\text { Study or subgroup } \\
\text { Richmond } 1995\end{array}$} & \multicolumn{2}{|c|}{ Extended } & \multicolumn{2}{|c|}{$\begin{array}{c}\text { Minimal/no } \\
\text { intervention }\end{array}$} & \multirow{2}{*}{\multicolumn{2}{|c|}{$\begin{array}{l}\text { Mean Difference } \\
\text { Random, 95\% Cl }\end{array}$}} & \multirow{3}{*}{$\begin{array}{r}\text { Weight } \\
6.02 \%\end{array}$} & \multirow{3}{*}{$\begin{array}{l}\text { Mean Difference } \\
\text { Random, 95\% Cl } \\
41[-40.79,122.79]\end{array}$} \\
\hline & \multirow{2}{*}{$\frac{\mathbf{N}}{66}$} & \multirow{2}{*}{$\frac{\text { Mean(SD) }}{331(261)}$} & \multirow{2}{*}{$\frac{\mathbf{N}}{61}$} & \multirow{2}{*}{$\begin{array}{r}\text { Mean(SD) } \\
290(208)\end{array}$} & & & & \\
\hline & & & & & & & & \\
\hline Israel 1996 & 35 & $\begin{array}{r}154.7 \\
(185.1)\end{array}$ & 38 & $252(277.9)$ & & 1 & $3.61 \%$ & $-97.22[-204.77,10.33]$ \\
\hline Maisto 2001 & 73 & $\begin{array}{r}170.3 \\
(204.1)\end{array}$ & 85 & $\begin{array}{r}214.7 \\
(215.3)\end{array}$ & & $\longrightarrow$ & $8.97 \%$ & $-44.45[-109.93,21.03]$ \\
\hline Monti 2007 & 78 & $71.2(97.2)$ & 83 & $\begin{array}{r}103.1 \\
(112.9)\end{array}$ & & — & $26.35 \%$ & $-31.86[-64.34,0.62]$ \\
\hline Bischof 2008 & 131 & $\begin{array}{r}268.1 \\
(344.4)\end{array}$ & 139 & $\begin{array}{r}244.3 \\
(342.3)\end{array}$ & & 1 & $6 \%$ & $23.8[-58.15,105.75]$ \\
\hline Moore 2011 & 213 & $109.6(93.4)$ & 294 & $124.9(98)$ & & \# & $49.04 \%$ & $-15.29[-32.11,1.53]$ \\
\hline Total $\star \star \star$ & 596 & & 700 & & & & $100 \%$ & $-19.5[-40.47,1.48]$ \\
\hline \multicolumn{9}{|c|}{ Heterogeneity: $\mathrm{Tau}^{2}=159.85 ; \mathrm{Chi}^{2}=6.51, \mathrm{df}=5(\mathrm{P}=0.26) ; \mathrm{I}^{2}=23.16 \%$} \\
\hline \multicolumn{9}{|c|}{ Test for overall effect: $Z=1.82(P=0.07)$} \\
\hline
\end{tabular}

Analysis 2.2. Comparison 2 Extended intervention versus minimal or no intervention, Outcome 2 Frequency of binge drinking (number binges/week) at 12 months.

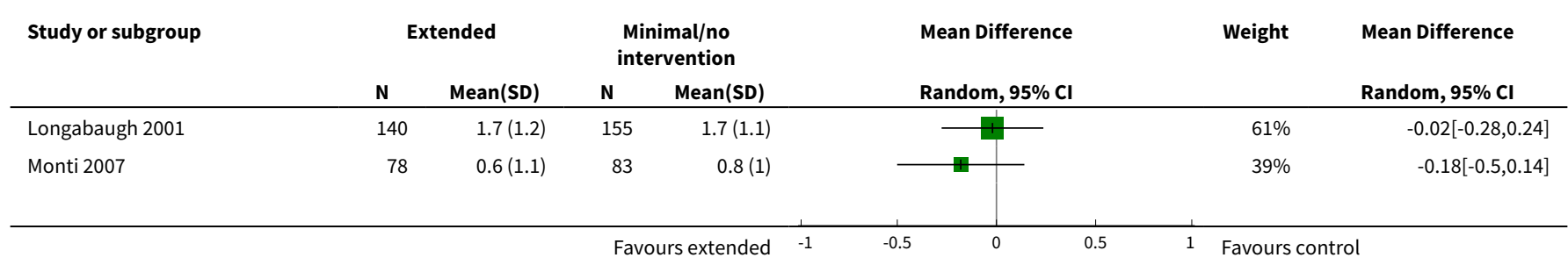




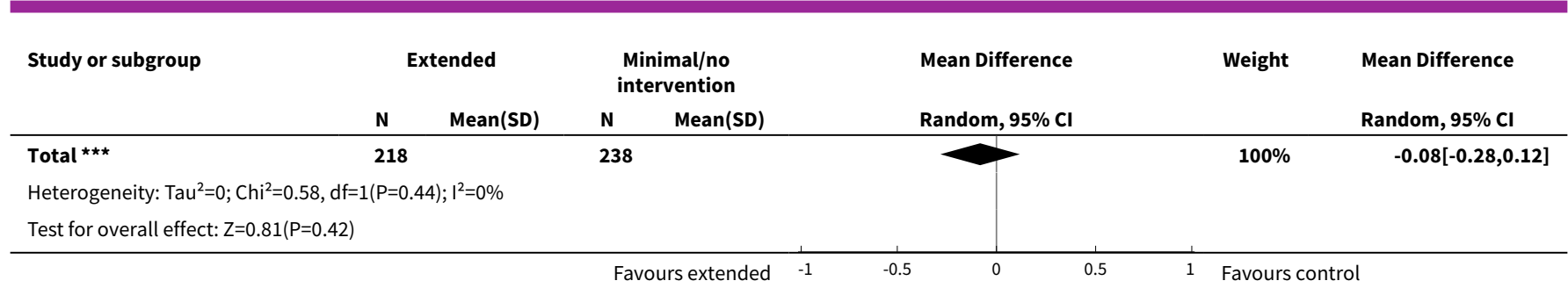

Analysis 2.3. Comparison 2 Extended intervention versus minimal or no intervention, Outcome 3 Frequency of drinking (number days drinking/week) at 12 months.

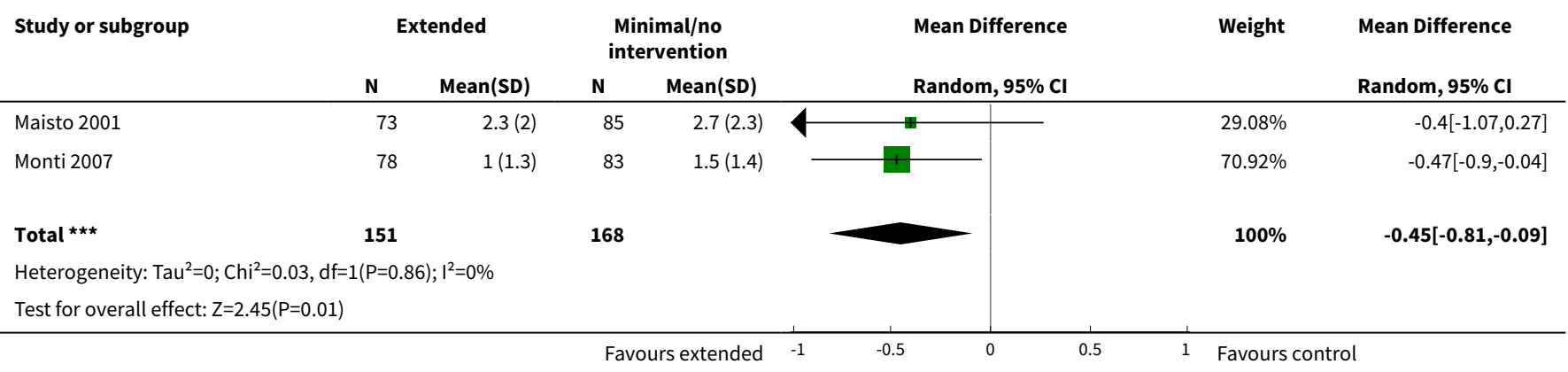

Analysis 2.4. Comparison 2 Extended intervention versus minimal or no intervention, Outcome 4 Intensity of drinking (g/drinking day) at 12 months.

\begin{tabular}{|c|c|c|c|c|c|c|c|c|}
\hline \multirow[t]{2}{*}{ Study or subgroup } & \multicolumn{2}{|c|}{ Extended } & \multicolumn{2}{|c|}{$\begin{array}{l}\text { Minimal in- } \\
\text { tervention }\end{array}$} & \multirow{2}{*}{\multicolumn{2}{|c|}{$\begin{array}{l}\text { Mean Difference } \\
\text { Random, } 95 \% \mathrm{Cl}\end{array}$}} & \multirow[t]{2}{*}{ Weight } & \multirow{2}{*}{$\begin{array}{l}\text { Mean Difference } \\
\text { Random, } 95 \% \mathrm{Cl}\end{array}$} \\
\hline & $\mathbf{N}$ & $\operatorname{Mean}(S D)$ & $\mathbf{N}$ & $\operatorname{Mean}(S D)$ & & & & \\
\hline Maisto 2001 & 73 & $68(51)$ & 85 & 76.6 (59.2) & & & $0 \%$ & $-8.51[-25.69,8.67]$ \\
\hline
\end{tabular}

Analysis 2.5. Comparison 2 Extended intervention versus minimal or no intervention, Outcome 5 Heavy drinkers at 12 months.

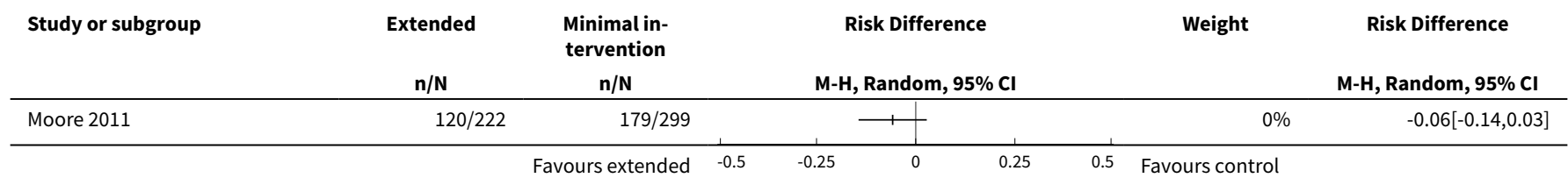


Analysis 2.6. Comparison 2 Extended intervention versus minimal or no intervention, Outcome 6 Binge drinkers at 12 months.

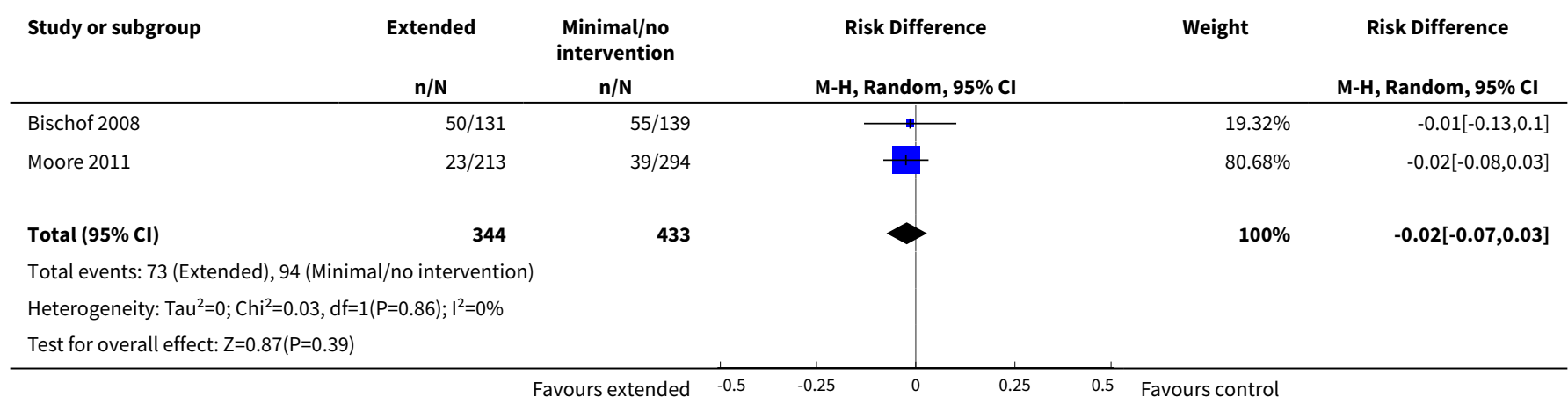

Analysis 2.7. Comparison 2 Extended intervention versus minimal or no intervention, Outcome 7 Laboratory markers - GGT (IU/L) at 12 months.

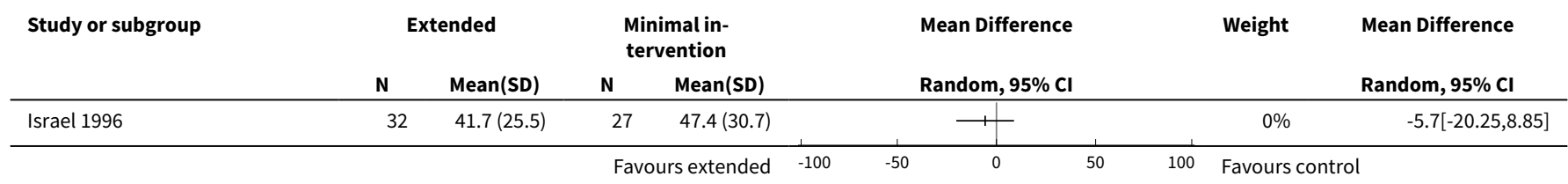

\section{Comparison 3. Extended versus brief intervention}

\begin{tabular}{|c|c|c|c|c|}
\hline Outcome or subgroup title & No. of studies & $\begin{array}{l}\text { No. of partici- } \\
\text { pants }\end{array}$ & Statistical method & Effect size \\
\hline $\begin{array}{l}1 \text { Quantity of drinking (g/week) at } \\
12 \text { months }\end{array}$ & 3 & 552 & $\begin{array}{l}\text { Mean Difference (IV, Random, } \\
95 \% \mathrm{CI})\end{array}$ & $1.54[-42.01,45.10]$ \\
\hline $\begin{array}{l}2 \text { Quantity of drinking (g/week) at } \\
12 \text { months, with imputation of un- } \\
\text { known standard deviations }\end{array}$ & 4 & 635 & $\begin{array}{l}\text { Mean Difference (IV, Random, } \\
95 \% \mathrm{CI})\end{array}$ & $1.13[-37.00,41.26]$ \\
\hline $\begin{array}{l}3 \text { Frequency of drinking (number } \\
\text { days drinking/week) at } 12 \text { months }\end{array}$ & 1 & & $\begin{array}{l}\text { Mean Difference (IV, Random, } \\
95 \% \mathrm{CI})\end{array}$ & Subtotals only \\
\hline $\begin{array}{l}4 \text { Intensity of drinking (g/drinking } \\
\text { day) }\end{array}$ & 1 & & $\begin{array}{l}\text { Mean Difference (IV, Random, } \\
95 \% \mathrm{CI})\end{array}$ & Subtotals only \\
\hline 5 Binge drinkers at 12 months & 2 & 339 & $\begin{array}{l}\text { Risk Difference (M-H, Random, } \\
95 \% \mathrm{Cl})\end{array}$ & $0.02[-0.08,0.12]$ \\
\hline $\begin{array}{l}6 \text { Laboratory markers - MCV (fl) at } 12 \\
\text { months }\end{array}$ & 1 & 95 & $\begin{array}{l}\text { Mean Difference (IV, Random, } \\
95 \% \mathrm{CI})\end{array}$ & $0.62[-1.58,2.81]$ \\
\hline 6.1 Men & 1 & 81 & $\begin{array}{l}\text { Mean Difference (IV, Random, } \\
95 \% \mathrm{CI})\end{array}$ & $0.80[-1.70,3.30]$ \\
\hline
\end{tabular}




\begin{tabular}{lllll}
\hline Outcome or subgroup title & No. of studies & $\begin{array}{l}\text { No. of partici- } \\
\text { pants }\end{array}$ & Statistical method & Effect size \\
\hline 6.2 Women & 1 & 14 & $\begin{array}{l}\text { Mean Difference (IV, Random, } \\
95 \% \mathrm{Cl})\end{array}$ & $0.0[-4.57,4.57]$ \\
\hline
\end{tabular}

Analysis 3.1. Comparison 3 Extended versus brief intervention, Outcome 1 Quantity of drinking (g/week) at 12 months.

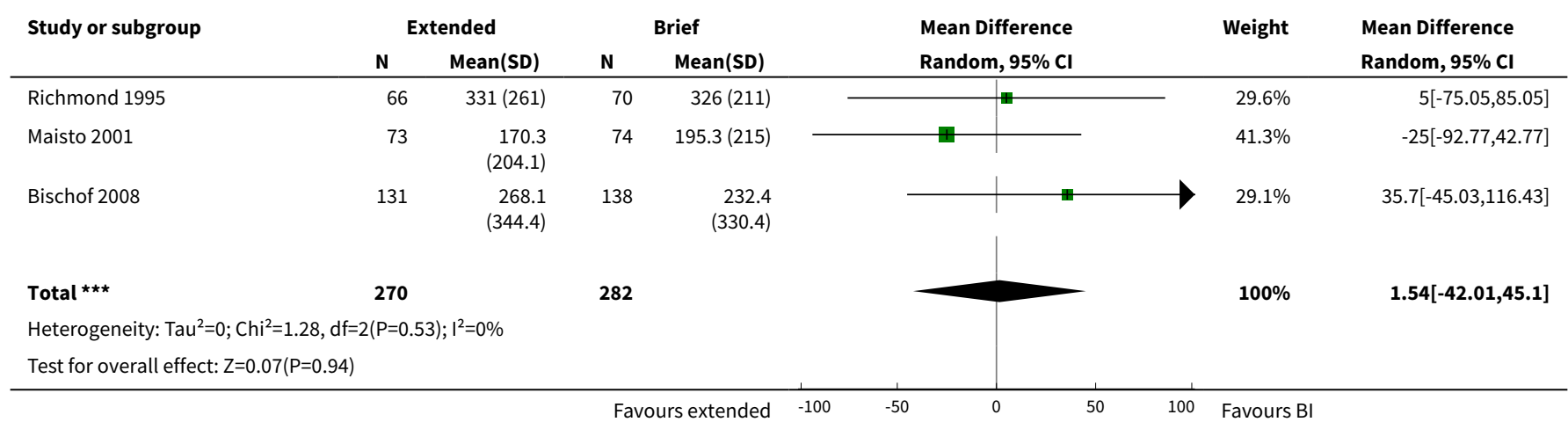

Analysis 3.2. Comparison 3 Extended versus brief intervention, Outcome 2 Quantity of drinking (g/week) at 12 months, with imputation of unknown standard deviations.

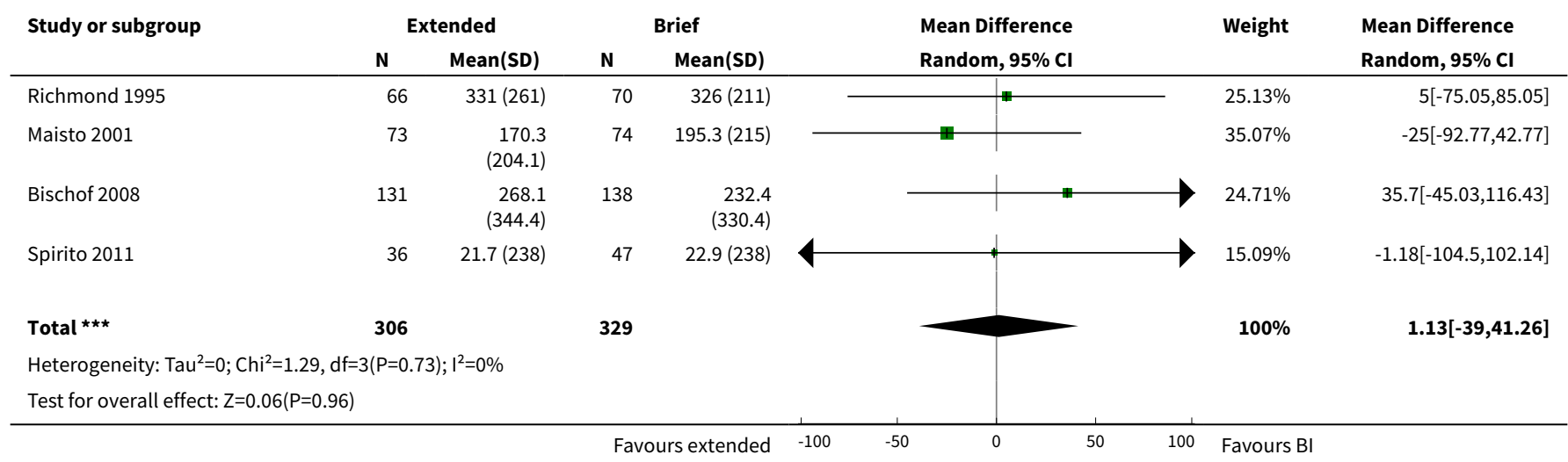

Analysis 3.3. Comparison 3 Extended versus brief intervention, Outcome 3 Frequency of drinking (number days drinking/week) at 12 months.

\begin{tabular}{|c|c|c|c|c|c|c|c|c|}
\hline \multirow[t]{2}{*}{ Study or subgroup } & \multicolumn{2}{|c|}{ Extended } & \multicolumn{2}{|c|}{ Brief } & \multirow{2}{*}{\multicolumn{2}{|c|}{$\begin{array}{l}\text { Mean Difference } \\
\text { Random, } 95 \% \mathrm{Cl}\end{array}$}} & \multirow[t]{2}{*}{ Weight } & \multirow{2}{*}{$\begin{array}{l}\text { Mean Difference } \\
\text { Random, } 95 \% \mathrm{CI}\end{array}$} \\
\hline & $\mathbf{N}$ & Mean(SD) & $\mathbf{N}$ & $\operatorname{Mean}(S D)$ & & & & \\
\hline Maisto 2001 & 73 & $2.3(2)$ & 74 & $2.8(2.3)$ & & 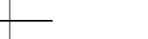 & $0 \%$ & $-0.51[-1.21,0.19]$ \\
\hline
\end{tabular}


Analysis 3.4. Comparison 3 Extended versus brief intervention, Outcome 4 Intensity of drinking (g/drinking day).

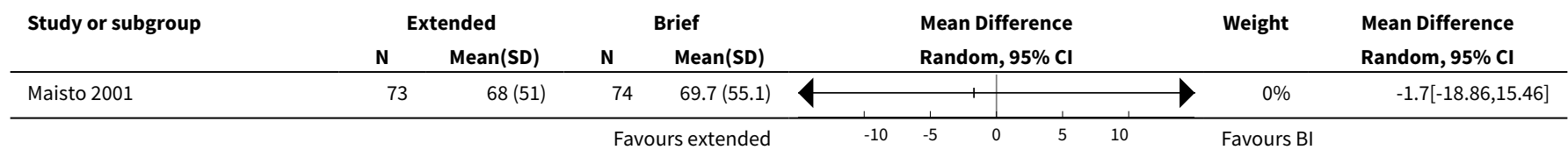

Analysis 3.5. Comparison 3 Extended versus brief intervention, Outcome 5 Binge drinkers at 12 months.

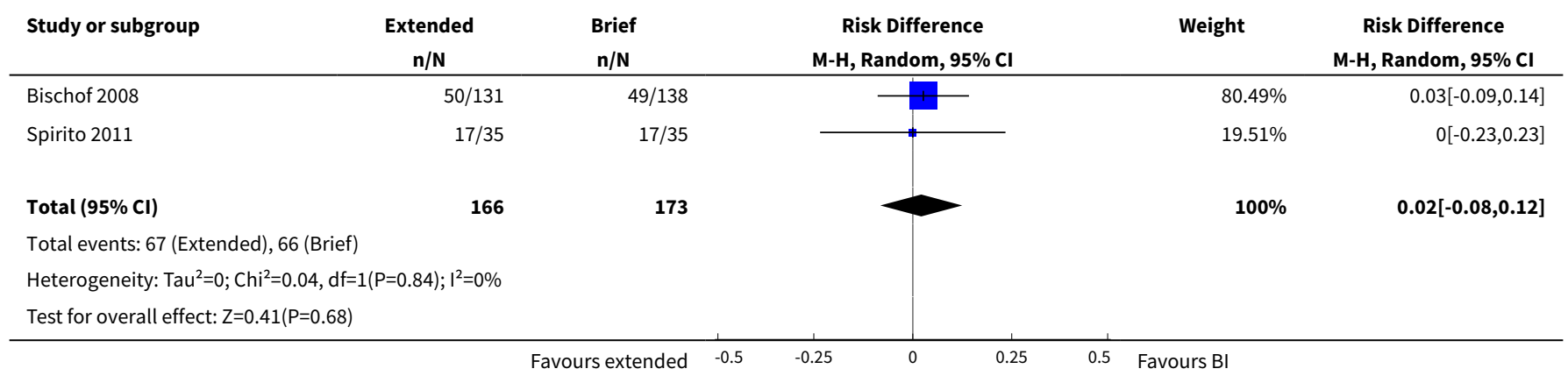

Analysis 3.6. Comparison 3 Extended versus brief intervention,

Outcome 6 Laboratory markers - MCV (fl) at 12 months.

\begin{tabular}{|c|c|c|c|c|c|c|c|}
\hline \multirow[t]{2}{*}{ Study or subgroup } & \multicolumn{2}{|c|}{ Brief intervention } & \multicolumn{2}{|c|}{$\begin{array}{c}\text { Minimal/no } \\
\text { intervention }\end{array}$} & \multirow{2}{*}{$\begin{array}{l}\text { Mean Difference } \\
\text { Random, } 95 \% \mathrm{Cl}\end{array}$} & \multirow[t]{2}{*}{ Weight } & \multirow{2}{*}{$\begin{array}{l}\text { Mean Difference } \\
\text { Random, } 95 \% \mathrm{CI}\end{array}$} \\
\hline & $\mathbf{N}$ & Mean(SD) & $\mathbf{N}$ & Mean(SD) & & & \\
\hline \multicolumn{8}{|l|}{ 3.6.1 Men } \\
\hline Seppa 1992 & 35 & $101.9(5.9)$ & 46 & $101.1(5.4)$ & & $76.93 \%$ & $0.8[-1.7,3.3]$ \\
\hline Subtotal $* \star \star$ & 35 & & 46 & & & $76.93 \%$ & $0.8[-1.7,3.3]$ \\
\hline \multicolumn{8}{|c|}{ Heterogeneity: Not applicable } \\
\hline \multicolumn{8}{|l|}{ 3.6.2 Women } \\
\hline Seppa 1992 & 6 & $98.5(4.4)$ & 8 & $98.5(4.2)$ & & $23.07 \%$ & $0[-4.57,4.57]$ \\
\hline Subtotal $\star \star \star$ & 6 & & 8 & & & $23.07 \%$ & $0[-4.57,4.57]$ \\
\hline \multicolumn{8}{|c|}{ Heterogeneity: Not applicable } \\
\hline \multicolumn{8}{|c|}{ Test for overall effect: Not applicable } \\
\hline Total *** & 41 & & 54 & & & $100 \%$ & $0.62[-1.58,2.81]$ \\
\hline \multicolumn{8}{|c|}{ Heterogeneity: $\mathrm{Tau}^{2}=0 ; \mathrm{Chi}^{2}=0.09, \mathrm{df}=1(\mathrm{P}=0.76) ; \mathrm{I}^{2}=0 \%$} \\
\hline \multicolumn{8}{|c|}{ Test for overall effect: $\mathrm{Z}=0.55(\mathrm{P}=0.58)$} \\
\hline Test for subgroup dif & $.09, \mathrm{df}=$ & $P=0.76), I^{2}=0 \%$ & & & & & \\
\hline
\end{tabular}

\section{ADDITIONAL TABLES}


Table 1. Effectiveness - efficacy scale

\begin{tabular}{|c|c|c|}
\hline Scale item & Score & Meaning \\
\hline \multirow[t]{3}{*}{ Patients and problems } & 2 & $\begin{array}{l}\text { Clinically representative people initially present with a typically wide range of } \\
\text { problems via self-referral or invitation for a health check }\end{array}$ \\
\hline & 1 & $\begin{array}{l}\text { Mixed: e.g. routine patients but paid for participation in study, or patients pre- } \\
\text { screened then invited research representative subjects may be paid patients }\end{array}$ \\
\hline & 0 & $\begin{array}{l}\text { Researcher-solicited volunteers (e.g. via advertisement) or referrals from spe- } \\
\text { cialist services }\end{array}$ \\
\hline \multirow[t]{3}{*}{ Practice context } & 2 & $\begin{array}{l}\text { Clinically representative is a community-based setting in which a range of clin- } \\
\text { ical services are usually provided to patients }\end{array}$ \\
\hline & 1 & Mixed \\
\hline & 0 & $\begin{array}{l}\text { Research representative is a setting in which the research function clearly } \\
\text { dominates any clinical one (e.g. clinic at a university or hospital) }\end{array}$ \\
\hline \multirow[t]{3}{*}{$\begin{array}{l}\text { Practitioners and ther- } \\
\text { apists }\end{array}$} & 2 & $\begin{array}{l}\text { Clinically representative practitioners are practising doctors, nurses and qual- } \\
\text { ified therapists who earn their main living by providing health services in pri- } \\
\text { mary care }\end{array}$ \\
\hline & 1 & Qualified clinician but specifically recruited for the study \\
\hline & 0 & $\begin{array}{l}\text { Research representative practitioners are non-clinicians, or clinicians in train- } \\
\text { ing, who are contracted to deliver interventions for the purposes of the study }\end{array}$ \\
\hline \multirow[t]{2}{*}{ Intervention content } & 2 & $\begin{array}{l}\text { Clinically representative intervention fits with current practice in terms of tim- } \\
\text { ing, content or style (e.g. for primary care } 5 \text { to } 15 \text { minutes for a GP; } 20 \text { to } 30 \\
\text { minutes for a nurse or initial screening accompanied by a return visit for brief } \\
\text { intervention; for emergency settings motivational interviewing-style interven- } \\
\text { tion fits in here, e.g. } 45 \text { minutes }\end{array}$ \\
\hline & 0 & $\begin{array}{l}\text { Research representative treatment would not normally occur in routine prac- } \\
\text { tice e.g. unusually long consultations }\end{array}$ \\
\hline \multirow[t]{3}{*}{ Therapeutic flexibility } & 1 & $\begin{array}{l}\text { Clinically representative: allows professional judgement in how an interven- } \\
\text { tion is delivered e.g. freedom to focus on particular issues according to patient } \\
\text { need }\end{array}$ \\
\hline & $1 / 2$ & Flexible protocol (tailored to participants) \\
\hline & 0 & $\begin{array}{l}\text { Research representative: strict adherence to a prescribed protocol or script } \\
\text { that does not allow for variability in practice }\end{array}$ \\
\hline \multirow[t]{4}{*}{ Pre-therapy training } & 1 & $\begin{array}{l}\text { Clinically representative training in intervention procedures occurs according } \\
\text { to typical CPD/CME procedures (e.g. outreach visits, seminars, one-off training } \\
\text { days). }\end{array}$ \\
\hline & & Full day off-site (for emergency care staff) \\
\hline & $1 / 2$ & Full day off-site (for primary care staff) \\
\hline & 0 & $\begin{array}{l}\text { Research representative training is unusually intensive or requiring of atypi- } \\
\text { cal levels of interest or motivation, e.g. prolonged or intensive courses, formal } \\
\text { qualification }\end{array}$ \\
\hline
\end{tabular}


Table 1. Effectiveness - efficacy scale (Continued)

\begin{tabular}{lll} 
Intervention support & 1 & $\begin{array}{l}\text { Clinically representative support occurs within standard practice resources } \\
\text { (e.g. colleague assistance with screening, IT flagging, provision of general (un- } \\
\text { customised) manual. Note for emergency care settings some procedures are } \\
\text { clinically representative (e.g. taking bloods and doing various tests) }\end{array}$ \\
\cline { 2 - 3 } & 0 & $\begin{array}{l}\text { Research representative support would not typically be available (e.g. re- } \\
\text { searcher help to flag notes, extra staff for period of the trial) }\end{array}$ \\
\hline Intervention monitor- & 1 & $\begin{array}{l}\text { Clinically representative monitoring of intervention delivery does not interfere } \\
\text { with practitioners' behaviour or their relationships with patients }\end{array}$ \\
\cline { 2 - 4 } & 0 & $\begin{array}{l}\text { Research representative monitoring would be direct observation of therapist } \\
\text { behaviour or ongoing/immediate feedback to practitioners after each session }\end{array}$
\end{tabular}

Abbreviations: CPD: continuing professional development; CME: continuing medical education; GP: general practitioner; IT: information technology

Table 2. Conversion factors for alcohol consumption and efficacy scores of trials

\begin{tabular}{|c|c|c|c|c|c|}
\hline Trial & Reported units & $\begin{array}{l}\text { Conversion } \\
\text { factor }\end{array}$ & $\begin{array}{l}\text { Source of conver- } \\
\text { sion }\end{array}$ & Efficacy score & $\begin{array}{l}\text { Treatment } \\
\text { exposure }\end{array}$ \\
\hline Aalto 2000 & g/week & 1 & NA & 10.5 & 45,105 \\
\hline Altisent 1997 & Units/week & 8 & Altisent 1997 & 8.5 & 20 \\
\hline Babor 2006 & Drinks/week & 14 & Babor 2006 & 11 & 4 \\
\hline Bazargan-Hejazi 2005 & Alcohol consumption & NR & NA & 9 & 17.5 \\
\hline Beckham 2007 & Drinks/day & $11.671 \times 7$ & Miller 1991 & 4.5 & 52.5 \\
\hline Beich 2007 & Drinks/week & 12 & Beich 2007 & 11 & 10 \\
\hline Bernstein 2010 & Drinks/week & 11.671 & Miller 1991 & 6.5 & 32.5 \\
\hline Bischof 2008 & g/day & 7 & NA & 6.5 & 60 \\
\hline Blow 2006 & Drinks/week & 13 & Blow 2009* & 7.5 & 7.5 \\
\hline Cherpitel 2009 & Drinks/week & 11.671 & Miller 1991 & 9 & 17.5 \\
\hline Córdoba 1998 & Units/week & 8 & Córdoba 1998 & 11 & 15 \\
\hline Crawford 2004 & Units/week & 8 & Miller 1991 & 10.5 & 30 \\
\hline Crawford 2010 & Alcohol consumption & NR & NA & 8.5 & 30 \\
\hline Curry 2003 & Drinks/week & 11.671 & Miller 1991 & 8.5 & 22.5 \\
\hline D'Amico 2008 & Basic statistics & NR & NA & 7.5 & 25 \\
\hline D'Onofrio 2008 & Drinks/week & 11.671 & Miller 1991 & 10.5 & 6.7 \\
\hline D'Onofrio 2012 & Drinks/week & 11.671 & Miller 1991 & 10.5 & $7 ; 17$ \\
\hline
\end{tabular}


Table 2. Conversion factors for alcohol consumption and efficacy scores of trials (Continued)

\begin{tabular}{|c|c|c|c|c|c|}
\hline Daeppen 2007 & Drinks/week & 10 & Daeppen 2007 & 7 & 15 \\
\hline Dent 2008 & Alcohol consumption & NR & NA & 11.5 & $5 ; 45$ \\
\hline Désy 2010 & Drinks/week & 11.671 & Miller 1991 & 10.5 & 7.5 \\
\hline Díez 2002 & Units/week & 8 & Díez 2002 & 10.5 & 10 \\
\hline Drummond 2009 & Drinks previous 180 days & $8 \times(7 / 180)$ & Drummond 2009 & 10.5 & $40 ; 200$ \\
\hline Drummond 2014 & Drinks/day & $8 \times 7$ & Drummond 2009 & 8 & 26 \\
\hline Ettner 2014 & Drinks/week & 11.671 & Miller 1991 & 11 & 108 \\
\hline Fernández 1997 & Units/week & 10 & Miller 1991 & 7.5 & 10 \\
\hline Field 2010 & Drinks/week & 11.671 & Miller 1991 & 7.5 & 17.5 \\
\hline Fleming 1997 & Drinks/week & 12 & Fleming 1997 & 10.5 & 40 \\
\hline Fleming 1999 & Drinks/week & 12 & Fleming 1999 & 9 & 40 \\
\hline Fleming 2004 & Drinks/month & $\begin{array}{l}11.671 x \\
(12 / 52)\end{array}$ & Miller 1991 & 4.5 & 40 \\
\hline Fleming 2010 & Drinks in previous 28 days & $11.671 \times(7 / 28)$ & Miller 1991 & 8.5 & 42.5 \\
\hline Heather 1987 & Units/month & $8 \times(12 / 52)$ & Heather 1987 & 8.5 & 7.5 \\
\hline Helstrom 2014 & Drinks/day & $11.671 \times 7$ & Miller 1991 & 7 & 37.5 \\
\hline Huas 2002 & Units/week & 10 & Heather 2006 & 10 & 7.5 \\
\hline Israel 1996 & Drinks/month & $13.456 \times(7 / 28)$ & Miller 1991 & 7.5 & 150 \\
\hline Kaner 2013 & Drinks/day & $8 \times 7$ & Kaner 2013 & 11 & 26 \\
\hline Kunz 2004 & Drinks/week & 11.671 & Miller 1991 & 6 & 37.5 \\
\hline L'Engle 2014 & Alcohol consumption & NR & NA & 8 & 180 \\
\hline Lane 2008 & Alcohol consumption & NR & NA & 10.5 & 7.5 \\
\hline Lock 2006 & Drinks/week & 8 & Miller 1991 & 12 & 7.5 \\
\hline Longabaugh 2001 & Alcohol consumption & NR & NA & 6 & 50 \\
\hline Maisto 2001 & Drinks/month & $17.01 \times(7 / 30)$ & Miller 1991 & 5 & $13.5 ; 65$ \\
\hline McDevitt-Murphy 2014 & Drinks/week & 11.671 & Miller 1991 & 5.5 & 60 \\
\hline McIntosh 1997 & Drinks/month & $\begin{array}{l}13.456 x \\
(12 / 52)\end{array}$ & Miller 1991 & 10.5 & 60 \\
\hline Mello 2008 & Alcohol consumption & NR & NA & 7 & 45 \\
\hline
\end{tabular}


Table 2. Conversion factors for alcohol consumption and efficacy scores of trials (Continued)

\begin{tabular}{|c|c|c|c|c|c|}
\hline Mertens 2014 & Alcohol consumption & NR & NA & 7.5 & 10 \\
\hline Monti 2007 & Drinks/week & 11.671 & Miller 1991 & 7.5 & 85 \\
\hline Moore 2011 & Standard drinks/week & 11.671 & Miller 1991 & 9.5 & 83 \\
\hline Noknoy 2010 & Drinks/week & 10 & Furtwaengler 2013 & 11 & 45 \\
\hline Ockene 1999 & Drinks/week & 12.8 & Ockene 1999 & 10 & 7.5 \\
\hline Richmond 1995 & Drinks/week & 10 & Richmond 1995 & 9.5 & $5,57.5$ \\
\hline Rodríguez 2003 & Alcohol consumption & NR & NA & 10.5 & 17.5 \\
\hline Romelsjö 1989 & g/day & $1 \times 7$ & NA & 4.5 & 7.5 \\
\hline Rubio 2010 & Drinks/week & 12.8 & Rubio 2010 & 9.5 & 32.5 \\
\hline Schaus 2009 & Drinks/week & 11.671 & Miller 1991 & 8 & 40 \\
\hline Scott 1990 & Units/week & 8 & Miller 1991 & 11 & 10 \\
\hline Segatto 2011 & Alcohol consumption & NR & NA & 6 & 45 \\
\hline Senft 1997 & Drinks/3 months & $11.671 \times(4 / 52)$ & Miller 1991 & 9 & 16 \\
\hline Seppa 1992 & Alcohol consumption & NR & NA & 8.5 & 15 \\
\hline Soderstrom 2007 & Drinks/last 90 days & $11.671 \times(7 / 90)$ & Miller 1991 & 6.5 & 32.5 \\
\hline Sommers 2006 & Alcohol consumption & NR & NA & 7 & 40 \\
\hline Sommers 2013 & Drinks/week & 11.671 & Miller 1991 & 7.5 & 40 \\
\hline Spirito 2004 & Standard drinks/month & $\begin{array}{l}11.671 x \\
(12 / 52)\end{array}$ & Miller 1991 & 7 & 40 \\
\hline Spirito 2011 & Alcohol consumption & NR & NA & 7.5 & 52.5 \\
\hline Tait 2004 & alcohol consumption & NR & NA & 8 & 37.5 \\
\hline Tomson 1998 & g/week & 1 & NA & 8.5 & 37.5 \\
\hline Wallace 1988 & Units/week & 8 & Miller 1991 & 9.5 & 7.5 \\
\hline Walton 2010 & Alcohol consumption & NR & NA & 7 & 37 \\
\hline Watson 2013 & Drinks/week & 8 & Watson 2013 & 9.5 & 20 \\
\hline Woolard 2013 & Alcohol consumption & NR & NA & 5.5 & 72.5 \\
\hline
\end{tabular}

* Blow 2009 is a report of Blow 2006.

1 Treatment exposure was calculated in minutes. Where two values appear, these are the durations of different intervention arms. Abbreviations: NA: not applicable; NR: not reported. 


\section{AP PEN DICES}

\section{Appendix 1. Cochrane Library (Wiley) search strategy}

http://www.thecochranelibrary.com/

Searched 19 June 2012, 6 January 2015, 25 September 2017

Databases searched: CENTRAL, CDSR, DARE, HTA, NHS-EED

\#1 MeSH descriptor: [General Practice] explode all trees

\#2 MeSH descriptor: [Primary Health Care] this term only

\#3 MeSH descriptor: [Community Health Services] this term only

\#4 MeSH descriptor: [Emergency Service, Hospital] explode all trees

\#5 MeSH descriptor: [Physicians, Family] this term only

\#6 MeSH descriptor: [Physicians, Primary Care] this term only

\#7 (general pract* or family pract* or GP or physician* or emergency department or emergency room or "accident and emergency" or community):ti,ab

\#8 (primary near/2 care):ti,ab

\#9 (shared next care):ti,ab

$\# 10 \# 1$ or \#2 or \#3 or \#4 or \#5 or \#6 or \#7 or \#8 or \#9

$\# 11$ MeSH descriptor: [Alcohol-Related Disorders] explode all trees

\#12 MeSH descriptor: [Alcohol Drinking] this term only

\#13 (alcohol near/3 (drink* or intoxicat* or abus* or misus* or risk* or consum* or withdraw* or detox* or treat* or therap* or excess ${ }^{\star}$ or $^{\star}$ reduc $^{*}$ or cessation or intervention)):ti,ab

\#14 (drink* near/3 (excess or heavy or heavily or hazard* or binge or harmful or problem*)):ti,ab

\#15 ("alcohol use" or alcoholic*):ti,ab

\#16 \#11 or \#12 or \#13 or \#14 or \#15

$\# 17$ MeSH descriptor: [Counseling] this term only

\#18 MeSH descriptor: [Psychotherapy, Brief] this term only

\#19 MeSH descriptor: [Interview, Psychological] this term only

\#20 MeSH descriptor: [Behavior Therapy] this term only

\#21 MeSH descriptor: [Cognitive Therapy] this term only

\#22 MeSH descriptor: [Motivation] this term only

\#23 (brief near/3 (intervention* or therap* or interview* or advice)):ti,ab

\#24 (minimal near/3 (intervention* or therap* or interview* or advice)):ti,ab

\#25 (early near/3 (intervention* or therap* or interview* or advice)):ti,ab

\#26 (motivat near/3 (intervention* or therap* or interview* or advice)):ti,ab

$\# 27$ (counselling or counseling or advice):ti,ab

$\# 28 \# 17$ or \#18 or \#19 or \#20 or \#21 or \#22 or \#23 or \#24 or \#25 or \#26 or \#27

$\# 29 \# 10$ and \#16 and \#28

\#30 "brief alcohol intervention*":ti,ab

\#31 \#29 or \#30

\section{Appendix 2. Cochrane Drugs \& Alcohol Group Specialised Register search strategy}

Searched 23rd May 2012, subsequently searched via CENTRAL

In the fields "diagnosis" or in tile or abstract : alcohol* AND In all fields: counsel* or advice or screen* or ((behaviour* or brief*or minimal or early or motivat*) AND (intervention* or therap* or interview*)) AND In all fields: "general practice" or GP or "primary care" or "primary health" or "family practice" or or emergency or physician* or ((family or community or district or practice*) and (doctor or practitioner* or health* or nurse))

\section{Appendix 3. CENTRAL search strategy}

Database(s): EBM Reviews - Cochrane Central Register of Controlled Trials June 2012

Searched 26 June 2012 (superseded by search in Appendix 1)

1. exp General Practice/

2. Primary Health Care/

3. Community Health Services/

4. exp Emergency Service, Hospital/

5. Physicians, Primary Care/ or Physicians, Family/ 
6. General Practitioners/

7. (general pract\$ or family pract\$ or GP or physician\$ or emergency department\$ or emergency room\$ or trauma care or "accident and emergency" or community).tw.

8. ((family or community or practice* $)$ adj $\left(\right.$ medic $^{\star}$ or doctor ${ }^{\star}$ or physician $\left.\left.{ }^{\star}\right)\right) . t w$.

9. (primary adj2 care).tw.

10.shared care.tw.

11.or/1-10

12.exp Alcohol-Related Disorders/

13.Alcohol Drinking/

14. (alcohol adj3 (drink\$ or use\$ or abus\$ or misus\$ or risk\$ or consum $\$$ or withdraw\$ or intoxicat $\$$ or detox\$ or treat\$ or therap\$ or excess $\$$ or reduc $\$$ or cessation or intervention)).tw.

15. (drink\$ adj3 (excess or heavy or heavily or hazard\$ or binge or harmful or problem\$)).tw.

16. ("alcohol use" or alcoholic\$).tw.

17.or/12-16

18.Counseling/

19.Psychotherapy, Brief/

20.Interview, Psychological/

21. Behavior Therapy/

22. Cognitive Therapy/

23. Motivation/

24. ((brief or minimal or early or motivat\$) adj3 (intervention\$ or therap\$ or interview\$ or advice)).tw.

25. (counselling or counseling or advice).tw.

26.or/18-25

27. and $/ 11,17,26$

\section{Appendix 4. MEDLINE search strategy}

Database(s): Ovid MEDLINE(R) In-Process \& Other Non-Indexed Citations and Ovid MEDLINE(R) 1946 to September week 22017

Searched 21 September 2017 - thesaurus headings updated compared to previous search (see below)

1. $\exp$ General Practice/

2. Primary Health Care/

3. Community Health Services/

4. exp Emergency Service, Hospital/

5. Physicians, Primary Care/ or Physicians, Family/

6. General Practitioners/

7. (general pract\$ or family pract\$ or GP or physician\$ or emergency department\$ or emergency room\$ or trauma care or "accident and emergency" or community).tw.

8. ((family or community or practice\$) adj (medic\$ or doctor\$ or physician\$ or health\$ or nurs\$)).tw.

9. (primary adj2 care).tw.

10.shared care.tw.

11.or/1-10

12.exp Alcohol-Related Disorders/

13.Alcohol Drinking/

14. (alcohol adj3 (drink\$ or intoxicat\$ or use $\$$ or abus $\$$ or misus $\$$ or risk\$ or consum $\$$ or withdraw\$ or detox\$ or treat or therap\$ or excess $\$$ or reduc\$ or cessation or intervention\$)).tw.

15. (drink\$ adj3 (excess or heavy or heavily or harm or harmful or hazard\$ or binge or harmful or problem\$)).tw.

16.("alcohol use" or alcoholic\$).tw.

17.or/12-16

18. Counseling/

19.Psychotherapy, Brief/

20. Interview, Psychological/

21. Behavior Therapy/

22. Cognitive Therapy/

Effectiveness of brief alcohol interventions in primary care populations (Review) 
23. Motivation/

24. ((brief or minimal or early or motivat\$) adj3 (intervention\$ or therap\$ or interview\$ or advice)).tw.

25. (counselling or counseling or advice).tw.

26.or/18-25

27.and/11,17,26

28. brief alcohol intervention\$.tw.

29.or/27-28

30. randomized controlled trial.pt.

31.controlled clinical trial.pt.

32. randomi\$.ab.

33. placebo.ab.

34.drug therapy.fs.

35.randomly.ab.

36.trial.ab.

37. groups.ab.

38.30 or 31 or 32 or 33 or 34 or 35 or 36 or 37

39.(animals not (humans and animals)).sh.

40.38 not 39

41.29 and 40

42.limit 41 to $y r=" 2005$-Current"

The following search strategy was used to search MEDLINE (OVID) in 2005

1. family practice/

2. family pract\$.tw.

3. general practice.sh.

4. general pract\$.tw.

5. primary health care/

6. primary care/

7. community health services/

8. Community Care/

9. shared care.mp.

10.Patient Care/ or patient care team.mp.

11.family medicine/

12.family physician/

13.family phys $\$$.tw.

14.exp alcohol/

15.alcohol\$.tw.

16.1 or 2 or 3 or 4 or 5 or 6 or 7 or 8 or 9 or 10 or 11 or 12 or 13

17.14 or 15

18.16 and 17

19. alcohol reduction.mp.

20.brief intervention.mp.

21.early intervention.mp.

22. minimal intervention.mp.

23.alcohol therapy.mp.

24.harm reduction,.mp.

25.screening.mp.

26. (counseling or counselling).mp.

27.controlled drinking.mp.

28. (brief counseling or brief counselling).mp.

29. physician based intervention.mp.

30.general practitioner intervention.mp. 
31.secondary prevention.mp.

32.general practitioner's advice.mp.

33. brief physician-delivered counseling.mp.

34.brief nurse-delivered counseling.mp.

35.identification.mp.

36.intervention.mp.

37.19 or 20 or 21 or 22 or 23 or 24 or 25 or 26 or 27 or 28 or 29 or 30 or 31 or 32 or 33 or 34 or 35 or 36

38.(alcohol or alcohol consumption).mp.

39.37 and 38

40.39 and 18

41.randomized controlled trial.mp.

42. controlled clinical trial.mp.

43.randomized controlled trials. $\mathrm{mp}$.

44.random allocation.mp.

45. double blind method.mp.

46.single blind method.mp.

47.or/41-46

48.(animal not human).mp.

49.47 not 48

50.clinical trial.mp.

51.exp clinical trials/

52. (clin\$ adj2 trial\$).ti,ab.

53. ((singl\$ or doubl\$ or trebl\$ or tripl\$) adj2 (blind\$ or mask\$)).ti,ab.

54. placebos.mp.

55. placebo\$.ti,ab.

56.random\$.ti,ab.

57.research design.mp.

58.or/50-57

59.58 not 48

60.59 not 49

61.comparative study.mp.

62.exp evaluation studies/

63.follow up studies.mp.

64. prospective studies.mp.

65. (control\$ or prospectiv\$ or volunteer\$).ti,ab.

66.or/61-65

67.66 not 48

68.66 not (49 or 60$)$

69.49 or 60 or 68

70.69 and 40

\section{Appendix 5. Embase search strategy}

Database(s): Embase 1980 to 2017 week 38

Searched 21 September 2017

1. random\$.tw.

2. clinical trial\$.mp.

3. exp treatment outcome/

4. or/1-3

5. general practice/

6. exp primary health care/

7. community care/

8. emergency health service/

Effectiveness of brief alcohol interventions in primary care populations (Review) 
9. general practitioner/

10. (general pract\$ or family pract\$ or GP or physician\$ or emergency department\$ or emergency room\$ or trauma care or "accident and emergency" or community).tw.

11.((family or community or practice\$) adj (medic\$ or doctor\$ or physician\$ or health\$ or nurs\$)).tw.

12.(primary adj2 care).tw.

13.shared care.tw.

14.or/5-13

15.alcoholism/

16.alcohol intoxication/

17.alcohol abuse/

18.drinking behavior/

19. (alcohol adj3 (drink\$ or intoxicat $\$$ or use $\$$ or abus $\$$ or misus $\$$ or risk\$ or consum $\$$ or withdraw\$ or detox\$ or treat $\$$ or therap\$ or excess \$ or reduc\$ or cessation or intervention)).tw.

20.(drink\$ adj3 (excess or heavy or heavily or hazard\$ or binge or harmful or problem\$)).tw.

21.("alcohol use" or alcoholic\$).tw.

22.or/15-21

23.counseling/

24.psychotherapy/

25.psychologic test/

26. behavior therapy/

27.cognitive therapy/

28. motivation/

29. ((brief or minimal or early or motivat\$) adj3 (intervention\$ or therap\$ or interview\$ or advice)).tw.

30. (counselling or counseling or advice).tw.

31.or/23-30

32.14 and 22 and 31

33.brief alcohol intervention\$.tw.

34.or/32-33

35.4 and 34

\section{Appendix 6. CINAHL search strategy}

CINAHL (EBSCO) 1981-2017

Searched 25 September 2017

\section{S31 S18 AND S30}

$\mathrm{S} 30 \mathrm{~S} 19$ or $\mathrm{S} 20$ or $\mathrm{S} 21$ or $\mathrm{S} 22$ or $\mathrm{S} 23$ or $\mathrm{S} 24$ or $\mathrm{S} 25$ or $\mathrm{S} 26$ or $\mathrm{S} 27$ or $\mathrm{S} 28$ or $\mathrm{S} 29$

S29 TX allocat* random $^{\star}$

S28 (MH "Quantitative Studies")

S27 (MH "Placebos")

S26 TX placebo*

S25 TX random* allocat*

S24 (MH "Random Assignment")

S23 TX randomi $^{\star}$ control $^{\star}$ trial $^{\star}$

S22 TX ((singl ${ }^{\star} \mathrm{n} 1$ blind $\left.{ }^{\star}\right)$ or $\left(\right.$ singl ${ }^{\star} \mathrm{n} 1$ mask $\left.\left.^{\star}\right)\right)$

S21 TX clinic* N1 trial ${ }^{*}$

S20 PT Clinical trial

S19 (MH "Clinical Trials+") 


\section{S18 S16 OR S17}

S17 TI ("brief alcohol intervention*") OR AB ("brief alcohol intervention*")

S16 S5 and S10 and S15

\section{S15 S11 or S12 or S13 or S14}

S14 TI (counseling OR counselling OR advice) OR AB (counseling OR counselling OR advice)

S13 TI ((brief N3 intervention*) OR (brief N3 therap*) OR (brief N3 interview*) OR (minimal N3 intervention*) OR (minimal N3 therap $\left.{ }^{\star}\right)$ OR (minimal N3 interview*) OR (early N3 intervention*) OR (early N3 therap*) OR (early N3 interview*) OR (motivat* N3 intervention $\left.{ }^{\star}\right)$ OR (motivat* N3 therap*) OR (motivat* N3 interview*)) OR AB ((brief N3 intervention*) OR (brief N3 therap $\left.{ }^{\star}\right)$ OR (brief N3 interview*) OR (minimal N3 intervention*) OR (minimal N3 therap*) OR (minimal N3 interview*) OR (early N3 intervention*) OR (early N3 therap*) OR (early N3 interview* ${ }^{\star}$ OR (motivat* N3 intervention $\left.{ }^{\star}\right)$ OR (motivat* N3 therap $\left.{ }^{\star}\right)$ OR (motivat* N3 interview*))

S12 (MH "Behavior Therapy+")

S11 (MH "Counseling") OR (MH "Motivational Interviewing")

$\mathrm{S} 10 \mathrm{~S} 6$ or $\mathrm{S} 7$ or $\mathrm{S} 8$ or $\mathrm{S} 9$

\section{S9 TI (alcohol N2 use $)$ OR AB (alcohol N2 use*)}

S8 TI (drink* N3 (heavy OR heavily OR hazard* OR binge OR harmful)) OR AB (drink* N3 (heavy OR heavily OR hazard* OR binge OR harmful))

S7 TI (alcohol N3 (drink* OR abus* OR misus* OR risk* OR consum* OR withdraw* OR intoxicat* OR detox* OR treat* OR therap* OR excess* OR reduc ${ }^{\star}$ OR cessation OR intervention)) OR AB (alcohol N3 (drink* OR abus ${ }^{\star}$ OR misus ${ }^{\star}$ OR risk ${ }^{\star}$ OR consum $^{\star}$ OR withdraw $^{\star}$ OR intoxicat ${ }^{\star}$ OR detox ${ }^{\star}$ OR treat ${ }^{\star} O R$ therap ${ }^{\star}$ OR excess ${ }^{\star} O R$ reduc ${ }^{\star}$ OR cessation OR intervention))

S6 (MH "Alcohol-Related Disorders") OR (MH "Alcohol Abuse") OR (MH "Alcoholic Intoxication") OR (MH "Alcoholism") OR (MH "Alcohol Drinking") OR (MH "Alcohol Rehabilitation Programs")

\section{S5 S1 or S2 or S3 or S4}

S4 TI (shared care) OR AB (shared care)

\section{S3 TI (primary N2 care) OR AB (primary N2 care)}

S2 TI (general pract* OR family pract * OR GP OR physician* OR emergency department OR emergency room OR "accident and emergency" OR community) OR AB (general pract ${ }^{\star}$ OR family pract ${ }^{\star}$ OR GP OR physician* OR emergency department ${ }^{\star}$ OR emergency room $^{\star}$ OR trauma care OR "accident and emergency" OR community)

S1 (MH "Family Practice") OR (MH "Primary Health Care") OR (MH "Community Health Services") OR (MH "Rehabilitation, CommunityBased") OR (MH "Emergency Service+") OR (MH "Physicians, Emergency") OR (MH "Physicians, Family")

\section{Appendix 7. PsycINFO search strategy}

Database(s): PsycINFO 1806 to September week 32017

Searched 21 September 2017

1. primary health care/

2. general practitioners/

3. emergency services/

4. family physicians/

5. (general pract\$ or family pract\$ or GP or physician\$ or emergency department\$ or emergency room\$ or trauma care or "accident and emergency" or community).ti,ab.

6. ((family or community or practice $\left.{ }^{\star}\right)$ adj $\left(\right.$ medic $^{\star}$ or doctor ${ }^{\star}$ or physician $\left.\left.{ }^{\star}\right)\right) . t w$.

7. (primary adj2 care).ti,ab.

8. shared care.ti,ab.

9. $o r / 1-8$

10.exp alcohol intoxication/

11.exp alcohol abuse/

12.alcohol rehabilitation/ 
13.alcohol drinking patterns/

14. (alcohol adj3 (drink\$ or intoxicat $\$$ or use $\$$ or abus $\$$ or misus $\$$ or risk\$ or consum $\$$ or withdraw $\$$ or detox $\$$ or treat $\$$ or therap\$ or excess $\$$ or reduc\$ or cessation or intervention)).ti,ab.

15.(drink\$ adj3 (excess or heavy or heavily or hazard\$ or binge or harmful or problem\$)).ti,ab.

16.("alcohol use" or alcoholic\$).ti,ab.

17.or/10-16

18.counseling/ or rehabilitation counseling/

19.brief psychotherapy/

20.motivational interviewing/

21.cognitive behavior therapy/ or behavior therapy/

22.((brief or minimal or early or motivat\$) adj3 (intervention\$ or therap\$ or interview\$)).ti,ab.

23. (counselling or counseling or advice).ti,ab.

24.or/18-23

25.9 and 17 and 24

26.brief alcohol intervention\$.tw.

27.or/25-26

28. control\$.tw.

29.random\$.tw.

30.exp Treatment/

31.or/28-30

32.27 and 31

\section{Appendix 8. Science Citation Index, Social Science Citation Index, Conference Proceedings Citation Index-Science, Emerging Sources Citation Index search strategy}

SCI-EXPANDED/SSCI (Web of Science) 1970-2017

CPCI-S (Web of Science) 1990-2017

ESCI (Web of Science) 2015-2017

Searched 25 September 2017

\# 15 \#14 AND \#13

\# 14 TS=randomi ${ }^{\star}$ OR TS=randomly OR TS=placebo* OR TS=trial*

\# 13 \#11 AND \#8 AND \#4

\# 12 \#11 AND \#8 AND \#4

\# 11 \#10 OR \#9

\# 10 TS=(counselling or counseling or advice)

\# 9 TS=((brief NEAR/3 intervention*) OR (brief NEAR/3 therap*) OR (brief NEAR/3 interview*) OR (minimal NEAR/3 intervention*) OR (minimal NEAR/3 therap*) OR (minimal NEAR/3 interview*) OR (early NEAR/3 intervention*) OR (early NEAR/3 therap*) OR (early NEAR/3

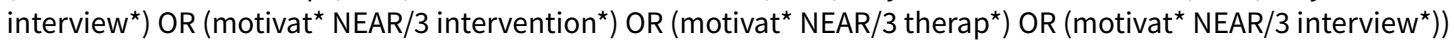

\# 8 \#7 OR \#6 OR \#5

\# 7 TS="alcohol use" OR TS=alcoholic*

\# 6 TS=((drink NEAR/3 excess) OR (drink NEAR/3 heavily) OR (drink* NEAR/3 heavy) OR (drink* NEAR/3 hazard*) OR (drink* NEAR/3 binge) OR (drink* NEAR/3 harmful) OR (drink* NEAR/3 problem*))

\# 5 TS $=\left(\left(\right.\right.$ alcohol NEAR/3 drink $\left.{ }^{\star}\right)$ OR (alcohol NEAR/3 intoxicat $\left.{ }^{\star}\right)$ OR (alcohol NEAR/3 abus $\left.{ }^{\star}\right)$ OR (alcohol NEAR/3 misus $\left.{ }^{\star}\right)$ OR (alcohol NEAR/3 risk $^{*}$ ) OR (alcohol NEAR/3 consum ${ }^{\star}$ ) OR (alcohol NEAR/3 withdraw ${ }^{\star}$ ) OR (alcohol NEAR/3 detox ${ }^{\star}$ ) OR (alcohol NEAR/3 treat $\left.{ }^{\star}\right)$ OR (alcohol NEAR/3 therap ${ }^{\star}$ ) OR (alcohol NEAR/3 excess ${ }^{\star}$ ) OR (alcohol NEAR/3 reduc*) OR (alcohol NEAR/3 cessation) OR (alcohol NEAR/3 intervention))

\# 4 \#3 OR \#2 OR \#1

\# 3 TS="shared care" 
\# 2 TS=("primary care" OR "primary health care")

\# 1 TS=("general pract*" OR "family pract*" OR GP OR physician* OR "emergency department" OR "accident and emergency" OR community)

\section{Appendix 9. Clinicaltrials.gov search strategy}

http://clinicaltrials.gov/

Searched 25 September 2017

Advanced search

Search terms: alcohol

Interventions: brief

\section{Appendix 10. Risk of bias assessment criteria}

\begin{tabular}{lll}
\hline Item & Judgment & Description \\
\hline $\begin{array}{l}\text { 1. Random sequence } \\
\text { generation (selection } \\
\text { bias) }\end{array}$ & Low risk & $\begin{array}{l}\text { The investigators describe a random component in the sequence generation } \\
\text { process such as: random number table, computer random number generator, } \\
\text { coin tossing, shuffling cards or envelopes, throwing dice, drawing of lots, min- } \\
\text { imisation }\end{array}$
\end{tabular}

High risk

The investigators describe a non-random component in the sequence generation process such as: odd or even date of birth; date (or day) of admission; hospital or clinic record number; alternation; judgement of the clinician; results of a laboratory test or a series of tests; availability of the intervention.

Unclear risk Insufficient information to permit judgement of low or high risk.

\begin{tabular}{|c|c|c|}
\hline $\begin{array}{l}\text { 2. Allocation conceal- } \\
\text { ment (selection bias) }\end{array}$ & Low risk & $\begin{array}{l}\text { Investigators enrolling participants could not foresee assignment because one } \\
\text { of the following, or an equivalent method, was used to conceal allocation: cen- } \\
\text { tral allocation (including telephone, web-based, and pharmacy-controlled, } \\
\text { randomisation); sequentially numbered, opaque, sealed envelopes. Very few } \\
\text { studies which used envelopes to conceal allocation described them as seri- } \\
\text { ally numbered, opaque and sealed, but some studies nevertheless reported } \\
\text { enough to suggest adequate allocation concealment. We used all the text de- } \\
\text { scribing allocation concealment to inform our judgement of this item. }\end{array}$ \\
\hline
\end{tabular}

High risk Investigators enrolling participants could possibly foresee assignments because one of the following method was used: open random allocation schedule (e.g. a list of random numbers); assignment envelopes without appropriate safeguards (e.g. if envelopes were unsealed or nonopaque or not sequentially numbered); alternation or rotation; date of birth; case record number; any other explicitly unconcealed procedure.

Unclear risk Insufficient information to permit judgement of low or high risk.

3. Blinding of providers Low risk (performance bias)
No blinding or incomplete blinding, but the review authors judge that the outcome is not likely to be influenced by lack of blinding.

Blinding of providers and unlikely that the blinding could have been broken.

If the study was a cluster randomised study where the arms were physically separated and the intervention providers only had contact with a single arm.

If the pre-intervention steps (e.g. screening, randomisation, baseline assessment) were carried out by an independent person (e.g. researcher, research or practice nurse), and the intervention provider only had contact with the in- 

by lack of blinding;

Blinding of key study participants and personnel attempted, but likely that the blinding could have been broken, and the outcome is likely to be influenced by lack of blinding.

\begin{tabular}{lll}
\cline { 2 - 3 } & Unclear risk & Insufficient information to permit judgement of low or high risk. \\
\hline $\begin{array}{l}\text { 4. Blinding of partic- } \\
\text { ipants (performance } \\
\text { bias) }\end{array}$ & Low risk & $\begin{array}{l}\text { Blinding of participants and unlikely that the blinding could have been broken. } \\
\text { At screening or assessment, participants were unaware that the trial specifi- } \\
\text { cally focused on alcohol consumption, e.g. tools encompassed wider health or } \\
\text { lifestyle questions. }\end{array}$ \\
\cline { 2 - 4 } & $\begin{array}{l}\text { No blinding or incomplete blinding, and the outcome is likely to be influenced } \\
\text { by lack of blinding; }\end{array}$ \\
& $\begin{array}{l}\text { Blinding of key study participants and personnel attempted, but likely that the } \\
\text { blinding could have been broken, and the outcome is likely to be influenced by } \\
\text { lack of blinding. } \\
\text { Studies received "high risk" as default unless there was an explicit attempt to } \\
\text { blind participants. }\end{array}$ \\
\hline Unclear risk & Insufficient information to permit judgement of low or high risk.
\end{tabular}

$\begin{array}{ll}\begin{array}{l}\text { 5. Blinding of outcome } \\ \text { assessors (detection }\end{array} & \text { Low risk } \\ \text { come measurement is not likely to be influenced by lack of blinding. }\end{array}$

bias)

Blinding of outcome assessors and unlikely that the blinding could have been broken.

\begin{tabular}{ll}
\hline High risk & No blinding or incomplete blinding \\
\hline Unclear risk & $\begin{array}{l}\text { Outcome collection was not automated and insufficient information is provid- } \\
\text { ed to assess blinding. }\end{array}$ \\
\hline
\end{tabular}

\begin{tabular}{|c|c|c|}
\hline 6. Incomplete outcome & Low risk & No missing outcome data; \\
\hline For all outcomes except & & $\begin{array}{l}\text { Reasons for missing outcome data unlikely to be related to true outcome (for } \\
\text { survival data, censoring unlikely to be introducing bias); }\end{array}$ \\
\hline
\end{tabular}

retention in treatment

or drop out
Missing outcome data balanced in numbers across intervention groups, with similar reasons for missing data across groups;

For dichotomous outcome data, the proportion of missing outcomes compared with observed event risk not enough to have a clinically relevant impact on the intervention effect estimate;

For continuous outcome data, plausible effect size (difference in means or standardised difference in means) among missing outcomes not enough to have a clinically relevant impact on observed effect size;

Missing data have been imputed using appropriate methods 
All randomised patients are reported/analysed in the group they were allocated to by randomisation irrespective of non-compliance and co-interventions (intention to treat).

High risk Reason for missing outcome data likely to be related to true outcome, with either imbalance in numbers or reasons for missing data across intervention groups;

For dichotomous outcome data, the proportion of missing outcomes compared with observed event risk enough to induce clinically relevant bias in intervention effect estimate;

For continuous outcome data, plausible effect size (difference in means or standardised difference in means) among missing outcomes enough to induce clinically relevant bias in observed effect size;

'As-treated' analysis done with substantial departure of the intervention received from that assigned at randomisation.

Unclear risk Insufficient information to permit judgement of low or high risk (e.g. number randomised not stated, no reasons for missing data provided; number of drop out not reported for each group).

\section{Selective reporting Low risk} (reporting bias)

The study protocol is available and all of the study's pre-specified (primary and secondary) outcomes that are of interest in the review have been reported in the pre-specified way;

The study protocol is not available but it is clear that the published reports include all expected outcomes, including those that were pre-specified (convincing text of this nature may be uncommon).

High risk Not all of the study's pre-specified primary outcomes have been reported;

One or more primary outcomes is reported using measurements, analysis methods or subsets of the data (e.g. subscales) that were not pre-specified;

One or more reported primary outcomes were not pre-specified (unless clear justification for their reporting is provided, such as an unexpected adverse effect);

One or more outcomes of interest in the review are reported incompletely so that they cannot be entered in a meta-analysis;

The study report fails to include results for a key outcome that would be expected to have been reported for such a study.

\section{FEE D B A C K}

\section{Anders Beich, 27 May 2009}

\section{Summary}

The effect of brief interventions for hazardous drinking among primary care patients has been investigated in several controlled trials and meta-analyses. In most trials accomplished during the last 25 years intervention groups, mostly men, have subsequently reported lower alcohol consumption than their matching controls at follow-up. Therefore, it is no surprise that Kaner et al. in their meta-analysis [1] conclude that brief alcohol intervention in primary care contexts results in significant reductions in weekly consumption at least for men.

The crucial point is whether these results represent effectiveness rather than efficacy [2], because if so then health care professionals should be able to contribute to less hazardous drinking habits among their patients by adopting this technology. One question to address 
could then be how the technology fits within the context of primary care and how these results could be used out there where health professionals meet patients on a continuous basis.

The Cochrane-analysis [1] aims to examine to which degree the included trials have reported results that are externally valid and it is claimed that ?The lack of evidence of any difference in outcomes between efficacy and effectiveness trials suggests that the current literature is relevant to routine primary care and we feel that the current body of brief alcohol intervention research is applicable to clinical practice. I find this part of the analysis/interpretation to be problematic and the methods they use for reaching this conclusion to be inappropriate. The strength of their argument is obviously weak and their way of reasoning is deceptive. Just because two objects have the same colour you can hardly conclude, that this suggests they can be used for a specific purpose, and feelings should in my opinion be kept out of the argumentation.

I find the analysis and the discussion of the meta-analysis results to have several serious weaknesses:

1) Which drinkers are we dealing with?

The heterogeneity among trial groups in relation to baseline consumption is substantial among the included studies. Average consumption ranges from about 17 drinks/week to 54 , that is, from slightly hazardous drinking to obviously harmful consumption and possible dependency. The risk reduction by reducing from 54 to 49 drinks per week can hardly be comparable to a reduction from 17 to 12 drinks per week and the report lacks a qualified discussion of this issue.

2) Study quality analysis as an invocation

Although a quality analysis of the included studies is carried out, the results are not allowed to affect the calculation of average intervention effects: Poor quality studies are given the same weight as high quality studies. I am aware that this is often the case in meta-analyses, but when results rely on self-reports I believe this issue is at least worth a discussion, which leads to the next weakness

3) The "Garbage in" "garbage out" problem

The analysis is not concerned with the quality and quality control of data (self-reported drinking). Self-reported drinking has been shown to be influenced by situational and contextual matters and the impossibility of blinding of study subjects may constitute a major source of bias in several of the included studies and this is not discussed in the report. A sensitivity analysis focusing on effects in studies that had other more objective data available could have been attempted or at least discussed.

4) Biased effectiveness perspective

One of the aims of the work is to investigate to which degree the included trials can be characterized as effectiveness trials and thereby relevant to routine primary care. This is done by analysing to which degree the setting can be characterized as a clinical rather than a research setting (reasons for encounter, the advisor/interventionist and the character of the clinic, as well as support, help and supervision provided in clinical trials).

The analysis avoids to analyse to which degree the trial groups can be characterized as clinical rather than research groups, that is, no attempts were made to find out how representative the included individuals were in relation to how many were actually screened hazardous drinking positive in the first place. Because screening and brief intervention recommendations come together [3] brief intervention seems to involve some kind of screening as it did the included trials it should at least have been clarified how refined the trial groups were compared to the groups that screened positive at baseline.

An example of the problem: A heavy weight study in the present meta-analysis is a study by Fleming et al.[4], who screened 17,695 patients, found $2,925(17 \%)$ to be hazardous drinkers, of which 774 were included in the trial after all. That is, 2,151 hazardous drinkers were lost before the trial started for reasons poorly described. It is indeed possible that the most interested (/ready /motivated) drinkers were over represented in the trial groups. This may in more than one way lead to biased results and it is not justified to claim that the results do also count for the majority of hazardous drinkers who were excluded in this study.

This issue is not at all new to most of the Cochrane-group though they manage to maintain absolute silence about the lost-subjects-beforerandomization issue and a meta-analysis on exactly that issue in 2003[5], one that caused them to react very strongly at the time and later on in public accuse the authors of the analysis for causing the death of hazardous drinkers because these discussions might delay implementation efforts that they were in charge of.

\section{5) Conflict of interests}

The trustworthiness of the interpretation by Kaner et al. is in my opinion severely weakened by the fact that the authors claim no conflict of interests when more of them are well known for their involvement in implementation activities regarding brief interventions for decades. It is an open question what should be included as conflict of interests, but when more of the authors, the first author inclusive, have had implementation of these brief intervention technologies as a main employment for years, it seems unlikely that this would not affect which questions they wish to answer and the basic choices they make in the process of a meta-analysis of the effectiveness the very technology.

When the authors state that they have made inquiries on non-published studies I find it strange that they do not mention a Danish pragmatic randomised trial [7] that was not yet published when they ended their literature search, but I have personally presented the results for at least three of the authors more than once, results indicating that brief intervention had no effect on men and might be worse than no intervention for women when it was put out in real life circumstances and all recommendations were followed. Also, other results from this Danish group of independent researchers indicating that screening based brief intervention is not compatible with the work of the general practitioner [8] and that for the documentation so far rest on highly refined trial groups [5] are carefully ignored in this Cochrane-paper. 
This meta-analysis tells us that some hazardous drinking male patients in primary health care can benefit from a brief intervention. But we can not say anything about the proportion, how much they will reduce their drinking or how we should find them from this analysis. I find the approach of this meta-analysis to be selective and biased and the purpose of it to be doubtful.

I propose that The Cochrane Collaboration encourage future author groups to declare all possible conflict of interests, not just obviously commercial ones.

\section{References}

1. Kaner EF, Beyer F, Dickinson HO et al. Effectiveness of brief alcohol interventions in primary care populations. Cochrane Database Syst Rev 2007:CD004148.

2. Flay BR. Efficacy and effectiveness trials (and other phases of research) in the development of health promotion programs. Prev Med 1986;15:451-74.

3. Babor TF, Higgins-Biddle JC. Brief Intervention for Hazardous and Harmful Drinking - A Manual for Use in Primary Care. Geneva: World Health Organization, 2001: 1-29

4. Fleming MF, Barry KL, Manwell LB et al. Brief physician advice for problem alcohol drinkers - A randomised controlled trial in communitybased primary care practices. JAMA 1997;277:1039-45.

5. Beich A, Thorsen T, Rollnick S. Screening in brief intervention trials targeting excessive drinkers in general practice: systematic review and meta-analysis. BMJ 2003;327:536-40.

6. Kaner EF, Lock CA, McAvoy BR, Heather N, Gilvarry E. A RCT of three training and support strategies to encourage implementation of screening and brief alcohol intervention by general practitioners. Br J GenPract 1999;49:699-703.

7. Beich A, Gannik D, Saelan H et al. Screening and Brief Intervention Targeting Risky Drinkers in Danish General Practice A Pragmatic Controlled Trial. Alcohol Alcohol 2007.

8. Beich A, Gannik D, Malterud K. Screening and brief intervention for excessive alcohol use: qualitative interview study of the experiences of general practitioners. BMJ 2002;325:870-3.

\section{Reply}

We are pleased that the commentator confirms the validity of our primary review finding that brief interventions are effective at reducing excessive alcohol consumption, particularly in men. We welcome critique of our approach in exploring the efficacy-effectiveness question indeed we pointed out in our discussion some weaknesses that we felt were inherent in our approach. Despite this, we felt it was worth trying to unravel the efficacy-effectiveness issue and believe our work has made a start, even if this is an imperfect approach. This said, we feel there is merit in trying to clarify important parameters such as whether if the interventions are delivered in typical practices by practitioners who deliver primary care as their main occupation and if the interventions are delivered to routinely presenting patients. Furthermore, we also tried to assess whether brief interventions were delivered within normal consultation times and if preparatory training is what most practitioners are likely to be able access. These are just 4 of the 8 parameters we assessed trials on in our attempt to establish the interval or external validity of the trial design.

1) We have described the characteristics of subjects in the brief intervention trials and we state both narratively and statistically in the review that there is a great deal of heterogeneity in the field.

2) The extensive sensitivity analysis that we carried out deals with the range of well-accepted quality criteria for research trials. Studies that were lacking on various quality criteria were omitted from the numerous sensitivity analyses that we reported and the key findings of the review were not substantially altered by this process.

3) This review was based on a range of outcome measures reported in 29 trials, some of which were self-reported by patients and some of which were more objectively measured. Thomas Greenfield and Lorraine Midanik have published a number of papers on the issue of selfreport as a measure of alcohol use and have found this to be a valid approach. Furthermore, Babor and colleagues have confirmed that self-reported data if collected in the right way are sufficiently valid for research and less intrusive for patients [Babor T, Steinberg K, Anton RF, Del Boca F. Talk is cheap: measuring drinking outcomes in clinical trials. Journal of Studies on Alcohol 2000;61:55-63].

In addition, whilst self-reported drinking may not be a gold-standard measure of alcohol consumption, this approach was employed in both the control and treatment arms of the trials and so this issue would not essentially alter the outcome findings of the review. Lastly, we conducted a meta-analysis which considered the outcomes of individually randomised trials compared to cluster randomised trials (analysis 01.08) and found no statistically significant difference in outcome. Thus we do not think that the self-reported outcomes or the lack of blinding in individually randomised trials substantively affects the findings of our review. Finally, two included trials reported both self-reported outcomes and laboratory markers (GGT) of alcohol intake; both studies were consistent in finding that the intervention was more effective than control on the basis of both self-reported and objective outcomes.

4) We are aware that more individuals are screened than enrolled into the treatment or control conditions of the trials, this is indeed the purpose of screening. The number of patients that need to be screened in order to identify patients suitable for intervention is an important implementation issue for practice (and practitioners) which has been specifically investigated elsewhere (reference 5 below) but it was not central to the aims of our effectiveness review. 
In our review, we specifically report the loss to follow-up of patients post intervention which was greater in brief intervention conditions compared to control conditions. We cite this as a weakness in the brief intervention evidence-base. However, the loss of patients between screening and enrolment into the trial was not relevant to the aim of our review which was to ascertain the relative effectiveness of brief intervention versus control conditions in reducing excessive drinking. Since allocation at enrolment was randomly determined, it is clear that post-screening attrition would be equally experienced in both control and brief intervention conditions. Thus this issue would not substantively alter the findings of our review.

The efficiency of screening prior to brief intervention was covered in a BMJ review in 2003 and there was a considerable debate on this issue at the time (in which 2 out of the nine authors of the current review participated). Since the majority of the co-authors were not involved in that debate, it is not accurate or helpful to state that most of the Cochrane group have maintained a silence on the discussion. As stated above, the issue as to whether screening is an efficient means of identifying excessive drinkers in primary care was not relevant to our key aim of evaluating the effectiveness of brief intervention at reducing heavy drinking.

5) Of the nine co-authors of the current review, three have been involved in both implementation research and outcome evaluation trials in the field of brief alcohol interventions. Indeed, two of these individuals were involved in conducting three of the null-effect trials that contributed to the review (Heather et al. 1987, Richmond et al. 1995 and Lock et al. 2006). The statement that implementation of brief intervention technologies has been the main employment for years of any of the review authors is inaccurate. In addition, we do not agree with the proposition that involvement in implementation research is in of itself favourable towards brief intervention (for an example see reference 5) and the findings of null-effect outcome evaluation research highlighted above substantiates this view. Finally, all the meta-analysis conducted in the Cochrane review was conducted by two research scientists who have never previously worked in the brief intervention field the respective contribution of all the review co-authors to each aspect of the review process is clearly outlined on the published review (page 44). Thus we feel confident about our statement concerning conflict of interest regarding the review.

The current review clearly reported that its search strategy extended to 2006. Thus it obviously would not have included reference 7 which was published in 2007. Indeed the initial review analysis was completed in November 2006 (the group was awarded a small grant by the Cochrane Collaboration to complete the review by this time). However, we re-ran our analysis in February 2007 after correspondence from a trial author (Curry 2003) whose work had been excluded from the review in error. The published version of reference 7 states that it was published (following amendment made after peer-review) in July 2007. Thus the peer-reviewed version of this work was not available for this review. However, this work will, of course, be included in any future update of the Cochrane review. Nevertheless, since the current review clearly contains both null-effect and positive-effect trials of brief intervention, it is clear that we have not selectively included only work with positive outcomes. The Cochrane review meta-analysis clearly reports both the average reduction in the percentage of heavy drinkers (Analysis 1.21) and the average weekly reduction in drinking after brief alcohol intervention (Analysis 1.15) along with a wide range of other relevant outcome measures.

\section{References}

1. Kaner EF, Beyer F, Dickinson HO et al. Effectiveness of brief alcohol interventions in primary care populations. Cochrane Database Syst Rev 2007:CD004148.

2.Flay BR. Efficacy and effectiveness trials (and other phases of research) in the development of health promotion programs. Prev Med 1986;15:451-74.

3.Babor TF, Higgins-Biddle JC. Brief Intervention for Hazardous and Harmful Drinking - A Manual for Use in Primary Care. Geneva: World Health Organization, 2001: 1-29

4.Fleming MF, Barry KL, Manwell LB et al. Brief physician advice for problem alcohol drinkers - A randomised controlled trial in communitybased primary care practices. JAMA 1997;277:1039-45.

5.Beich A, Thorsen T, Rollnick S. Screening in brief intervention trials targeting excessive drinkers in general practice: systematic review and meta-analysis. BMJ 2003;327:536-40.

6. Kaner EF, Lock CA, McAvoy BR, Heather N, Gilvarry E. A RCT of three training and support strategies to encourage implementation of screening and brief alcohol intervention by general practitioners. Br J Gen Pract 1999;49:699-703.

7. Beich A, Gannik D, Saelan H et al. Screening and Brief Intervention Targeting Risky Drinkers in Danish General Practice A Pragmatic Controlled Trial. Alcohol Alcohol 2007.

8. Beich A, Gannik D, Malterud K. Screening and brief intervention for excessive alcohol use: qualitative interview study of the experiences of general practitioners. BMJ 2002;325:870-3.

\section{Contributors}

Feedback from Anders Beich

Reply from Kaner EF, Dickinson HO, Beyer FR, Campbell F, Schlesinger C, Heather N, Saunders JB, Burnand B, Pienaar ED

\section{WHAT'S NEW}




\begin{tabular}{lll}
\hline Date & Event & Description \\
\hline 8 June 2018 & Amended & $\begin{array}{l}\text { Corrections were made to data from two studies in analysis 2.1, } \\
\text { and consequently to Summary of Findings table 2 and review } \\
\text { text. }\end{array}$ \\
\hline
\end{tabular}

\section{H I S T O R Y}

Protocol first published: Issue 2, 2003

Review first published: Issue 2, 2007

\begin{tabular}{lll}
\hline Date & Event & Description \\
\hline 25 September 2017 & $\begin{array}{l}\text { New citation required and conclusions } \\
\text { have changed }\end{array}$ & $\begin{array}{l}\text { 1. The addition of } 42 \text { new studies changed conclusions with re- } \\
\text { spect to the effect for women, and enabled further subgroup } \\
\text { analyses. }\end{array}$ \\
& 2. The review authorship changed.
\end{tabular}

25 September $2017 \quad$ New search has been performed

1. The search was updated in September 2017 and 42 new trials (24,057 participants) were included, bringing the total to 69 included studies (33,642 participants). Two trials in the original review were excluded from this update.

2. The review has been substantially revised in accordance with Cochrane guidance, including the implementation of GRADE assessment, creation of 'Summary of findings' tables for the main comparisons, and further subgroup analyses.

\begin{tabular}{lll}
\hline 28 July 2009 & Feedback has been incorporated & We have replied to feedback from Dr Anders Beich \\
\hline 19 June 2008 & Amended & corrected figures, estimates and add minor changes \\
\hline 29 April 2008 & Amended & little changes \\
\hline 29 April 2008 & New search has been performed & Add one study but conclusions are not changed \\
\hline 15 February 2007 & $\begin{array}{l}\text { New citation required and conclusions } \\
\text { have changed }\end{array}$ & Substantive amendment \\
\hline
\end{tabular}

\section{CONTRIBUTIONSOF AUTHORS}

Kaner conceived, designed and co-ordinated the review. Kaner and Campbell wrote the original protocol with advice from Heather and Saunders to develop the efficacy/effectiveness scale, from Dickinson on statistical issues and from Pienaar on other issues. Pienaar, Campbell and Kaner conducted the searches. Beyer conducted the updated searches. Campbell and Beyer managed the reference databases. Kaner, Schlesinger, Bertholet, Daeppen, Bernand and Pienaar sifted the references. Kaner, Schlesinger, Pienaar, Campbell, Beyer and Dickinson extracted data. Dickinson and Muirhead performed statistical analysis. Dickinson, Beyer, Campbell and Kaner wrote the review. Muirhead, Campbell, Kaner and Beyer updated the text for this version. All authors read and commented on the updated review.

\section{DECLARATIONS OF INTEREST}

Nicolas Bertholet is salaried by Lausanne University Hospital, a public institution; he has received grants from the Swiss National Science Foundation, the Swiss Foundation for Alcohol Research, and the Department of Community Medicine and Health from the Lausanne University Hospital. He has received no personal support from industry sources such as pharmaceutical, alcohol and tobacco companies and holds no personal stock. Dr Bertholet is an author of a previous systematic review on the subject (Bertholet 2005), and has participated 
in numerous studies on screening and brief intervention (not limited to the scope of this review), including as a primary investigator of a randomised trial of an electronic screening and brief intervention.

Bernard Burnand, MD, MPH, is Chief Physician at the Institute of Social and Preventive medicine, Lausanne University Hospital. He is salaried full time by the this public institution (Canton of Vaud, Switzerland) and a full professor at the Faculty of Biology and Medicine, University of Lausanne. Bernard Burnand is also Director of Cochrane Switzerland (Cochrane associated centre). His research is supported by Lausanne University Hospital and funding from public granting institutions. ORCID ID: orcid.org/0000-0002-5678-6044

Fiona Campbell has no conflicts of interest to declare.

Jean-Bernard Daeppen received personal fees from Lundbeck SAS for lectures and advice and was involved in the Daeppen 2007 trial, which is an included trial in this systematic review.

Elizabeth Pienaar is in the full-time employ of the South African Medical Research Council and has no conflicts of interest to declare.

John B Saunders has no conflicts of interest to declare.

Eileen Kaner, Fiona Beyer and Colin Muirhead are authors on a related Cochrane Review on interventions for reducing hazardous and harmful alcohol consumption (Kaner 2017).

Eileen Kaner is an investigator on the ongoing SIPS Junior trial (NIHR programme grant number NIHR RP-PG-0609-10162). She was also involved in the SIPS trial (Kaner 2013) and the Lock 2006 trial which are included studies in this systematic review.

\section{SOURCES OF SUPPORT}

\section{Internal sources}

- Small Grant from the University of Newcastle upon Tyne, UK.

\section{External sources}

- Department of Health Primary Care Career Scientist Award, UK.

- Cochrane Collaboration, UK.

\section{DIFFERENCES BETWEEN PROTOCOLANDREVIEW}

\section{Authorship}

Dr Heather Dickinson, Dr Carla Schlesinger and Professor Nick Heather were unable to contribute to this review update and are no longer authors. We would like to acknowledge their earlier input. Dr Colin Muirhead, Dr Nicolas Bertholet and Professor Jean-Bernard Daeppen have become authors.

\section{Objective}

The objective in the original review contained the sentence "To assess whether outcomes differ between trials in research settings and those in routine clinical settings", reflecting the fact that there was a strong focus on our efficacy effectiveness tool, and we reported every analysis with trials subgrouped by efficacy or effectiveness. This update does not contain such a strong focus on efficacy/effectiveness because validated tools have superseded ours. The review includes a single subgroup analysis focused on efficacy/effectiveness so no longer warrants a statement in the objective.

\section{Included studies}

When compared to the broader range of trials available to include in this review update, two previously included studies did not really fit and we decided it would be more robust to exclude them from the review. Participants in the Gentilello 1999 trial were inpatients and the trial is included in a Cochrane Review of brief interventions in patients admitted to hospital. Chang 1997 compared brief intervention to alcohol treatment referral, which is not an analogous control group with the included trials.

\section{Outcomes}

Although not specified in the protocol, we reported when participants were categorised as 'heavy drinker' or 'binge drinker' at follow up.

\section{Meta-analyses}

All analyses comprise 12 month outcomes, except where otherwise stated.

Some of the studies added for this update provided data for a new comparison (extended versus minimal or no intervention) and, on reflection, some studies from the previous version of the review also fitted into this comparison and were added. 


\section{Subgroup analyses}

\section{Emergency versus general practice settings}

Since publication of the previous version of this review, the effectiveness of brief interventions has been tested more commonly in emergency departments. It is plausible that patients in emergency departments may have a different response to a brief intervention, particularly if alcohol consumption has contributed to their visit. Therefore, we carried out a subgroup analysis of emergency versus general practice settings.

\section{Theoretical basis or modality of intervention}

Another change over time is that more brief interventions have incorporated counselling or motivational interviewing techniques. Again, it is plausible this would have an impact on the effectiveness of the intervention.

\section{Control group content}

As described in the Discussion, more recent studies exploring the screening and assessment reactivity effect have been published since our 2007 review appeared. We decided to explore effects in a subgroup analysis according to the intervention received by control group participants: explicitly alcohol-related content versus not.

\section{Trials included in the previous version of this review}

Given the modifications made since our 2007 review was published, we also performed subgroup analysis according to whether trials appeared in the previous version or the updated version of the review.

\section{Efficacy/effectiveness score}

Meta-analyses were dichotomised according to trials effectiveness/efficacy scores to assess whether these were relevant to clinical settings in the 2007 review. However, little difference was detected between trials categorised as efficacy versus effectiveness trials; hence, we conducted a single subgroup analysis only for this update.

\section{Loss to follow-up}

We planned analyses linked of losses to follow up for both this update and the 2007 review. However, because of differing definitions of loss to follow up, and despite many trials presenting results adjusted for missing data, it was not always clear if allowance had been made for loss to follow up. It was decided that a sensitivity analysis of losses to follow-up would not be practicable. However, an analysis that excluded trials at high risk of bias due to incomplete outcome data gave similar results to those from the primary meta-analysis.

\section{Additional tables}

'Summary of Findings' tables and risk of bias tables have been added to the review.

\section{NDEX TERMS}

\section{Medical Subject Headings (MeSH)}

Age Factors; Alcohol Drinking [ ${ }^{\star}$ therapy]; Alcoholism [^therapy]; Emergencies [epidemiology]; Family Practice [statistics \& numerical data]; Randomized Controlled Trials as Topic

\section{MeSH check words}

Female; Humans; Male 